\title{
A gravity analysis of the Alpine Fault and the DFDP-2 drill site, Whataroa valley, South Westland, South Island, New Zealand
}

\author{
Steve Jenkins
}

A thesis submitted to Victoria University of Wellington in fulfilment of the requirements for the degree of Master of Science in Geology

Victoria University of Wellington

2016 



\section{Abstract}

The second phase of drilling into the Alpine Fault (DFDP-2), was completed in the Whataroa River valley, a former glacial valley located in central Westland, South Island, New Zealand. The site is located next to a steep hillside on the hanging-wall, $\sim 1 \mathrm{~km}$ southeast of the mapped surface trace of the Alpine Fault. Projection of the hillside suggests a sediment thickness of $100 \pm 40 \mathrm{~m}$ at the drill site; however, the sediment thickness was approximately double pre-drill estimates. Additionally, the surface expression and shallow geometry of the Alpine Fault in the Whataroa River valley, is not well-defined due to post-glacial burial of the fault zone. This thesis describes a gravity study designed to better constrain sub-surface structure beneath the DFDP-2 drill site and across the Alpine Fault.

During this study, 466 new high-precision gravity observations were collected (standard error $=0.015 \mathrm{mGal}$ ) and amalgamated with 134 existing gravity stations, yielding comprehensive coverage of gravity data across the study area. A high density of observations was achieved within pre-determined zones, in addition to regional measurements so that residual gravity anomaly maps could be produced. The maps reveal: a negative residual gravity anomaly interpreted as a dextrally-offset glacial channel at least 350-450 m deep; steep localised gravity gradients near the Alpine Fault and DFDP-2 drill site that are interpreted as faulted and/or eroded boundaries; and a negative gravity anomaly adjacent to the DFDP-2 drill site that is interpreted as the deepest point of an over-deepened glacial lake.

Gravity models were used to estimate the bedrock-sediment interface geometry near the DFDP-2 drill site and Alpine Fault. Structural inversion of the density boundary next to the drill site suggests either a moderately-dipping reverse fault or subvertical erosional wall exists beneath the hillside. Additional constraints on physical properties from direct density measurements or seismic velocity determinations and direct constraints on sediment thickness and layer geometry from seismic surveys will in future allow this new high-precision gravity dataset to be modelled more effectively. 



\section{Acknowledgments}

Thank you to my supervisors Rupert Sutherland and John Townend for your time and effort towards this project. Without your support, encouragement and guidance this project would not have been possible. Thanks to John and Rupert's hard work, I was awarded a Marsden Grant Scholarship, provided by the Royal Society of New Zealand.

Thank you to Euan Smith for your direction and experience with challenging data reduction problems and for providing your time even in your retirement. Emeritus professors such as Euan are invaluable to the university and deserve our recognition.

Thank you to Nic Barth for insightful comments on Alpine Fault structure, and for providing fascinating discussion on geologic interpretation of gravity data.

Thank you to all the staff and students at Victoria University of Wellington who provided technical expertise and moral support, Dez Tessler, Cam Watson, Adrian Benson, Andrew Rae, Aleksandr Beliaev, Matt Ryan, and particularly my dedicated field assistants, Jesse Kearse and Hubert Zal.

Thank you to my late friend Nick, for being there when times were tough. Your memory constantly inspires me to be the best that I can be.

I would like to express my gratitude to my parents, Tim and Donna, Mike and Margaret. Thanks for your love and support.

And finally, to my two greatest loves, my beautiful wife Isla and my daughter Fria, for your love, your encouragement, and your putting up with me, thank you. 
"We find no vestige of a beginning, - no prospect of an end"

James Hutton, 1788 


\section{Table of Contents}

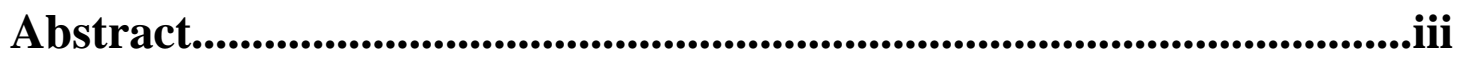

Acknowledgments ..........................................................................................

Table of Contents ................................................................................................vii

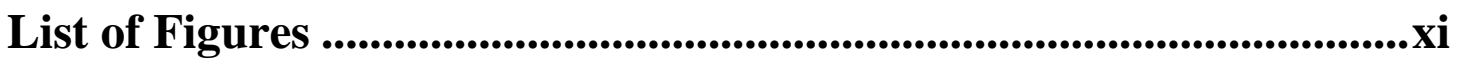

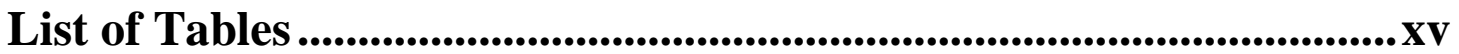

Chapter 1 Introduction .................................................................................... 1

1.1 Project motivation and objectives ………………………......................... 1

1.1.1 Project motivation ........................................................................ 1

1.1.2 Project objectives...................................................................... 6

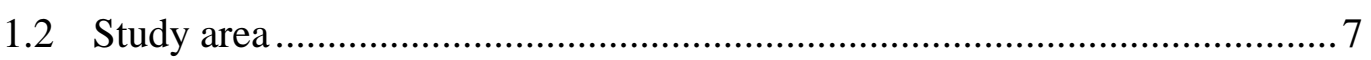

1.2.1 Whataroa River valley …………………………………….....

1.2.2 Tectonic setting of the South Island ................................................

1.2.3 Geological setting ....................................................................... 15

1.2.4 South Island glacial history and geomorphology ............................2 23

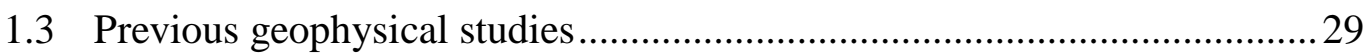

1.3.1 South Island Geophysical Transect ..............................................2 29

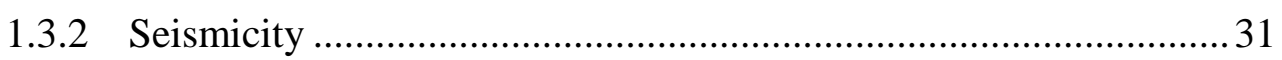

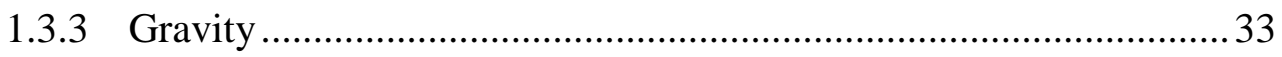

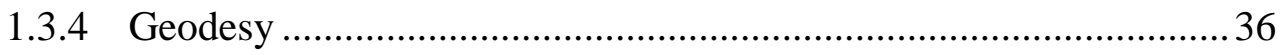

1.4 Gravity model constraints ……………………………………………........ 37

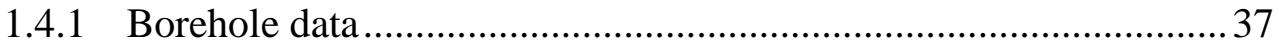

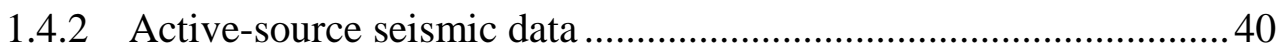

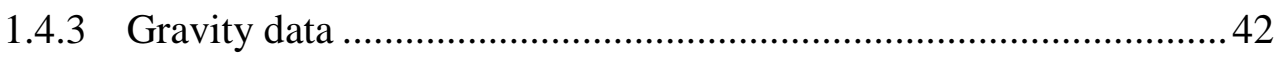

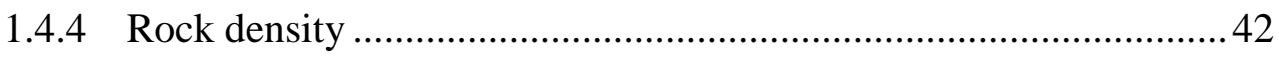

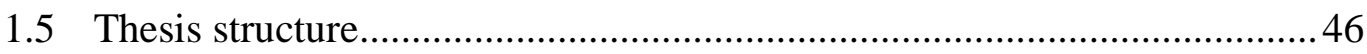


Chapter 2 Gravity and methodology .......................................................48

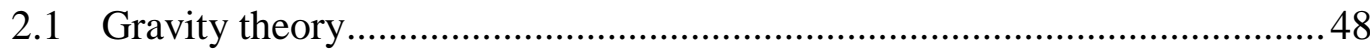

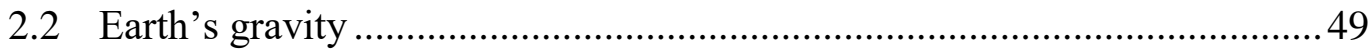

2.2.1 Relative and absolute gravity measurement ................................50

2.2.2 Temporal variation of measured gravity ....................................51

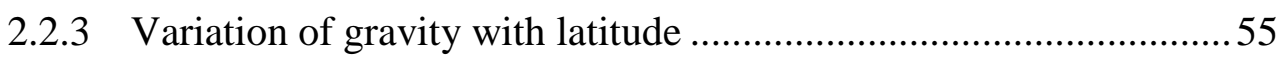

2.2.4 Variation of gravity with elevation............................................57

2.2.5 Variation of gravity with topography ...........................................59

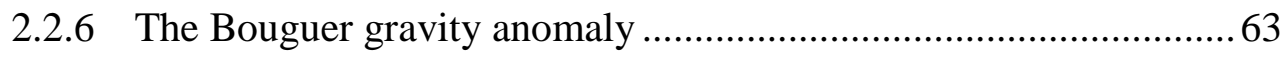

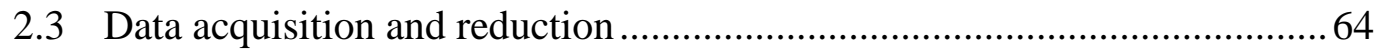

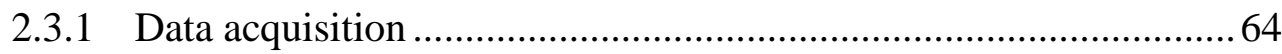

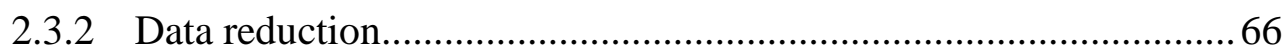

2.3.3 Uncertainty in the Bouguer gravity anomaly ...............................67

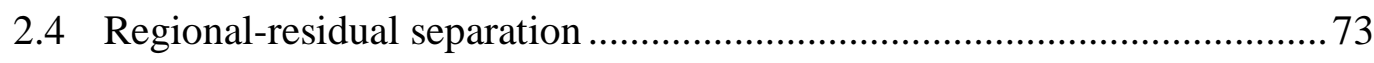

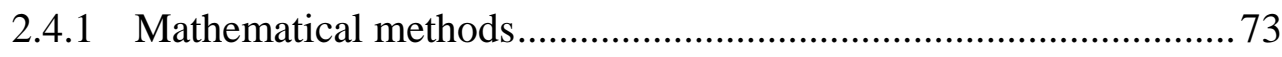

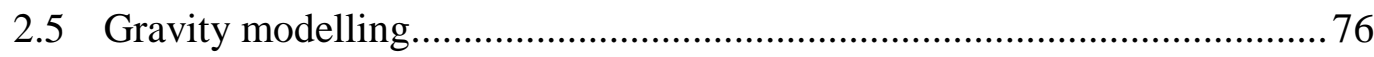

2.5.1 Two-Dimensional modelling ........................................................ 76

Chapter 3 Results ................................................................79

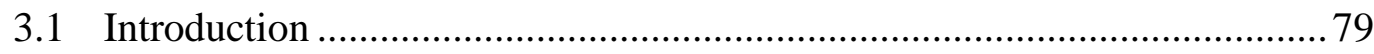

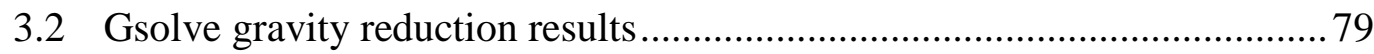

3.2.1 Gsolve gravity reduction methods ................................................ 79

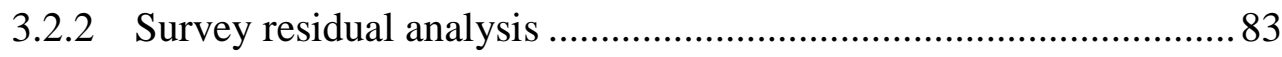

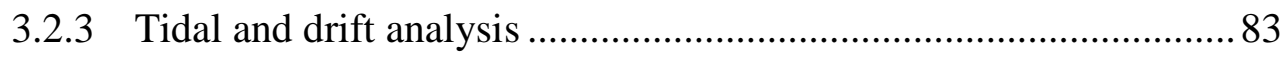

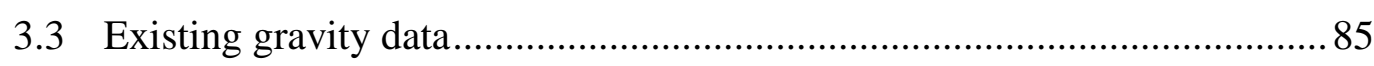

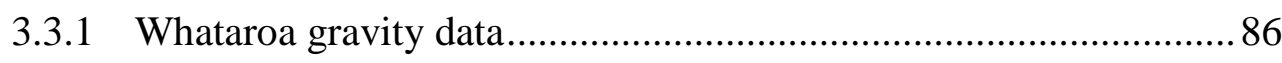

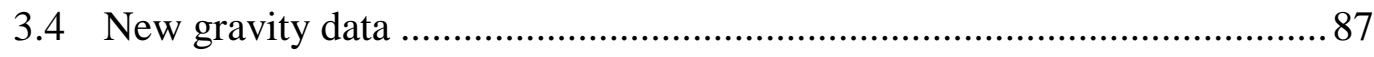

3.4.1 New gravity station locations ................................................. 87

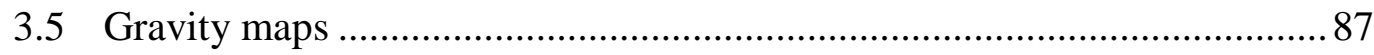

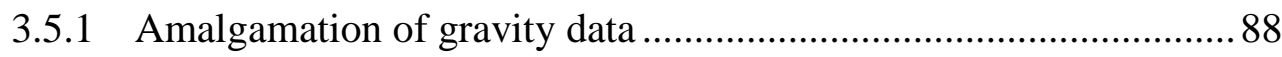

3.5.2 Bouguer gravity anomaly map ................................................ 90

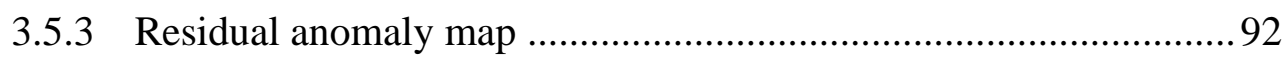

Chapter 4 Gravity models ..............................................................100 


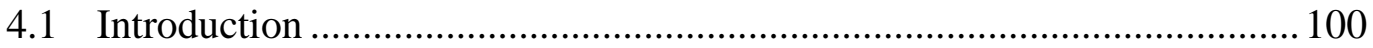

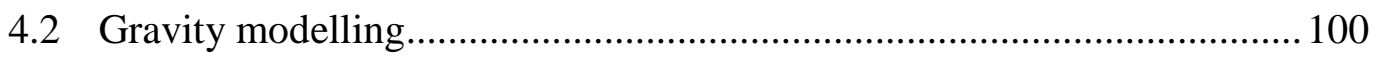

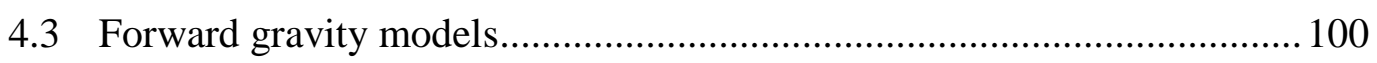

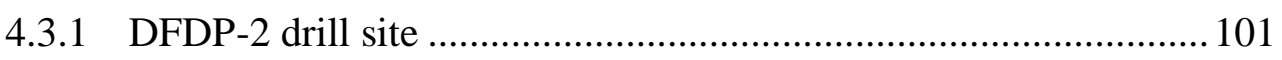

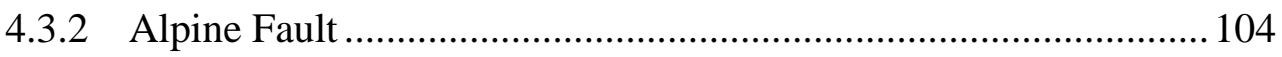

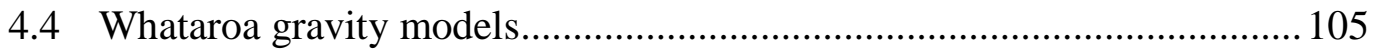

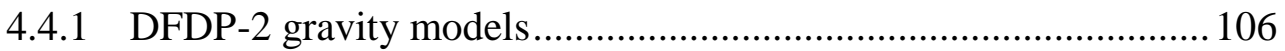

4.4.2 Alpine Fault gravity models ..................................................... 110

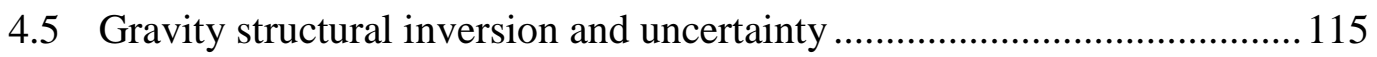

Chapter 5 Discussion and conclusions.........................................120

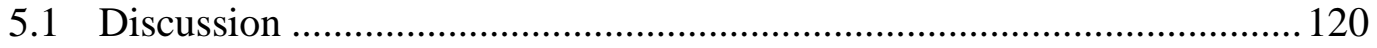

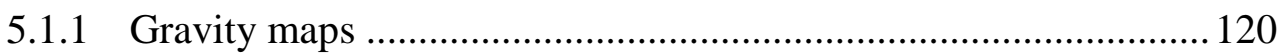

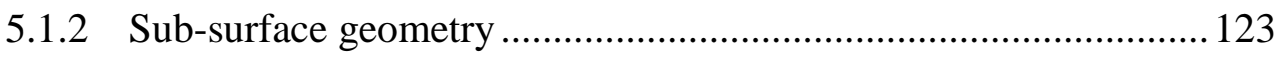

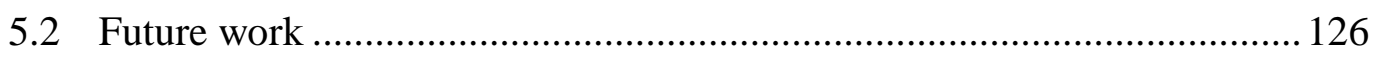

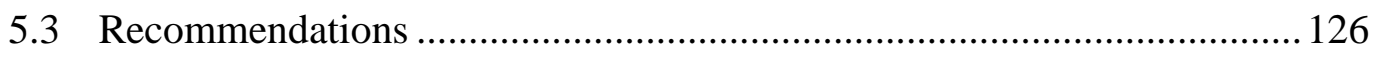

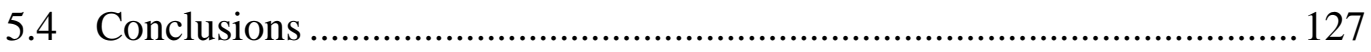

Appendix A Gravity Charts...........................................................128

Appendix B Detailed Gravity Meter Technique...................................132

Appendix C Gravity Data ...........................................................134

Appendix D Position survey data ................................................................157

Appendix E Gsolve Data .....................................................................169

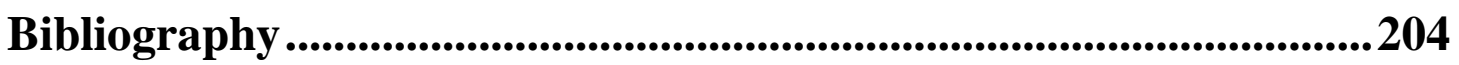




\section{List of Figures}

Figure 1.1: Map of the plate tectonic setting of New Zealand......................................2

Figure 1.2: Diagram of the orographic climate regime over the western slopes of the

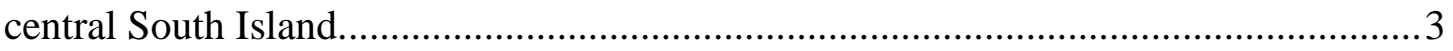

Figure 1.3: Simplified geological map of central Westland in the South Island...........5

Figure 1.4: Topographic map of the study area and the Whataroa floodplain. .............8

Figure 1.5: Cross-section showing crustal structure beneath central South Island...... 10

Figure 1.6: Estimates of Late Quaternary strike-slip rates along the Alpine Fault...... 12

Figure 1.7: Topographic map showing the surface expression of the Alpine Fault at

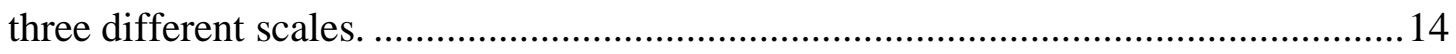

Figure 1.8: Cross-section of shallow Alpine Fault showing fault wedge structure. .... 15

Figure 1.9: Basement geology of New Zealand......................................................... 16

Figure 1.10: Surface geology map of the Whataroa study area................................22

Figure 1.11: Ice extent of the Late Otiran glaciation in Central Westland..................23

Figure 1.12: The NZ-INTIMATE climate event stratigraphy...................................25

Figure 1.13: SIGHT transects 1 and 2 extending across the central South Island........30

Figure 1.14: 2-D gravity model across the Whataroa floodplain.................................. 34

Figure 1.15: Gravity maps of the Whataroa floodplain. ............................................... 35

Figure 1.16: Cross-section through DFDP-1 boreholes............................................. 38

Figure 1.17: Geological log of Quaternary sediments sampled in DFDP-2A.............39

Figure 1.18: Seismic refraction model along SIGHT transect 1 across the Whataroa floodplain and Alpine Fault.

Figure 1.19: Gravity model of a portion of SIGHT transect 1 across the Whataroa

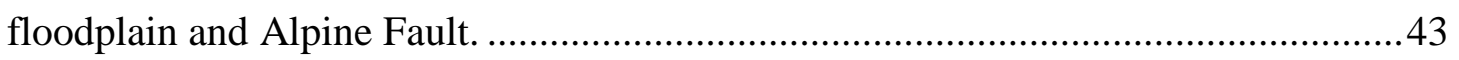

Figure 2.1: Earth-tide variations, Whataroa study area, May 2015 ...........................52

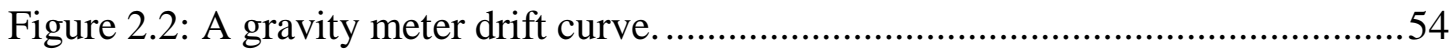

Figure 2.3: Earth's topographic, ellipsoid and geoid surfaces.................................56 
Figure 2.4: The free-air correction for an observation at a height $\boldsymbol{h}$ above the vertical

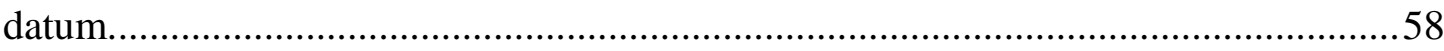

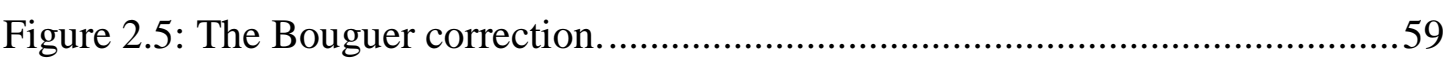

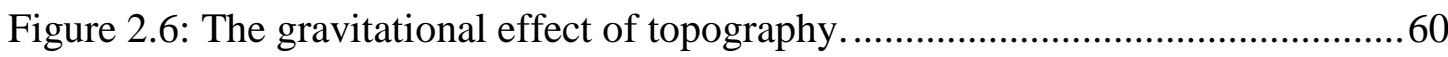

Figure 2.7: The Hammer (1939) graticule used for the calculation of terrain corrections.

Figure 2.8: Key examples of LiDAR inner terrain correction. ................................. 70

Figure 2.9: Empirical CDF plot of the difference between GPS heights and LiDAR

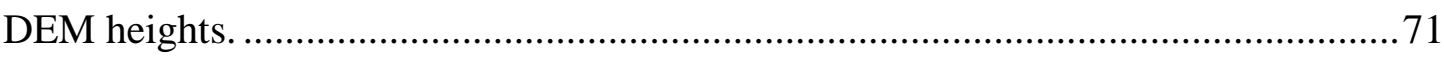

Figure 2.10: Modelling of a linear and quadratic polynomial surface fitted in $\mathrm{x}-\mathrm{y}-\mathrm{g}$

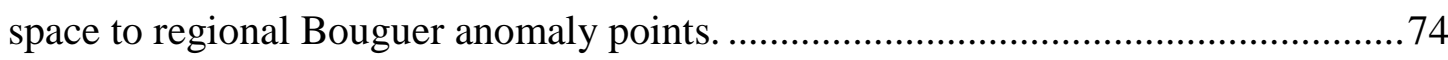

Figure 2.11: Schematic of a two-dimensional model and relative coordinate system. 77

Figure 3.1: Regional topographic map of the central West Coast. ............................. 81

Figure 3.2: CDF plot of the residuals from Gsolve's normal least squares solution (Method 1)

Figure 3.3: CDF plot of the residuals from Gsolve's decoupled least squares solution (Method 2). .84

Figure 3.4: CDF plot of the calculated tidal effects for repeat gravity readings. .84 Figure 3.5: Scatter plot of the calculated tidal effects and residuals for repeat gravity readings. 85

Figure 3.6: Existing gravity stations over the Whataroa floodplain and Whataroa River valley. 86

Figure 3.7: New gravity stations over the study area in the Whataroa River valley. .. 88 Figure 3.8: Absolute gravity difference and separation distance between existing and

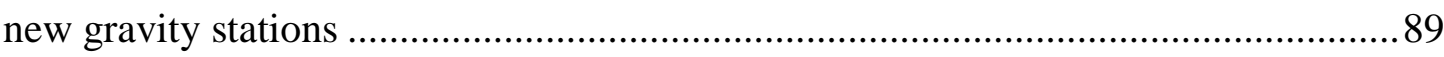

Figure 3.9: Bouguer gravity anomaly map of the Whataroa floodplain.....................91 Figure 3.10: Bouguer gravity anomaly map of the study area in the Whataroa River

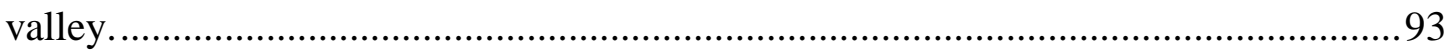

Figure 3.11: Regional-residual separation of the Whataroa River valley....................94 Figure 3.12: Residual anomaly map of the DFDP-2 drill site in the Whataroa River valley.

Figure 3.13: Residual anomaly map of the Alpine Fault at the entrance of the Whataroa River valley. .98 


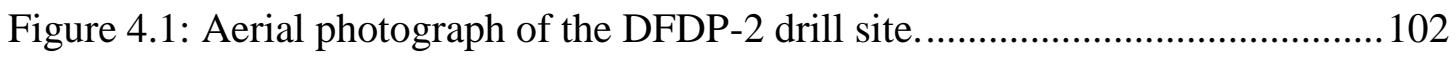

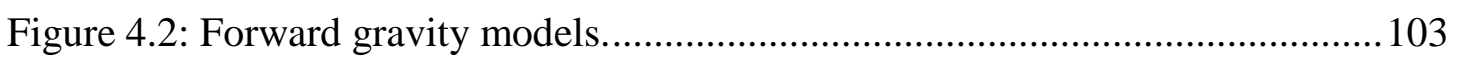

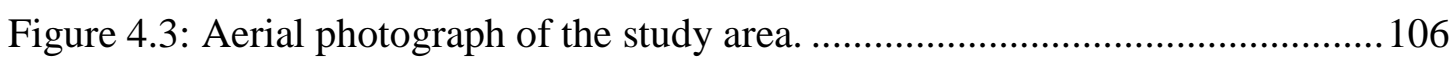

Figure 4.4: Residual gravity map of the DFDP-2 drill site showing Profile 1......... 107

Figure 4.5: Gravity Model 1A for Profile 1 at the DFDP-2 drill site. ........................ 108

Figure 4.6: Gravity Model 1B for Profile 1 at the DFDP-2 drill site......................... 109

Figure 4.7: Residual gravity map showing all five gravity profiles. ......................... 110

Figure 4.8: Gravity Model 2 for Profile 2 across the Alpine Fault............................ 111

Figure 4.9: Gravity Model 3 for Profile 3 across the Alpine Fault............................ 112

Figure 4.10: Gravity Model 4 for Profile 4 across the Alpine Fault......................... 113

Figure 4.11: Gravity Model 5 for Profile 5 across the Alpine Fault.......................... 114

Figure 4.12: Inferred location of the Alpine Fault surface trace across the Whataroa

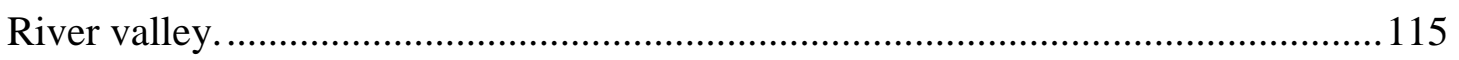

Figure 4.13: Model 1A structural inversion and uncertainty................................. 117

Figure 4.14: Model 1B structural inversion and uncertainty.................................. 118

Figure 5.1: Calculated mean density of lake silts sampled in DFDP-2 .................... 124

Figure E.1: Drift curves for all 34 survey loops produced using Gsolve. .................203 


\section{List of Tables}

Table 1.1: Mean P-wave velocities and bulk densities of rock types known in the study

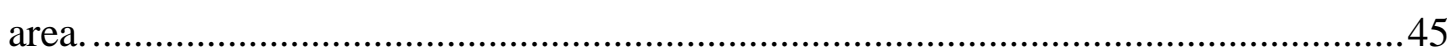

Table 1.2: Mean wet densities from the PETLAB rock catalogue. …..........................45

Table 3.1: Absolute gravity difference between observed and recorded values at 9 reference stations from the New Zealand gravity network. ...................................... 82

Table A.1: Hammer terrain correction chart.............................................................. 130

Table A.2: Calibration table for a Lacoste \& Romberg model G-519 gravity meter.131

Table C.1: Gravity data collected during this study.

Table E.1: Survey measurements processed using Gsolve for 10 absolute gravity reference stations of the New Zealand gravity network. 170

Table E.2: Survey measurements processed using Gsolve for the entire gravity survey. 194 


\section{Chapter 1 Introduction}

\subsection{Project motivation and objectives}

\subsubsection{Project motivation}

The New Zealand continent straddles the highly-active and complex Australian/Pacific Plate boundary. The Pacific Plate migrates westward and subducts beneath the Australian Plate along the Hikurangi Trench in the northeast, while the Australian Plate migrates eastward and subducts beneath the Pacific Plate along the Puysegur Trench in the southwest of New Zealand (Litchfield et al., 2014; Okaya et al., 2007; Sutherland et al., 2000; Wallace et al., 2007). The Alpine Fault connects the Hikurangi and Puysegur subduction zones, forming a continental-convergence boundary extending $\sim 740 \mathrm{~km}$ through the central South Island of New Zealand (Figure 1.1) (Litchfield et al., 2014; Okaya et al., 2007; Sutherland et al., 2000; Walcott, 1978).

The current and 3-Myr-average estimates of relative Australian/Pacific plate velocities near the Alpine Fault are each $36 \mathrm{~mm} / \mathrm{yr}$, with a $6-9 \mathrm{~mm} / \mathrm{yr}$ shortening component perpendicular to the fault (Beavan et al., 2002; DeMets et al., 2010). Plate motion during the past $45 \mathrm{Myr}$ has resulted in $\sim 850 \mathrm{~km}$ of dextral offset, of which 440 $470 \mathrm{~km}$ has been accommodated along the Alpine Fault (Sutherland, 1999b; Wellman and Willett, 1942). Uplift southeast of the fault adds a significant high-angle reverse oblique component to its displacement, responsible for $\sim 20 \mathrm{~km}$ of tectonic uplift and formation of the Southern Alps since 6-7 Ma (Cox and Sutherland, 2007; Norris and Cooper, 2007; Sutherland et al., 2000; Van Avendonk et al., 2004; Walcott, 1998).

The Southern Alps lie in the path of a westerly atmospheric circulation pattern, resulting in a dramatic orographic climate regime over the western slopes (Koons, 1990; Shulmeister et al., 2004). Heavy rainfall (> 10 m/yr) occurs west of the Main Divide, while precipitation rates are significantly lower to the east $(\leq 1 \mathrm{~m} / \mathrm{yr})$, creating a rain shadow (Henderson and Thompson, 1999). Due to the mid-latitude setting and high 


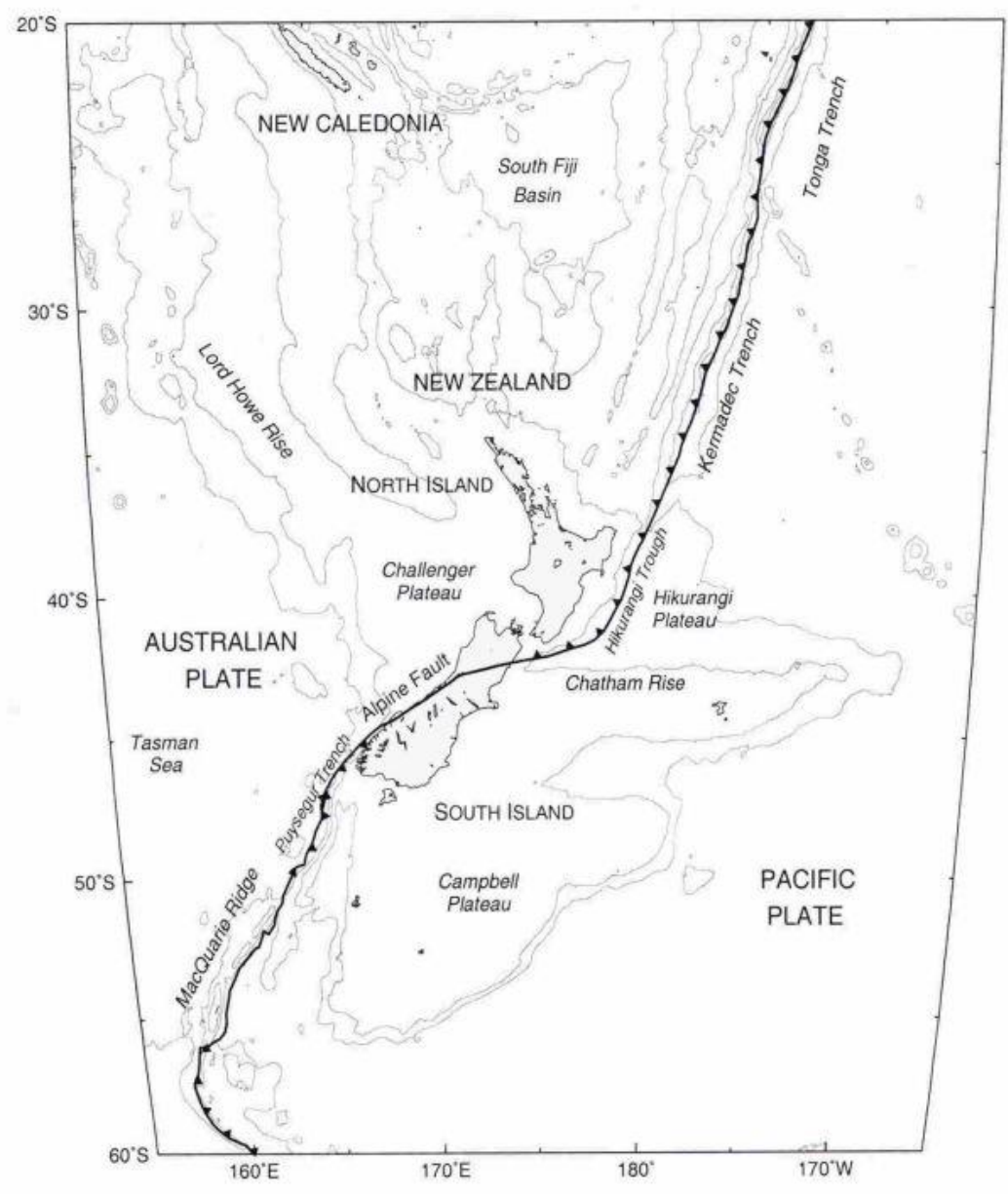

Figure 1.1: Map of the plate tectonic setting of New Zealand.

The Pacific plate migrates west and subducts beneath the Australian plate along the Hikurangi Trench in the northeast, while the Australian plate migrates east and subducts beneath the Pacific plate along the Puysegur Trench to the southwest of New Zealand. Both subduction zones are connected by the Alpine Fault through the central South Island. Figure from Kleffmann (1999).

elevations associated with the Southern Alps $(\leq 3.8 \mathrm{~km})$, much of the precipitation falls as snow and widespread glaciation occurs periodically within glacial cycles (Petit et al., 1999; Suggate, 1990; Suggate and Almond, 2005). Erosion correlates strongly with precipitation, where more extensive erosion $(\sim 10 \mathrm{~mm} / \mathrm{yr})$ occurs on the western slopes creating an orographic asymmetry (Figure 1.2) (Adams, 1980a, b; Cox and Sutherland, 2007; Fitzsimons and Veit, 2001; Hicks et al., 1996).

The rate of erosion correlates with the rate of uplift in the western and central Southern Alps keeping them in a dynamic equilibrium, while also restricting the width of transpressional deformation to a zone 90-100 km wide (Koons, 1990; Norris and Cooper, 2003; Tippett and Kamp, 1995; Walcott, 1998). Uplift rates and regional 


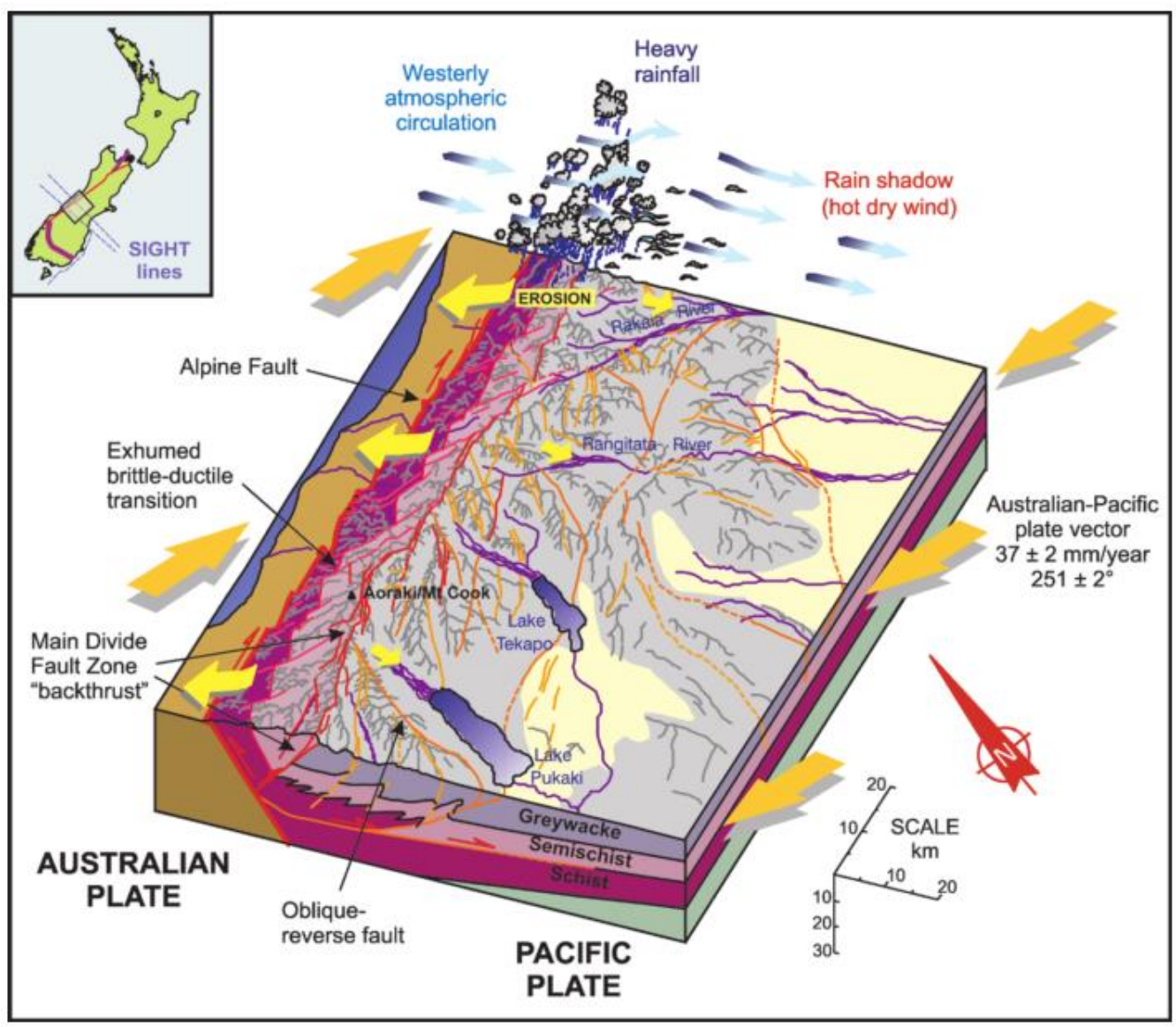

Figure 1.2: Diagram of the orographic climate regime over the western slopes of the central South Island.

Geology and the effects of Australian-Pacific plate transpression are also shown in block diagram. High rates of erosion on the western slopes $(\sim 10 \mathrm{~mm} / \mathrm{yr})$ have developed an orographic asymmetry. Figure from Cox and Sutherland (2007).

elevation diminish both in the northern and southern sections of the fault, restricting the area of maximum deformation to the central South Island (Kamp and Tippett, 1993; Little et al., 2005; Norris and Cooper, 2003; Walcott, 1998), making it a particularly useful area for investigating transpressional tectonics, faulting and mountain formation (Okaya et al., 2007).

The Alpine Fault is thought to accommodate $\sim 60-80 \%$ of the plate motion which has been estimated using Quaternary slip-rates (Norris and Cooper, 2001; 2007; Sutherland et al., 2000; Sutherland and Norris, 1995; Walcott, 1978). However, wellconstrained estimates of Alpine Fault Quaternary slip-rates are restricted to the northern and southern sections of the fault where offset surface markers are widely available (Barth et al., 2013; Norris and Cooper, 2001, 2007; Sutherland et al., 2006). High rates of erosion on the western slopes of the central Southern Alps have erased offset surface 
markers along the central Alpine Fault, making it a difficult area to quantify and constrain fault kinematics (Norris and Cooper, 2007). Gravity surveying can be used to model offset sub-surface features, providing an alternative option to quantify fault kinematics in areas that lack traditional offset surface markers, such as the central Alpine Fault. However, uncertainties associated with the offset and slip-rates estimated with this technique can be significant (Davy, 2012; 2013).

The surface expression and sub-surface structure of the central Alpine Fault has been refined using recent light detection and ranging data (LiDAR) (Barth et al., 2012; Langridge et al., 2014), and a synthesis of surface mapping data (Norris et al., 2012), confirming the non-linear form of the fault trace and serial partitioning of the fault zone that was originally recognised by Norris and Cooper (1995) and Norris and Cooper (1997). However, the surface expression and shallow geometry of the Alpine Fault at the mouth of the Whataroa River valley, near the site of a large-scale Alpine Fault drilling project (Townend, 2009), is not well-defined due to post-glacial burial of the fault zone. Reliable sub-surface data is required to further constrain the location of the fault trace and shallow fault structure.

The Alpine Fault represents the largest seismic hazard in the South Island, and a detailed earthquake record has been constructed. Over the last 7900 years, there have been 24 large-scale earthquakes (Mw 7.6-8.2) occurring along the fault approximately every 330 years (Berryman et al., 1992, 2012; Hull and Berryman, 1986; Sutherland and Norris, 1995). The most recent was in 1717 C.E. (Sutherland et al., 2007; Wells et al., 1999), resulting in a $27 \%$ model-dependent probability of a large-scale earthquake occurring on the Alpine Fault in the next 50 years (Biasi et al., 2015). The Alpine Fault is, therefore, late in its earthquake cycle, and provides an opportunity to survey and understand the characteristics of a fault before the occurrence of a large-scale earthquake.

The Deep Fault Drilling Project (DFDP) is an international science project involving researchers from more than a dozen countries (Townend et al., 2009). The project involves drilling through the sub-surface plane of the Alpine Fault to investigate the tectonic signal associated with exposed surface rocks, seismogenesis, and mineralization (Sutherland et al., 2012; Townend et al., 2013; Toy et al., 2015). The first phase of drilling (DFDP-1) was completed in 2011 at Gaunt Creek, where two boreholes were successfully drilled through the principal slip zone (PSZ) at depths of 
$91 \mathrm{~m}$ and $128 \mathrm{~m}$ (Sutherland et al., 2012). The second phase of drilling (DFDP-2) was completed early in 2015 in the Whataroa River valley, $\sim$ km northeast of Gaunt Creek (Figure 1.3). DFDP-2 aimed to target the fault plane at $1 \mathrm{~km}$ depth, and drill to a total depth of $1.3 \mathrm{~km}$. However, technical difficulties resulted in a total drilled depth of 893 m, 200 m short of the PSZ (Sutherland et al., 2015).

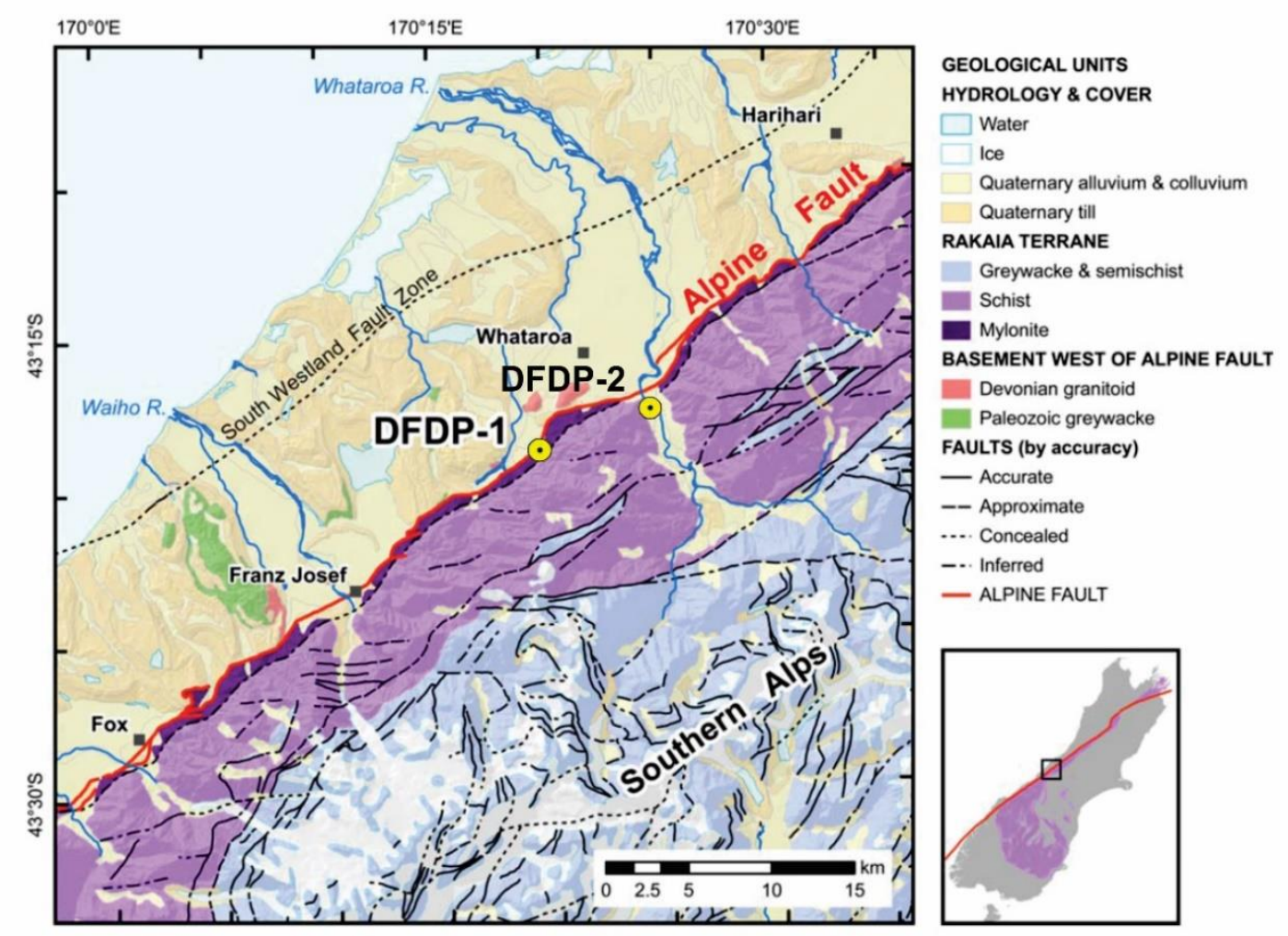

Figure 1.3: Simplified geological map of central Westland in the South Island. DFDP-1 was completed at Gaunt Creek $\sim 7 \mathrm{~km}$ southwest of the Whataroa township. DFDP-2 was completed early in 2015 in the Whataroa River valley. Also shown are the Southern Alps, and the surface trace of the Alpine Fault (red line). Figure modified from Townend et al. (2013).

Pre-drill estimates of sediment thickness at DFDP-2 were $100 \pm 40 \mathrm{~m}$; however, the observed sediment thickness in the DFDP-2B borehole was $240 \mathrm{~m}$ (Sutherland et al., 2015). Additional analysis of geophysical constraints is needed to fully understand the sub-surface geometry surrounding the DFDP-2 drill site. This was a key motivation for this project. 


\subsubsection{Project objectives}

The aim of this project is to acquire new gravity data and construct a gravity map of the Whataroa River valley, particularly near the DFDP-2 drill site and the Alpine Fault. By making measurements of the Earth's gravity field at appropriately spaced intervals, and analysing the data to extract the gravity signal associated with near-surface rock units, it is possible to model the bedrock-sediment interface geometry near the DFDP-2 borehole, and define the shallow structure of the nearby Alpine Fault. Existing gravity data will be amalgamated with new gravity measurements to maximise the coverage of the dataset. This project is a necessary contribution to the ongoing multi-disciplinary research of an active continental plate boundary, and is important in understanding the broader structure surrounding the DFDP-2 borehole, as well as the complex interplay between tectonics, glacial processes, and sedimentation.

The primary objectives of this project are prioritised as follows:

1. Acquire new gravity data and integrate with existing gravity measurements to produce a comprehensive gravity map of the Whataroa River valley near the Alpine Fault and DFDP-2 drill site.

2. Extract a regional gravity field of the Whataroa River valley so that gravity anomalies associated with short-wavelength shallow $(<500 \mathrm{~m})$ density anomalies can be isolated i.e. effects of long-wavelength surface topography and crustal root removed.

3. Produce preliminary gravity models of: the bedrock-sediment interface near the DFDP-2 drill site and across the Alpine Fault. Further modelling will require integration with other geophysical data, such as seismic-reflection data. These data are not yet published and hence more sophisticated modelling is outside the scope of this thesis. 


\subsection{Study area}

\subsubsection{Whataroa River valley}

This study encompasses an approximate $5 \times 5 \mathrm{~km}$ geographic area located at the entrance of the Whataroa River valley in central Westland, 30 km north of Franz Josef and $\sim 70 \mathrm{~km}$ south of Hokitika. The Alpine Fault strikes northeast $\left(\sim 055^{\circ}\right)$ through the centre of the study area and dips to the southeast at an angle of $\sim 30-60^{\circ}$ (Barth et al., 2012; Davey et al., 1995; Davey, 2010; Kleffmann, 1999; Norris et al., 2012; Sutherland et al., 2015). DFDP-2 is located on the hanging-wall $\sim 1 \mathrm{~km}$ southeast of the mapped fault trace. The study area is bound to the west by the Price Range and to the east by Adams Range, where elevations exceed $1000 \mathrm{~m}$ a.s.l. (Figure 1.4).

A glacio-fluvial outwash plain with low topographic relief and well-defined lateral and terminal moraines extends north-north-east and west of the study area as far as the western coastline. The Whataroa floodplain contains two lakes of glacial origin that define western and eastern termini of the last glacial maximum (LGM) (Almond et al., 2001). During the LGM, the Whataroa glacier occupied a deep trough and extended from the Whataroa valley onto the coastal plain (Almond et al., 2007; Suggate, 1990; Suggate and Almond, 2005). The trough was later filled by late-glacial and post-glacial alluvium following the retreat of the Whataroa glacier (Cox and Barrell, 2007). Ongoing dextral-reverse movement along the Alpine Fault has displaced the subparallel Whataroa River that flows through the study area and across the fault, creating a distinct bend in its trajectory, a common pattern observed along the entire length of the fault. Uplift associated with the reverse component of fault slip has created raised fluvial terraces upstream of the fault. 


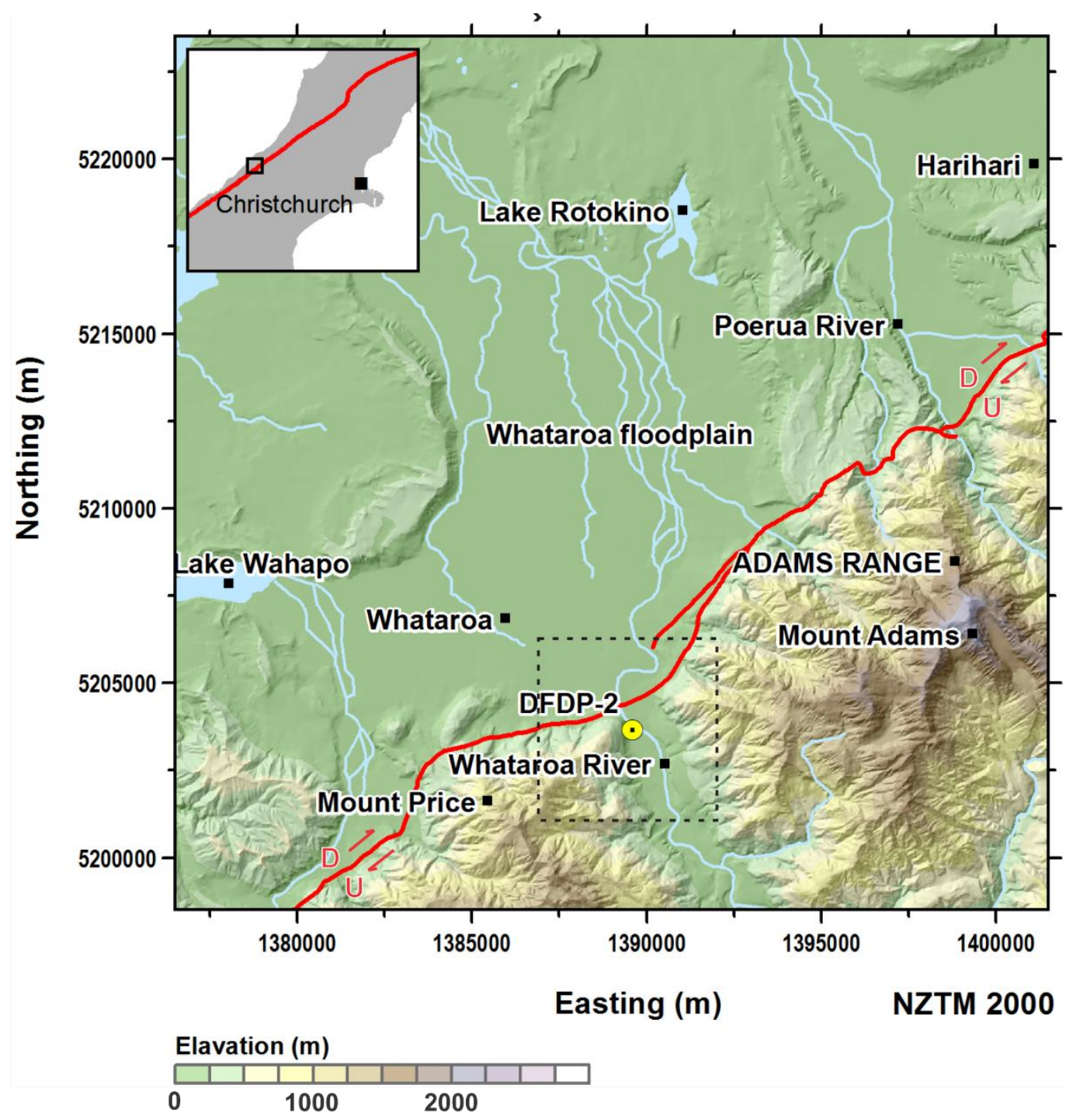

Figure 1.4: Topographic map of the study area and the Whataroa floodplain. Other points of interest are the Whataroa township, Price Range, Adams Range, the DFDP-2 drill site (yellow dot), and the two glacial lakes (Wahapo \& Rotokino). The Alpine Fault (red line) strikes NE through the $\sim 5 \times 5 \mathrm{~km}$ study area (dashed box), where ongoing dextral offset has displaced the Whataroa River. Inset map shows the position of the study area with respect to the central South Island. Fault data obtained from the New Zealand Active Faults Database (NZAFD). 


\subsubsection{Tectonic setting of the South Island}

The Alpine Fault is characterised by dextral (horizontal) slip, with a component of vertical displacement to the southeast of the fault trace. It is continuous at the surface for $\sim 740 \mathrm{~km}$, extending from offshore near Fiordland to the northern South Island, forming an oblique continental-convergence zone between the Australian and Pacific plates (Okaya et al., 2007; Sutherland et al., 2000). In the upper South Island, the northern section of the Alpine Fault is linked to the Hikurangi subduction zone via a series of predominantly continental strike-slip fault zones, known as the Marlborough Fault System (Walcott, 1978), while the southern section of the Alpine Fault links directly to the Puysegur subduction zone near the Fiordland region (Barnes et al., 2001; Okaya et al., 2007; Sutherland et al., 2000).

The Alpine Fault was inherited from an Eocene rift and passive margin that formed at $\sim 45$ Ma during the initiation of the Cenozoic plate boundary through New Zealand (Cox and Sutherland, 2007; Sutherland, 1995, 1999b; Sutherland et al., 2000). Horizontal displacement along the Alpine Fault initiated during the late Oligocene and early Miocene as oceanic crust of the Australian plate was subducted below the Fiordland region at the Puysegur trench, while rigid continental crust of the Australian plate (northwestern South Island, North Island and Challenger Plateau) acted as an indentor into weaker continental crust of the Pacific plate (eastern South Island, Chatham Rise and Campbell Plateau) (Cox and Sutherland, 2007; Sutherland et al., $2000 ; 2009$ ). The long term result of horizontal and vertical displacement is $\sim 440-470$ $\mathrm{km}$ dextral offset of bedrock terranes (Berryman et al., 1992; Sutherland, 1999b; Wellman, 1955), and uplift of the Southern Alps (Adams, 1979; Wellman, 1953, 1979).

\section{Crustal shortening and thickening due to convergence}

There has been $~ 90-100 \mathrm{~km}$ of crustal shortening in the South Island since 6-7 Ma (Walcott, 1998), of which 60-80\% has been accommodated on the southeast-dipping Alpine Fault, resulting in $\sim 20 \mathrm{~km}$ of tectonic uplift (Beaumont et al., 1996; Beavan et al., 1999; Koons, 1990; Norris and Cooper, 2001; Sutherland et al., 2000; Sutherland and Norris, 1995; Tippett and Kamp, 1993; Walcott, 1978). The remaining 20-40\% of plate-perpendicular motion is accommodated on reverse faulting both east and west of the Alpine Fault within the $\sim 90 \mathrm{~km}$ deformation zone (Beavan et al., 1999; Sutherland 
et al., 2006), as well as a component of shallow shortening through folding within the fault wedge of the central Alpine Fault (Barth et al., 2012).

During plate convergence along the Alpine Fault, $\sim 17 \mathrm{~km}$ of crustal thickening has occurred $\sim 20 \mathrm{~km}$ east of the Main Divide of the Southern Alps (Scherwath et al., 2003). Crustal thickness increases from 20-30 km east and west of the South Island to 37-48 $\mathrm{km}$ beneath the region of crustal shortening (Figure 1.5) (Bourguignon et al., 2007b; Davey et al., 2007; Davey et al., 1998; Kleffmann et al., 1998; Scherwath et al., 2003; Smith et al., 1995; Stern and McBride, 1998; Stern et al., 2000; Stern, 1995; Van Avendonk et al., 2004; Wellman, 1979).

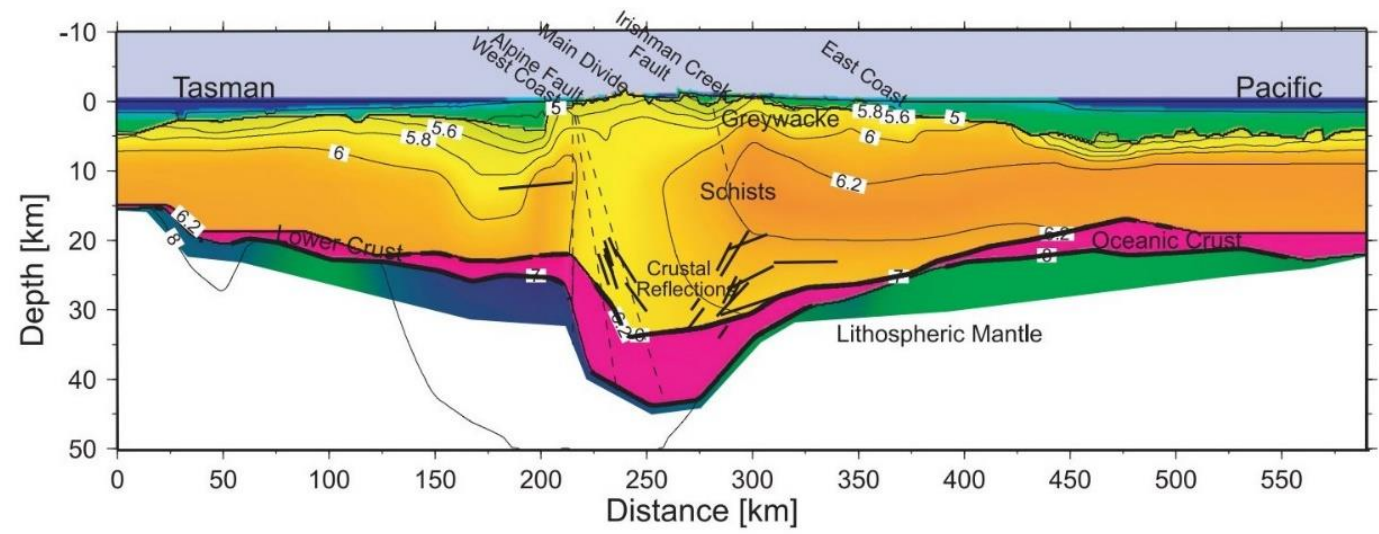

Figure 1.5: Cross-section showing crustal structure beneath central South Island.

Plate convergence causes crustal thickening beneath the Main Divide of the Southern Alps forming a 37-48 km thick crustal root. Colour scale and contour values represent seismic velocity. Figure from Stern et al. (2007).

South Island crustal thickening may be the result of a decollement located at the base of the Pacific crust (Koons, 1987), which is weaker and less resistant than the Australian crust (Beaumont et al., 1996; Sutherland et al., 2000; 2009; Van Avendonk et al., 2004). Convergence causes detachment of the over-riding metamorphosed sedimentary rocks from underlying oceanic lithosphere along the decollement (Beaumont et al., 1996; Stern et al., 2007; Stern, 1995). After detachment, the old oceanic lithosphere thickens with the mantle lithosphere (Stern, 1995; Walcott, 1998), while the detached schists and greywackes are obducted along the Alpine Fault, forming the Southern Alps (Davey et al., 1998; Smith et al., 1995; Sutherland, 1995; Walcott, 1998). Consequently, the brittle-ductile transition shallows from $\sim 15 \mathrm{~km}$ to 
5-8 km beneath the region of crustal shortening (Koons, 1987; Norris and Cooper, 1995; Walcott, 1998).

Simple models of continental-convergence in the underlying mantle lithosphere show thickening is driven by intracontinental subduction, in which crust and mantle lithosphere are delaminated and one slab of mantle lithosphere underthrusts the other (Mattauer, 1986; Matte et al., 1996; Meyer et al., 1998), which has been suggested as the driving mechanism of mantle lithosphere thickening below the Southern Alps (Beaumont et al., 1996; Wellman, 1979). However, teleseismic P-wave delay data suggests a more uniform thickening of mantle lithosphere below the Southern Alps, as if mantle lithosphere beneath continental crust behaves as a continuum (Stern et al., 2000). Additionally, the thick crustal root is at least twice as thick as expected for Airy isostatic compensation of the Southern Alps topographic load, which is thought to be due to a colder and, hence, denser mantle lithosphere acting as an effective load at the base of the crust (Bourguignon et al., 2007a).

\section{Relative Australian/Pacific plate motion and surface displacement rate}

The current and 3-Myr-average estimates of relative Australian/Pacific plate velocities near the Alpine Fault are each $36 \mathrm{~mm} / \mathrm{yr}$, with a 6-9 mm/yr shortening component perpendicular to the fault (Beavan et al., 2002; DeMets et al., 2010). The rate of plateparallel-motion for the past $24 \mathrm{Myr}$ has resulted in $\sim 850 \mathrm{~km}$ of dextral offset, of which 440-470 km has been accommodated along the Alpine Fault (Sutherland, 1999b; Wellman and Willett, 1942). This amount of accommodation is evident from estimates of Quaternary strike-slip rates, indicating that as much as $50-80 \%$ of plate-parallel motion is accommodated along the Alpine Fault (Barth et al., 2013; Cox and Sutherland, 2007; Sutherland et al., 2006).

Figure 1.6 shows estimates of Quaternary strike-slip rates on the Alpine Fault. The most southern sections of the Alpine Fault are almost pure dextral strike-slip (Barnes et al., 2001; 2005; Cooper and Norris, 1995; Norris and Cooper, 2001), which have the highest net dextral-slip rate along the fault (31 $\pm 3 \mathrm{~mm} / \mathrm{yr}$ ) (Barnes, 2009), while the rate decreases northwards to between $23-29 \mathrm{~mm} / \mathrm{yr}$ in South Westland (Barth et al., 2013; Sutherland et al., 2006; Sutherland and Norris, 1995). Central sections of the fault, located between Haast River and Taramakau River, have estimates of dextral 


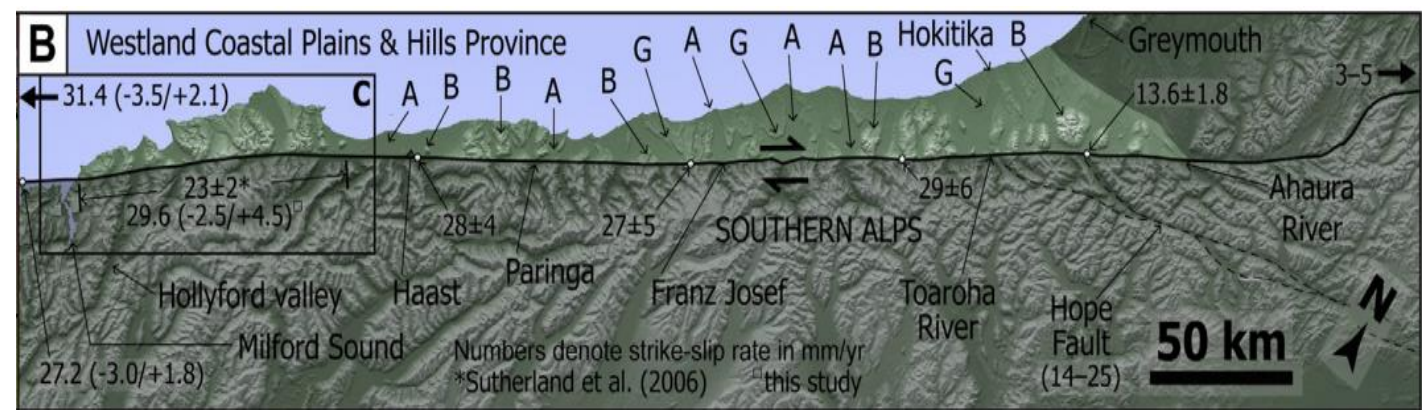

Figure 1.6: Estimates of Late Quaternary strike-slip rates along the Alpine Fault.

Alpine Fault strike-slip rates are highest in the southwest where they steadily diminish northeast through the central fault sections toward the Hope Fault. Figure from Barth et al. (2013).

strike-slip rates of $28 \pm 4 \mathrm{~mm} / \mathrm{yr}$ (Norris and Cooper, 2001), $27 \pm 5 \mathrm{~mm} / \mathrm{yr}$ (Norris and Cooper, 1997), > 22 mm/yr at Gaunt Creek (Cooper and Norris, 1994), $29 \pm 6$ mm/yr (Wright, 1998), and $13.6 \pm 1.8 \mathrm{~mm} / \mathrm{yr}$ at Inchbonnie (Langridge et al., 2010).

High rates of erosion on the western slopes of the Southern Alps have erased offset surface markers along the central Alpine Fault (Henderson and Thompson, 1999; Koons, 1989), making it a difficult area to quantify and constrain fault kinematics. Better data are still required from the central Alpine Fault to demonstrate a variable strike-slip rate (Norris and Cooper, 2007). Horizontal motion diminishes northwards (Norris and Cooper, 2001), where the remaining 20-50\% of parallel-plate motion is partitioned onto the Marlborough Fault System, particularly the Hope Fault (Langridge et al., 2010), as well as a component of horizontal motion by clockwise block rotations and oblique-dextral reverse faulting up to $80 \mathrm{~km}$ southeast of the Alpine Fault (Sutherland et al., 2006; Wallace et al., 2007).

Uplift rates and elevation diminish both in the northern and southern sections of the fault, restricting the area of maximum deformation to the central South Island, where the dip-slip rate on the Alpine Fault near Aoraki/Mt Cook is locally up to 10 $\mathrm{mm} / \mathrm{yr}$ (Norris and Cooper, 2001), and uplift rates to the east of the fault are $>8 \mathrm{~mm} / \mathrm{yr}$ (Batt, 2001; Little et al., 2005; Simpson et al., 1994).

\section{Alpine Fault surface expression and shallow geometry}

The Alpine Fault can be divided into three geographic segments based on fault geometry, named here as the southern sections, central sections and northern sections. 
South of Haast River, the southern sections of the Alpine Fault consist of linear enechelon traces, striking $050-055^{\circ}$, which are sub-vertical to steeply southeast-dipping (Barnes et al., 2001; 2005; Norris and Cooper, 2007). Between Haast River and Taramakau River, the central sections of the Alpine Fault are best described at three different scales (Figure 1.7) (Barth et al., 2012). At the first order $\left(<10^{6}-10^{4} \mathrm{~m}\right)$, the central Alpine Fault is remarkably straight with a continuous surface expression and no step-overs $>1 \mathrm{~km}$ (Sutherland et al., 2007). At the second order $\left(10^{4}-10^{3} \mathrm{~m}\right)$, the central sections of the fault are serially partitioned, consisting of non-linear, $\sim 055^{\circ}$-striking, shallow-dipping $\left(30^{\circ}-40^{\circ}\right)$, oblique-slip thrust faults (Norris et al., 1990), connected by ENE-WSW- to ESE-WNW-striking, strike-slip transfer faults (Cooper and Norris, 1995). At the third order $\left(10^{3}-10^{0} \mathrm{~m}\right)$, the fault is parallel-partitioned into asymmetric positive (reverse) flower structures, or fault wedges, in the hanging-wall. The fault wedges are $\sim 300 \mathrm{~m}$ wide and are bounded by dextral-normal and dextral thrust faults rooted at shallow depths $(<600 \mathrm{~m})$ on a planar, moderately southeast dipping, dextralreverse fault plane (Figure 1.8) (Barth et al., 2012). South of Taramakau River, the northern sections of the Alpine Fault consist of linear traces that are consistent with oblique-slip faulting on a steeply-dipping fault that merges into the Marlborough Fault System near Inchbonnie in the central South Island (Langridge et al., 2010).

Surface geological data (Sibson et al., 1979) indicate the central Alpine Fault zone dip at depth is $\sim 45^{\circ}$ towards the southeast, which is consistent with more recent models based on magnetotelluric, seismic and GPS data (Beavan et al., 1999; Davey et al., 1998; Eberhart-Phillips, 1995; Leitner et al., 2001; Stern et al., 2007). Analysis of fractures and foliation planes identified in basement rock from borehole data in the Whataroa valley (DFDP-2) reveal a fabric dip of $45-55^{\circ}$ towards the southeast $\left(145^{\circ}\right)$ (Sutherland et al., 2015), consistent with regional fracture patterns and basement rock foliations east of the fault trace (Hanson et al., 1990; Little et al., 2002; Norris et al., 2012). Seismic imaging of the shallow Alpine Fault structure in the centre of the Whataroa valley, $\sim 2 \mathrm{~km}$ below the DFDP-2 borehole, reveals a sharp and pronounced reflector dipping to the southeast at $\sim 40^{\circ}$, interpreted as the main fault plane of the Alpine Fault (Kovacs et al., 2013; Lay et al., 2015).

West of the Whataroa River, near Arthur Creek, a steep fault zone strikes ESE $\left(075^{\circ}\right)$ and contains at least two prominent lineaments dominated by dextral strike-slip. 

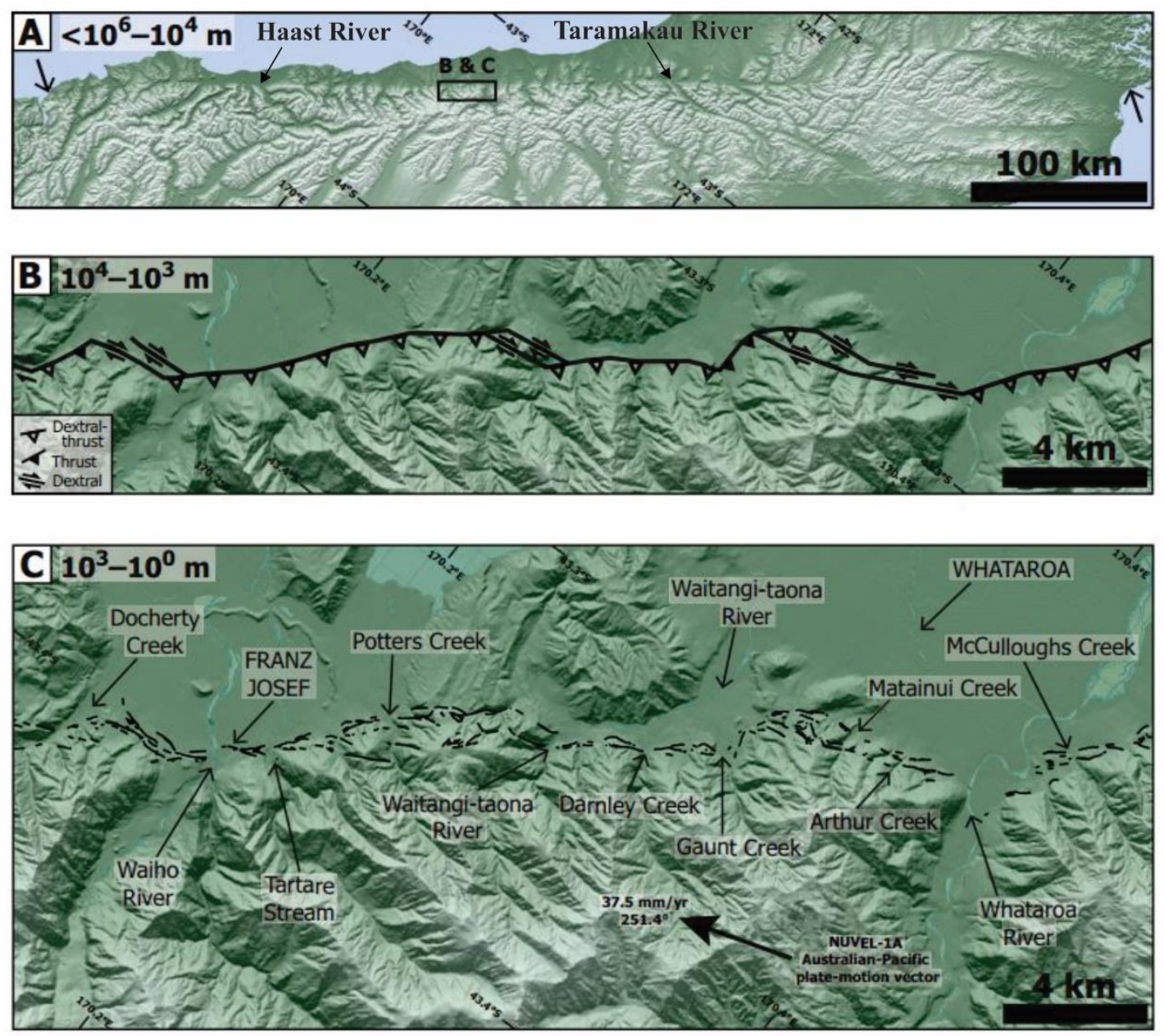

Figure 1.7: Topographic map showing the surface expression of the Alpine Fault at three different scales.

(A) Large-scale $\left(<10^{6}-10^{4} \mathrm{~m}\right)$ extent of the central Alpine Fault between Haast River and Taramakau River. Notice the remarkably straight surface trace. (B) Serially partitioned segments of oblique-slip thrust faults connected by strike-slip transfer faults of the order of $10^{4}-10^{3} \mathrm{~m}$ in length. (C) Small-scale $\left(10^{3}-10^{0}\right)$ extent of the central Alpine Fault showing parallel partitioned asymmetric faulting. The Whataroa River valley is shown on the far right of the image. Figure from Barth et al. (2012).

Conversely, to the north of Whataroa River, the Alpine Fault strikes $055^{\circ}$ as an oblique thrust zone (Barth et al., 2012; Norris et al., 2012), highlighting the complexity of the fault zone across the Whataroa valley, because it is near a junction between a strikeslip and oblique thrust segment (Barth et al., 2012; Norris et al., 2012). In the immediate sub-surface, the dip of the fault plane shallows to sub-horizontal at the base of the thrust sheet due to gravitational collapse of the range front (Cooper and Norris, 1994; Norris and Cooper, 1995). 


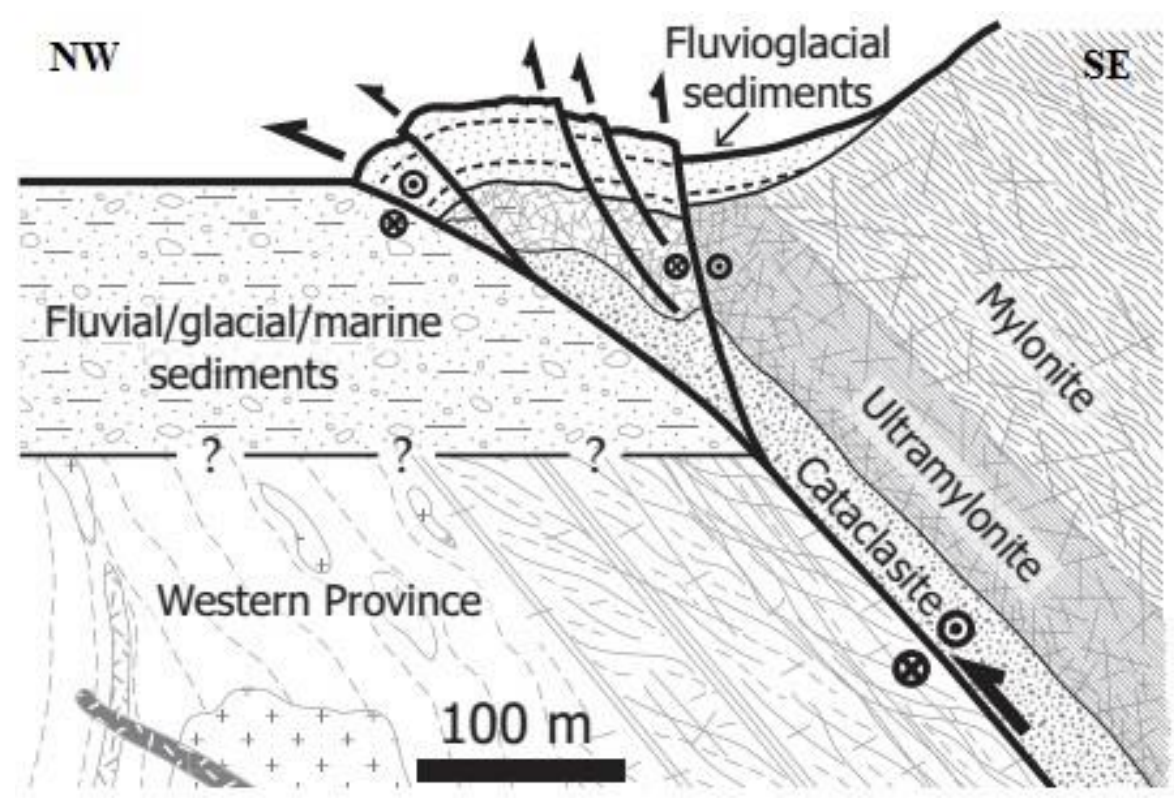

Figure 1.8: Cross-section of shallow Alpine Fault showing fault wedge structure.

The southeastern half of the fault wedge is bounded by dextral-normal faults and the northwestern half comprise dextral thrust faults, forming an anticlinal ridge. This complex array of faults are inferred to be rooted at shallow depths $(<600 \mathrm{~m})$ on a planar, moderately southeast dipping, dextral-reverse fault plane (Barth et al., 2012).

\subsubsection{Geological setting}

\section{South Island basement terranes}

The basement geology of South Island is separated into two continental fragments with different histories, the Western Province and Eastern Province (Mortimer, 2004). Figure 1.9 shows the distribution of basement rock in New Zealand.

Basement rocks of the Western province are a fragment of Gondwana continental crust (Cooper, 1989; Münker and Cooper, 1999), which extend from northwest Nelson to Fiordland along the west coast of the South Island and occur on Stewart Island (Cooper and Tulloch, 1992; Turnbull et al., 2010; Turnbull and Allibone, 2003). Similar rocks occur on the offshore Campbell and Challenger plateaus (Beggs et al., 1990, Wood, 1991, Wodzicki, 1974). Two dominant basement units of the Western province are the Takaka and Buller terranes (Cooper, 1989; Mortimer, 2004; Münker and Cooper, 1999). 


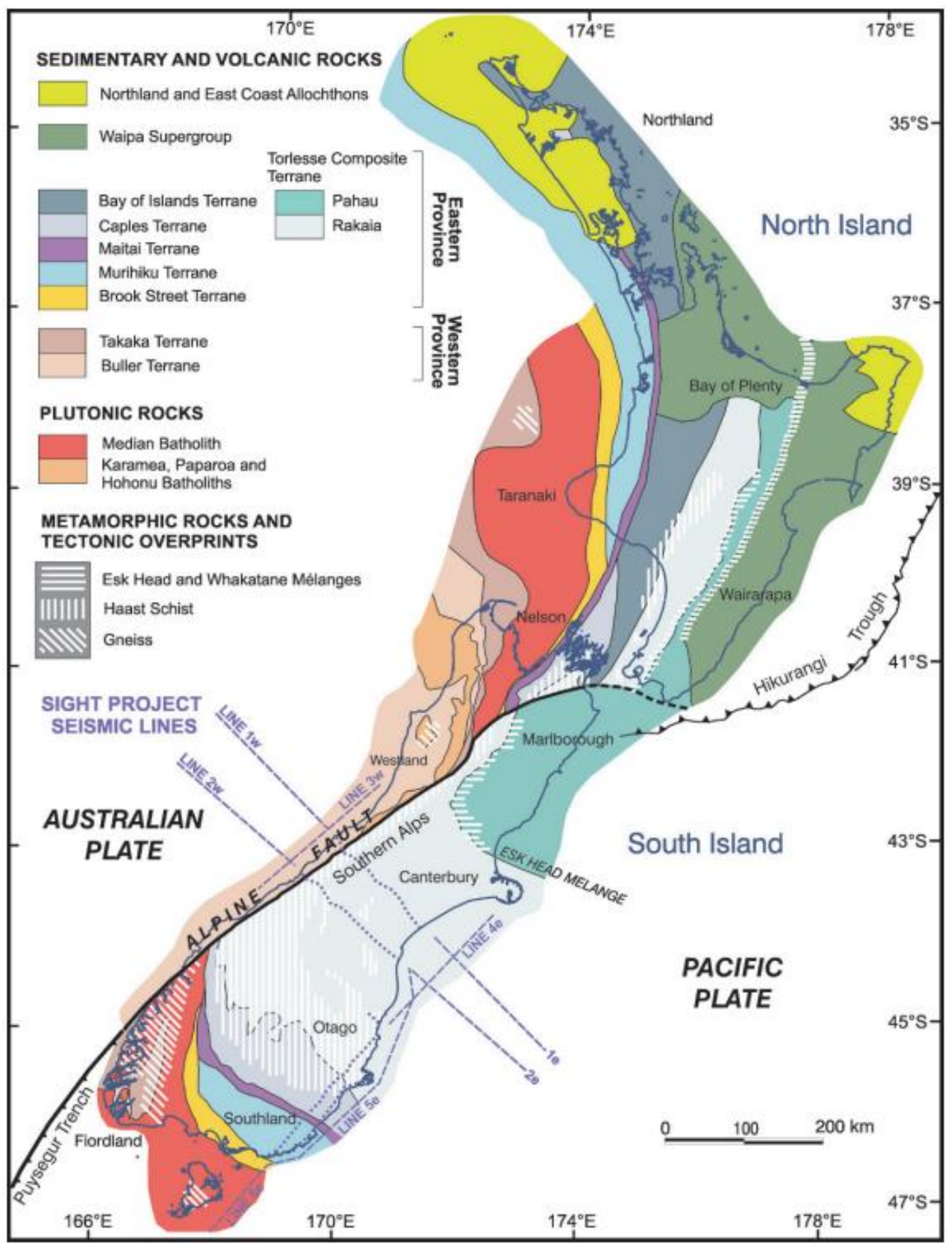

Figure 1.9: Basement geology of New Zealand.

The map shows the main terranes once accreted to the Gondwana margin. These have since been intruded by batholiths, overprinted by metamorphism and deformation, then twisted and offset during the formation of the Australian/Pacific plate boundary. Figure from Cox and Sutherland (2007).

The Takaka terrane consists of siliciclastic, carbonate and volcanic rocks of Cambrian to Early Devonian age (Cooper, 1989; Cooper and Tulloch, 1992), which record a history of terrane accretion onto the Gondwana margin (Münker and Crawford, 2000). 
The Buller terrane is the westernmost terrane in New Zealand and forms the basement rock of the West Coast of the South Island (Cooper and Tulloch, 1992), consisting of metamorphosed Ordovician quartz-rich clastics, siltstone and black shale (Cooper, 1989). Both terranes were intruded by granites in two main episodes, once during the Karamea Suite intrusive event in the Late Devonian (Muir et al., 1998; Tulloch, 1988), and again during the formation of the Paparoa and Hohonu batholiths, which were emplaced in the Cretaceous (Tulloch and Kimbrough, 1989; Waight et al., 1997). Along the West Coast of the South Island, the Buller terrane is overlain by $2000-4000 \mathrm{~m}$ of Cenozoic sediments (Cox and Barrell, 2007; Davey, 2010; Davy et al., 2013; Nathan et al., 1986).

Basement rocks of the Eastern Province extend throughout the southern, central and northern South Island, comprising of five basement terranes accreted onto the Western Province crust of Gondwana (Mortimer, 2004). In the north and central South Island, the Rakaia subterrane of the Torlesse terrane is dominated (>95\%) by a turbiditic submarine Permian to Late Triassic quartzofeldspathic sandstone-mudstone (argillite) that was deposited as an accretionary wedge complex, derived from a relatively unweathered source averaging near granodiorite composition, likely from an active continental volcanoplutonic arc (Mortimer, 2004; Roser and Korsch, 1999; Wandres et al., 2004). In the south, the Caples terrane is a tectonically imbricated, weakly metamorphosed sequence of poorly fossiliferous marine volcaniclastic Permian-Triassic greywacke and argillite that was deposited as submarine fan deposits in lower trench-slope basins and on a trench floor adjacent to an island arc, before juxtaposition with the Rakaia terrane (Roser et al., 1993). The Rakaia/Caples terrane contact has been overprinted by Haast schists, a metamorphic belt that has been buried to a maximum of 30-35 km (Grapes and Watanabe, 1992; 1994; Holm et al., 1989), where most prograde mineral growth took part in the Middle Jurassic to Early Cretaceous (Mortimer, 2000, 2004). South of the Caples terrane is the Dun MountainMaitai, Murihiku and Brook Street terrane metasediments that show cooling age patterns that indicate low-grade metamorphism in earliest Permian to latest Jurassic times (Adams et al., 2002).

Exhumation of the Haast schist belt was episodic, with most of the low-grade (greenschist and lower) section being at the surface by $110 \mathrm{Ma}$, during ridge subduction at the Gondwana margin in the mid-Cretaceous (Bradshaw, 1989; Mortimer, 2004). 
Following ridge subduction at the Gondwana margin, the New Zealand region underwent northeast directed extension (Bradshaw, 1989; Laird and Bradshaw, 2004), resulting in continental breakup $\sim 83$ Ma between New Zealand, Australia and Antarctica, and the development of the Tasman Sea and Southwest Pacific Ocean (Gaina et al., 1998; Sutherland, 1995, 1999a; Weissel et al., 1977). Further extension and post-rift thermal subsidence between 80-60 Ma occurred over the New Zealand region (Laird and Bradshaw, 2004), followed by the cessation of Tasman Sea spreading at $\sim 52 \mathrm{Ma}$ (Gaina et al., 1998), and the formation of the Australian/Pacific plate boundary since $\sim 45 \mathrm{Ma}$, transforming an initial Eocene passive margin into the present day Alpine Fault (Kamp, 1986; Sutherland, 1999b; Sutherland et al., 2000). Deeper $(\sim 25 \mathrm{~km})$ amphibolite facies Haast schists, as well as Torlesse greywackes, were exhumed along the Alpine Fault from $\sim 20$ Ma to the present day due to Australia/Pacific plate convergence (Adams, 1981; Cooper, 1980; Davey et al., 1998; Holm et al., 1989; Smith et al., 1995; Sutherland, 1995; Walcott, 1998). Additionally, the Alpine Fault offsets basement terranes horizontally by $440-470 \mathrm{~km}$ in South Island, consistent with dextral strike-slip motion (Berryman et al., 1992; Sutherland, 1999b; Wellman, 1955), and has juxtaposed the Eastern and Western provinces (Figure 1.9).

\section{Fault rocks}

Exhumation of amphibolite facies Haast schists during the past 5 Myr (Adams, 1981; Cooper, 1980; Holm et al., 1989) has also resulted in exposure of mylonite and protomylonite up to $1 \mathrm{~km}$ wide adjacent to the Alpine Fault east of the surface trace (Reed, 1964; Sibson et al., 1979, 1981). The degree of mylonitisation decreases heterogeneously eastwards across the fault zone from gouge and cataclasite in contact with Late Quaternary sediments or Western Province bedrock, through ultramylonite, mylonite and protomylonite over a distance of $\sim 1 \mathrm{~km}$, before transitioning into the amphibolite facies schist protolith (Cox and Barrell, 2007; Norris and Cooper, 2003; 2007; Sibson et al., 1979). This transition was observed in the Whataroa valley when drilling into basement from $\sim 1 \mathrm{~km}$ southeast of the Alpine Fault (DFDP-2), where a moderately-dipping strongly-foliated sequence transitioned from schist to protomylonite to mylonite downhole to a depth of $893 \mathrm{~m}$ (Sutherland et al., 2015). The fault zone of the Alpine Fault has been observed in detail at Gaunt Creek, $\sim 7 \mathrm{~km}$ southwest of the Whataroa valley, where field studies and drilling (DFDP-1) define 
four main types of fault rock (Cooper and Norris, 1994; Norris and Cooper, 2007; Schleicher et al., 2015; Sibson, 1977; Sibson et al., 1981; Sutherland et al., 2012; Toy et al., 2015; Toy et al., 2008):

- Hanging-wall ultramylonite: The hanging-wall of the Alpine Fault within $\sim 100 \mathrm{~m}$ of the principal slip zone (PSZ) is composed of ultramylonitic fault rocks exhibiting a planar foliation formed during ductile shearing at temperatures exceeding that of the brittle-creep transition at $\sim 300^{\circ} \mathrm{C}$.

- Hanging-wall cataclasite: Within $\sim 20 \mathrm{~m}$ of the PSZ, there is a progressive downward transition from ultramylonite to paler green cataclasite. These cataclasites are typically faulted and exhibit random-fabric structure, resulting from brittle deformation at depths of $\sim 4-8 \mathrm{~km}$.

- Fault gouge and ultracataclasite: The central part of the fault zone consists of ultracataclasite and fault gouge, which forms in a narrow, discrete, ultrafinegrained, brownish-grey interval with very high smectite clay concentration at shallow depths.

- Footwall cataclasite: The footwall section of the fault zone consists of a greywhite structureless quartz- and feldspar-rich cataclasite beneath the PSZ, distinct from hanging-wall cataclasite. Over the next $\sim 15 \mathrm{~m}$, this material is interlayered on a sub-meter scale with foliated and unfoliated cataclasites.

\section{Quaternary sedimentary rocks}

Glaciers covered the Whataroa floodplain extending from the Whataroa River valley out toward the current coastline during the New Zealand Last Glacial Maximum (LGM), between 26-17 ka (Alloway et al., 2007; Barrell et al., 2013; Barrell, 2011; Barrows et al., 2013; Golledge et al., 2012; Herman and Braun, 2008). During multiple glacial cycles, of progressively lesser extent, ice abutted and modified hills of older Quaternary glacial tills, producing moraines of Otiran (LGM) and pre-Otiran age, and associated aggradational outwash plains (Cox and Barrell, 2007; Cox et al., 2013; Evans et al., 2010; Suggate, 1990; Suggate and Almond, 2005). West Coast glacial tills are generally grey in colour and consist of bouldery gravels, sands, silt and clay; and glacial outwash is a poorly sorted silty gravel (Cox and Barrell, 2007). 
During glacial retreat, beginning at the end of the LGM ( 18 ka) (Barrows et al., 2013; Suggate, 1990; Vandergoes et al., 2005), the deep trough once occupied by the Whataroa glacier was infilled with late-glacial alluvium (Cox and Barrell, 2007; Cox et al., 2013). Coseismic uplift on the hanging-wall of the Alpine Fault, followed by subsequent down-cutting by Whataroa River, led to raised terraces southeast of the fault and development of aggradational fans at the margins of the coastal plain (Cox and Barrell, 2007; Cox et al., 2013; Sutherland, 1996). An offset late-glacial aggradational terrace on the hanging-wall of the Alpine Fault in the Whataroa Valley provides a record of vertical displacement on the fault (Adams, 1979; 1980a, b; De Pascale and Davies, 2014; De Pascale, 2014; Wellman, 1953).

Sedimentation is highly episodic, involving infrequent pulses of aggradation following major earthquakes (Almond et al., 2000; Howarth et al., 2012; McSaveney, 2002), high-intensity rainstorms (Henderson and Thompson, 1999), large landslides (Korup et al., 2004), and historic migration of river channels (Griffiths and McSaveney, 1986). Alluvial sediments exposed by the Whataroa River are typically coarse-to-fine grained angular schist gravels, separated by young soil horizons containing rooted tree stumps, evidence of infrequent pulses of river aggradation, with intervening periods of relative stability and river down-cutting (Almond et al., 2000; McSaveney, 2002).

West of the Alpine Fault, beneath Quaternary sediments, Ordovician Greenland Group quartz-rich metasediments of the Buller Terrane and gneissic intrusions of Late Devonian and Cretaceous granitoids are overlain by a sequence of Paleogene to Neogene sedimentary rocks $\sim 2000-3000$ m thick (Nathan et al., 1986), although some granitic intrusions are exposed near the range front (Cox and Barrell, 2007; Cox et al., 2013). Where the Whataroa River valley crosses the Alpine Fault, a paleo-glacial channel is now filled with $\sim 200-350 \mathrm{~m}$ of post-glacial alluvium, highlighting the dramatic decrease in sediment thickness toward the range front (Davey, 2010; Davy et al., 2013; Kovacs et al., 2013; Lay et al., 2015). The old glacial channel is thought to represent an ice-erosion surface dating from $\sim 17-18 \mathrm{ka}$, when the retreat of LGM ice began (Barrows et al., 2013; Cox and Barrell, 2007; Vandergoes et al., 2005). Immediately southeast of the Alpine Fault, a thicker-than-predicted layer of Quaternary sediment was encountered during drilling (DFDP-2), which sampled a rapidly deposited glaciolacustrine sequence, overlain by deltaic sands and post-glacial 
alluvium, indicating the presence of a large pro-glacial lake (Cox et al., 2015; Sutherland et al., 2015).

\section{Geological map}

The surface geology of the study area and Whataroa floodplain are shown in Figure 1.10. East of the Alpine Fault is an approximate $1 \mathrm{~km}$ wide mylonitic and curly schist zone adjoining the amphibolite facies schist protolith. The metamorphic grade decreases steadily eastwards, with pumpellyite-actinolite Permian to Late Triassic quartzofeldspathic sandstone-mudstone of the Rakaia subterrane within $15 \mathrm{~km}$ of the fault trace (not shown). West of the Alpine Fault, quartz-rich Paleozoic sediments and granites of the Australian plate are buried below moraines of Otiran (LGM) and preOtiran age, limiting basement outcrop to isolated hills and the cores of some hill ranges. Late-glacial and post-glacial alluvium occupies the Whataroa glacifluvial outwash plain between moraine covered hill ranges (Cox and Barrell, 2007; Cox et al., 2013).

\section{South Westland Fault}

The South Westland Fault (SWF) is a thrust fault system on the central West Coast striking subparallel to and lying $\sim 5 \mathrm{~km}$ west of the Alpine Fault near Whataroa (Figure 1.10), according to a joint interpretation between seismic and gravity data (Davey, 2010; Davy et al., 2013). The SWF marks the northwest limit of plate boundary deformation (Kamp et al., 1992; Sircombe and Kamp, 1998; Walcott, 1998), and bounds the southeast limit of the South Westland Basin, a predominantly offshore sedimentary basin which partially overlaps the coastal plain west of the Alpine Fault (Davy et al., 2013; Nathan et al., 1986; Sircombe and Kamp, 1998). During the MidMiocene, the SWF developed as a series of southeast-dipping thrust faults, where dipslip displacement of $\sim 3500 \mathrm{~m}$ resulted in the formation of a crustal monocline structure (Cotton, 1956). 


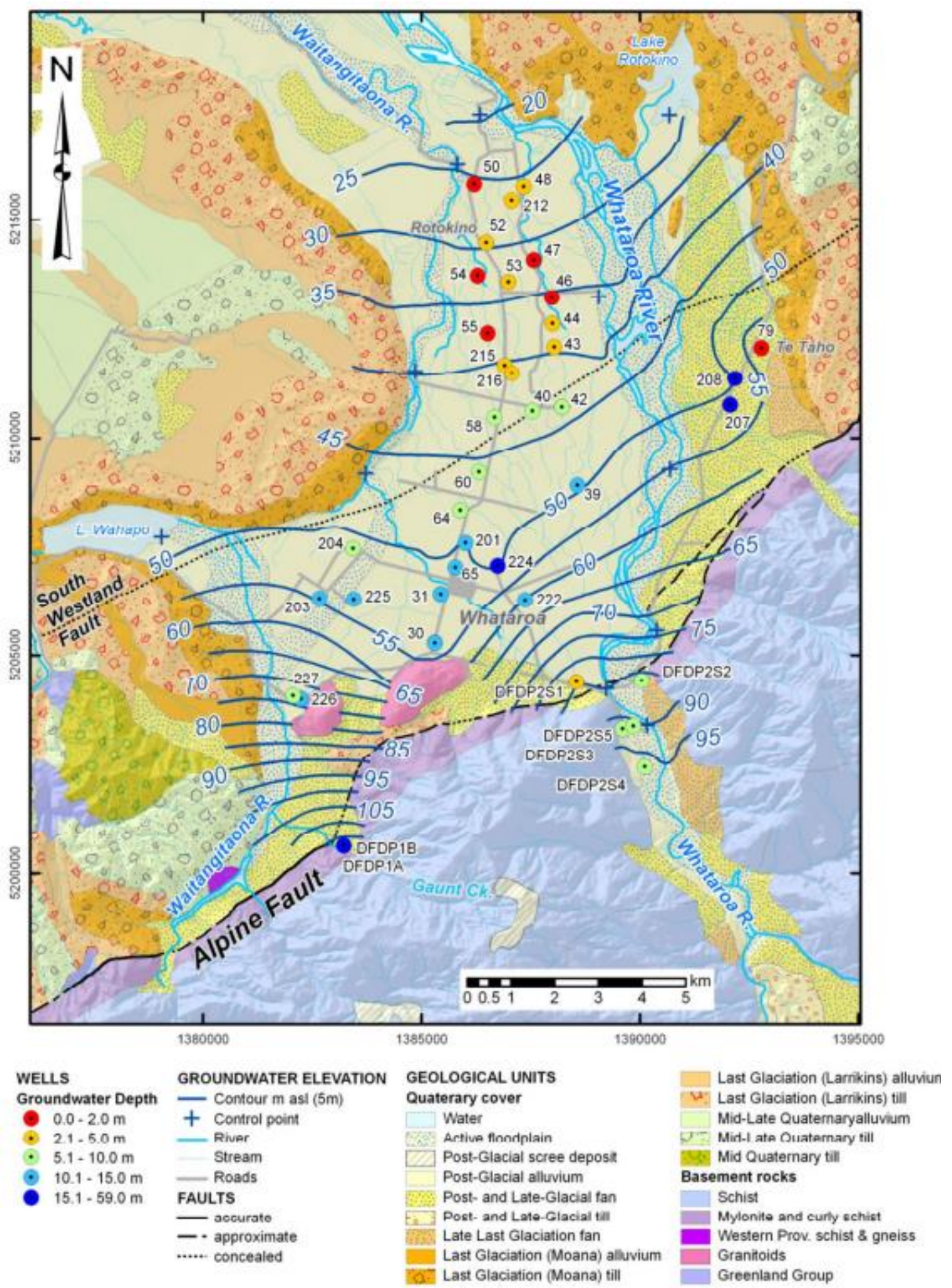

Figure 1.10: Surface geology map of the Whataroa study area.

Blue contours represent groundwater elevation above sea level in shallow alluvium. Various wells and boreholes are also shown. Note the location of the South Westland Fault relative to the Alpine Fault. Figure from (Cox et al., 2013). 


\subsubsection{South Island glacial history and geomorphology}

\section{Glacial history}

The Southern Alps have experienced cyclic glaciations that were initiated in the Pliocene $\sim 2.5 \pm 0.1 \mathrm{Ma}$ (Suggate, 1990). The most recent cold period, known as the Otiran glaciation, from 75-18 ka (Nelson et al., 1993; Suggate, 1990; Suggate and Almond, 2005), culminated in a glacial maximum on the West Coast of the South Island between 26-17 ka (Barrows et al., 2013). During this period, ice coalesced in front of the main mountain valleys to form piedmont lobes extending as far as the western coastline (Figure 1.11) (Golledge et al., 2012; Herman and Braun, 2008; Suggate and Almond, 2005).

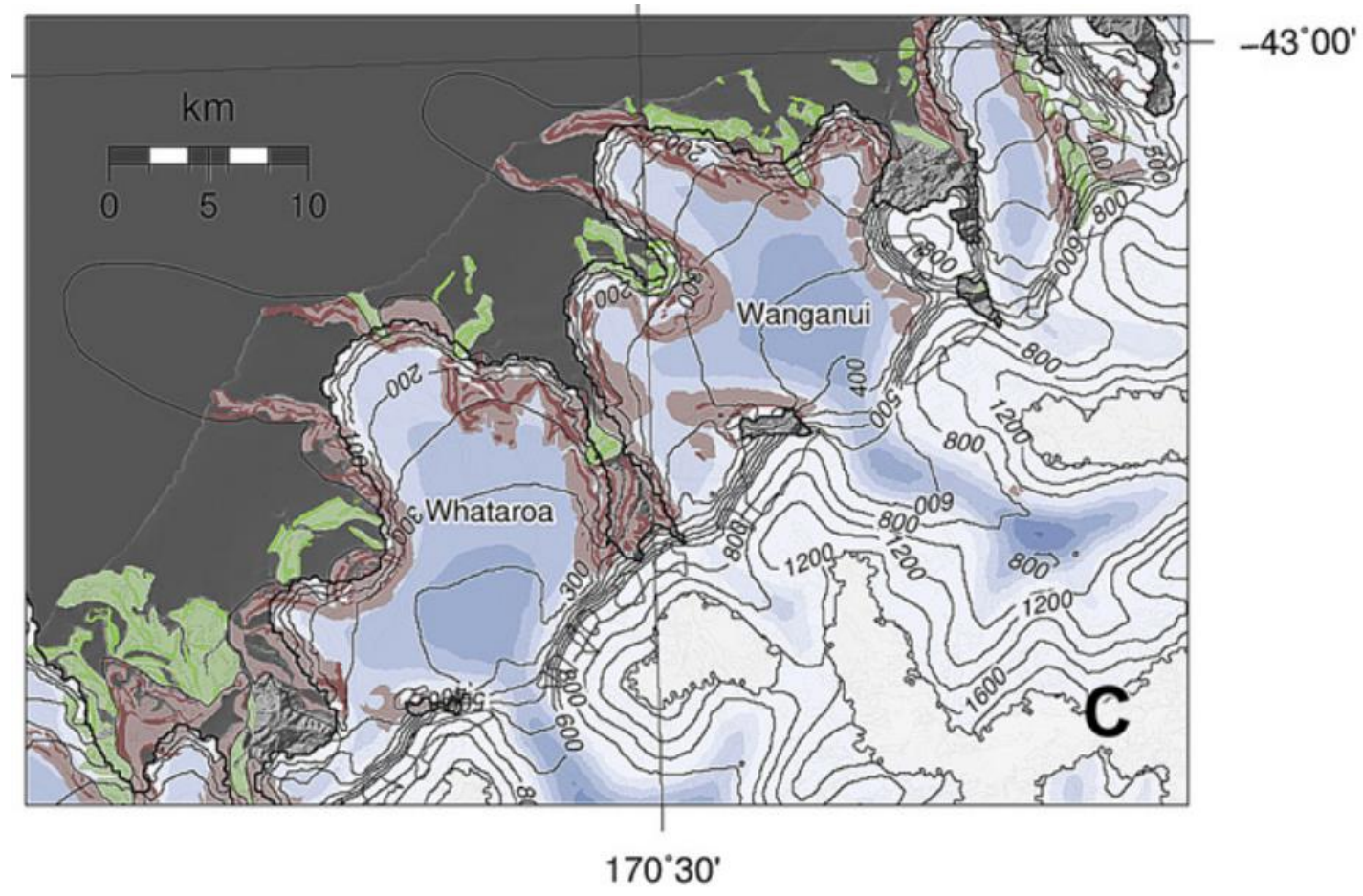

Figure 1.11: Ice extent of the Late Otiran glaciation in Central Westland.

Modelled ice extent shaded by thickness and contoured by surface elevation. Geomorphological data is shown overlying modelled ice extent, with modelled glacier outlines over geomorphology. Brown areas represent LGM moraines, and green areas are pre-LGM moraines. Figure from Golledge et al. (2012).

Three major glacial advances, of progressively lesser extent, have been wellconstrained on the West Coast within the last glacial cycle based on the tephrachronology, mapping and exposure dating of glacial deposits (Barrows et al., 2013; Suggate, 1990; Suggate and Almond, 2005). These distinct glacial advances are 
represented by the Loopline, Larrikins, and Moana Formations, separated by brief interstadials (Barrows et al., 2013). Refer to Figure 1.10 for the glacial geomorphology near the study area with formations labelled. The Loopline Formation advance culminated at $24.9 \pm 0.8 \mathrm{ka}$, and stratigraphically lies immediately below the widespread Kawakawa/Oruanui tephra deposited 25.4 \pm 0.08 ka (Barrows et al., 2013; Vandergoes et al., 2013a; Wilson, 2001). The Larrikins Formation was deposited during a single glacial advance lasting $\sim 1000$ years between $20.8 \pm 0.5$ to $20.0 \pm 0.5$ ka (Barrows et al., 2013). The Moana Formation represents the deposits of the last major ice advance on the West Coast culminating at $17.3 \pm 0.5 \mathrm{ka}$ (Barrows et al., 2013). These observations can be correlated with cooling of the adjacent oceans (Barrows and Juggins, 2005; Barrows et al., 2007), lowering of the treeline on the West Coast and throughout New Zealand (Heusser and Van de Geer, 1994; Vandergoes et al., 2013b), and the extent of glaciers on other land masses within the Southern Hemisphere (Barrows et al., 2011; Douglass et al., 2006; McCulloch et al., 2005). Moreover, the timing of glacial advances on the West Coast determined by Barrows et al. (2013) fits within the NZ-INTIMATE climate event stratigraphy, which defines three cold events in the period from $30 \mathrm{ka}$ to Termination 1 at $\sim 18 \mathrm{ka}$ (Figure 1.12) (Barrell et al., 2013). The Loopline Formation advance occurred at the end of NZce-10, the Larrikins Formation advance occurred midway through NZce-6, and the Moana Formation advance occurred immediately following Termination 1 in early NZce-5.

The emergence from glacial conditions following the termination of the LGM in New Zealand (post-Termination amelioration; NZce-5) spans a period from $\sim 18$ ka to $15.64 \pm 0.41$ k.y. (Barrell et al., 2013), with evidence of an initial and rapid retreat of ice from LGM positions $\sim 18$ ka occurring on both sides of the Southern Alps and in the North Island (Almond et al., 2001; Newnham et al., 2003; Putnam et al., 2013; Shulmeister et al., 2005; Vandergoes and Fitzsimons, 2003; Williams, 1996). Evidence from south Westland (Sutherland and Norris, 1995), and more recently from Whataroa (Cox et al., 2015) suggests that following retreat from LGM limits, West Coast glaciers had receded over the Alpine Fault by $\sim 16.3-14.8 \mathrm{ka}$, which is the onset of the Lateglacial mild episode (NZce-4) (Barrell et al., 2013). Mild late-glacial conditions were succeeded at $13.74 \pm 0.13$ ka by a cooler climate (Late-glacial cool episode; NZce-3), which after $12.55 \pm 0.14 \mathrm{ka}$ gave way to a progressive ascent to full interglacial 


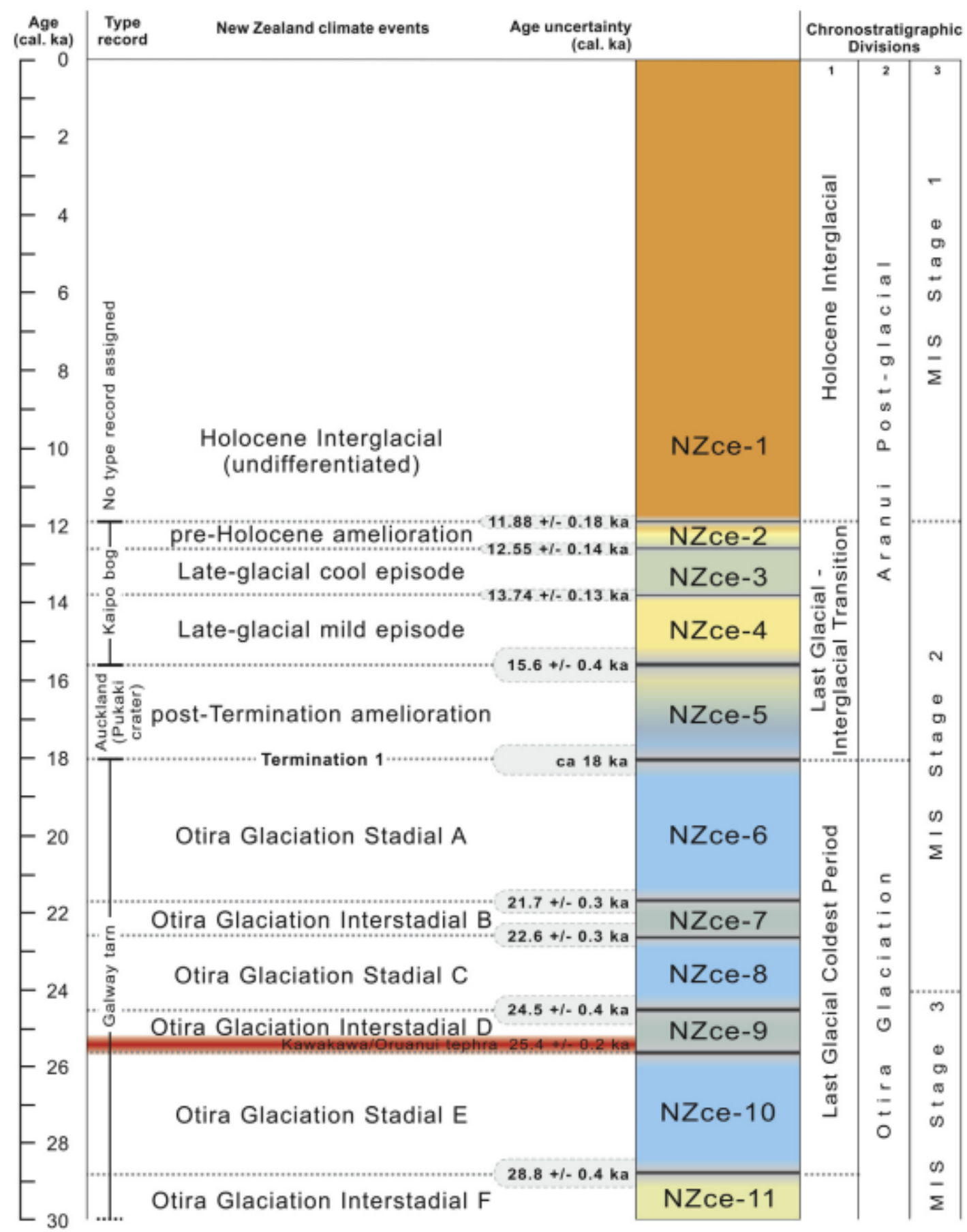

Figure 1.12: The NZ-INTIMATE climate event stratigraphy.

Colours represent characteristic atmospheric temperatures (orange $=$ warm, blue = cold). Chronostratigraphic divisions are (1) major climate phases in New Zealand; (2) New Zealand climate-based time-stratigraphic stages; and (3) global marine-oxygen isotope scale (MIS) stages (Barrell et al., 2013).

conditions that were achieved by $11.88 \pm 0.18 \mathrm{ka}$ and continue to the present day (Holocene Interglacial; NZce-1) (Barrell et al., 2013; Vandergoes et al., 2005). 
During the Late-glacial cool episode (NZce-3), it is suggested that widespread glacier resurgence in the Southern Alps culminated $\sim 13 \mathrm{ka}$, at the peak of the Antarctic Cold Reversal (ACR), which is a well-constrained period of reverse cooling in Antarctica from 14.54 to $12.76 \mathrm{ka}$ (Anderson and Mackintosh, 2006; Lemieux-Dudon et al., 2010; Putnam et al., 2010; Turney et al., 2007).

West Coast glaciers, such as Fox and Franz Josef, are characterised by some of the highest mass turnover rates on Earth, with annual precipitation of up to $\sim 14 \mathrm{~m}$ (Henderson and Thompson, 1999), ice velocities of $\sim 1 \mathrm{~m} /$ day (Purdie et al., 2008), and response times of 7-20 years (Anderson et al., 2008; Fitzharris et al., 1992; Purdie et al., 2008). These glaciological characteristics combine with high sediment yield in a tectonically active mountain terrain to create active subglacial and proglacial river and outwash fan systems (Davies and Smart, 2007; Davies et al., 2003). These large depocentres are reworked by glacier snouts to construct latero-frontal moraine loops during periods of ice advance (Tovar et al., 2008). Glacial advance and retreat, and therefore the subsequent formation of moraines and pro-glacial lakes, is not necessarily climatic in origin. Debris from large rock avalanches deposited on ablation zones can affect glacier mass balance significantly, with corresponding implications for glacier behaviour and moraine emplacement (Shulmeister et al., 2009; Tovar et al., 2008).

\section{Denudation and uplift}

The crest of the Southern Alps lies 15-30 km southeast of the Alpine Fault, and corresponds to the Main Divide (drainage divide). Elevation increases toward the central South Island where the highest peak, Aoraki/Mount Cook, reaches $3754 \mathrm{~m}$ a.s.l. The Southern Alps orogen is asymmetric, changing eastward across the mountain range from steep and intensely dissected western slopes, to strongly glaciated mountains

along the Main Divide, to more subdued eastern landscapes characterised by intermontane basins and broad alluvial plains (Cox and Sutherland, 2007; Tippett and Kamp, 1995).

The Southern Alps form a barrier to dominant westerly atmospheric circulation, intercepting air masses of both temperate and sub-tropical origin (Koons, 1990; Shulmeister et al., 2004). Under prevailing westerly flow, moisture evaporated from the Tasman Sea is forced to rise up and over the Southern Alps, resulting in significant precipitation, especially on the western slopes (Henderson and Thompson, 1999). 
Erosion correlates strongly with precipitation, where more extensive erosion $(\sim 10$ mm/yr) occurs on the western slopes (Adams, 1980a, b; Cox and Sutherland, 2007; Fitzsimons and Veit, 2001; Hicks et al., 1996). Erosion rates produce an expected geomorphic pattern consistent with the observed orogenic asymmetric geomorphology across the Southern Alps (Whitehouse, 1986).

The primary mode of erosion within the South Island is gravitational mass wasting produced by debris flows, landslides and rock avalanches which are more common in areas of fault-zone weakened bedrock, such as the highly-active central Southern Alps (Hovius et al., 1997; Korup et al., 2004; McSaveney, 2002). Present sediment yields from glaciated and deglaciated basins in the South Island are similar (Griffiths, 1979; Griffiths, 1981), leading to the hypothesis that erosion rates are equal during glacial and interglacial periods (Whitehouse, 1986). In regions of rapid tectonic uplift, such as the central Southern Alps, the rate of fluvial and glacial erosion, and therefore relief amplitude is controlled by the rate of uplift, irrespective of climate (Herman et al., 2007; 2010). A coupled system is proposed whereby the removal of Pacific plate material by erosion enhances uplift, and uplift of rocks into the westerly circulation pattern concentrates erosion, forming a dynamic equilibrium between uplift and erosion (Koons, 1990; Norris and Cooper, 2003; Walcott, 1998). Consequently, the Southern Alps have been maintained in a near steady-state elevation for the past million years, with a steady rate of uplift and erosion during both glacial and interglacial cycles (Herman et al., 2010; Koons, 1989, 1995). However, the geomorphology of valleys and ridges are unlikely to reach steady-state, due to the differing characteristics in geomorphic expressions of fluvial and glacial erosion (Herman and Braun, 2006).

Glacial erosion widens and deepens valleys while removing little material from the valley walls, forming U-shaped valleys (Adams, 1980a; Herman et al., 2007). Fluvial erosion involves downcutting and removing material from the valley walls, forming $\mathrm{V}$ shaped valleys, enhanced by coseismic slip on the Alpine Fault and uplift of the hanging-wall (Adams, 1980a; Sutherland, 1996). After total glacial retreat on the West Coast at the onset of the Holocene Interglacial $~ 11.88 \pm 0.18 \mathrm{ka}$ (Barrell et al., 2013), the dominant mode of erosion has been fluvial. Since then, most valleys have changed from U- to V-shaped and have been incised by rivers and dissected by debris flows, landslides and rock avalanches (Herman and Braun, 2006; Hovius et al., 1997; Korup et al., 2004). The Whataroa valley has experienced substantial denudation, where 
estimates of the total present-day erosion rate and sediment discharge rate in the Whataroa valley is $11.4 \mathrm{~mm} / \mathrm{yr}$ and $1.1 \times 10^{6} \mathrm{~m}^{3} / \mathrm{yr}$ respectively (Korup et al., 2005). In Whataroa valley, denudation is concentrated $\sim 10 \mathrm{~km}$ upstream from the Alpine Fault (Nibourel et al., 2015), where rates of erosion are broadly equivalent to Alpine Fault dip-slip rates and rock uplift rates east of the fault trace (Adams, 1980a; Batt, 2001; Cox and Sutherland, 2007; Little et al., 2005; Norris and Cooper, 2001).

\section{Pro-glacial lakes}

The large Whataroa outwash plain contains two moraine-dammed lakes (Lake Wahapo and Lake Rotokino) that mark ice termini of the last glacial maximum (Almond et al., 2001). Recent drilling (DFDP-2) has revealed the presence of previously unknown and older pro-glacial lake sediments, which may even be contiguous with the oldest sediments in Lakes Wahapo and Rotokino. These DFDP-2B lake sediments have since been buried beneath post-glacial alluvium (Cox et al., 2015; Sutherland et al., 2015).

Pro-glacial lakes can be impounded by ice, moraine, landslide debris or bedrock (Carrivick and Tweed, 2013). Depending on the local topography and hydraulic pressure gradients, ice-dammed lakes can form supraglacially, subglacially, or icemarginally, and are usually associated with ice margin advance or thickening, which results in the impounding of water (Carrivick and Tweed, 2013; Tweed, 2011). Icedammed lake formation is a gradual process usually linked to glacier mass balance and ultimately, climatic forcing. However, sudden glacial advance during surging can block drainage channels and form ice-dammed lakes independently of climate (Carrivick and Tweed, 2013; Tweed, 2011).

The formation of moraine-dammed lakes is quasi-periodic and usually associated with periods of glacier retreat or down-wasting following previous ice advance (Carrivick and Tweed, 2013; Korup and Tweed, 2007). However, it has been suggested that the development of large terminal moraines result from non-climatic processes, such as large landslides (e.g. the Waiho Loop moraine) (Shulmeister et al., 2009; Tovar et al., 2008). Moraine-dammed lakes expand rapidly into topographic lows formerly occupied by ice or major meltwater channels, fed by precipitation and glacial meltwater during glacial retreat (Carrivick and Tweed, 2013). Moraine-dammed lakes often develop on debris-covered glaciers as debris-charged glacial snouts become separated from more rapidly ablating ice up-glacier and eventually stagnate. The resulting ice- 
cored moraine serves an effective dam to meltwater runoff leading to pro-glacial lake development (Carrivick and Tweed, 2013; Lukas, 2011). Moraine-dammed lakes also develop in depressions formed by large masses of buried ice (Carrivick and Tweed, 2013; Kääb and Haeberli, 2001).

Formation of landslide-dammed lakes in glacial environments is stochastic and usually associated with slope de-buttressing on glacier retreat (Carrivick and Tweed, 2013; Korup, 2002; Korup and Tweed, 2007). Steep U-shaped glacial valleys once occupied by ice are particularly prone to slope failure (Korup et al., 2004). Riverdamming landslides are triggered by heavy rainfall and snowmelt, seismicity or by undercutting (Korup, 2002). Landslide-dammed lakes are often ephemeral since the dam is typically made from unconsolidated material that is prone to failure. Moreover, landslide-dammed lakes generally form in steep mountain terrain where denudation rates are high, consequently decreasing their size due to rapid infill of sediment (Hicks et al., 1990; Korup et al., 2006).

Bedrock-dammed lakes are common in mountainous terrain where glacial erosion of sub-glacial bedrock and/or sediment develops a glacial over-deepening, resulting in reigels (bedrock ridge) which form effective dams (Cook and Swift, 2012). Depending on its location, the evolution of a pro-glacial lake may involve a combination of dam types, or evolve through a sequence of different lake/dam configurations (Carrivick and Tweed, 2013).

\subsection{Previous geophysical studies}

\subsubsection{South Island Geophysical Transect}

The South Island Geophysical Transect (SIGHT), was a New Zealand-USA collaborative project in the early 1990's that aimed to understand the deformation of lithosphere at a continent-continent collisional plate boundary (Davey et al., 1998). The SIGHT project involved a comprehensive range of geophysical measurements to derive 3-D structural models of the South Island orogen. These measurements include activesource and passive (earthquake) seismology, magnetotelluric and electrical studies, petrophysics and gravity measurements (Davey et al., 1998; Eberhart-Phillips et al., 2010; Eberhart-Phillips and Bannister, 2002; Okaya et al., 2007; Scherwath et al., 2006; Scherwath et al., 2003; Stern et al., 2000; 2007; Van Avendonk et al., 2004). The data 
were acquired along two main onshore/offshore transects across the central South Island, perpendicular to the Australian/Pacific plate boundary (Figure 1.13).

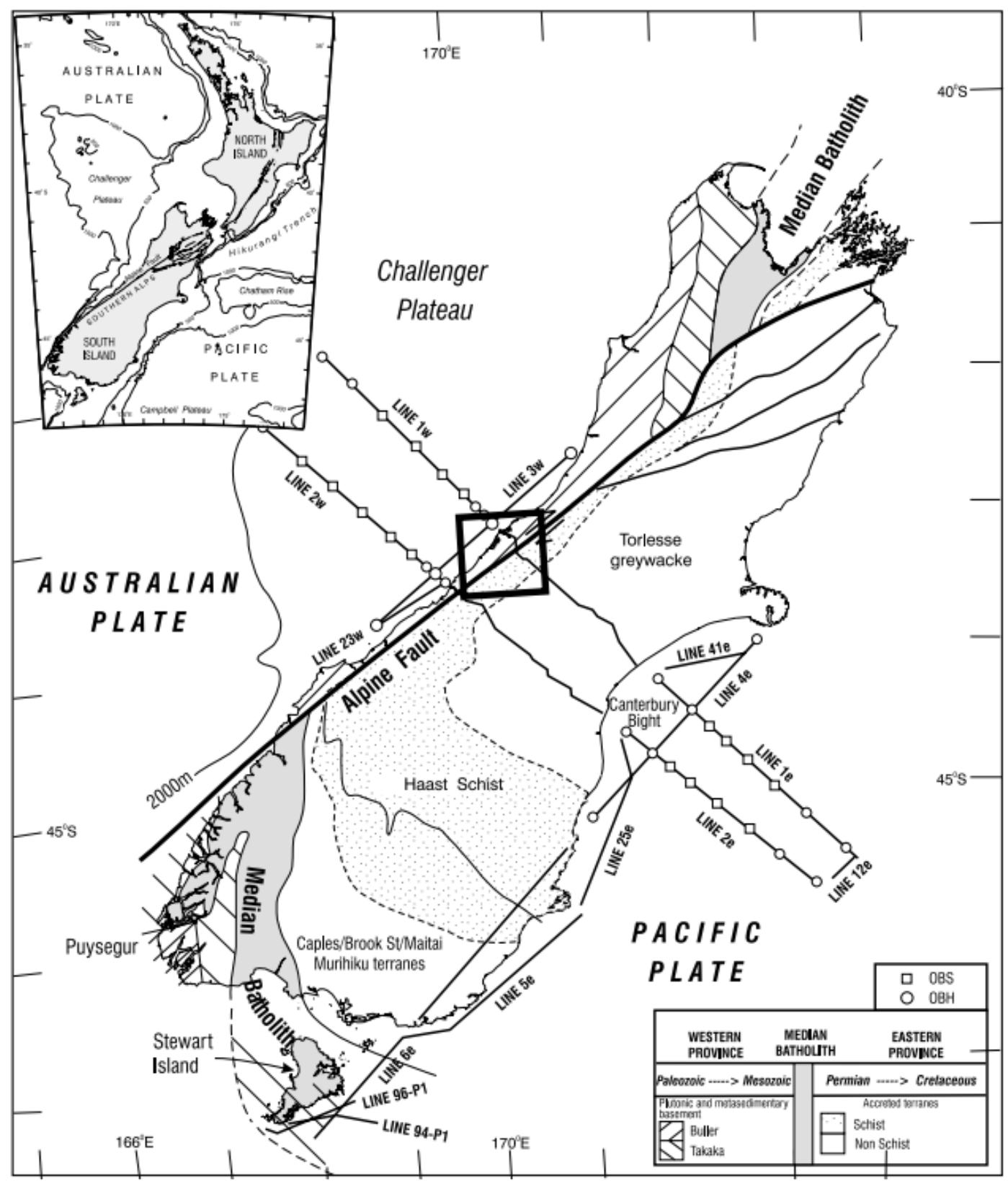

Figure 1.13: SIGHT transects 1 and 2 extending across the central South Island.

The black box indicates where SIGHT transect 1 passes through the study area near Whataroa. Figure from Davey (2010).

The onshore section of SIGHT transect 1 extends southeastward from the West Coast near the mouth of the Whataroa River, across the Alpine Fault and over the Main Divide to the east coast along the Rangitata River (Van Avendonk et al., 2004). SIGHT 
transect 2 runs parallel to transect 1, extending southeastwards from the Karangarua River in south Westland, across the Alpine Fault and over the Main Divide before passing through Tekapo and the Cannington Basin to the east coast, south of Timaru (Scherwath et al., 2003).

Seismic velocity models derived from refracted and reflected arrivals along transect 1 (Van Avendonk et al., 2004) and transect 2 (Scherwath et al., 2003), as well as first arrival travel-time tomography of passive seismic data (Eberhart-Phillips and Bannister, 2002) provide an image of a crustal root $\sim 100 \mathrm{~km}$ wide, which reaches a maximum depth of $\sim 45 \mathrm{~km}$ directly below a regional (-80 mGal) Bouguer gravity low (Henrys et al., 2004). In order to satisfy the regional gravity low, a high-density mantle body is inferred to be lying $\sim 100-200 \mathrm{~km}$ beneath the crustal root, as indicated by teleseismic P-wave delays (Scherwath et al., 2006; Stern et al., 2000).

\subsubsection{Seismicity}

The distribution of seismicity in New Zealand provides information on Alpine Fault processes and deformation distribution along the Australian/Pacific plate boundary. The pattern of seismicity in New Zealand has been recorded since the mid 1880's, but was first analysed between 1956-75 (Hatherton, 1980), and later between 1964-87 (Reyners, 1989), before an upgrade to the New Zealand National Seismograph Network (NZNSN) between 1986-2001 allowed more comprehensive analysis (Anderson and Webb, 1994; Petersen et al., 2011).

The Australian/Pacific plate boundary can be separated into three zones based on the distribution of seismicity. Deep seismicity identifies subducting Pacific lithosphere to depths of $\sim 200 \mathrm{~km}$ southwards along the eastern margin of the North Island to the northern South Island where it abruptly terminates at the junction between the Marlborough Fault System and the Alpine Fault (Davey et al., 2007). The central Alpine Fault is characterised by low rates of shallow seismicity (Leitner et al., 2001) that vary systematically with distance from the fault (Bourguignon et al., 2015). In the southern South Island, deep seismicity identifies subducting Australian lithosphere at depths of $\sim 140 \mathrm{~km}$ beneath the Fiordland region (Davey et al., 2007).

Between 1995-96, the South Island Passive Seismic Experiment (SAPSE) accurately improved the knowledge of seismicity in the South Island, particularly under the Southern Alps (Anderson et al., 1997). The SAPSE experiment included an array 
of 26 broadband and 14 short-period recording seismographs deployed over the South Island, concentrated over the central Southern Alps for up to 12 months. A total of 5491 earthquakes were recorded, as well as the majority of the shots of the active source seismic shooting of SIGHT (Davey et al., 1998). Leitner et al. (2001) investigated the long-term regional seismicity of the Southern Alps using data from the SAPSE experiment, the NZNSN, and from a local network at Lake Pukaki in the central Southern Alps (Reyners, 1988). A uniform seismogenic depth of $12 \pm 2 \mathrm{~km}$ for the central South Island was observed, except for a shallower depth of 8-9 km beneath the highest topography of the Alps. Additionally, a low seismogenic rate for the central Alpine Fault suggests elastic strain is being stored, indicating the potential for largescale earthquakes (Leitner et al., 2001).

Between 2006-07 O'Keefe (2008) investigated microseismicity along the central Alpine Fault using data from a temporary seismic network installed between Harihari and Fox Glacier. A maximum seismogenic depth of $15 \mathrm{~km}$ for the region was observed, reducing to $10 \mathrm{~km}$ below regions with the highest orogenic uplift rates. The seismicity takes on a "horseshoe" pattern for earthquakes above a magnitude of Mw 1.6, where a low seismicity zone is apparent in the central survey region, noted previously (EberhartPhillips, 1995; Leitner et al., 2001) as a 20-30 km wide low-seismicity triangle between Harihari and Franz Josef.

The Southern Alps Microearthquake Borehole Array (SAMBA) of ten short-period seismometers was established between 2008-09 (Boese et al., 2012), offering a dense station spacing $(\sim 8 \mathrm{~km})$ near the central Alpine Fault. To date, SAMBA has been recording continuously and was temporarily supplemented in 2010 by the DFDP10 network as part of the Deep Fault Drilling Project (Sutherland et al., 2012; Townend et al., 2009; 2013). In early 2012, the 20-station WIZARD network commenced operation, replacing and expanding the DFDP10 network (Boese et al., 2012; Thurber et al., 2015). The central area of the SAMBA network near Franz Josef exhibits the highest seismicity rate in the region, while the central Alpine Fault is a region of anomalously low background microseismicity (Boese et al., 2012; Bourguignon et al., 2015). The spatial variations in current seismicity observed in the central Southern Alps, as well as localised seismic tremor and low-frequency earthquakes are indicative of variable fluid and stress conditions near the Alpine Fault (Boese et al., 2014; Boese et al., 2012; Chamberlain et al., 2014; Wech et al., 2012). 


\subsubsection{Gravity}

Prior to a gravimetric and active-source seismic study across the Whataroa Floodplain (Brikke, 2007), the shallow structure of the Alpine Fault had received relatively minor geophysical attention. With a focus on the basement geometry and upper-crustal velocity structure of the Alpine Fault, Brikke (2007) used seismic data of the SIGHT transect 1 (Davey et al., 1998), gravity data from GNS Science, and new gravity observations to construct a seismic and gravity model of the Whataroa floodplain. Figure 1.14 shows Brikke's 2-D gravity model oriented parallel to the Alpine Fault intersecting the Whataroa River. The key results of this study are:

- $\quad$ Deep U-shaped glacial channels buried beneath the floodplain to a maximum depth of $550 \mathrm{~m}$ below the Whataroa River;

- The presence of an elongated southeast-northwest oriented negative residual gravity anomaly, dextrally offset by 3-4 km northeast from the entrance to the Whataroa River valley. Assuming the gravity anomaly represents a glacial erosion surface carved during the Waimea glaciation $(\sim 140 \mathrm{ka})$, a mean strike-slip rate of $25 \mathrm{~mm} / \mathrm{yr}$ is inferred on the Alpine Fault at Whataroa;

- Two kettle holes below the Whataroa Floodplain, inferred to have been carved by the Waimea and subsequent Otira glaciations;

- The horizons of Quaternary and Tertiary sediments, as well as the basement rock of the Australian plate appear to be unperturbed by the plate boundary.

In 2012, a gravimetric study of the central West Coast (Davy, 2012; Davy et al., 2013) combined existing and new gravity observations to expand the gravity coverage of the Wanganui, Whataroa, and Fox River floodplains. The aim of the study was to model glaciotectonic structures in the footwall of the central Alpine Fault and explain the processes responsible for their formation. The gravity data were used to produce gravity maps (Figure 1.15) and 2-3/4D gravity models of the sub-surface structure beneath the floodplains. Gravity models revealed possible dextral offsets of buried geomorphology by the Alpine Fault since the LGM. The key findings of the study are: 

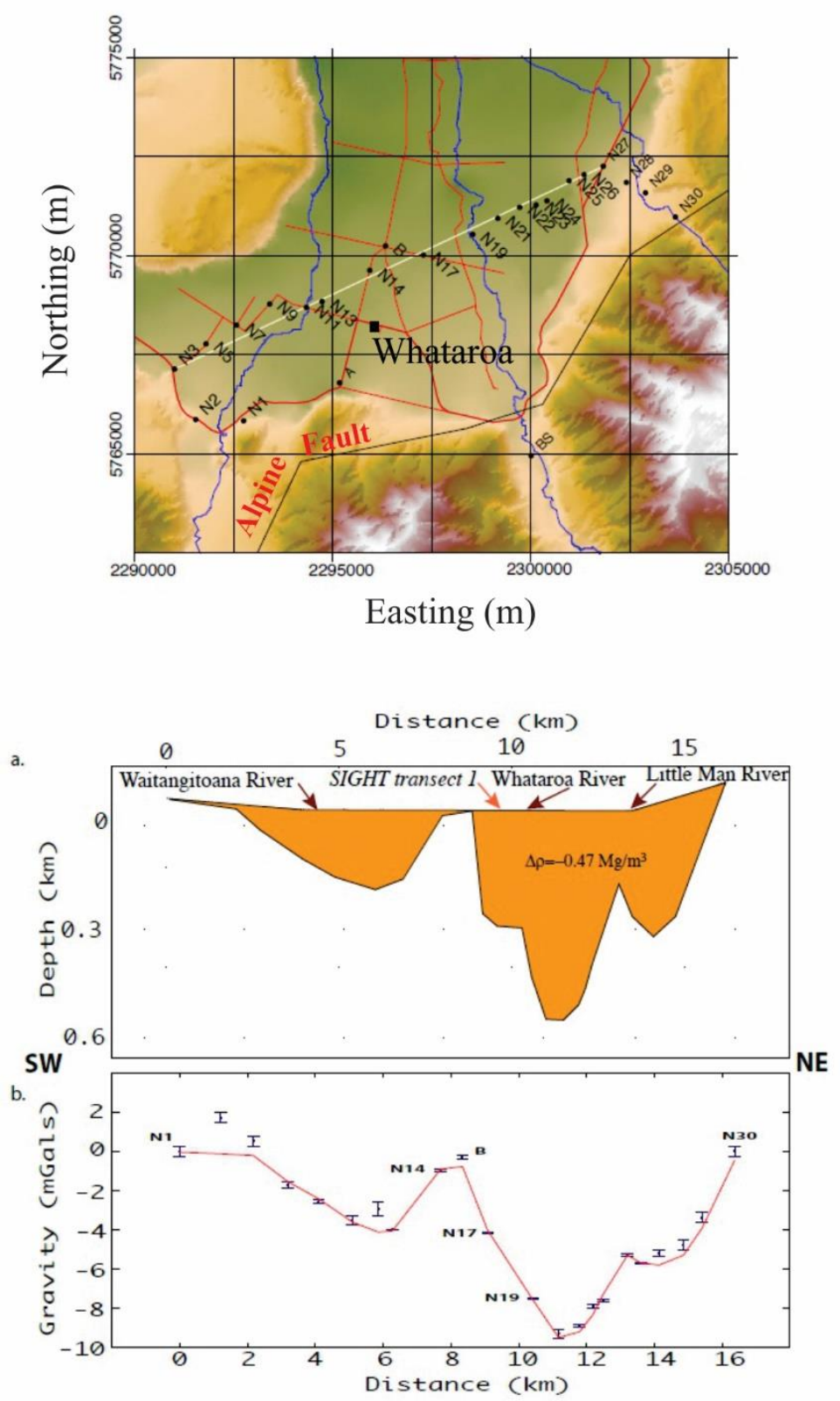

Figure 1.14: 2-D gravity model across the Whataroa floodplain.

Above: map showing the location of the gravity profile. Below: 2-D gravity model. (a) shows the observed and modelled gravity anomaly, and (b) shows the modelled gravity signature (Brikke, 2007).

- Three buried glacial channels in the Whataroa floodplain that are dextrally offset from the originating Whataroa valley. The deepest channel has a maximum depth of $\sim 800 \mathrm{~m}$ beneath the Whataroa River, consistent with a large negative gravity anomaly northwest of the Alpine Fault that was originally recognised by Brikke (2007); 

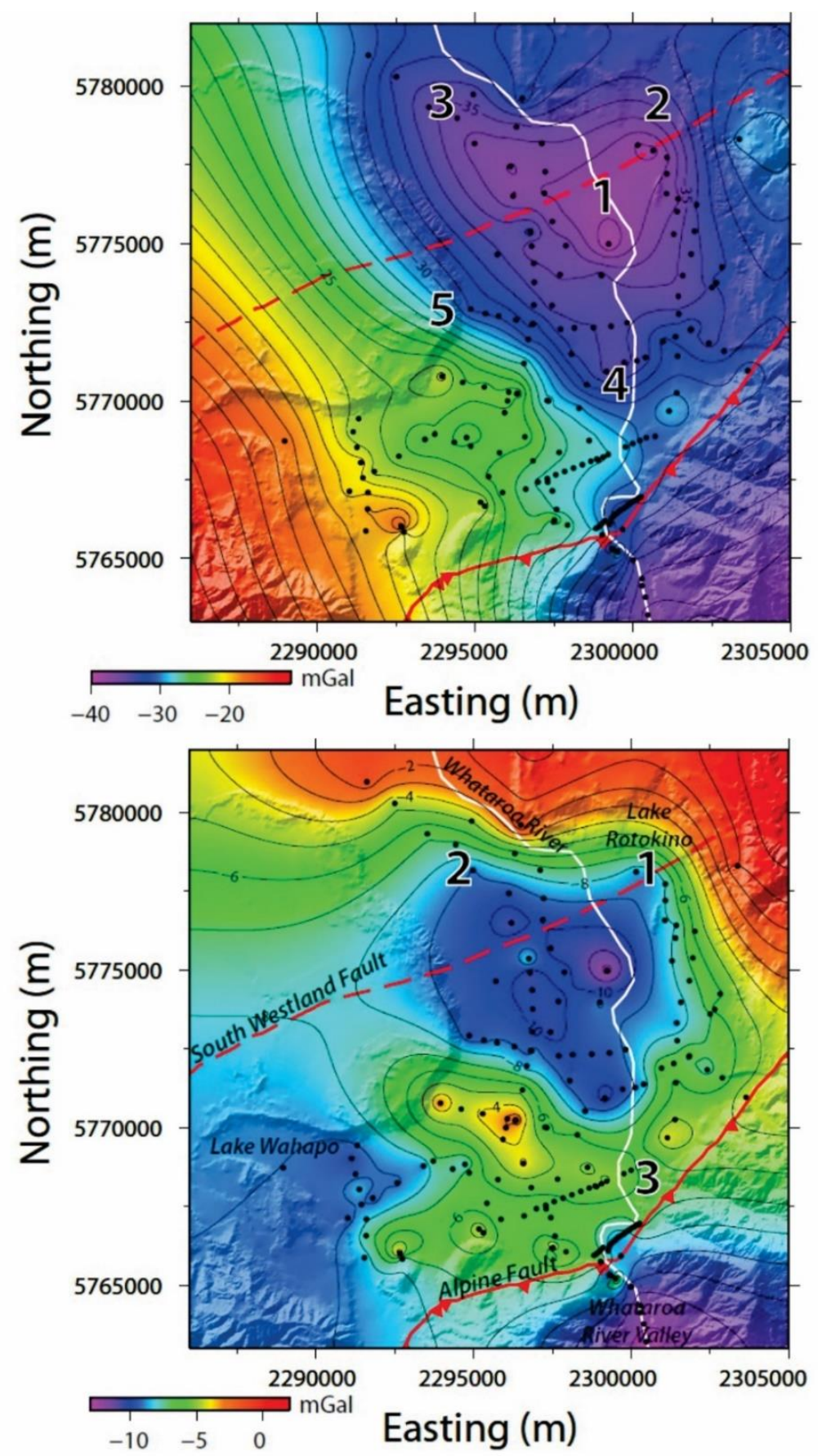

Figure 1.15: Gravity maps of the Whataroa floodplain.

Above: Bouguer gravity anomaly map showing a large (-35 mGal) anomaly (1) extending northeast towards Lake Rotokino (2), northwest towards the western coastline (3), and south towards the Whataroa River valley (4). A strong trend in the Bouguer gravity field appears perpendicular to the Alpine Fault (5). Below: residual gravity map showing a large negative gravity anomaly ( -8 to $-9 \mathrm{mGal})$ extending northeast towards Lake Rotokino (1), northwest into the northwestern splay of the floodplain (2), and south towards the Whataroa River valley (3), where the anomaly is thought to be dextrally offset by $\sim 2 \mathrm{~km}$. Black dots represent gravity stations. Gravity data has been extrapolated. Maps from Davy (2012). 
- Dextral offset of an ice-erosion channel along the Alpine Fault since the LGM is estimated to be $370 \pm 160 \mathrm{~m}$ in the Whataroa floodplain;

- Assuming a channel formation age of $19 \pm 1 \mathrm{k} . \mathrm{y}$., an approximate $370 \mathrm{~m}$ offset corresponds to a dextral strike-slip rate of $19 \pm 9 \mathrm{~mm} / \mathrm{yr}$ for the Whataroa floodplain;

- A gravity profile along SIGHT transect 1 with a focus on the footwall of the Alpine Fault, allows for a joint interpretation of gravity and seismic data. The gravity model defines the South Westland Basin and delineates the location of the South Westland Fault, which is 2-3 km closer to the Alpine Fault than previously thought.

\subsubsection{Geodesy}

GPS-derived site velocities within the Australian/Pacific plate boundary zone through New Zealand help to quantify where strain is accumulating and how slip is partitioned, allowing for quantification of the total 'plate motion budget' (Wallace et al., 2007). Consistency between datasets spanning millions of years (paleomagnetic and structural geology), thousands of years (active fault data), and decades (GPS), suggests that shortterm datasets such as GPS are highly relevant to understanding longer-term plate boundary zone deformation (Wallace et al., 2012). GPS studies of vertical and horizontal velocities of the bounding Australian/Pacific plates in the South Island provide the following interpretations of plate boundary zone deformation (Beavan et al., 2010; Beavan et al., 2007; Beavan et al., 1999; Wallace et al., 2007):

- $50-70 \%$ of the Australian/Pacific plate motion is occurring as steady slip or shear on a down-dip extension of the Alpine Fault below a locking depth of 5$8 \mathrm{~km}$

- Vertical velocity rates of $\sim 5 \mathrm{~mm} / \mathrm{yr}$ occur either side of the crest of the Southern Alps and $\sim 20-30 \mathrm{~km}$ southeast of the Alpine Fault;

- The observed vertical velocity distribution over the Southern Alps suggests that interseismic coupling on the Alpine Fault falls to zero by 13-18 km depth; 
- Up to $5 \mathrm{~mm} / \mathrm{yr}$ of inter-plate movement is accommodated on fault zones within the Southern Alps up to $100 \mathrm{~km}$ east of the Alpine Fault.

\subsection{Gravity model constraints}

\subsubsection{Borehole data}

Borehole data provide valuable information on the lithology and stratigraphy of the Whataroa valley and nearby Alpine Fault, providing a useful geological constraint on gravity data. In 2011, Deep Fault Drilling Project (DFDP) boreholes DFDP-1A and DFDP-1B were drilled at Gaunt Creek, $\sim 7 \mathrm{~km}$ southwest of the Whataroa River valley during the first phase of DFDP (Sutherland et al., 2012; Townend et al., 2009). As previously discussed in section 1.2.3, four main fault-rock units with different thicknesses were identified in DFDP-1 boreholes (Sutherland et al., 2012; Toy et al., 2015). Figure 1.16 shows a cross-section through the fault zone at Gaunt Creek.

For this study, we assume a correlation between the shallow fault zone stratigraphy sampled at Gaunt Creek and the shallow fault zone stratigraphy expected in the Whataroa River valley. The shallow fault zone stratigraphy provided by Sutherland et al. (2012), coupled with an interpretation of shallow fault zone structure adjacent to the Whataroa River (Barth et al., 2012; Norris et al., 2012), is an important consideration when attempting to model the shallow Alpine Fault structure in Whataroa valley using gravity data.

Late in 2014, the second phase of drilling in the Whataroa River valley (DFDP-2) produced two boreholes (DFDP-2A \& DFDP-2B) $\sim 1 \mathrm{~km}$ southeast of the mapped surface trace of the Alpine Fault, revealing a thicker than predicted Quaternary sediment overlying a basement sequence that transitioned from schist to protomylonite to mylonite downhole to a depth of 893 m (Sutherland et al., 2015). Figure 1.17 shows the Quaternary sediments sampled in DFDP-2A. 


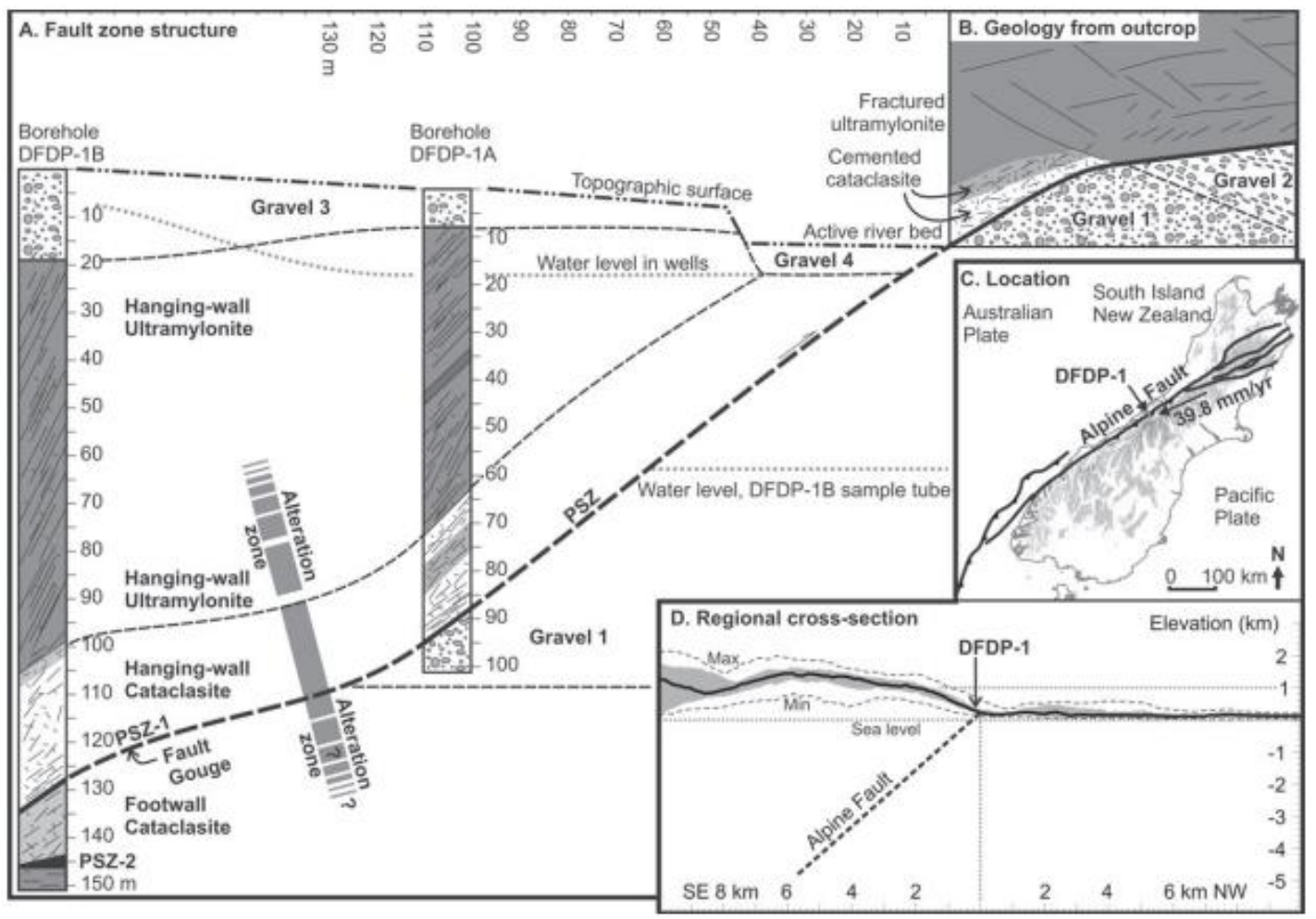

Figure 1.16: Cross-section through DFDP-1 boreholes.

(A): Fault zone structure consisting of four main fault-rock units with different thicknesses sampled in DFDP-1A \& 1B. Outcrop geology shown in (B) on the Alpine Fault at Gaunt Creek in the central South Island (C). Bold line is the principal slip zone (PSZ). Figure from Sutherland et al. (2012).

The DFDP-2A Quaternary sequence is interpreted to comprise (Cox et al., 2015; Sutherland et al., 2015): fluvial-glacial gravels (0-58 m); grading downward into sandy lake delta sediments (59-77 m); overlying a monotonous sequence of lake mud and silts, with rare pebble-cobble diamictite (77-206 m); with a basal unit (206-240 m) containing coarse cobbles and boulders that may represent a distinct till/diamictite. The contact between Quaternary sediments and schist bedrock was sampled at $240 \mathrm{~m}$ depth in DFDP-2B. Radiocarbon dating of plant fragments indicate $70 \mathrm{~m}$ of upper lacustrine and deltaic sediments $(129-59 \mathrm{~m})$ were deposited rapidly between 16.35-15.8 ka. Overlying alluvial gravels are much younger $(<1 \mathrm{ka})$, with evidence of pulses of rapid aggradation (Cox et al., 2015). 


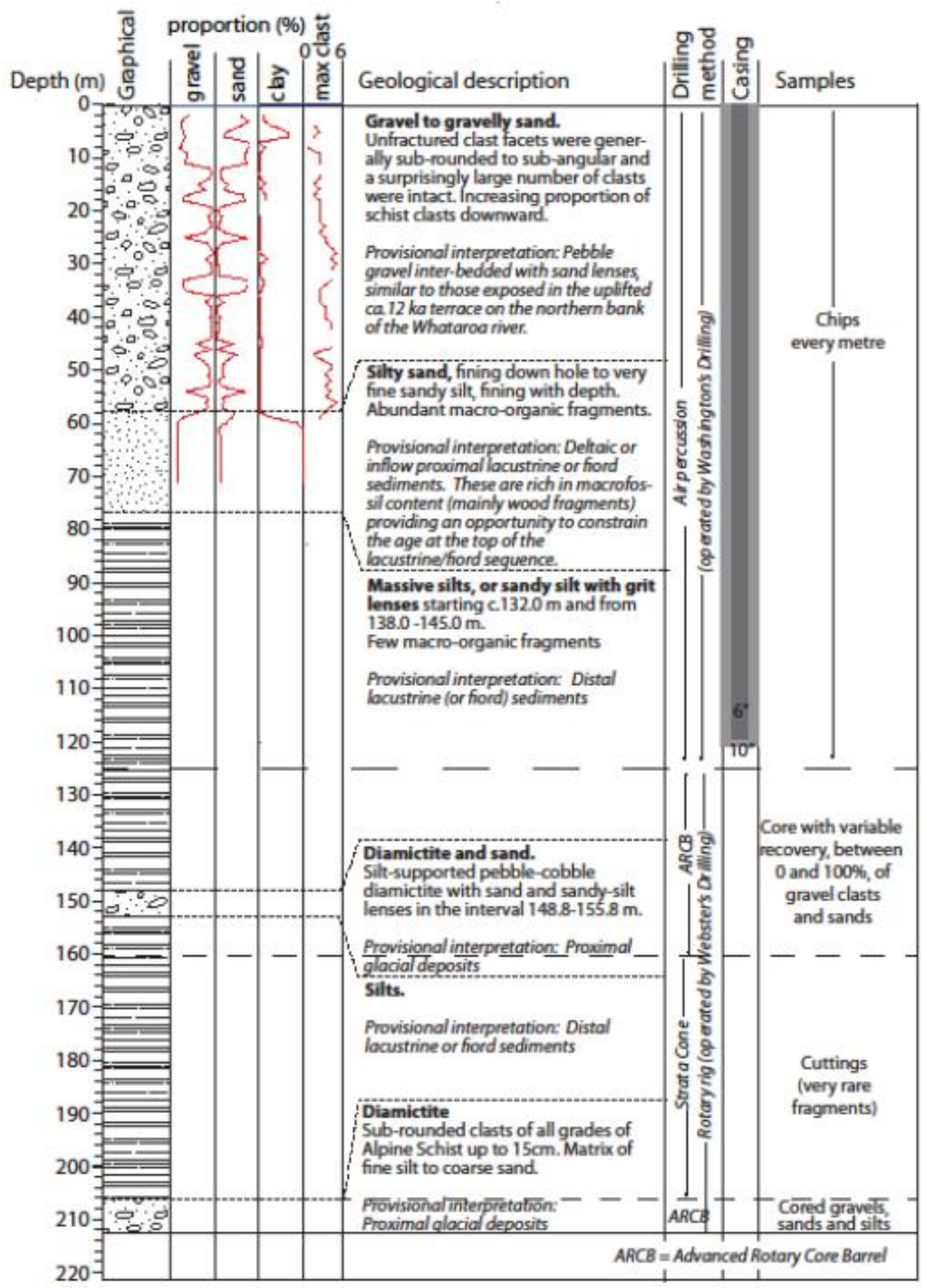

Figure 1.17: Geological log of Quaternary sediments sampled in DFDP-2A. Figure from Sutherland et al. (2015). 


\subsubsection{Active-source seismic data}

Crustal seismic reflection data acquired from SIGHT transect 1 (Davey et al., 1998) were used by Davey (2010) to construct a seismic refraction model striking perpendicular to the Alpine Fault in the Whataroa valley. Figure 1.18 shows SIGHT transect 1 and the seismic model of Davey (2010). Within the bounds of the study area, the model defines the geometry of two main sedimentary layers with P-wave velocities of $2.0-2.7 \mathrm{~km} / \mathrm{s}$ and $3.5 \mathrm{~km} / \mathrm{s}$, overlying a basement rock with a P-wave velocity of 4.7$5.6 \mathrm{~km} / \mathrm{s}$. The thicknesses of the sedimentary layers near the Alpine Fault range from $150-400 \mathrm{~m}$ for the upper layer and 100-300 $\mathrm{m}$ for the lower layer. These layers correlate to onshore drill holes Harihari-1 and Waiho-1 (Smart, 1971, 1972), as well as offshore seismic data in the region (Nathan et al., 1986; Sircombe and Kamp, 1998), and are inferred to be Quaternary glacial sediments overlying Mid-Late Miocene sediments (Davey, 2010).

The WhataDUSIE controlled-source seismic project, led by researches from the University of Otago (New Zealand), TU Bergakademie Freiberg (Germany), and the University of Alberta (Canada), provided high-resolution coverage (4-8 m geophone spacing, 25-100 $\mathrm{m}$ shot spacing) along a $5 \mathrm{~km}$ profile across the Alpine Fault in the Whataroa valley (Glomb et al., 2013; Kovacs et al., 2013; Lay et al., 2015). The profile extends upstream from the Whataroa bridge along the SIGHT transect 1 (Davey et al., 1998), with a focus on the shallow (upper $1 \mathrm{~km}$ ) hanging-wall of the Alpine Fault, and is supplemented by focused hammer-source seismic data (Kovacs, 2011). Preliminary P-wave velocity models of the upper $5 \mathrm{~km}$ reveal a 200-350 m thick sedimentary layer with velocities of $\sim 2.3 \mathrm{~km} / \mathrm{s}$ above a schist basement with velocities of $4.5-5.5 \mathrm{~km} / \mathrm{s}$. A pronounced low-velocity layer with velocities of approximately $3.5 \mathrm{~km} / \mathrm{s}$ can be observed within the basement at 0.8-2 km depth. Small-scale low-velocity anomalies appear at the top of the basement and can be correlated to the Alpine Fault zone (Lay et al., 2015). 

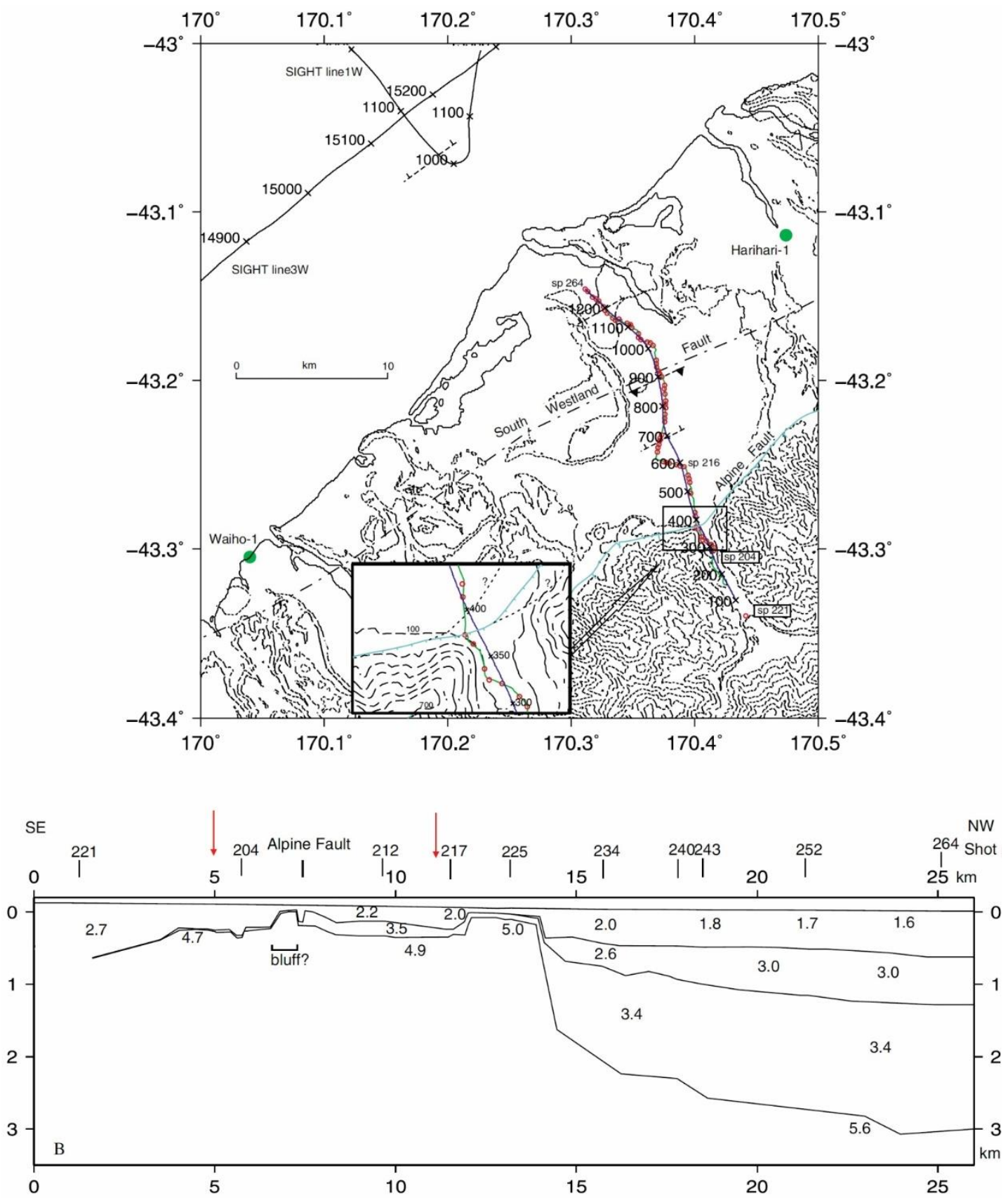

Figure 1.18: Seismic refraction model along SIGHT transect 1 across the Whataroa floodplain and Alpine Fault.

Above: simplified topography of the Whataroa region showing the SIGHT receiver transect. Inset map shows the study area for this project. Below: refraction model of Davey (2010) showing dimensions and velocities for each layer. Red arrows indicate approximate bounds of the study area for this project. Figures from Davey (2010). 


\subsubsection{Gravity data}

With a focus on the Whataroa floodplain, Davy et al. (2013) provides a gravity model along a $20 \mathrm{~km}$ section of the SIGHT transect 1 (Davey et al., 1998), allowing for a joint interpretation with the seismic model of Davey (2010). The gravity model of Davy et al. (2013) is shown in Figure 1.19. Between the South Westland Fault (SWF) and the Alpine Fault, the model defines the geometry of two main sedimentary layers inferred to be Quaternary glacial sediments overlying Mid-Late Miocene sediments. East of the Alpine Fault, the model defines the geometry of a single sedimentary unit, inferred to be Quaternary glacial sediments overlying basement rock. There are slight differences between the seismic model of Davey (2010) and the gravity model of Davy et al. (2013), the most significant being a difference in basin depth directly east of the SWF with the gravity model $\sim 500 \mathrm{~m}$ shallower. However, the two models are broadly consistent, providing a comprehensive joint interpretation along the footwall portion of SIGHT transect-1 on the Whataroa floodplain.

\subsubsection{Rock density}

Gravity anomalies result from a density contrast between a rock body and its surroundings. The density among rock types is therefore the most critical and least variable gravimetric parameter, where the most common rock types have densities in the range between $1.60 \mathrm{~g} / \mathrm{cc}$ and $3.20 \mathrm{~g} / \mathrm{cc}$ (Kearey et al., 2013).

The bulk densities of rock types within the study area can be estimated using the Nafe-Drake velocity-density relationship following Ludwig et al. (1970), and Gardner's rule (Gardner et al., 1974), derived for sedimentary rocks. Both methods are discussed below. 


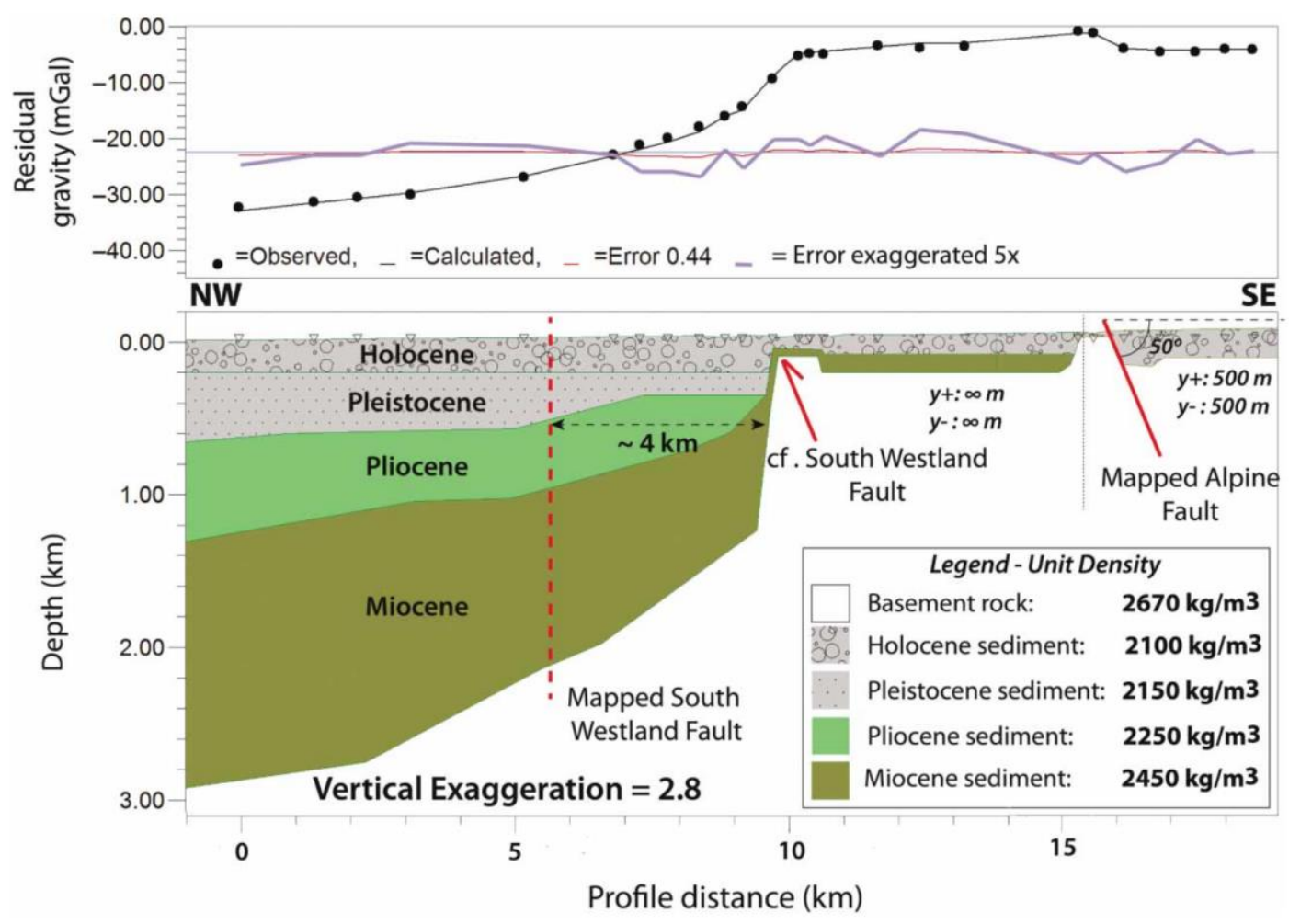

Figure 1.19: Gravity model of a portion of SIGHT transect 1 across the Whataroa floodplain and Alpine Fault.

Model dimensions and bulk densities are based on the seismic modelling of Davey (2010) and rock catalogues of Whiteford and Lumb (1975). Rock units are based on onshore boreholes Harihari-1 and Waiho-1 (Smart, 1971, 1972). Gravity model from Davy et al. (2013).

\section{Seismic velocity relations}

Variation in porosity is the main cause of density variation in sedimentary rocks. Thus, in sedimentary rock sequences, density increases with depth, due to compaction, and with age, due to progressive cementation (Kearey et al., 2013). As cementation and rock density increases with depth, so does compressional seismic velocity allowing for density determination from seismic velocity relations (Gardner et al., 1974; Ludwig et al., 1970; Nafe and Drake, 1963). Ludwig et al. (1970) present this relation graphically, known as the Nafe-Drake curve, which is expressed numerically in equation 1.1 (Brocher, 2005):

$$
\begin{aligned}
\rho\left(\mathrm{g} / \mathrm{cm}^{3}\right)= & 1.6612\left(V_{p}\right)-0.4721\left(V_{p}\right)^{2}+0.0671\left(V_{p}\right)^{3} \\
& -0.0043\left(V_{p}\right)^{4}+0.000106\left(V_{p}\right)^{5}
\end{aligned}
$$


Equation 1.1 is valid for $V_{p}$ between 1.5 and $8.5 \mathrm{~km} / \mathrm{s}$.

Gardner's rule (Gardner et al., 1974), derived for sedimentary rocks, is valid for $V_{p}$ between 1.5 and $6.1 \mathrm{~km} / \mathrm{s}$, expressed in equation 1.2 (Brocher, 2005):

$$
\rho\left(g / \mathrm{cm}^{3}\right)=1.74\left(V_{p}\right)^{0.25}
$$

Table 1.1 shows the range of calculated bulk densities for the geological units in the study area using the P-wave velocities of Christensen and Okaya (2007), Davey (2010), and Lay et al. (2015) in equations 1.1 and 1.2.

\section{Rock catalogues}

Presently, no direct measurement of rock density from DFDP-2 is available. However, a catalogue of rock samples from throughout the South Island can be used to infer appropriate bulk densities to be analysed during gravity modelling.

PETLAB is the rock catalogue and geo-analytical database of New Zealand (Mortimer, 2005). The database contains locations, descriptions and analyses of rock samples collected throughout New Zealand. Wet density measurements complied from many sources (e.g., Hatherton and Leopard, 1964; Whiteford and Lumb, 1973) cover 89 rock types collected at 9256 locations in New Zealand. Table 1.2 gives the mean wet density for rock types known in the study area. Note that this does not include any fracture porosity, which is likely in damaged rocks within $\sim 1 \mathrm{~km}$ of the Alpine Fault. 
Table 1.1: Mean P-wave velocities and bulk densities of rock types known in the study area.

Mean P-wave velocities calculated from laboratory measurements (Christensen and Okaya, 2007), and from the seismic models of Davey (2010) and Lay et al. (2015). Bulk densities of geological units calculated using Nafe-Drake and Gardner empirical relations (Brocher, 2005).

\begin{tabular}{|c|c|c|c|c|c|c|c|}
\hline \multirow{2}{*}{ Rock type } & \multirow{2}{*}{$\begin{array}{l}\text { Mean } V_{p} \\
(\mathbf{k m} / \mathbf{s})\end{array}$} & \multirow{2}{*}{$\begin{array}{r}\text { STD } \\
(\mathrm{km} / \mathrm{s})\end{array}$} & \multirow{2}{*}{$\begin{array}{r}\text { Max } \\
(\mathbf{k m} / \mathbf{s}\end{array}$} & \multirow{2}{*}{$\begin{array}{c}\text { Min } \\
(\mathbf{k m} / \mathbf{s})\end{array}$} & \multirow{2}{*}{$(\mathbf{N})$} & \multicolumn{2}{|c|}{$\rho\left(\mathrm{g} / \mathrm{cm}^{3}\right)$} \\
\hline & & & & & & Nafe-Drake & Gardner \\
\hline $\begin{array}{c}\text { Quaternary } \\
\text { gravel }\end{array}$ & 2.3 & 0.3 & 2.7 & 2.0 & 4 & 2.03 & 2.14 \\
\hline $\begin{array}{c}\text { Miocene } \\
\text { sediments }\end{array}$ & 3.5 & - & - & - & 1 & 2.32 & 2.38 \\
\hline $\begin{array}{c}\text { Schist } \\
\text { (Alpine Schist) }\end{array}$ & 5.6 & 0.5 & 6.7 & 4.9 & 12 & 2.64 & 2.68 \\
\hline $\begin{array}{l}\text { Alpine Fault } \\
\text { mylonite }\end{array}$ & 5.8 & 0.2 & 6.0 & 5.6 & 3 & 2.68 & 2.70 \\
\hline $\begin{array}{c}\text { Phyllite } \\
\text { (Buller Terrane) }\end{array}$ & 5.6 & 0.7 & 6.5 & 3.9 & 12 & 2.64 & 2.68 \\
\hline $\begin{array}{l}\text { Granite } \\
\text { (Tuhua) }\end{array}$ & 5.9 & 0.1 & 6.0 & 5.7 & 6 & 2.70 & 2.71 \\
\hline
\end{tabular}

Table 1.2: Mean wet densities from the PETLAB rock catalogue.

\begin{tabular}{|c|ccccc|}
\hline Rock type & $\begin{array}{c}\text { Mean } \\
\left(\mathbf{g} / \mathbf{c m}^{3}\right)\end{array}$ & $\begin{array}{c}\text { STD } \\
\left(\mathbf{g} / \mathbf{c m}^{3}\right)\end{array}$ & $\begin{array}{c}\text { Max } \\
\left(\mathbf{g} / \mathbf{c m}^{3}\right)\end{array}$ & $\begin{array}{c}\text { Min } \\
\left(\mathbf{g} / \mathbf{c m}^{3}\right)\end{array}$ & Samples \\
\hline $\begin{array}{c}\text { Quaternary } \\
\text { gravel }\end{array}$ & 2.31 & 0.27 & 2.58 & 1.87 & 9 \\
\hline $\begin{array}{c}\text { Miocene } \\
\text { sediments }\end{array}$ & 2.38 & 0.90 & 2.60 & 2.24 & 12 \\
\hline $\begin{array}{c}\text { Schist } \\
\text { (Alpine Schist) }\end{array}$ & 2.73 & 0.12 & 3.10 & 2.12 & 419 \\
\hline $\begin{array}{c}\text { Alpine Fault } \\
\text { mylonite }\end{array}$ & 2.76 & 0.09 & 2.93 & 2.62 & 11 \\
\hline $\begin{array}{c}\text { Phyllite } \\
\text { (Buller Terrane) }\end{array}$ & 2.66 & 0.04 & 2.71 & 2.64 & 4 \\
\hline $\begin{array}{c}\text { Granite } \\
\text { (Tuhua) }\end{array}$ & 2.64 & 0.08 & 2.94 & 2.33 & 288 \\
\hline
\end{tabular}




\subsection{Thesis structure}

The thesis is structured as follows:

- Chapter 1: An introduction to the study area and its geological history, providing the motivation and objectives of the project and discusses previous work completed by others.

- Chapter 2: Provides the theory of gravity and its use as a geophysical tool for exploring the sub-surface, and covers field measurement and data reduction methods used for this gravimetric survey.

- Chapter 3: Presents results of the new gravity survey. Key outputs are new Bouguer and regionally-corrected residual gravity anomaly maps of the Whataroa study area.

- Chapter 4: Presents two-dimensional forward gravity models, which were initially used during gravity survey design, and then developed and improved on the basis of new data. Targeted features include the Alpine Fault and the area surrounding the DFDP-2 drill hole in the Whataroa River valley.

- Chapter 5: Discusses the results found in Chapters 3, and 4, and their implications for understanding the broader structure surrounding the DFDP-2 borehole, as well as the complex interplay between tectonics, glacial processes, and sedimentation. 


\section{Chapter 2 Gravity and methodology}

This chapter summarises the theory of gravity and the methods used to acquire and reduce gravity data.

\subsection{Gravity theory}

Newton's universal law of gravitation states that any two objects exert a gravitational force $(F)$ of attraction on one another. The magnitude of the force is proportional to the product of the gravitational mass of each object $\left(m_{1}\right.$ and $\left.m_{2}\right)$, and inversely proportional to the square of the distance between them $\left(r^{2}\right)$, as expressed by equation 2.1 (Burger et al., 2006; Gerkens, 1989):

$$
F=G \frac{m_{1} m_{2}}{r^{2}}
$$

where $G$ is Newton's universal gravitational constant (Mohr et al., 2012):

$$
G=6.673 \pm 0.001 \times 10^{-11} \mathrm{~m}^{3} / \mathrm{kg} / \mathrm{s}^{2}
$$

If we assume the Earth is a uniform sphere with a radius $\left(R_{e}\right)$ and a mass $\left(M_{e}\right)$, the force $(F)$ acting on a mass $(m)$ on Earth's surface is given by equation 2.3:

$$
F=G \frac{m M_{e}}{R_{e}^{2}}
$$

Newton's second law of motion states that the acceleration $(a)$ of an object produced by a net force $(F)$ is directly proportional to the magnitude of the net force, in the same direction as the net force, and inversely proportional to the mass $(m)$ of the object, summarised in equation 2.4 (Burger et al., 2006; Gerkens, 1989): 


$$
F=m a
$$

Equating Newton's first law of universal gravitation (equation 2.3), and Newton's second law of motion (equation 2.4) we are left with acceleration due to gravity $(g)$ :

$$
\begin{gathered}
F=m a=m g=G \frac{m M_{e}}{R_{e}^{2}} \\
g=\frac{G M_{e}}{R_{e}^{2}}
\end{gathered}
$$

Hence, gravitational acceleration $(g)$ depends on the distribution of nearby mass, and can be used as a constraint on geological models of the sub-surface (Kearey et al., 2013). The SI units of acceleration ( $a$ ) are $\mathrm{m} / \mathrm{s}^{2}$. The Gal, after Galileo, is a CGS unit of acceleration used extensively in gravimetry and is defined as $1 \mathrm{~cm} / \mathrm{s}^{2}$ (Kearey et al., 2013).

\subsection{Earth's gravity}

Earth is not a perfect sphere with a uniform mass distribution (Telford et al., 1990). The magnitude of gravity on Earth's surface is affected by five primary factors: latitude, elevation, Earth's tidal fluctuations, nearby terrain (topography), and sub-surface density variations (Telford et al., 1990). There is a wide range in density among rock types, and therefore inferences can be made on the distribution of strata and sub-surface structure.

The gravity surveying method involves use of a highly-sensitive gravity meter to measure the gravitational attraction exerted by the Earth at a measurement station located on Earth's surface (Milsom, 2003). Lateral variations in gravity due to lateral changes in rock density result in gravitational anomalies in the vicinity of the observation point (Burger et al., 2006). The goal of processing gravity data is to identify and remove any measurement signals that are not related to geologic features. Such signals include: instrumental drift, time variability caused by Earth's tides, and the predictable gravitational effects of latitude, elevation, and topography. 


\subsubsection{Relative and absolute gravity measurement}

Absolute gravity is defined as the long-term average value of gravity at a point in space (Burger et al., 2006). Absolute gravity measurements can be directly compared with other older data (Schubert, 2015). In this study, surveying was conducted by obtaining relative gravity measurements from a grid of survey points using a relative gravity meter, which were later reduced to absolute gravity values through repeat measurements at absolute gravity reference sites.

To determine an accurate value for absolute gravity, corrections must be made for instrumental drift and tares between calibrations (McCubbine et al., 2016; Schubert, 2015; Telford et al., 1990). To correct for drift and obtain absolute gravity at each observation point it is essential to occupy at least one site of established absolute gravity before and after the course of surveying. An absolute gravity reference station, or tie site, serves as a control point for relating gravity observed at reference stations with gravity determined at survey sites.

The absolute gravity $\left(g_{a b s}\right)$ of each survey site is thus calculated using equation 2.7 (Burger et al., 2006; Telford et al., 1990):

$$
g_{a b s}=g_{\text {relative }}-g_{\text {ref }}+g_{\text {abs ref }}
$$

where $g_{\text {relative }}$ is the relative meter reading at a survey site, $g_{\text {ref }}$ is the relative meter reading at the absolute reference station, and $g_{a b s r e f}$ is the absolute gravity value recorded at the reference station.

\section{The New Zealand gravity network}

GNS Science maintains a database of terrestrial gravity observations made across New Zealand since the 1940's (Stagpoole, 2013). The gravity network consists of $\sim 40,000$ gravity observations made by different institutions primarily using Lacoste and Romberg D and G relative gravity meters. All observations in the database are tied to the New Zealand Primary Gravity Network (Robertson and Reilly, 1960) by a method of least squares (McCubbine et al., 2016; Woodward and Carman, 1984).

The New Zealand Primary Gravity Network was established in the 1960's as a series of absolute gravity control points for relative gravity observations (Robertson, 1960; Robertson and Reilly, 1960). The Primary Gravity Network stations were reoccupied during the 1980's and additional observations were made on survey 
benchmarks around New Zealand (Stagpoole, 2013). Today, many of the Primary Gravity Network stations that were located on railway station platforms or roads that have been demolished or realigned are no longer locatable. Consequently, absolute gravity reference stations established on permanent benchmarks maintained by Land Information New Zealand (LINZ) are now the recommended reference sites for gravity surveys using relative gravity meters, and reference value precision is typically $<0.01$ $\mathrm{mGal}$, i.e. better than the precision of most relative gravity meters (Stagpoole, 2013).

The New Zealand gravity network has been published in maps of Bouguer, freeair, and isostatic anomalies at scales of 1:250,000 and 1:1,000,000 (Reilly, 1972). In the central South Island, station density varies from $3-5$ per $\mathrm{km}^{2}$ to 1 per $10 \mathrm{~km}^{2}$ (Reilly and Whiteford, 1979; Reilly, 1972).

\section{Whataroa study area reference stations}

Within the study area, two absolute gravity reference stations of the New Zealand gravity network were routinely occupied during surveying: SA80 and SA86. The reference stations are recorded in the GNS gravity database, which includes absolute gravity values listed in International Gravity Standardisation Net 1971 (IGSN71), coordinates relative to the New Zealand Geographic Datum 2000 (NZGD2000), and orthometric heights relative to the Lyttelton Vertical Datum 1937 (LYTTHT1937).

\subsubsection{Temporal variation of measured gravity}

\section{Tidal variation}

The gravity meter is able to detect changes in gravity caused by Earth's tides (Burger et al., 2006; Telford et al., 1990). The range of gravity variation due to the Earth's tides can be significant, $\sim 0.3 \mathrm{mGal}$, changing at a rate of $\sim 0.05 \mathrm{mGal} / \mathrm{hr}$ (Burger et al., 2006; Telford et al., 1990). Figure 2.1 shows interpolated and measured tidal variations for a gravity meter located in the Whataroa study area during surveying in May 2015. As seen in Figure 2.1, the gravity variation is smooth and relatively slow, and is therefore included in the instrumental drift correction (Telford et al., 1990). 


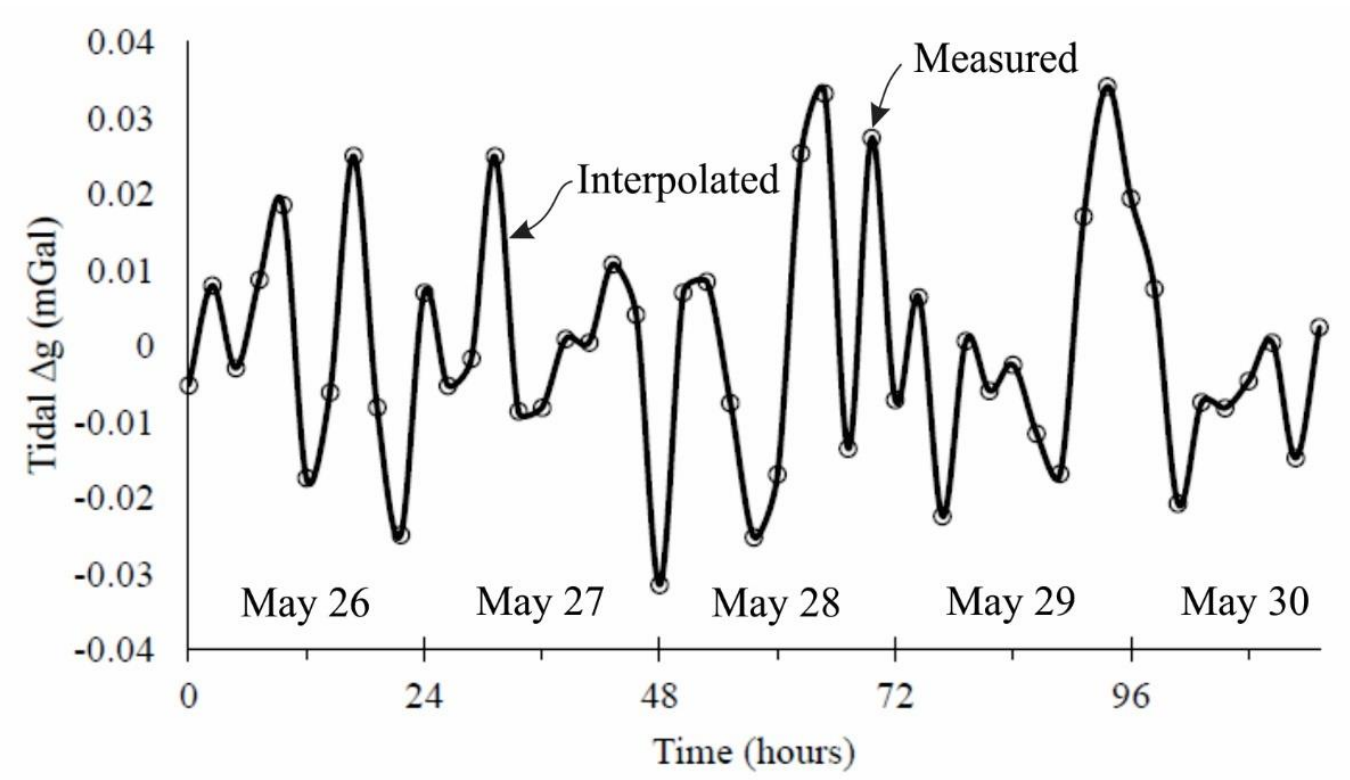

Figure 2.1: Earth-tide variations, Whataroa study area, May 2015. Gravity readings have been corrected for instrumental drift.

\section{Meter drift correction}

Instrumental drift is a phenomenon related to instrumental instabilities that cause the dial reading of the gravity meter to gradually drift with time even when gravitational acceleration remains constant (Burger et al., 2006; Telford et al., 1990). These instabilities are caused by several factors, including temperature changes and elastic creep in the meter's highly sensitive springs (Milsom, 2003). Additionally, drift may be caused by mechanical stresses and strains in the meter's mechanism as it is transported, subjected to vibrations, left unclamped, or subjected to heat stresses (Milsom, 2003). Older meters, such as the Lacoste-Romberg G-model meter used in this study, are highly susceptible to drift, which must be measured and eliminated from relative gravity measurements (Burger et al., 2006; Milsom, 2003).

\section{Measurement strategy}

The net result of instrumental drift and Earth's tidal effects is that repeated measurements at a single gravity station will change with time. To correct for drift, a looping procedure is adopted, whereby designated gravity reference stations are reoccupied every 3-4 hours (Telford et al., 1990). It is unnecessary and inefficient to use the same reference station for repeat measurements because any intermediate station can be reoccupied provided the station is well marked and upon solid structure. 
Intermediate stations that are only occupied once are then corrected for drift that occurred during surveying (Telford et al., 1990). Sites that have repeat measurements can be used to assess survey precision.

In this study, drift was corrected for by reoccupying the two absolute reference stations within the study area (SA80 \& SA86) at the beginning and end of each daily survey. Additionally, an intermediate station was reoccupied every 1-2 hours during surveying. The meter reading is plotted against time and drift is assumed to be linear between consecutive readings (Figure 2.2) (Kearey et al., 2013). For a linear drift condition, and if the terminating reference station is the same station, then the drift rate is given by equation 2.8 (Burger et al., 2006; Telford et al., 1990):

$$
\mu=\frac{g_{2}-g_{1}}{t_{2}-t_{1}}
$$

where $g_{1}$ and $g_{2}$ are observed gravity values at the reference station at time $t_{1}$ and $t_{2}$ respectively. The drift correction applied to an observed value at an intermediate station is given by equation 2.9 (Burger et al., 2006; Telford et al., 1990):

$$
\delta_{s}=\mu\left(t_{s}-t_{1}\right)
$$

where $t_{s}$ is the time of a meter reading at an intermediate station. The absolute gravity observed at an intermediate station, less tidal and drift effects, is called the observed absolute gravity $\left(g_{o b s}\right)$ :

$$
g_{o b s}=g_{a b s}-\delta_{s}
$$

\section{Gsolve - Accurate gravity observation reduction}

Relative gravity measurements are reduced to absolute gravity values adjusted for the effects of instrumental drift, Earth's tides, and a meter calibration scaling factor. Conventionally, this is done manually using the meter's latest calibration table, then separately using equations 2.7 to 2.10 .

In this study, a comprehensive Python-based computer program, Gsolve (McCubbine et al., 2016), is used to reduce raw gravity data and apply corrections simultaneously. 


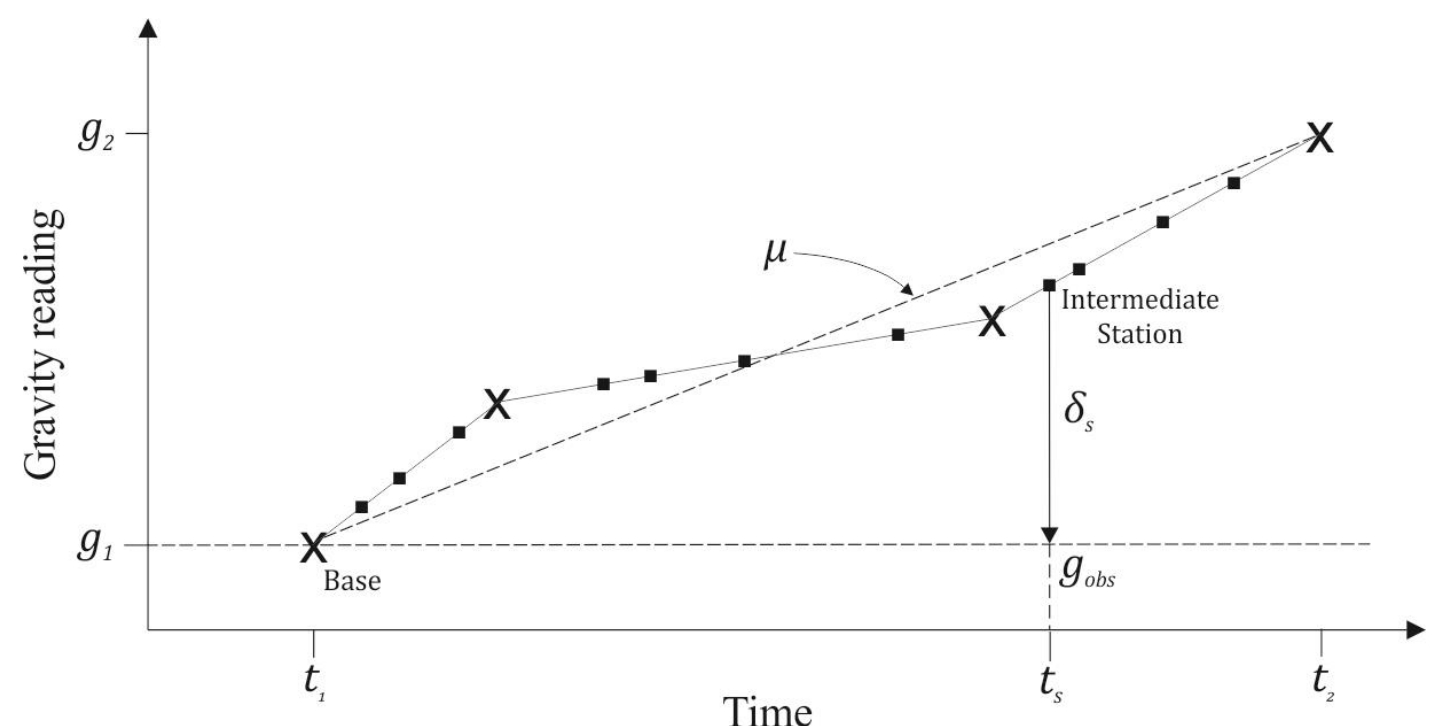

Figure 2.2: A gravity meter drift curve.

The curve is constructed from repeated readings at a fixed location (the base), and non-repeated readings at various locations (intermediate stations). The drift rate $(\mu)$ is found using equation 2.8. The drift correction $\left(\delta_{s}\right)$ is calculated using equation 2.9 , then subtracted for a reading taken at time $\left(t_{s}\right)$ using equation 2.10.

Gsolve reduces relative gravity observations, corrected for the meter calibration, drift and tidal gravitational effects, to absolute gravity values based on robust least squares formulae derived by Reilly (1970). Reilly's formulae transform relative gravity measurements to absolute gravity values as long as the survey includes at least one measurement at an absolute gravity reference station.

Gravity reduction using Gsolve is achieved by processing relative gravity meter readings in three key stages (McCubbine et al., 2016):

1. Relative readings are calibrated using scaling factors supplied by an input file containing the meter's latest calibration table. The gravitational effects of the Earth's tides are removed using tidal formulas following Longman (1959).

2. A least-squares absolute gravity value for each observation location is derived from drift-corrected and calibrated meter readings. Gsolve offers three methods of least squares regression, following Reilly (1970). The choice of method depends on the uncertainty of the previously recorded absolute gravity values at the designated reference station(s). For details of each method, refer to McCubbine et al. (2016). The selection process and details of the reduction method used in this study are described in Chapter 3. 
3. The residuals of the least squares fit are used to reject values outside of the specified confidence interval (CI). In this study, a CI of $100 \%$ was used and outliers were manually picked and discarded based on the quality of the regression combined with geographic location, i.e. no observations were automatically excluded.

During surveying, multiple loops (repeat measurements) were made in order to correct for drift and Earth's tides, and to establish precision of the survey. For the purposes of data reduction, a single loop constitutes an entire day of surveying, that is, from the absolute gravity reference station at the beginning of the survey day to the same reference station at the end of the survey day. During this period of time, gravity observations can be affected by sudden changes in the baseline (zero point) of the gravity meter, referred to as a tare in the data (McCubbine et al., 2016; Schubert, 2015). Gsolve incorporates the tare effect into the drift function by the least squares solution allowing for any sudden change in the gravity meter's baseline to be spread out across the entire solution, limiting the effects of individual tares.

For a large-scale survey consisting of relative gravity measurements being made over several days, such as in this study, it is advantageous to compute the meter drift function and meter baseline on a daily basis, confining tare effects across individual days or loops within a day (McCubbine et al., 2016). From these daily loops, Gsolve calculates a daily drift rate (mGal per hour) based on daily meter baseline values and drift function coefficients, producing a tidal effect that is subtracted from absolute gravity values as described in stage 1 .

\subsubsection{Variation of gravity with latitude}

Earth's gravity increases with latitude due to Earth's rotation. At latitudes nearer Earth's equator, the outward centrifugal force produced by Earth's rotation is larger than at polar latitudes. The centrifugal force acts oppositely to the force of gravity, up to a maximum of $0.3 \%$ at the equator, and thus gravitational acceleration at equatorial latitudes is reduced (Burger et al., 2006; Telford et al., 1990).

Additionally, Earth is not a perfect sphere, it is an oblate ellipsoid, a consequence of Earth's rotation and outward centrifugal force over long time-scales, forming an equatorial bulge and flattening of the polar regions (Burger et al., 2006; Telford et al., 1990). With respect to Newton's law of gravitation (equation 2.6), the increased radial 
distance due to Earth's equatorial bulge means gravitational acceleration will be weaker at the equator than at Earth's poles (Telford et al., 1990).

Conversely, a larger equatorial radius means that there is increased mass between the equator and the centre of the Earth relative to the mass between the Earth's centre and the poles. This change in mass between the equator and the poles acts to increase gravitational acceleration towards the equator (Burger et al., 2006).

In combination, the effects of the surface centrifugal force due to Earth's rotation, the resulting equatorial bulge, and the change in mass between the equator and the poles result in an overall decrease of sea-level effective gravity from $\sim 9.832 \mathrm{~m} / \mathrm{s}^{2}$ at the poles to $\sim 9.780 \mathrm{~m} / \mathrm{s}^{2}$ at the equator, a difference of $\sim 5.2 \mathrm{Gal}$ (Burger et al., 2006; Telford et al., 1990).

\section{The latitude correction}

To correct for gravity variations with latitude, it is necessary to define a reference surface that best fits Earth's gravity field. The reference ellipsoid is the equipotential surface of the Earth's gravity field which best fits a uniform Earth. In contrast, the geoid is the equipotential surface of the Earth's gravity field which best fits global mean sealevel. The height difference between these two surfaces rarely exceeds $100 \mathrm{~m}$ and is more commonly < 50 m (Figure 2.3) (Burger et al., 2006; Telford et al., 1990).

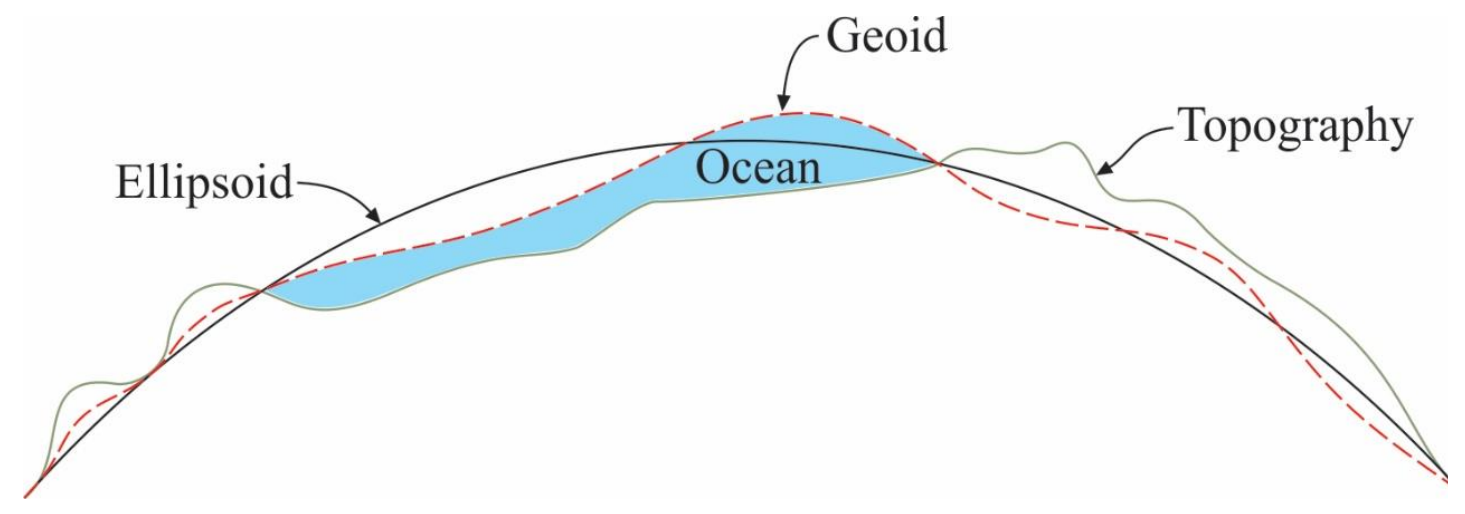

Figure 2.3: Earth's topographic, ellipsoid and geoid surfaces

The shape of the geoid is dominated by broad undulations, which do not spatially correlate with the continents, and are caused by Earth's heterogeneous mass distribution (Burger et al., 2006; Telford et al., 1990). The undulating form of the geoid relative to topography and Earth's density variations are second-order effects, both low in amplitude $(<10 \mathrm{~m})$ and short in wavelength $\left(<10^{6} \mathrm{~m}\right)$. Therefore, the reference ellipsoid 
is suitable as a first-order approximation of gravity at a given latitude $(\theta)$ (Telford et al., 1990).

The first internationally accepted reference ellipsoid was established in 1930, known as the 1930 International Gravity Formula:

$$
g_{\theta}=978049\left(1+0.0052884 \sin ^{2} \theta-0.0000059 \sin ^{2} 2 \theta\right) \mathrm{mGal}
$$

where $g_{\theta}$ is the normal gravity value. With the addition of satellite technology came better accuracy of various geodetic parameters, and a new ellipsoid was adopted in 1967, known as the 1967 International Gravity Formula:

$$
g_{\theta}=978031.846\left(1+0.0053024 \sin ^{2} \theta-0.0000058 \sin ^{2} 2 \theta\right) \mathrm{mGal}
$$

The reference ellipsoid was further updated in 1980, known as the Geodetic Reference System 1980 (GRS80), which eventually led to the current reference field, World Geodetic System 1984 (WGS84) Ellipsoidal Gravity Formula, given by equation 2.14 (Hinze et al., 2005):

$$
g_{\theta}=978032.67715 \frac{1+0.001931851353 \sin ^{2} \theta}{\sqrt{1-0.0066943800229 \sin ^{2} \theta}} \mathrm{mGal}
$$

\subsubsection{Variation of gravity with elevation}

A change in elevation on Earth's surface will have a significant gravitational effect since gravitational force varies inversely with the square of radial distance (refer to equation 2.6). To correct for elevation, gravity observations are reduced to that expected on a reference datum, known as the free-air, or height correction (Burger et al., 2006; Kearey et al., 2013). The free-air correction does not account for the excess mass underlying observation points located at elevations above and below the reference datum, which also introduces a large gravitational effect that must be corrected for separately, known as the Bouguer correction (Burger et al., 2006; Kearey et al., 2013). 


\section{The free-air correction}

The free-air correction accounts for the difference in gravity between the observation point and the adjacent reference point on the vertical datum, due to a difference in height (h) (Figure 2.4) (Kearey et al., 2013; Telford et al., 1990).

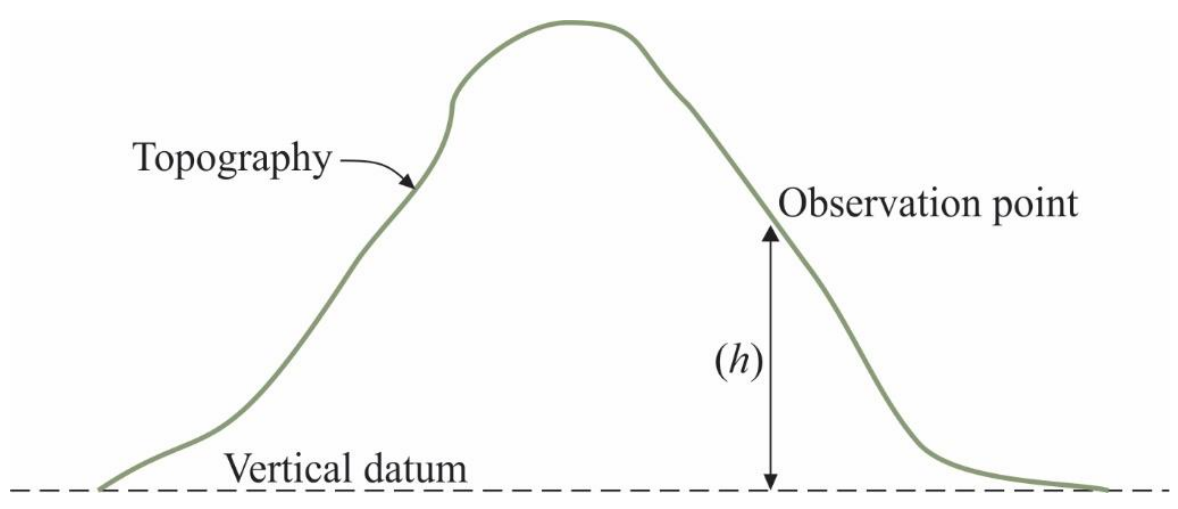

Figure 2.4: The free-air correction for an observation at a height $(h)$ above the vertical datum.

The free-air correction is based on orthometric height above the geoid (i.e. height above sea level), whereby the first-order approximation for the free-air gradient is $-0.3086 \mathrm{mGal} / \mathrm{m}$ and thus, the free-air correction $\left(g_{F A}\right)$ is applied as follows (Burger et al., 2006):

$$
g_{F A}=-0.3086 \times h \mathrm{mGal}
$$

where $h$ is the height above the geoid. Conventional gravity meters typically measure relative gravity to an accuracy of $0.01 \mathrm{mGal}$, therefore to ensure this level of accuracy, it is essential to measure station height to within 3-5 cm (Burger et al., 2006).

\section{The Bouguer correction}

The Bouguer correction accounts for the excess mass underlying observation points located at elevations higher than the vertical datum. Conversely, it accounts for a mass deficit at observation points located below the vertical datum (Figure 2.5) (Burger et al., 2006; Kearey et al., 2013). 


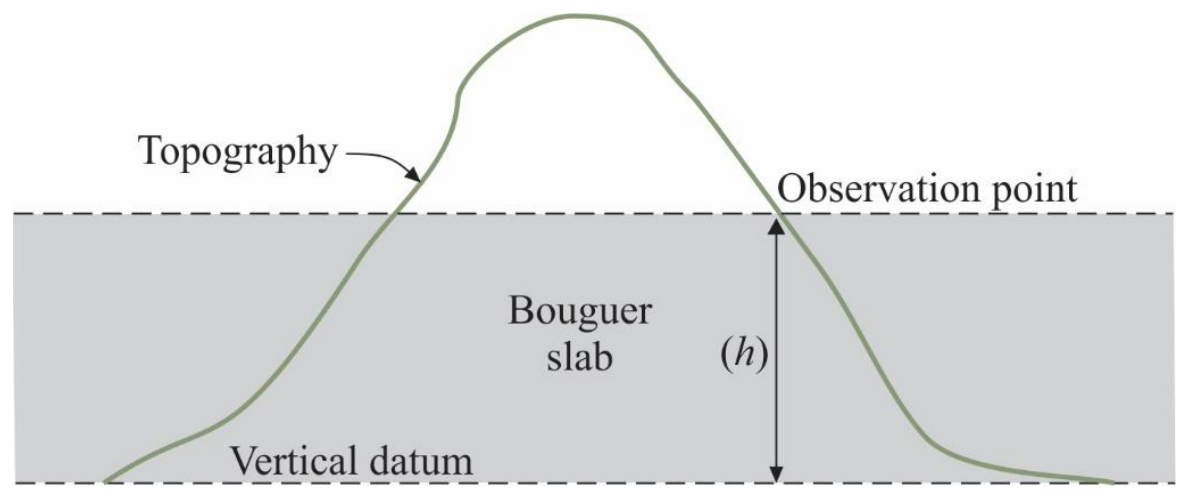

Figure 2.5: The Bouguer correction.

The grey region corresponds to an infinite horizontal slab of rock of thickness $(h)$ with a given density $(\rho)$.

The Bouguer correction $\left(g_{B C}\right)$ is calculated assuming the Earth between the observation point and the vertical datum is an infinite horizontal slab, given by equation 2.15 (Burger et al., 2006; Gerkens, 1989):

$$
g_{B C}=2 \pi G \rho h=0.04191 \rho h \mathrm{mGal}
$$

where $G$ is the gravitational constant (equation 2.2), $\rho$ is the density of the horizontal slab in $\mathrm{kg} / \mathrm{m}^{3}$, and $h$ is the height $(\mathrm{km})$ above the geoid (Burger et al., 2006; Gerkens, 1989).

A density of $2670 \mathrm{~kg} / \mathrm{m}^{3}$ is generally assumed for the density of the Bouguer slab in regional gravity surveys. This value is a reasonable estimate of the mean surface rock density of the continents that are crystalline and of granitic composition (Hinze, 2003).

\subsubsection{Variation of gravity with topography}

The Bouguer correction does not account for the gravitational effect of topography since it assumes the Earth between the observation point and the vertical datum is an infinite horizontal slab with a planar surface (Kearey et al., 2013; Telford et al., 1990). In reality, topographic highs above the observation point introduce excess mass, exerting an upward attraction at the observation point causing gravity to decrease. Conversely, topographic lows below the observation point introduce a mass deficit, causing the Bouguer correction to overcorrect for these areas (Figure 2.6) (Kearey et al., 2013; Telford et al., 1990). 


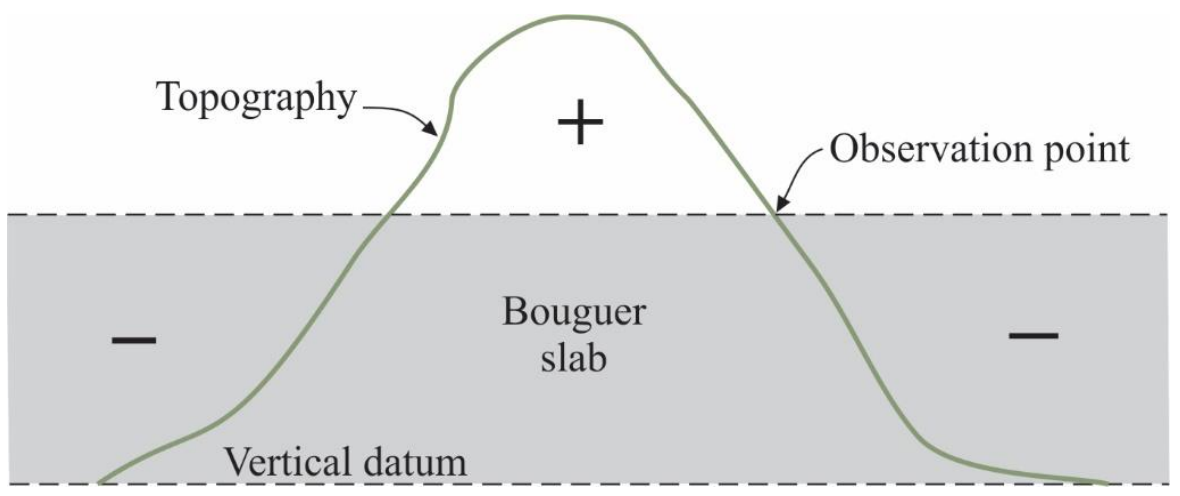

Figure 2.6: The gravitational effect of topography.

Topographic highs above the observation point introduce excess mass (+), while topographic lows below the observation point introduce a mass deficit $(-)$.

This mass imbalance produces terrain effects responsible for errors in the gravity anomalies of tens of milligals (Gerkens, 1989; Stern, 1995). To avoid a large terrain effect, gravity sites are typically selected in areas of low topographic relief, where features too small to be shown on a topographic map can be gravitationally significant (Milsom, 2003). However, in this case, the study area is surrounded by high (>1000 m a.s.l) mountainous terrain requiring a significant topographic correction, conventionally known as a terrain correction.

\section{The terrain correction}

The terrain correction accounts for variations in the observed gravitational acceleration caused by variations in topography near each observation point (Beck, 1981; Burger et al., 2006; Kearey et al., 2013; Telford et al., 1990)

Because of the assumptions made during the Bouguer slab correction, the terrain correction is positive regardless of whether the local topography consists of a mountain (mass excess) or valley (mass deficit) (Burger et al., 2006; Kearey et al., 2013). As can be appreciated from consideration of Figure 2.6, a positive topographic correction is added to the observed gravity at the observation location (Burger et al., 2006; Kearey et al., 2013; Telford et al., 1990).

Many methods for calculating terrain corrections exist in gravimetry, all of which require detailed knowledge of relief in the vicinity of each observation point and a reliable topographic source, such as a topographic map (contour interval $\sim 10 \mathrm{~m}$ ), and/or a high-resolution digital elevation model (DEM) (Burger et al., 2006; Telford et al., 1990). Classically, the terrain correction is applied using the Hammer (1939) method, 
which uses a graticule of segmented annuli, representing sections of cylinders of different radii centred on an observation point (Figure 2.7). The traditional method is applied by outlining the outer annular segments ( $E$ to $M$ ) of the graticule on a transparent sheet overlying a topographic map, and by observing the relief of inner annular segments (A to D) in the field (Burger et al., 2006; Hammer, 1939; Telford et al., 1990).

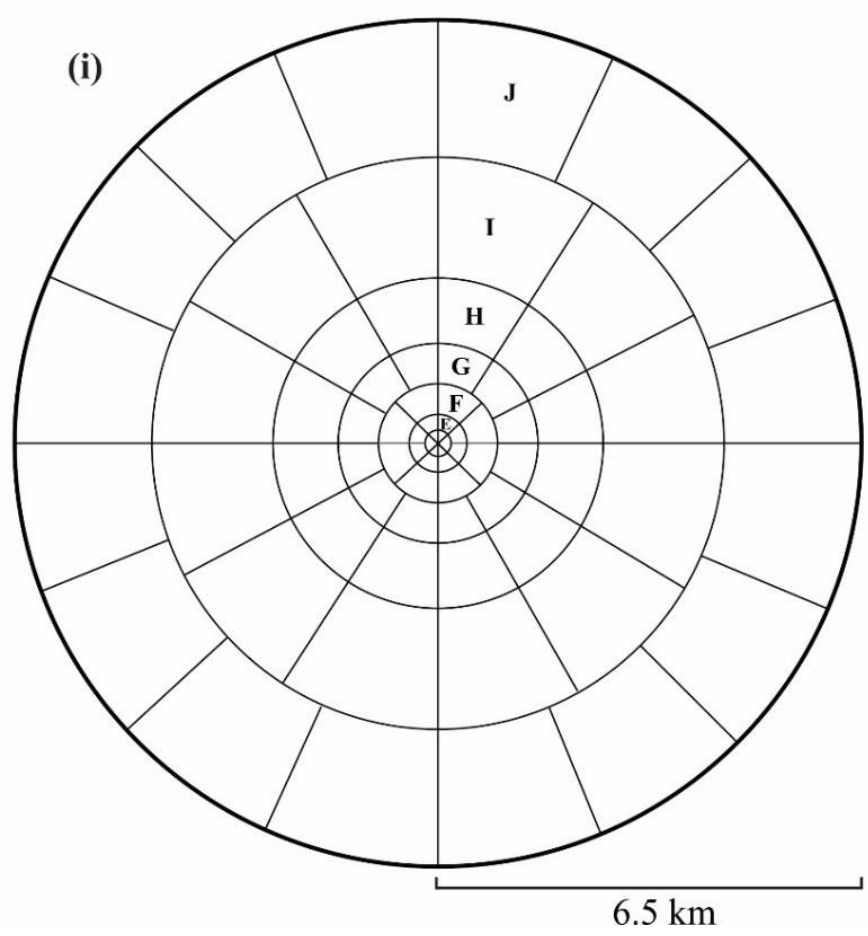

(ii)

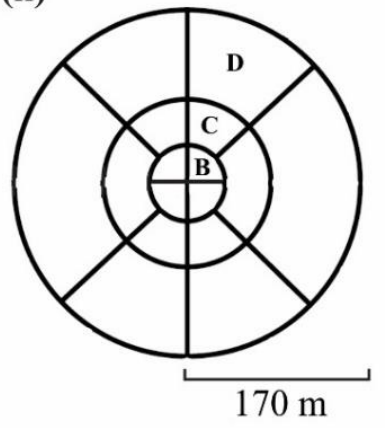

Figure 2.7: The Hammer (1939) graticule used for the calculation of terrain corrections.

(i) Outer Hammer zones E-J extending to a radius of $\sim 6.5 \mathrm{~km}$. The outermost zones (K-M), which extend to $\sim 22 \mathrm{~km}$ are not shown. (ii) Inner Hammer zones B$\mathrm{D}$ extending to a radius of $170.1 \mathrm{~m}$. The innermost zone (A), which is assumed to be flat is not shown. Figure modified from Kearey et al. (2013).

More recent techniques use high-resolution DEMs to compute terrain corrections. The outermost segment (M) extends almost $22 \mathrm{~km}$, beyond which topographic effects are usually negligible (Kearey et al., 2013). Conventional practice involves analysing the surrounding relief within each annular segment and calculating an average elevation. The height of the gravity station is subtracted from these values, and the gravitational effect of each annular segment is determined by reference to the Hammer (1939) terrain correction chart (Appendix A; Table A.1) (Kearey et al., 2013; Milsom, 2003; Telford et al., 1990). 
The chart is constructed using equation 2.16, which is a formula for the gravitational effect of an annular segment of a vertical cylinder at its axis (Kearey et al., 2013):

$$
T=0.04191 \frac{\rho}{n}\left(r_{2}-r_{1}+\sqrt{r_{1}^{2}+z^{2}}-\sqrt{r_{2}^{2}+z^{2}}\right) \quad \mathrm{mGal}
$$

where $T$ is the terrain correction of a single annular segment, $\rho$ is the Bouguer correction density $(2.67 \mathrm{~g} / \mathrm{cc}), n$ is the number of segments in a Hammer zone, $r_{1}$ is the inner radius of a zone $(\mathrm{m}), r_{2}$ is the outer radius of a zone $(\mathrm{m})$, and $z$ is the modulus of elevation difference between the gravity station and the average elevation of a single annular segment (m).

The total terrain correction $\left(g_{T C}\right)$ is the sum of the contributions of all segmented annuli in the graticule, and is added to the observed gravity at the observation location (Kearey et al., 2013; Telford et al., 1990):

$$
g_{T C}=T_{\text {inner }}+T_{\text {outer }} \mathrm{mGal}
$$

Use of the Hammer (1939) method requires skill in estimating relative distances and heights, which can be difficult in rugged terrain, introducing a large estimation error. For this study, a MATLAB-based code was used to compute both an inner and outer terrain correction for each station, incorporating equation 2.16. The code uses the New Zealand 8-m-resolution bare-earth digital elevation model (DEM) obtained from Land Information New Zealand (LINZ) to compute outer terrain corrections based on geoidal heights, covering Hammer zones E to M (170-22,000 m). To compute inner terrain corrections, the code uses a 2-m-resolution DEM, produced from a LiDAR swath of the study area (Barth et al., 2012; Langridge et al., 2014), and covers Hammer zones B (2-17 m), C (17-53 m) and D (53-170 m). Hammer zone A (0-2 m) is assumed to be level. Inner terrain corrections are based on LiDAR heights which are relative to the local geoid (NZVD2009) (Langridge et al., 2014). Inner and outer terrain corrections are then summed using equation 2.17 and added to the observed gravity for each site.

To compute an inner terrain correction for gravity stations located outside the range of the LiDAR swath, the conventional Hammer (1939) field procedure was implemented, which includes analysing the surrounding relief within each inner annular 
segment (B-D) and calculating an average elevation (refer to Figure 2.7). Details of the field procedure are discussed in section 2.3.1. Average elevations are incorporated into the same MATLAB code, which are summed, converted to milligal using equation 2.16, then added to the outer terrain correction using equation 2.17.

Outer terrain corrections were also re-processed for existing gravity stations using the same method described above. Additionally, inner terrain corrections were reprocessed for existing stations located within range of the LiDAR swath. Inner terrain corrections for existing stations located outside of LiDAR range were obtained from the raw dataset provided by Davy (2012).

\subsubsection{The Bouguer gravity anomaly}

The Bouguer gravity anomaly is the departure between the corrected gravity at the station and the expected gravity on the reference datum. The expected value of gravity $\left(g_{\text {exp }}\right)$, also known as the Bouguer model, is the combination of the gravitational effects of latitude, elevation, topography, drift and Earth's tides following equation 2.18:

$$
g_{\text {exp }}=g_{\theta}+g_{B C}+g_{F A}-g_{T C} \mathrm{mGal}
$$

where $g_{\theta}$ is the expected gravity at latitude $\theta, g_{B C}$ is the Bouguer correction, $g_{F A}$ is the free-air correction, and $g_{T C}$ is the total terrain correction.

Subtracting the value of gravity expected on the reference datum with the observed gravity at the observation point resolves the Bouguer gravity anomaly $\left(g_{B A}\right)$ :

$$
g_{B A}=g_{o b s}-g_{\text {exp }} \mathrm{mGal}
$$

Equating equations 2.18 and 2.19 yields:

$$
g_{B A}=g_{o b s}-g_{\theta}-g_{F A}-g_{B C}+g_{T C} \mathrm{mGal}
$$

where $g_{o b s}$ is the station reading (corrected for drift and Earth's tides), $g_{\theta}$ is the expected gravity at latitude $\theta, g_{F A}$ is the free-air correction, $g_{B C}$ is the Bouguer correction, and $g_{T C}$ is the total terrain correction. 
Since anomalies are equal to the difference between corrected values and the adjacent values on the reference datum, a positive anomaly represents a mass excess where there is a greater than expected gravitational attraction. Conversely, a negative anomaly represents a mass deficit where there is a less than expected gravitational attraction. If the Earth had no lateral variations in density, and the gravitational effects of latitude, elevation, topography, and drift had been removed, gravity readings would be identical.

The Bouguer anomaly is therefore the result of lateral variations in density, allowing for the modelling and the interpretation of the Earth's sub-surface (Kearey et al., 2013; Telford et al., 1990).

\subsection{Data acquisition and reduction}

\subsubsection{Data acquisition}

\section{Equipment}

New gravity measurements were collected using a Lacoste and Romberg gravity meter (Model G-519), which can measure relative gravity to a precision of $\pm 0.01 \mathrm{mGal}$ (Milsom, 2003). The meter measures the difference in gravity between two observation locations or over a time interval at one site. A relative calibration is obtained at numerous points over the entire range of the meter using the meter's latest calibration table (Appendix A; Table A.2).

Coordinate and elevation data for each observation point were collected using a Trimble ${ }^{\circledR}$ R8 GNSS system and Trimble ${ }^{\circledR}$ GeoExplorer ${ }^{\circledR} 6000$ series handheld unit. The R8 GNSS system achieves cm-level positioning accuracy by utilising real-time kinematic (RTK), and fast static corrections. In areas of rugged terrain where the R8 GNSS system was unsuitable, the more versatile GeoExplorer ${ }^{\circledR}$ handheld was used to achieve real-time decimetre $(10 \mathrm{~cm})$ positioning accuracy. Receiver locations were later corrected relative to the continuously operating GNSS station, Mt Price (MTPR) maintained by GeoNet, located $\sim 11 \mathrm{~km}$ from Whataroa.

Post-processing of relative GNSS data produced high-precision horizontal and vertical accuracy for each observation point by using a Transverse Mercator projection (NZTM2000), which is based on the New Zealand Geodetic Datum 2000 (NZGD2000) and uses the Geodetic Reference System 1980 (GRS80) reference ellipsoid. All 
horizontal positions are relative to NZGD2000 and all ground elevations are relative to NZVD2009. Additionally, existing GNSS positions recovered from past surveys were updated and corrected relative to NZGD2000 and NZVD2009 to ensure consistency across the amalgamated dataset.

\section{Field procedure}

The gravity survey was divided into four intervals. The first interval was completed by the author and Rupert Sutherland of Victoria University of Wellington (VUW) between the $30^{\text {th }}$ of November and the $3^{\text {rd }}$ of December 2013 during a VUW summer scholarship program designed to aid in the selection of a suitable location for the DFDP-2 drill hole (Sutherland et al., 2015). The second interval was completed between the $24^{\text {th }}$ of April and the $8^{\text {th }}$ of May 2015, the third interval completed between the $15^{\text {th }}$ of May and the $2^{\text {nd }}$ of June 2015, and the fourth interval completed between the $22^{\text {nd }}$ and the $30^{\text {th }}$ of September 2015. In total, 464 new gravity stations, and two absolute gravity reference stations of the GNS Science gravity network were occupied.

Station location and appropriate site spacing was planned using forward gravity models and aerial photography. Data were collected on a grid in the vicinity of the DFDP-2 borehole and the Alpine Fault, and on dense profiles of interest. Forward gravity models that aided survey design are presented in Chapter 4.

In order to constrain the regional gravity field and hence accurately model the shallow bedrock-sediment interface in the valley (240-350 m deep; expected gravity signal $\sim 3 \mathrm{mGal}$ ), sparse regional measurements were collected on sites with small local density variation, such as schist bedrock, as far from the valley fill as possible using the various creeks and gullies located within the bounds of the study area. During the final interval of surveying, a helicopter was available and used to access otherwise inaccessible sites located on Mt Price and Adams Range. Acquisition of the regional gravity signal and its subsequent separation from Bouguer gravity anomalies is explained in more detail in Section 2.4.

As previously mentioned, the study area is surrounded by high (>1000 m a.s.l) mountainous terrain making site selection difficult, and introducing large terrain effects (>10 mGal) (Stern, 1995). During surveying, some sites were selected outside the range of the LiDAR swath, requiring an alternative method of estimating the inner terrain correction. The conventional Hammer (1939) field procedure was utilised at these sites, which involves using a truncated graticule covering Hammer zones B (2-17 m), C (17- 
$53 \mathrm{~m}$ ) and D (53-170 m) (refer to Figure 2.7 (ii)). The observer stands on the observation point and estimates the average elevation of each annular segment within each Hammer zone. The inner and outer segment radii are not measured and are sometimes obscured, requiring a 'best guess' estimate. The observer rotates clockwise from segment to segment to maintain uniformity between sites, while estimating the segment angle.

Gravity measurements were made following the method of Milsom (2003). For specific details of the measurement procedures used in this survey refer to Appendix B.

As discussed earlier in this chapter, Earth's tidal signal is significant and is an important consideration when modelling small amplitude signals, as expected in the valley ( $<3 \mathrm{mGal}$ ). Drift was monitored during surveying by completing internal loops in areas away from reference sites by re-occupying a relative gravity station at regular intervals (1-2 hours), allowing possible errors to be identified. No errors were identified during surveying.

The precise time of each measurement was carefully recorded at each site using the atomic clock within the GPS unit, and later converted to Coordinated Universal Time (UTC).

\subsubsection{Data reduction}

The objective of most gravity surveys is to estimate the location and nature of subsurface structures. To achieve this, gravity observations are reduced to Bouguer gravity anomalies. Below is a summary of how the data were reduced.

1. Observed gravity values $\left(g_{o b s}\right)$ were adjusted for the effects of Earth's tides, instrumental drift, and a meter calibration scaling factor. The resultant absolute gravity values were calculated for all stations using a Python-based program, known as Gsolve (McCubbine et al., 2016), introduced in section 2.2.2 and discussed further in Chapter 3.

2. Observed gravity values were corrected for latitude $\left(g_{\theta}\right)$ using the WGS84 Ellipsoidal Gravity Formula, given by equation 2.13, and GNSS-determined ellipsoidal latitudes $(\theta)$.

3. Free-air corrections $\left(g_{F A}\right)$ were applied to each gravity value using equation 2.14 , and surveyed heights $(h)$. 
4. A Bouguer correction $\left(g_{B C}\right)$ was applied to each gravity value using equation 2.15 , the surveyed height $(h)$, and a mean rock density $(\rho)$ of $2670 \mathrm{~kg} / \mathrm{m}^{3}$.

5. An outer and inner terrain correction was computed for each observation point by incorporating a DEM or field observations, and equation 2.16 into a MATLAB-based code as described in section 2.2.5. The total terrain correction $\left(g_{T C}\right)$ was applied to each gravity value using equation 2.17 .

6. Bouguer gravity anomalies $\left(g_{B A}\right)$ were calculated for all stations using equation 2.20 .

\subsubsection{Uncertainty in the Bouguer gravity anomaly}

Potential sources of error or uncertainty in any individual gravity measurement are: reader error, instrument drift, over-simplification of the tidal model, errors in terrain corrections (density assumption, terrain measurement), as well as errors in latitude and height measurements.

\section{Reader error}

Reader error may be caused by several factors, including unstable terrain, wind, seismic activity, a faulty meter, or human error.

To reduce reader error, gravity sites were selected on solid (preferably rock) ground wherever possible. However, this is not always possible when surveying on grassy areas. To overcome this problem, top soil was removed and a metal survey plate was pushed firmly into the ground to create a solid platform for the gravity meter. Additionally, to reduce the effect of wind, each meter reading was taken while the reader had their back to the wind at each station.

During surveying, seismic events can play a role in reader error (Milsom, 2003). If the needle in the counter is fluctuating, then there is likely a current earthquake occurring. This was relatively common during this survey, and when it did occur, depending on the severity, common practice was to stop surveying and return later $(\sim 1$ hr) to re-measure the last station.

Particular care must be taken of the highly sensitive gravity meter as a faulty meter will introduce a large reading error (Milsom, 2003). This includes maintaining a 
constant power supply and handling the meter gently during transportation. To monitor the meter during surveying, the looping procedure previously discussed in Section 2.2.2 was implemented, allowing possible errors to be identified between repeat readings. No errors were detected during surveying.

To avoid misreading the meter dial, a consistent meter reading procedure was employed with the dial being turned only in one direction. For most gravity stations, the meter was read once, while multiple readings were made at a designated intermediate gravity station every 1-2 hours, including two readings that were made every day at each absolute gravity reference station (SA80 \& SA86), once before surveying began, and again after surveying had finished.

\section{Drift error}

During a typical survey loop, it is essential to ensure that no mechanical or thermal tare occurs. A tare is a single, sudden irreversible jump in a meter reading due to instrumental effects, sometimes as large as several milligal (Schubert, 2015). Tares can be identified when repeated readings are made and compared by re-occupying an intermediate gravity station (the base) at regular intervals (1-2 hours), so that tares can be isolated from normal gravity changes (Schubert, 2015). Gsolve incorporates the tare effect into the drift function by the least squares solution as discussed in Section 2.2.2. No tares were detected for this survey.

In total, 34 primary loops were achieved in the survey, where one primary loop is equivalent to a single day of surveying. The highest recorded rate of instrumental drift was $0.04 \mathrm{mGal} / \mathrm{hr}$ on the $30^{\text {th }}$ of November 2013 during the first interval of surveying. On all other survey loops, the drift rate was $<0.01 \mathrm{mGal} / \mathrm{hr}$.

The combined uncertainty associated with reader error, instrument drift, and tidal prediction is $\pm 0.015 \mathrm{mGal}$, which is determined from the repeatability of absolute gravity measurements. This result is described in detail in Chapter 3.

\section{Terrain correction uncertainty}

As discussed in Section 2.2.5, the inner terrain correction (2-170.1 m) was calculated using both a 2-m-resolution DEM for new and existing gravity stations located within range of the LiDAR swath, and using the traditional Hammer (1939) terrain estimation method for stations located outside the range of the LiDAR swath. 
The inner terrain correction for a total of 116 new gravity stations was calculated using the traditional Hammer (1939) method, whereby $95 \%$ of corrections were $<0.5$ $\mathrm{mGal}$, and $98 \%$ were $<1.0 \mathrm{mGal}$. Of the 116 new gravity stations, 15 were located in high-relief areas, and 101 were located in low-relief areas. Uncertainties in the inner terrain corrections are quoted to one standard deviation, where stations located in highrelief areas have a standard deviation of $\pm 0.35 \mathrm{mGal}$, and stations located in low-relief areas have a standard deviation of $\pm 0.02 \mathrm{mGal}$.

The 2-m-resolution DEM of the study area is more than sufficient for calculating an inner terrain correction with relatively low uncertainty for stations located within the range of the LiDAR swath, covering Hammer zones B (2-17 m), C (17-53 m) and D (53-170 m). However, not all stations are within full range of the LiDAR swath and some are only fractionally within range (Figure 2.8). A total of 316 gravity stations, including existing stations, had LiDAR coverage of $>95 \%$ within a 170 m radius (Figure 2.8a). Sites with LiDAR coverage of $<95 \%$ were corrected to $100 \%$ coverage by multiplying the inner terrain correction across the missing section only when (1) the entire coverage area was considered to be flat, and (2) when the missing section was no more than $50 \%$ (Figure 2.8b). Overall, 54 gravity stations, including existing stations, satisfied these requirements. In some cases, the LiDAR coverage within the graticule was partly or entirely an area of high-relief while the missing section was either partly or entirely flat (Figure 2.8c). It was therefore inappropriate to correct these sites to $100 \%$ coverage as it would lead to a terrain overcorrection. In total, 12 gravity stations were found in this situation with an average LiDAR coverage of $80 \%$. In total, 382 gravity stations, including existing stations, were located within full or adequate range of the LiDAR swath, where $86 \%$ of inner terrain corrections were $<0.5 \mathrm{mGal}$, and $91 \%$ were $<1.0 \mathrm{mGal}$.

The uncertainty in terrain corrections computed using DEMs is dependent upon the resolution of the model used to calculate them. For this reason, the uncertainty in inner terrain corrections for stations located within range of the LiDAR swath is considered to be negligible due to the high-resolution of the DEM (2 m). Additionally, the uncertainty in outer terrain corrections, which were computed for all gravity stations using the New Zealand 8-m-resolution bare-earth DEM, covering Hammer zones E to $\mathrm{M}(\sim 170-22,000 \mathrm{~m})$ is also considered to be negligible. 

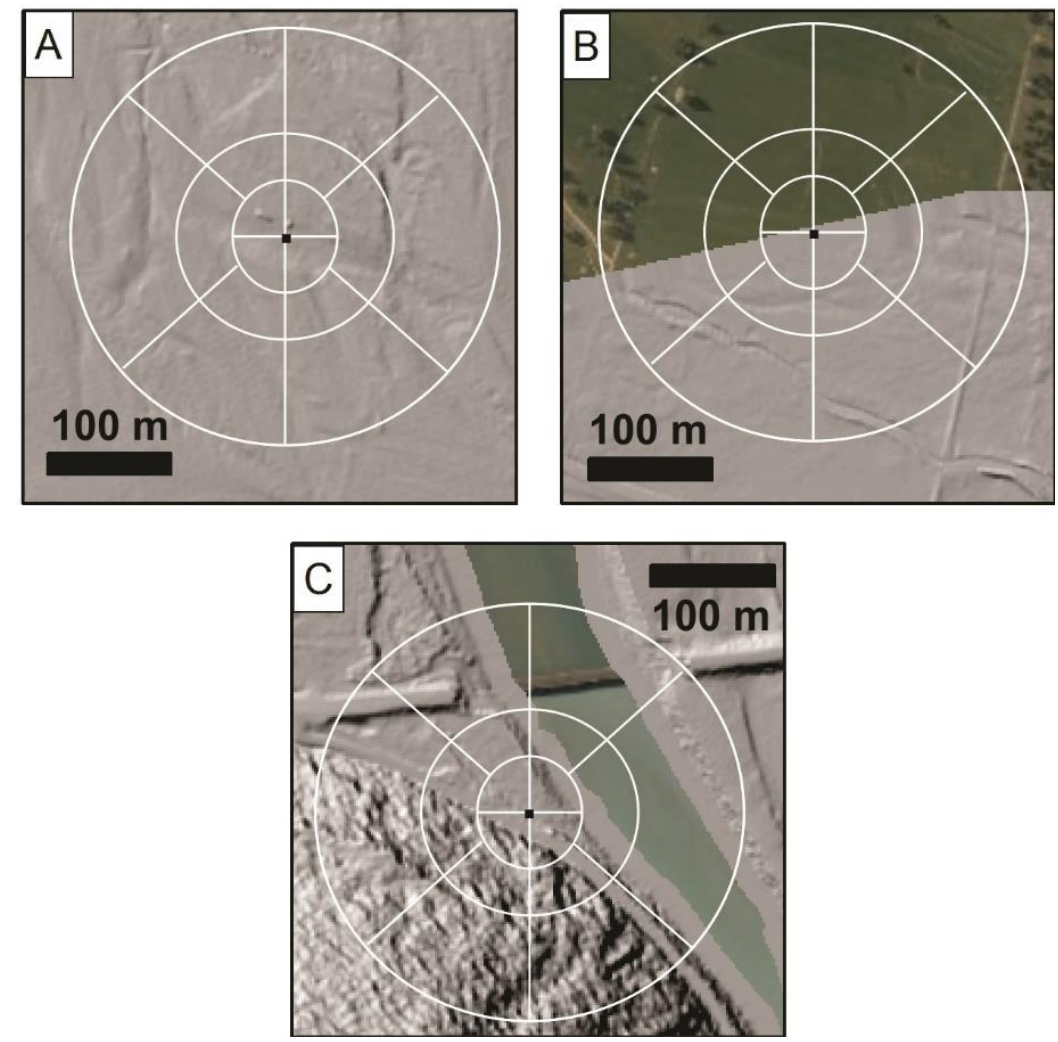

Figure 2.8: Key examples of LiDAR inner terrain correction.

Inner terrain correction graticule (Hammer zones B-D) shown in white (radius = $170.1 \mathrm{~m}$ ). Grey hill-shade is the LiDAR swath. (A) shows an example of a gravity station with $>95 \%$ LiDAR coverage. In (B) the graticule covers an area that is considered $100 \%$ flat; however, $~ 50 \%$ of the graticule is outside of LiDAR range. Complications in correcting for missing sections of LiDAR arise when the missing section sits adjacent to high-relief terrain (C). Note that missing LiDAR coverage due to the Whataroa River seen in (C) is considered flat.

\section{Height and latitude uncertainty}

As previously discussed at the beginning of the chapter, a change in elevation on Earth's surface will have a significant gravitational effect since gravitational force varies inversely with the square of radial distance (refer to equation 2.6). An error in height of $\pm 1 \mathrm{~m}$ will result in a $\pm 0.19 \mathrm{mGal}$ uncertainty in the Bouguer gravity anomaly

A total of 189 station heights were measured using the Trimble ${ }^{\circledR}$ R8 GNSS system, producing an average uncertainty in height of $\pm 0.03 \mathrm{~m}$, and a maximum uncertainty of $\pm 0.9 \mathrm{~m}$. In high-relief areas where the R8 GNSS system was unsuitable, the Trimble ${ }^{\circledR}$ GeoExplorer $^{\circledR} 6000$ series handheld unit was utilised. A total of 277 station heights were measured using the Trimble ${ }^{\circledR}$ GeoExplorer ${ }^{\circledR} 6000$ series handheld unit, producing an average uncertainty in height of $\pm 0.4 \mathrm{~m}$, and a maximum uncertainty of $\pm 1.9 \mathrm{~m}$. 
Additional error in height is introduced for stations located within range of the LiDAR swath due to a difference between the measured GPS heights of the stations and the DEM heights used to calculate inner terrain corrections. Figure 2.9 shows an empirical Cumulative Distribution Function (CDF) plot of the differences (in black) and the fitted normal distribution (in red).

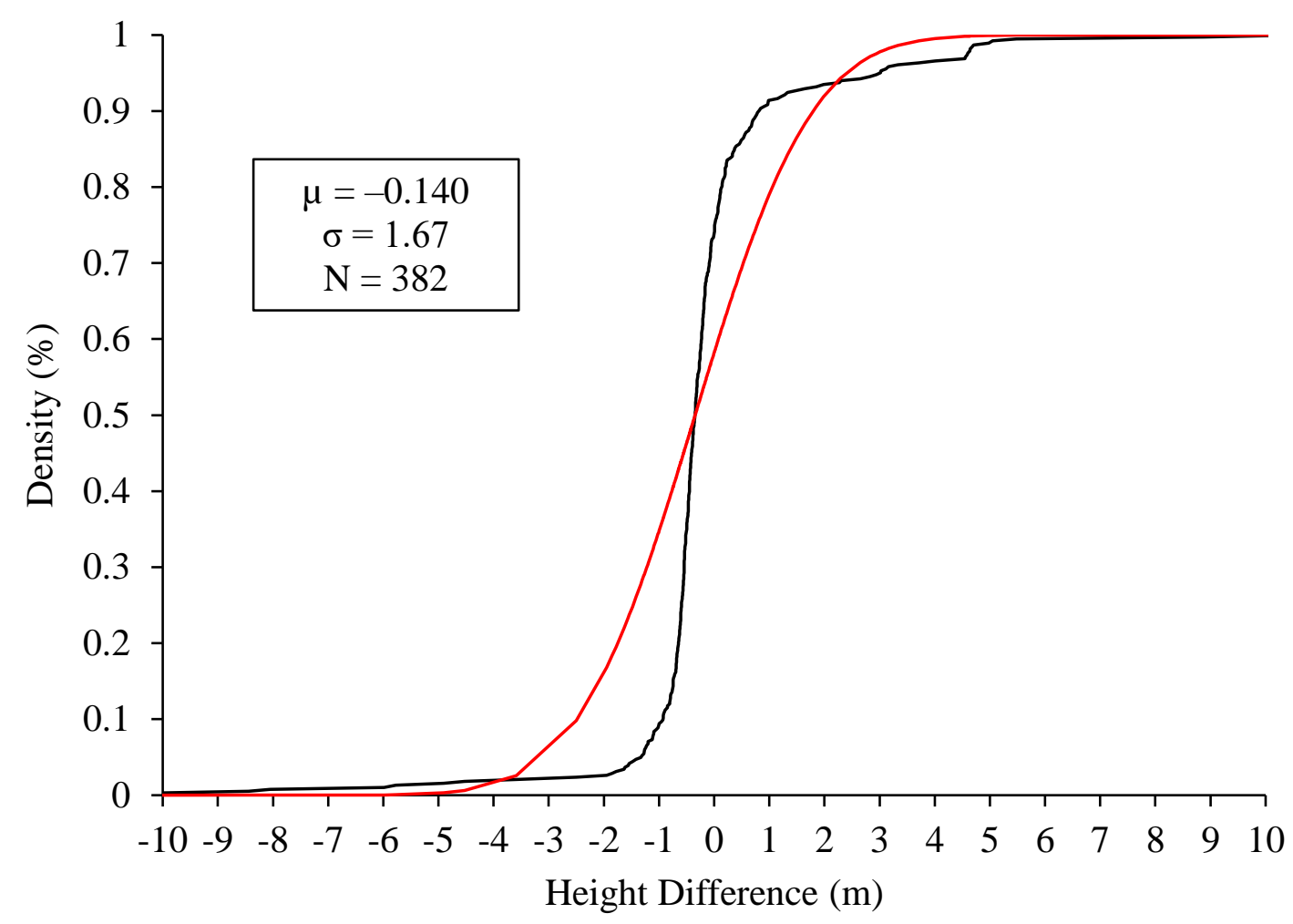

Figure 2.9: Empirical CDF plot of the difference between GPS heights and LiDAR DEM heights.

The black line represents the distribution of GPS measured heights minus heights derived from the LiDAR DEM. Red line represents the fitted normal distribution.

For a total of 382 gravity stations located within adequate range of the LiDAR swath, the difference between the measured GPS heights and the DEM heights has a standard deviation of $1.67 \mathrm{~m}$. A fixed estimated error with a standard deviation of 0.36 $\mathrm{m}$ was calculated for the measured GPS heights of both new and existing gravity stations. Therefore, the standard deviation of the LiDAR DEM can be approximated following equation 2.21:

$$
H^{\text {err }} \operatorname{LiDAR}=\sqrt{1.67^{2}+0.36^{2}}=1.71 \mathrm{~m}(2 . \mathrm{d} . \mathrm{p})
$$


For stations located outside the range of the LiDAR swath, it is assumed that only the measurement error contributes uncertainty, and are therefore assigned a fixed estimated error in height of $0.36 \mathrm{~m}$. Equation 2.22 shows that the fixed height error for gravity stations located within range of the LiDAR swath contributes $0.3 \mathrm{mGal}$, while stations located outside the range of the LiDAR swath contribute $0.07 \mathrm{mGal}$.

$$
H^{u n c}=h^{\text {err }}(-0.3086+0.04191 \rho)=-0.19 h^{\text {err }} \mathrm{mGal}
$$

where $H^{u n c}$ is the resulting uncertainty in the Bouguer anomaly due to an error in height $\left(h^{\text {err }}\right)$.

The latitude uncertainty in the Bouguer gravity anomaly is considered to be negligible compared to the height uncertainty. An uncertainty in latitude of $\pm 1 \mathrm{~m}$ results in a $\pm 0.0008 \mathrm{mGal}$ uncertainty in the Bouguer gravity anomaly. Consequently, any uncertainty in latitude was disregarded for this study.

\section{Total uncertainty}

The total uncertainty for each Bouguer gravity anomaly $(U)$ is the Root Mean Square (RMS) of each of the sources of error, assuming there are no correlations between sources of error:

$$
U=\sqrt{U_{m}^{2}+U_{t}^{2}+U_{h}^{2}} \mathrm{mGal}
$$

where $U_{m}$ is the measurement uncertainty (Chapter 3), $U_{t}$ is the terrain correction uncertainty, and $U_{h}$ is the height uncertainty.

The average total uncertainty for the Bouguer gravity anomalies, including existing gravity stations, is $\pm 0.2 \mathrm{mGal}$, with a maximum total uncertainty of $\pm 0.3 \mathrm{mGal}$. Bouguer gravity anomalies of each gravity station, and their respective uncertainties are listed in Appendix C; Table C.1. The measured height and latitude uncertainties for each gravity station are provided in Appendix D. 


\subsection{Regional-residual separation}

The Bouguer gravity anomaly is caused by the combined effects of deep-seated regional structure and shallow localised structure, both of which are reflected through long and short-wavelength components. In gravimetric analyses, it is often desirable to separate these components in order to observe the regional and residual anomalies individually, so that gravity signals associated with short-wavelength shallow density anomalies can be isolated and modelled (Burger et al., 2006). To accurately separate both long and short-wavelength components, gravity observations must be both extensive enough to capture the regional gravity trend and dense enough to resolve localised structure (Burger et al., 2006). However, the separation of both components is non-unique since the transition from long to short-wavelengths may be ambiguous (Kearey et al., 2013). A typical approach is to employ a combination of analytical and graphical methods to identify and remove the regional gravity trend (Burger et al., 2006).

\subsubsection{Mathematical methods}

A common mathematical approach to removing the regional trend involves fitting a low-degree polynomial to the Bouguer gravity data (Burger et al., 2006). Low-degree polynomials fit regional data appropriately compared to high-degree polynomials which also capture part of the residual anomaly. In this study, both first-degree (linear) and second-degree (quadratic) polynomial functions were used to fit the regional trend and subsequently separate it from a residual signal. This approach is shown in Figure 2.10 .

\section{Regional-residual separation for the Whataroa River valley}

The region surrounding the Whataroa valley is affected by two broad negative gravity anomalies either side of the Alpine Fault. The anomaly east of the fault is likely due to the deep crustal root of the Southern Alps (Davey et al., 2007) and the anomaly west of the fault is due to the sub-surface presence of low-density sediments of the South Westland Basin (Davy et al., 2013). In order to capture the regional gravity trend, Bouguer anomaly points were chosen on sites with small local density variations (bedrock sites) and widespread distribution following the method of Stern (1979). 

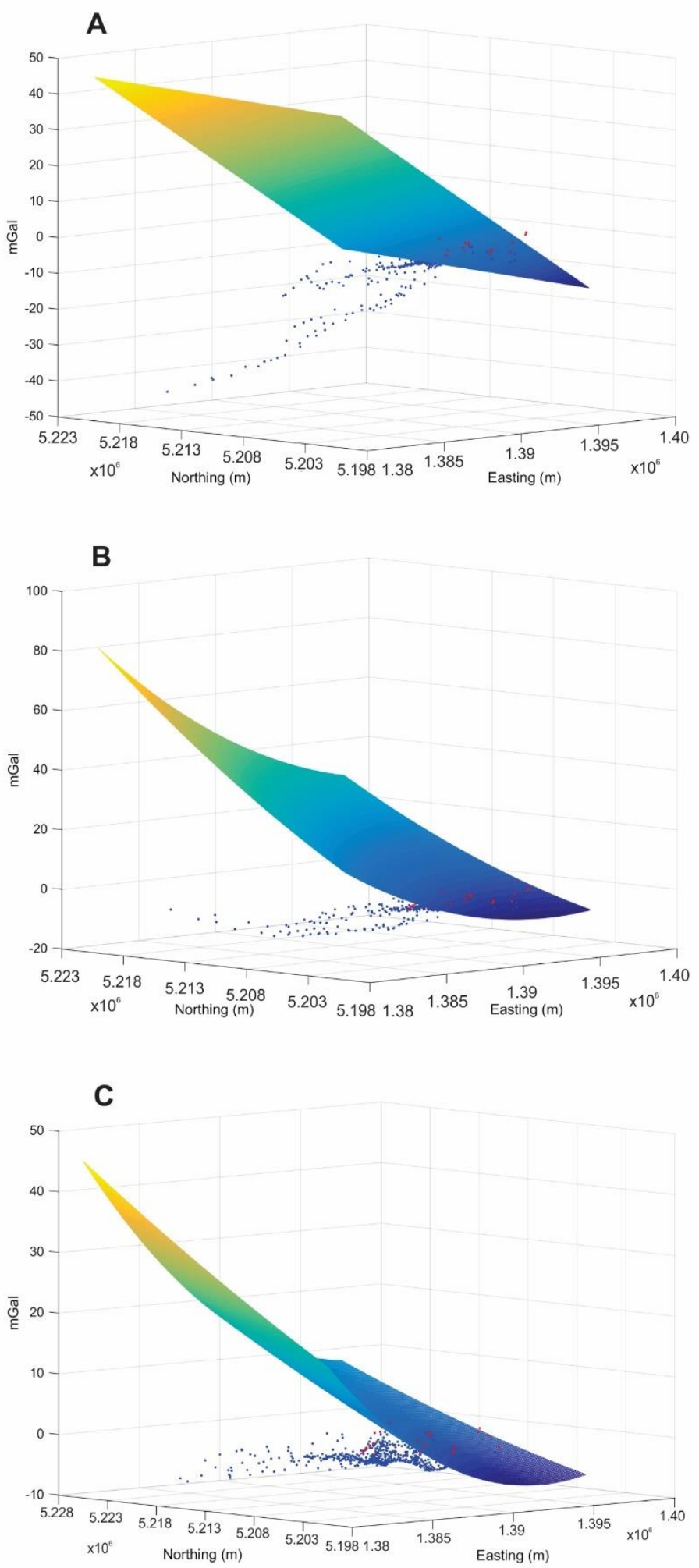

Figure 2.10: Modelling of a linear and quadratic polynomial surface fitted in $x-y-g$ space to regional Bouguer anomaly points.

(A) shows a first degree (linear) polynomial surface. (B) \& (C) show a second degree (quadratic) polynomial surface. Red points represent weighted bedrock stations. Blue points represent the remaining Bouguer gravity data. 
Bouguer anomaly points located on bedrock outcrops such as schist, made accessible by the various creeks and gullies in the study area, ensured the regional fit was independent of the residual anomaly generated by the sediment-based stations in the Whataroa valley.

A surface-fitting method was used to remove the regional trend from the Bouguer gravity signature of the Whataroa River valley. As a first-order approximation, a linear polynomial surface was fitted in $\mathrm{x}-\mathrm{y}-\mathrm{g}$ space to the regional Bouguer anomaly points using the method of least squares, producing a Root Mean Square Error (RMSE) of $8.5995 \mathrm{mGal}$ (Figure 2.10A). As a second-order approximation, a quadratic polynomial surface was fitted to the regional Bouguer anomaly points, producing a RMSE of $5.1433 \mathrm{mGal}$ (Figure 2.10B). To further improve the surface fit, the quadratic model was re-run with outliers removed, producing an improved RMSE of $2.9866 \mathrm{mGal}$ (Figure 2.10C). The second-degree polynomial surface was selected as the best fit for the data due to a reasonably low RMSE and its compatibility with the regional geological setting. As polynomial degree increases, the individual surfaces fit better with the Bouguer anomaly data; however, higher-degree surfaces are more complex and develop unrealistic curvature at their margins. Since surface-fitting methods do not consider local geological information (Burger et al., 2006), higher-degree polynomials become increasingly unreasonable. Therefore, it was appropriate to use a second-degree polynomial surface with a reasonably low RMSE and long-wavelength signature to represent the regional Bouguer anomaly signal.

Second-degree polynomials represent paraboloid surfaces, expressed in equation 2.24:

$$
g_{T S}=A x^{2}+B y^{2}+C x y+D x+E y+F
$$

where $g_{T S}$ is the gravity value of the trend surface at a spatial position $x$, and $y$. The coefficients $A, B, C, D, E$ and $F$ are determined through the method of least squares to reduce the residual value between the regional surface and the gravity data. The seconddegree polynomial representation of the regional Bouguer anomaly was subtracted from the Whataroa Bouguer anomaly points to obtain the residual anomaly. The effect of the regional-residual separation is presented in Chapter 3. 


\subsection{Gravity modelling}

Gravity models for this study were constructed using Geosoft ${ }^{\circledR}$ GM-SYS software by applying a simple two-dimensional technique (Northwest Geophysical Associates, 2004).

\subsubsection{Two-Dimensional modelling}

Two-dimensional (2-D) models assume the Earth is 2.5-dimensional in nature; i.e. density varies with depth (z direction) and in the direction of the profile (x direction). 2-D models exist but do not vary in the strike direction (y direction) and are assumed to extend to infinity. Figure 2.11 shows a schematic of a 2-D model and the relative coordinate system. The pink cross-section represents a one layer 2-D model, which extends to infinity in the y-plane. 2-D models are typically made up of different polygonal units of varying density. The gravitational response of the constructed 2-D polygonal model is calculated and compared at the location of the observed gravity to estimate the best fit of the model. 


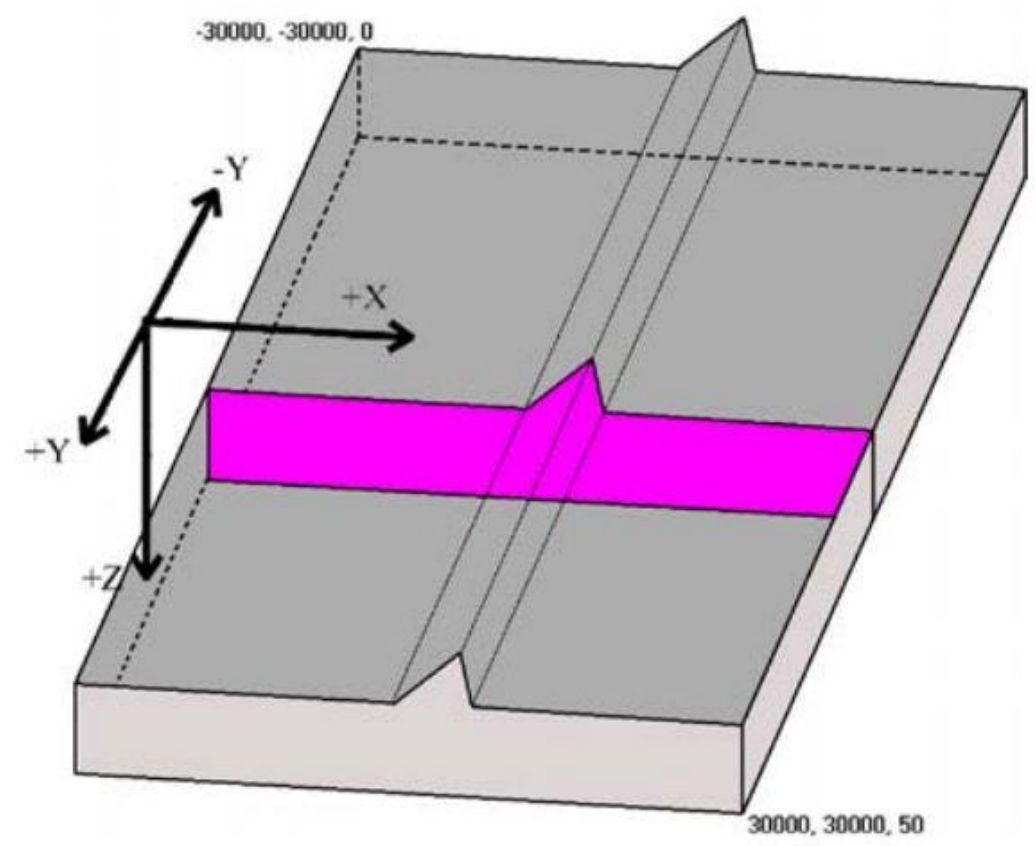

Figure 2.11: Schematic of a two-dimensional model and relative coordinate system.

Pink cross-section extends to infinity in the y-plane. Figure from Northwest Geophysical Associates (2004).

\section{Gravity modelling of the Whataroa River valley}

Two-dimensional gravity models are used in this study to define the shallow geometry surrounding the DFDP-2 drill site and nearby Alpine Fault in the Whataroa River valley. The 2-D gravity models were constructed using the GM-SYS package in Oasis montaj developed by Geosoft ${ }^{\circledR}$ following the method of Talwani et al. (1959). The models are oriented in $\mathrm{x}-\mathrm{z}$ space where $\mathrm{x}$ is profile distance in meters and $\mathrm{z}$ is depth in meters. Polygons with different densities, which represent geologic units, extend to infinity in the \pm -direction and $\pm 30,000 \mathrm{~km}$ in the $\mathrm{x}$-direction to eliminate edge effects. The 2-D gravity models are presented in Chapter 4. 


\section{Chapter 3 Results}

\subsection{Introduction}

This chapter begins with an analysis of results from Gsolve's different gravity reduction methods (first introduced in Chapter 2), followed by a detailed description of the results of the preferred reduction method. Also discussed is how existing gravity data were amalgamated with the new dataset. The combined dataset is presented as both Bouguer and residual gravity anomaly maps.

\subsection{Gsolve gravity reduction results}

Gsolve, a Python-based computer program (McCubbine et al., 2016), was used to transform relative gravity measurements to absolute gravity values. The transformation is based on comparisons of repeated measurements and at least one measurement at an absolute gravity reference site, where the absolute gravity value is known. Gsolve solves for absolute gravity at the observation sites by one of three methods of least squares regression, following Reilly (1970).

\subsubsection{Gsolve gravity reduction methods}

Gsolve's first reduction method (Method 1) is a normal least squares solution which allows the newly-estimated absolute gravity values at reference sites to differ from previously recorded values. Method 1 is advantageous to surveys where previously recorded absolute gravity values are expected to contain significant uncertainty, for example if reference absolute gravity values were measured with imprecise instrumentation, and multiple reference sites are available in the new survey (McCubbine et al., 2016).

Method 2 is a decoupled least squares solution following Reilly (1970) which is best suited to surveys where derived absolute gravity values are required to fit 
previously recorded values at reference sites precisely, while allowing gravity values at other locations surveyed to be derived with some flexibility around these observed values (McCubbine et al., 2016). Estimated variances at absolute gravity sites are nonzero, despite the attempt to fit exactly the given value. This corresponds to giving preference to the provided absolute gravity value in the solution.

Gsolve's third reduction method (Method 3) is a constrained least squares solution that is best suited to surveys where previously recorded absolute gravity values at reference sites are considered to be errorless. This method is advantageous when the history of the reference site is well known and measured regularly, usually with a highly accurate absolute gravity meter (McCubbine et al., 2016).

In order to select the best suited Gsolve gravity reduction method for this study, an experiment was conducted with the aim of testing the uncertainty of the recorded absolute gravity values at the study area reference sites.

\section{Absolute gravity reference site uncertainty assessment}

Two absolute gravity reference stations of the New Zealand gravity network (SA80 \& SA86) were routinely occupied during surveying. Since being established by GNS Science in the 1980's (Stagpoole, 2013), it is possible that both reference stations have been disturbed, introducing error to recorded values of absolute gravity (e.g. caused by mass movements such as road building near the benchmarks). By estimating the uncertainty of the recorded absolute gravity values at the study area reference sites, it is possible to determine their suitability for gravity surveying and select the most appropriate Gsolve method for reducing new gravity data.

For this experiment, a sample of 10 absolute gravity reference stations of the New Zealand gravity network, including SA80 and SA86 were occupied during the course of a day. The 10 stations were hand-picked from the GNS Science database, and are spread out along State Highway 6 (SH6) from Harihari to Fox Glacier (Figure 3.1).

In total, 27 gravity readings were made across the 10 absolute gravity reference stations (2-3 readings per station) during a single loop and tied to stations SA80 and 


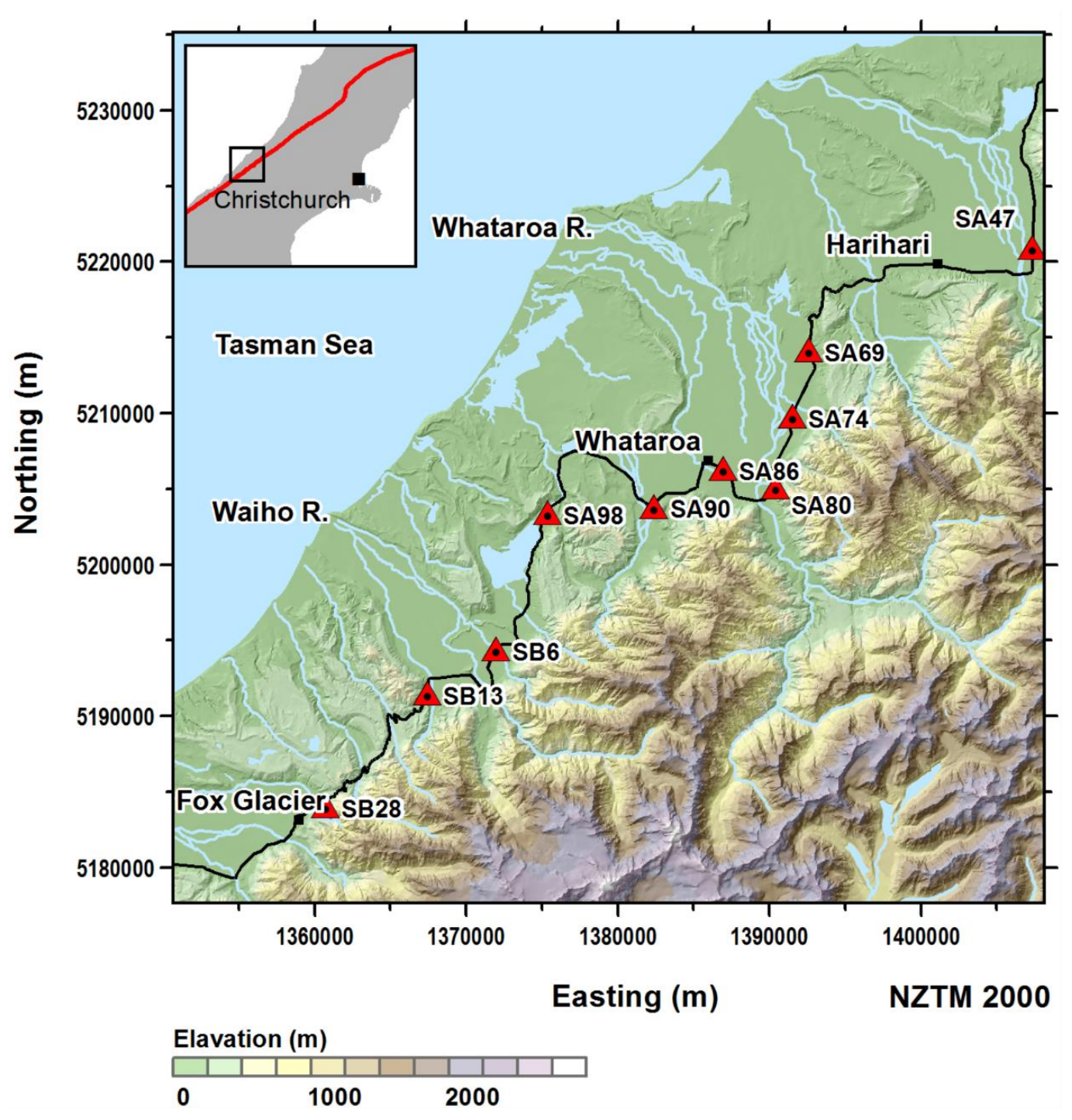

Figure 3.1: Regional topographic map of the central West Coast.

Red triangles represent 10 absolute gravity reference stations of the New Zealand Gravity Network (Stagpoole, 2013) occupied along SH6 (black line) between Harihari and Fox Glacier. SA80 and SA86 are located near Whataroa. Inset map shows the position of the central West Coast with respect to the central South Island.

SA86 using Gsolve's Method 1, which was the preferred method since it weights all observations equally. Reference station SA47 was found to be a large outlier with a difference of $-1.7 \mathrm{mGal}$ between measured and recorded values of absolute gravity. SA47 was subsequently removed from the dataset, reducing the total number of reference stations to 9 and the number of gravity readings to 25 across the loop. Table 3.1 shows the calculated difference between the observed and recorded values of absolute gravity for the 9 reference stations. Figure 3.2 shows a CDF plot of the residuals. 
Table 3.1: Absolute gravity difference between observed and recorded values at 9 reference stations from the New Zealand gravity network.

Survey measurements processed by Gsolve for this experiment are provided in Appendix E; Table E.1.

\begin{tabular}{cccccc}
\hline Station & $\begin{array}{c}\text { Observed } \\
\text { Absolute Gravity } \\
\text { (mGal) }\end{array}$ & $\begin{array}{c}\text { Gravity } \\
\text { Readings }\end{array}$ & $\begin{array}{c}\text { SE } \\
\text { (mGal) }\end{array}$ & $\begin{array}{c}\text { GNS Reference } \\
\text { (mGal) }\end{array}$ & $\begin{array}{c}\text { Observed - } \\
\text { Reference } \\
\text { (mGal) }\end{array}$ \\
\hline SA69 & 980405.919 & 3 & 0.019 & 980405.886 & 0.033 \\
SA74 & 980403.536 & 3 & 0.019 & 980403.593 & -0.057 \\
SA80 & 980397.201 & 3 & 0.014 & 980397.200 & 0.001 \\
SA86 & 980413.737 & 3 & 0.014 & 980413.739 & -0.002 \\
SA90 & 980418.165 & 3 & 0.019 & 980418.252 & -0.087 \\
SA98 & 980425.135 & 3 & 0.019 & 980425.269 & -0.134 \\
SB13 & 980413.969 & 2 & 0.019 & 980414.014 & -0.045 \\
SB28 & 980379.123 & 2 & 0.019 & 980379.117 & 0.006 \\
SB6 & 980411.166 & 3 & 0.019 & 980411.240 & -0.074 \\
\hline
\end{tabular}

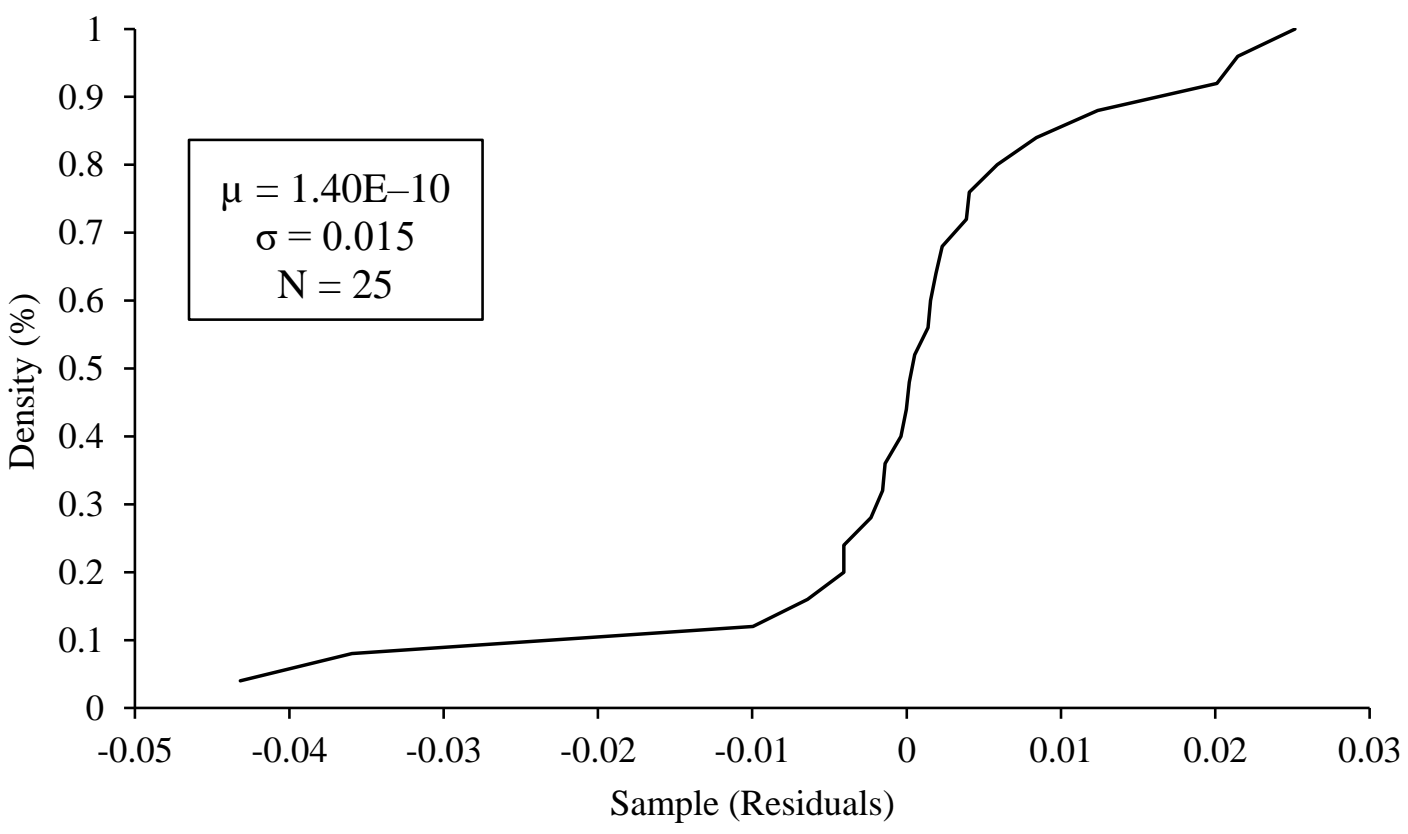

Figure 3.2: CDF plot of the residuals from Gsolve's normal least squares solution (Method 1)

The black line represents the distribution of the residuals for 25 gravity readings across 9 reference stations. 
From these results, it is reasonable to conclude that the normal distribution provides a satisfactory model for the data. Meter precision for the experiment is evaluated from the standard deviation of repeat measurements to be $\pm 0.015 \mathrm{mGal}$. There is no evidence that SA80 and SA86 have been disturbed and it is assumed that the recorded reference values of absolute gravity are accurate. Therefore, Gsolve's decoupled least squares solution (Method 2) was selected as the preferred reduction method for the entire survey. Sites identified as significant outliers (SA47, SA98, SA90 \& SB6) may be unreliable reference stations for future surveys.

\subsubsection{Survey residual analysis}

Using Gsolve's decoupled least squares solution (Method 2) (McCubbine et al., 2016), residuals of the least squares fit are computed for the entire survey. The gravity measurements processed by Gsolve for the entire survey are provided in Appendix E; Table E.2.

During processing, Gsolve discards those readings with corresponding residuals that fall outside of the specified confidence interval (CI). Recall from section 2.2.2, a CI of $100 \%$ was used in this analysis so that outliers could be identified and individually evaluated. Initial results identified 4 outliers from a total of 760 gravity readings, of which 325 were repeated more than once. The 4 outliers were erroneous gravity readings (i.e. large residual values) that were subsequently removed from the dataset. Non-repeat measurements were excluded from the analysis. Figure 3.3 shows a CDF plot of the residuals.

From these results, it is reasonable to conclude that the normal distribution provides an excellent model for the data. Meter precision for the entire survey is evaluated from the standard deviation of these repeat measurements to be $\pm 0.015 \mathrm{mGal}$.

\subsubsection{Tidal and drift analysis}

In total, 34 primary loops were achieved for the survey. The tidal correction calculated for each gravity reading is provided in Appendix E; Table E.2. For additional reference, drift curves produced by Gsolve for all 34 survey loops are also provided in Appendix E; Figure E.1.

Figure 3.4 shows the distribution of tidal effects calculated by Gsolve for 325 repeat gravity readings. 


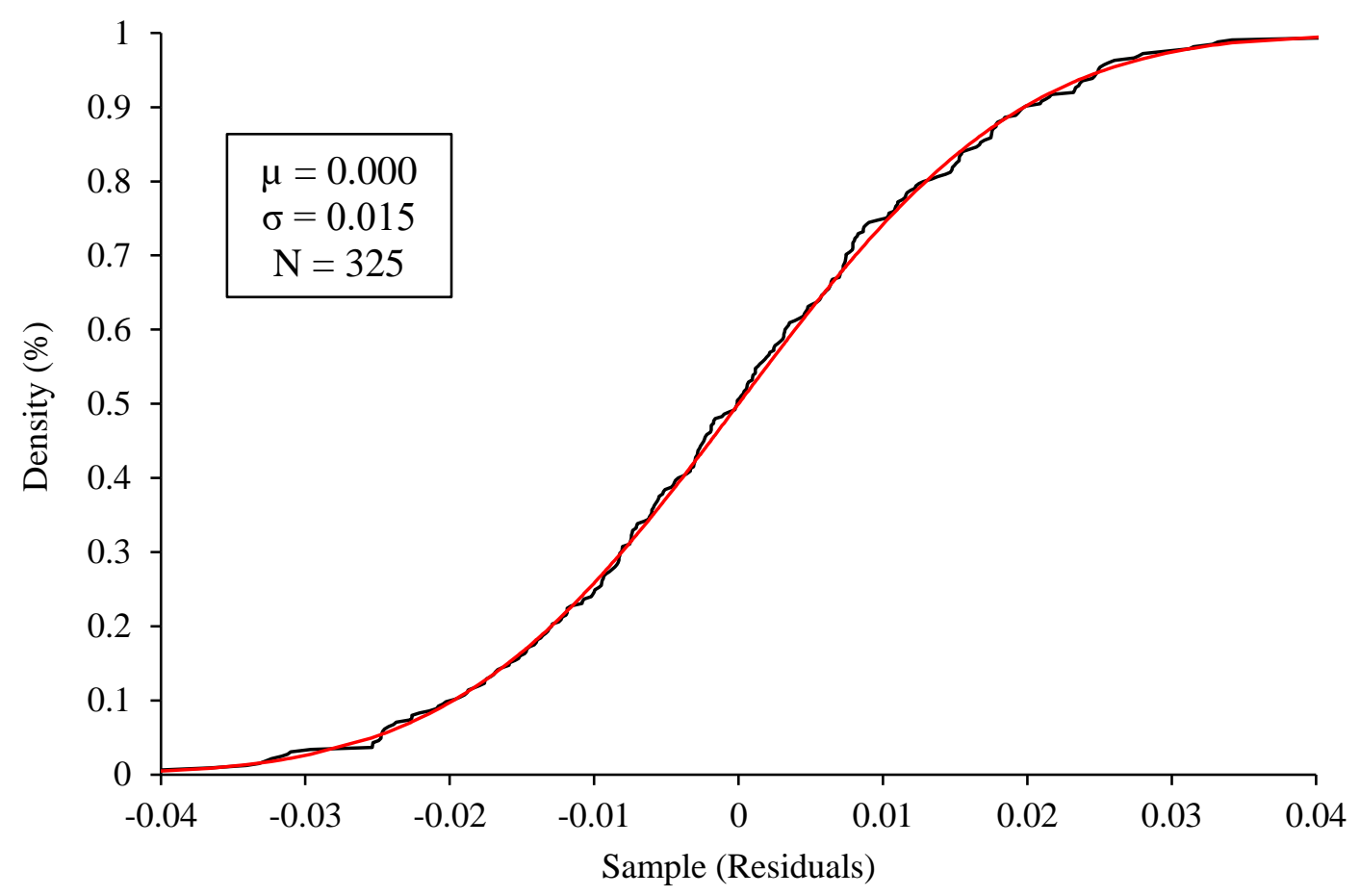

Figure 3.3: CDF plot of the residuals from Gsolve's decoupled least squares solution (Method 2).

The black line represents the distribution of the residuals and the red line represents the fitted normal distribution.

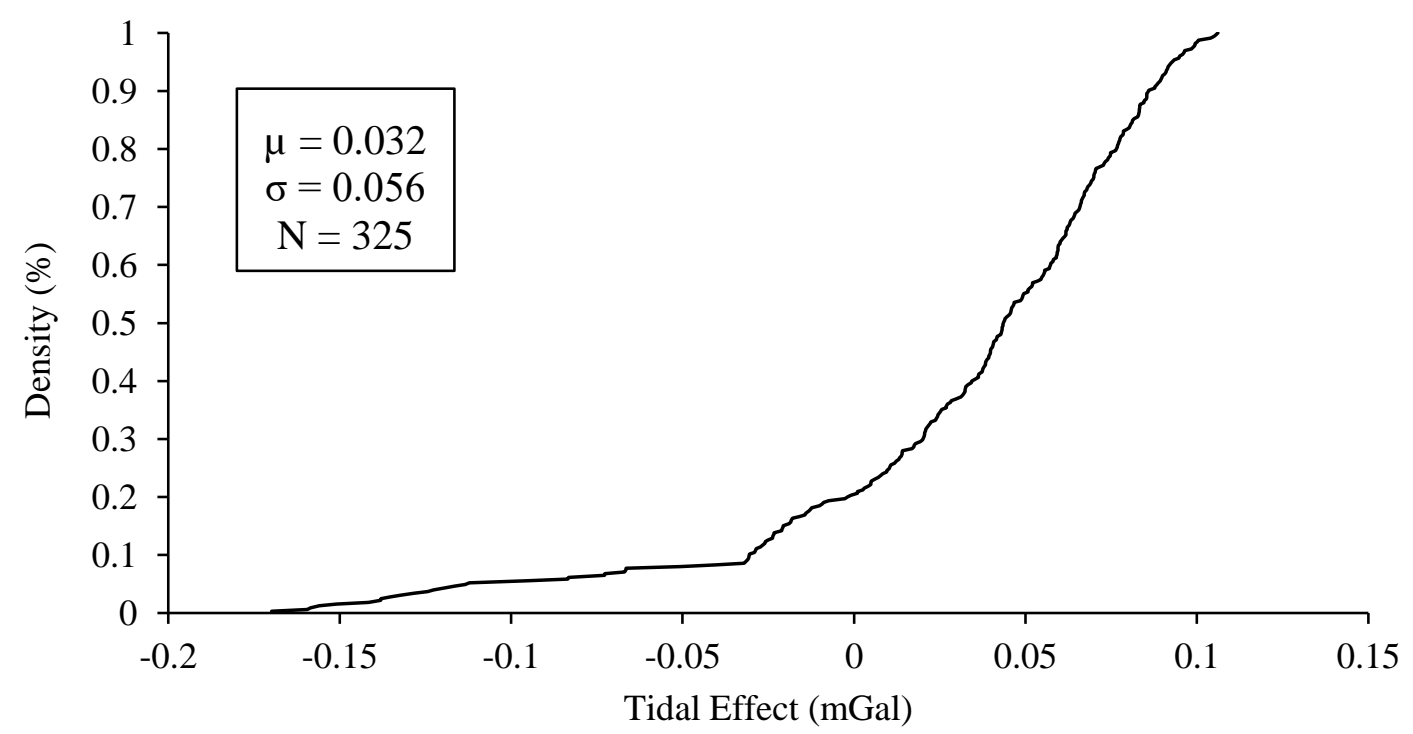

Figure 3.4: CDF plot of the calculated tidal effects for repeat gravity readings. 
The standard deviation of $0.056 \mathrm{mGal}$, shows that the tidal effect for the survey is at least 3 times the precision of the gravity meter, and hence highlights the importance of both tidal and drift corrections. If the magnitude of the tidal correction is wrong, but the phase correct, then a correlation might be expected with the remaining residuals. By plotting the tidal effects against the residuals for all repeat gravity readings it is hence possible to evaluate the validity of Gsolves tidal correction (Figure 3.5). As seen in Figure 3.5, there is no correlation between the tidal effects and residuals. The tidal effect calculated using Gsolve provides a satisfactory model for the survey, or there is some remaining tidal effect that is out of phase. No time-series analysis was attempted to look for remaining signals.

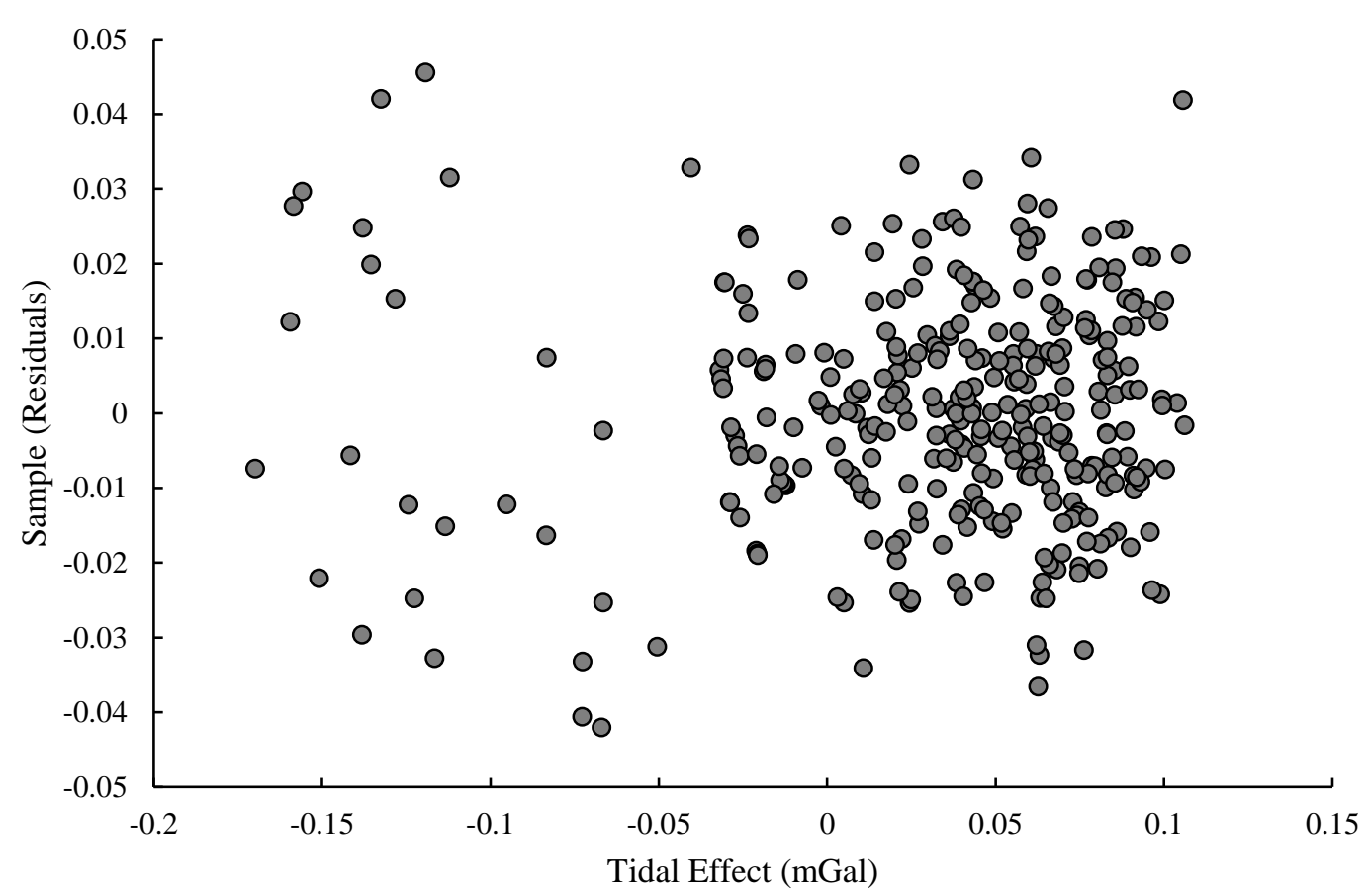

Figure 3.5: Scatter plot of the calculated tidal effects and residuals for repeat gravity readings.

\subsection{Existing gravity data}

The primary aim of this project is to acquire new gravity data and integrate with existing gravity measurements from sediment and bedrock locations to produce gravity maps of the Whataroa River valley that spans the Alpine Fault and the DFDP-2 drill site. To 
achieve this objective, existing gravity data were obtained from past surveys that overlap the study area and amalgamated with new gravity data.

\subsubsection{Whataroa gravity data}

In total, 134 gravity stations were acquired from Davy (2012), which span the Whataroa floodplain and have an estimated uncertainty in the Bouguer gravity anomalies of $\pm 0.06 \mathrm{mGal}$. The dataset from Davy (2012) includes 21 re-processed gravity stations originally established by Brikke (2007) across the Whataroa floodplain. The existing coverage of gravity stations overlapping the study area are shown in Figure 3.6.

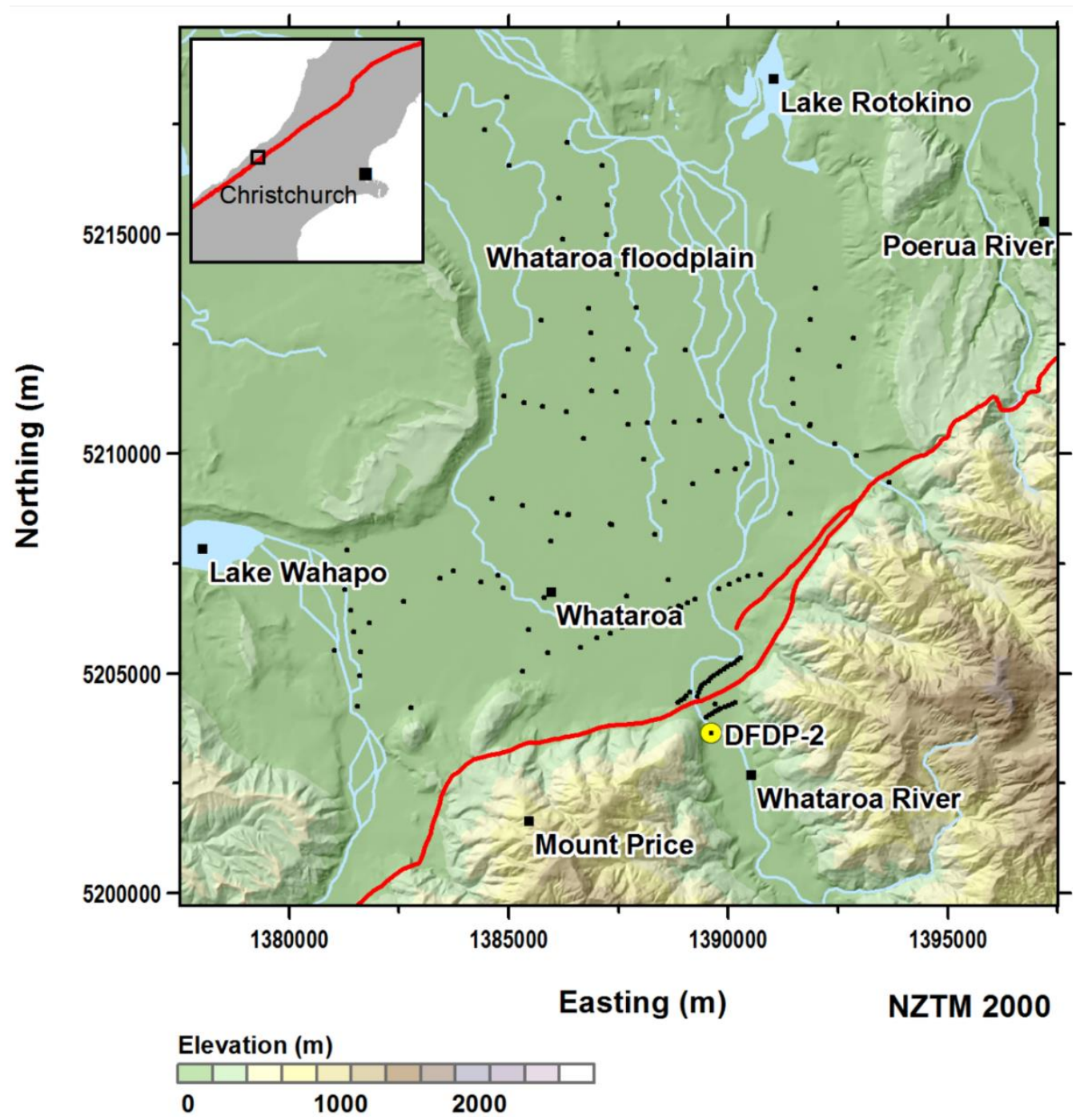

Figure 3.6: Existing gravity stations over the Whataroa floodplain and Whataroa River valley.

Black dots represent 134 gravity stations established by Davy (2012), which include 21 gravity stations originally established by Brikke (2007). Red line represents the mapped surface trace of the Alpine Fault (NZAFD). 


\subsection{New gravity data}

In total, 466 new gravity observations were established across the study area in the Whataroa River valley $(\sim 5 \times 5 \mathrm{~km})$, resulting in an even spread of gravity stations spanning the Alpine Fault and the DFDP-2 drill site.

\subsubsection{New gravity station locations}

The gravity survey was designed to collect a grid of appropriately spaced gravity stations across the study area to produce gravity maps, while also densifying station coverage over localised features of interest, such as the DFDP-2 borehole and nearby Alpine Fault. Sparse regional measurements were made on bedrock sites away from the valley fill with the aim of capturing the regional gravity trend and separating both long and short-wavelength components. The placement of localised gravity stations was planned before surveying commenced, involving the construction of forward gravity models to determine appropriate site spacing. Gravity models are presented in Chapter 4. Measurement density increases from about one measurement per $100 \mathrm{~m}^{2}$ in the centre of the study area to about one measurement per $500 \mathrm{~m}^{2}$ on the bounds of the study area. Figure 3.7 shows the coverage of new gravity stations across the study area.

\subsection{Gravity maps}

New absolute gravity data were amalgamated with existing absolute gravity data, then reduced to Bouguer and residual anomalies as described in Chapter 2. Anomaly maps were constructed with ArcGIS Spatial Analyst using an Inverse Distance Weighted (IDW) and/or an Empirical Bayesian Kriging surface interpolation function. 


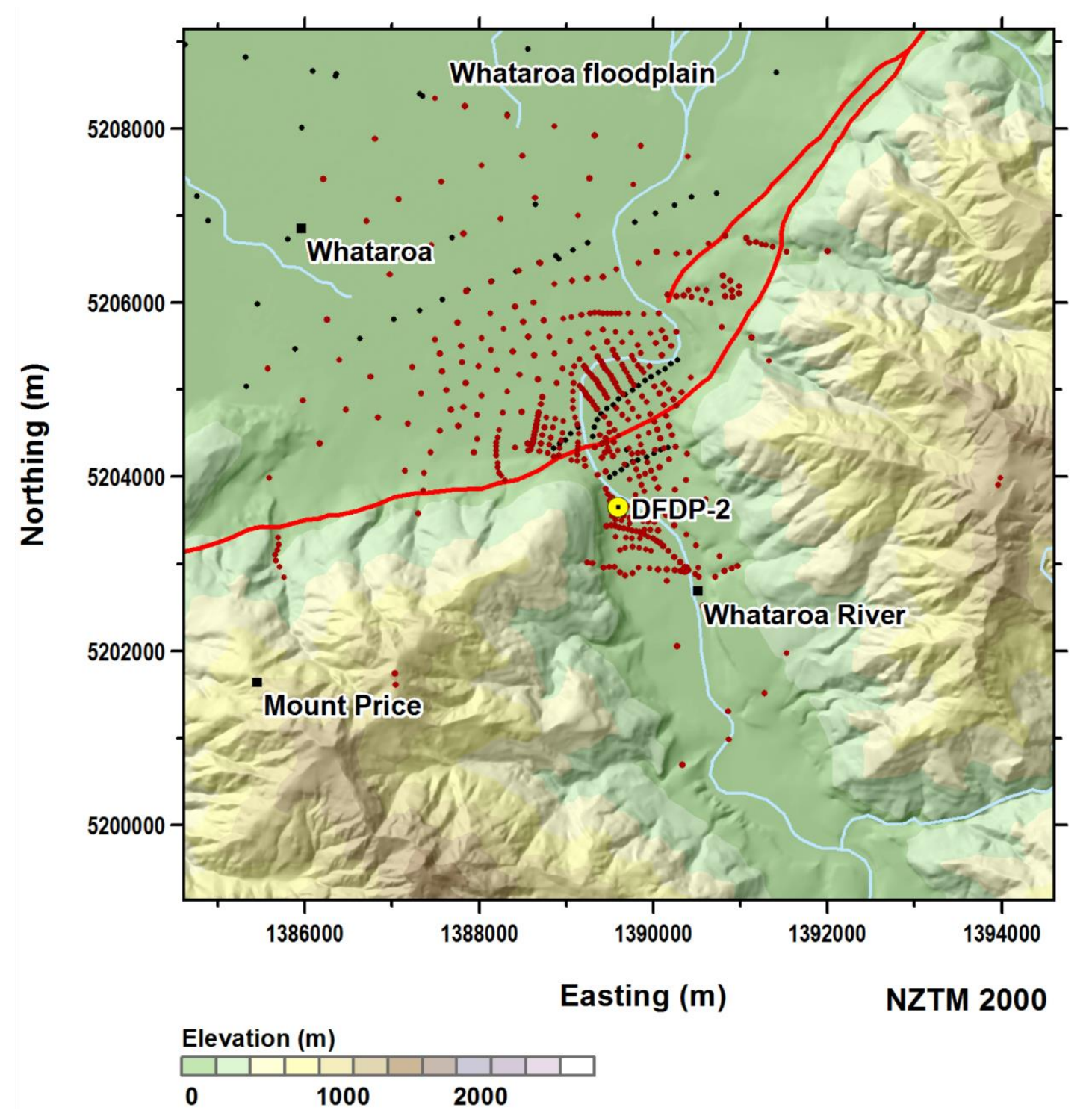

Figure 3.7: New gravity stations over the study area in the Whataroa River valley.

Black dots represent existing gravity stations; red dots represent new gravity stations. Red line represents the mapped surface trace of the Alpine Fault (NZAFD).

\subsubsection{Amalgamation of gravity data}

Before the amalgamation of existing and new gravity data, all absolute gravity values calculated by Davy (2012) were converted from the New Zealand Potsdam 1959 gravity datum to the IGSN71 gravity datum by subtracting $15.21 \mathrm{mGal}$ from each existing absolute gravity value as described by Stagpoole (2013). 
The amalgamation of the gravity surveys was evaluated by fitting a cubic spline surface through new values and interpolating to sites of existing measurements. Figure 3.8 shows the calculated absolute gravity difference and separation distance between new and existing gravity stations. Assuming a nominal error of $0.015 \mathrm{mGal}$ for the interpolated surface, based on the Gsolve solution, and quoted precision for new measurements, agreement between new and existing measurements was evaluated. The existing gravity stations were found to have been less precisely measured than the new gravity stations.

As seen in Figure 3.8, there is no significant disagreement between new and existing gravity stations where sites are closely spaced. There appears to be an outlier at $\sim 38 \mathrm{~m}$ separation distance; however, after $>80 \mathrm{~m}$ separation, there is significant disagreement between the surveys. Therefore, for mapping purposes, it is appropriate to amalgamate the surveys and remove existing measurements at separations $<80 \mathrm{~m}$ since they are less precise and represent 'repeat' measurements.

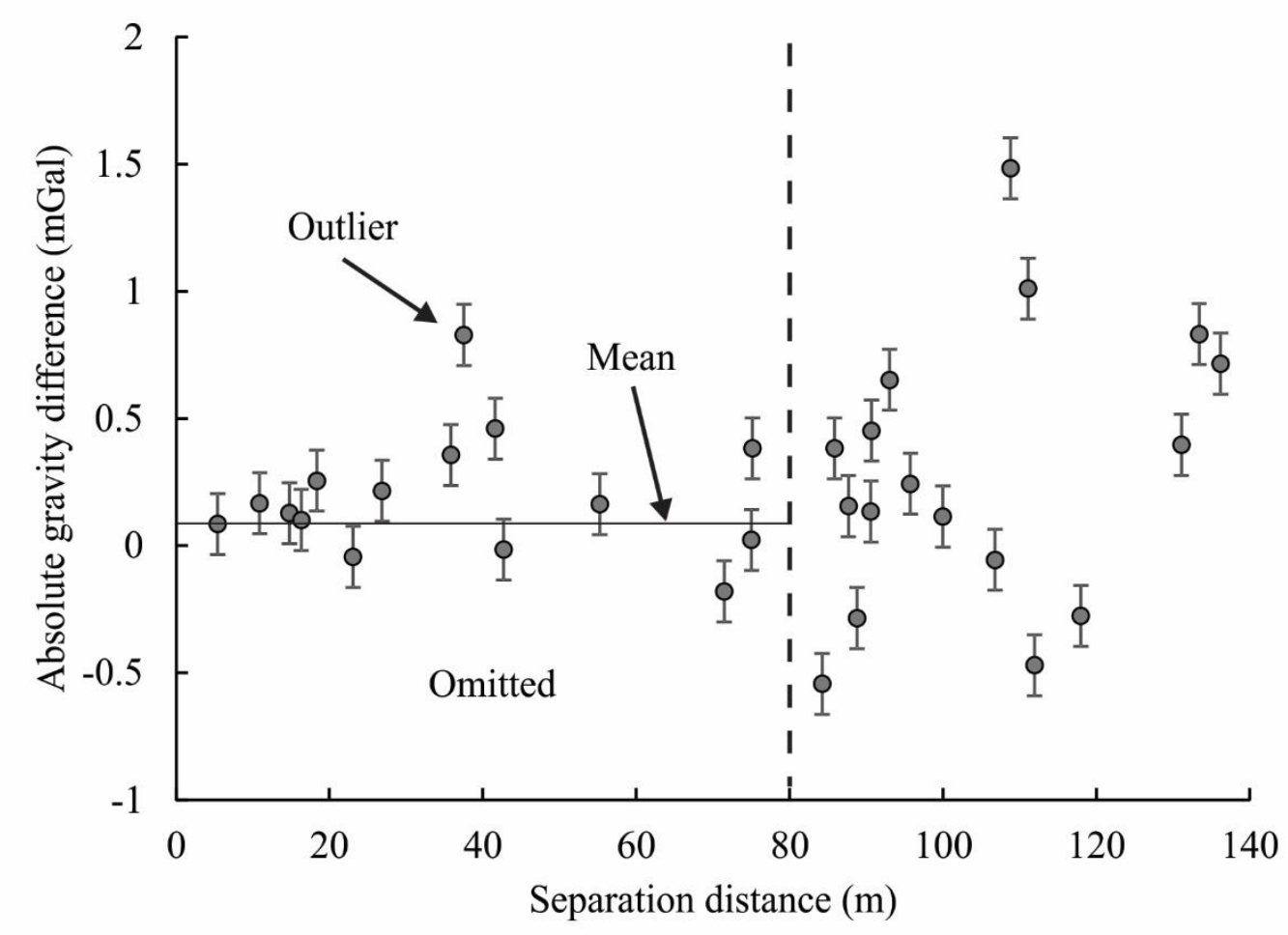

Figure 3.8: Absolute gravity difference and separation distance between existing and new gravity stations

A mean gravity difference of $0.12 \pm 0.24 \mathrm{mGal}$ was calculated for the 15 existing gravity stations located within $80 \mathrm{~m}$ of a new gravity station. To improve the fit between 
surveys, $0.12 \mathrm{mGal}$ was subtracted from existing gravity stations established by Davy (2012).

\subsubsection{Bouguer gravity anomaly map}

The Bouguer gravity anomaly map for both existing and amalgamated datasets are presented to illustrate the improvement in resolution in the Whataroa River valley, both at a regional scale (Whataroa floodplain) and local scale (study area).

\section{Regional scale Bouguer anomaly map}

Figure 3.9 shows the increased resolution in the Bouguer gravity anomaly of the Whataroa floodplain for both existing and amalgamated datasets.

Several features of interest are evident in the Bouguer gravity anomaly map constructed using the amalgamated dataset.

- A large gravity low on the Whataroa floodplain originally recognised by Brikke (2007) and later by Davy (2012).

- A prominent gravity gradient originally recognised by Davy (2012), orientated NW-SE on the floodplain becoming more defined and increasingly positive towards the southwest.

- A gravity low resembling a glacial channel appears to be dextrally offset near the range front.

- There is a regional gravity gradient towards the southeast, probably associated with a crustal root beneath the Southern Alps (Allis, 1986; Eberhart-Phillips and Bannister, 2002; Reilly, 1962; Stern, 1995; Woodward, 1979). 


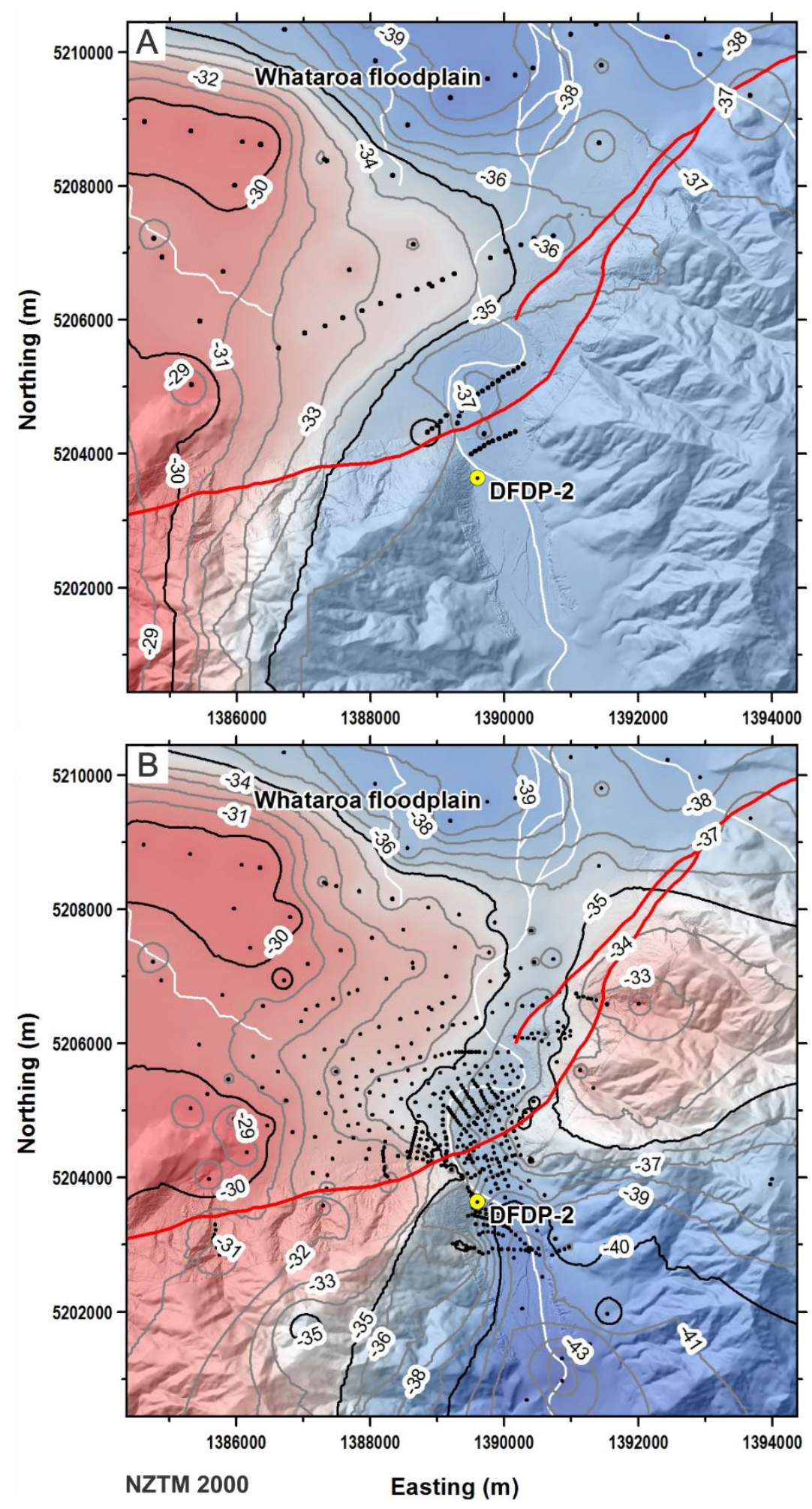

Figure 3.9: Bouguer gravity anomaly map of the Whataroa floodplain.

Regional-scale Bouguer gravity anomaly map based on existing data (A) and amalgamated new and existing data (B). Black dots are gravity stations. Red line represents the mapped surface trace of the Alpine Fault (NZAFD). White lines represent river systems. Gravity data has been extrapolated. 


\section{Local scale Bouguer anomaly map}

Figure 3.10 shows the increased resolution in the Bouguer gravity anomaly of the study area in the Whataroa River valley for both existing and amalgamated datasets.

Several features of interest are evident in the Bouguer gravity anomaly map constructed using the amalgamated dataset.

- The resolution of the Bouguer gravity field has improved significantly in the study area, going from broad and wide contours to sharp and narrow contours revealing significant structure.

- The large gravity low along the range front appears to follow the presentday river trend.

- There is some evidence of a gravity gradient near the range front.

- A dense set of gravity stations surrounding the DFDP-2 drill site indicates a decreasing trend in the Bouguer gravity anomaly toward the centre of the valley.

\subsubsection{Residual anomaly map}

The residual gravity anomaly map for the amalgamated dataset is presented to illustrate the effect of applying a regional-residual separation to the Bouguer gravity anomaly, both at a regional scale (Whataroa floodplain) and local scale (study area).

\section{Regional scale residual anomaly map}

Figure 3.11 shows the quadratic surface fitted to the amalgamated Bouguer gravity data over the Whataroa River valley and the resulting residual gravity anomaly map. The quadratic surface fitted to the overall gravity trend in the Whataroa River valley is expressed in equation 3.1:

$$
\begin{gathered}
g_{s}(x, y)=\left(0.083 x^{2}-0.024 y^{2}+0.163 x y+1.692 x-1.089 y-\right. \\
35.874) \mathrm{mGal}
\end{gathered}
$$



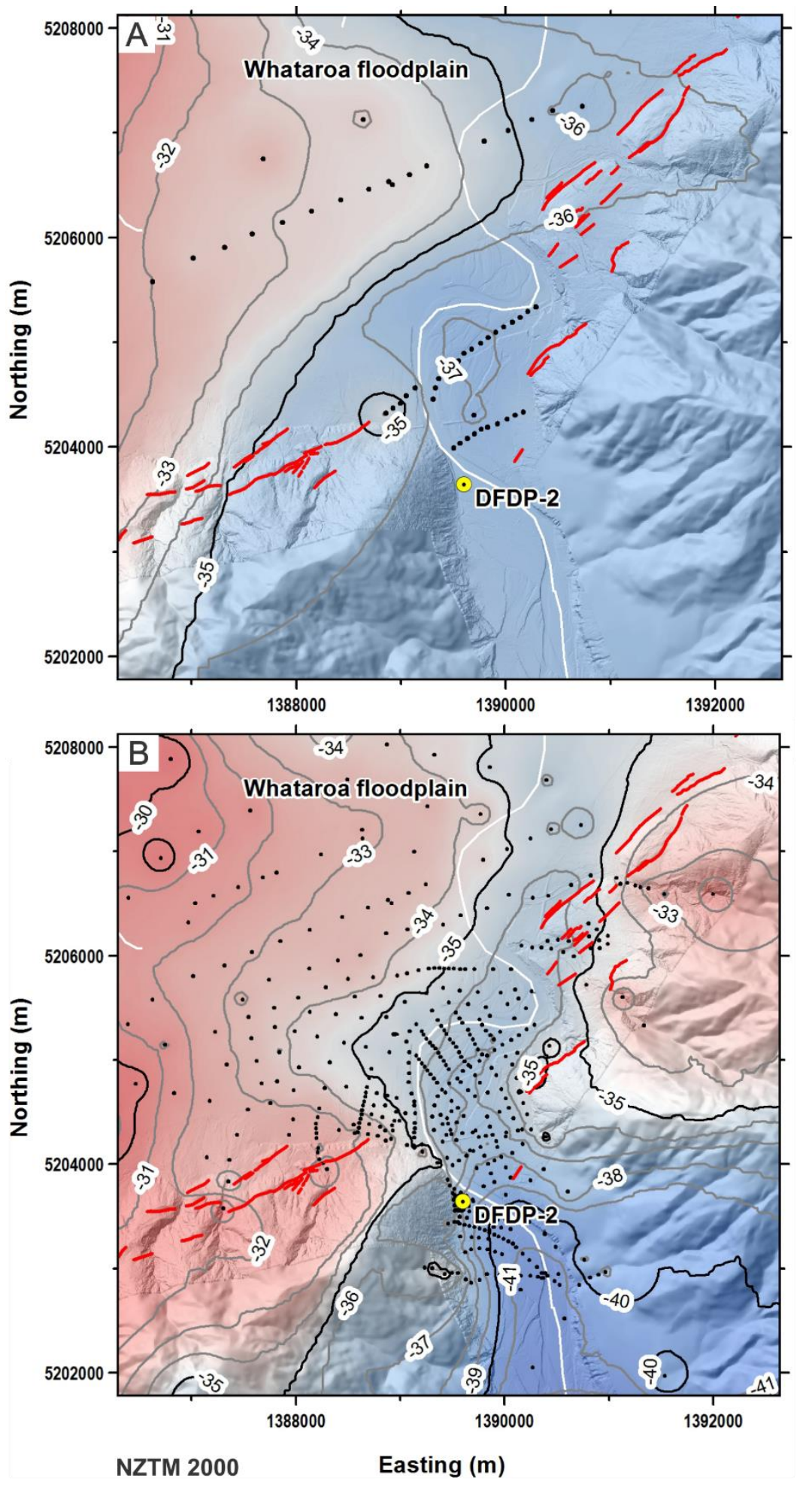

Figure 3.10: Bouguer gravity anomaly map of the study area in the Whataroa River valley.

Local-scale Bouguer gravity anomaly map based on existing data (A) and amalgamated new and existing data (B). Black dots are gravity stations. Red lines are surface tectonic lineaments mapped from LIDAR data by Barth et al. (2012). White line represents the Whataroa River. Gravity data has been extrapolated. 

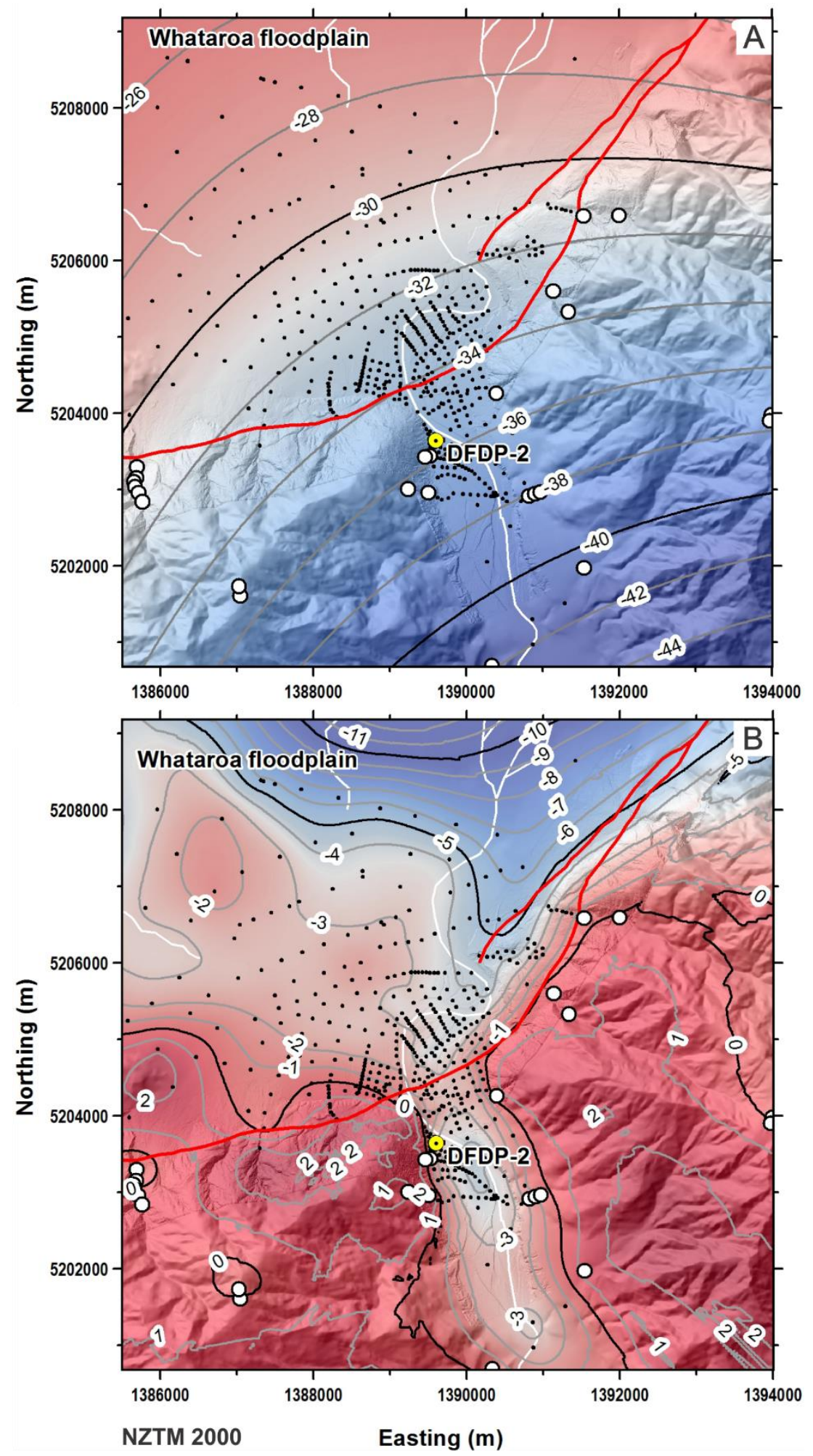

Figure 3.11: Regional-residual separation of the Whataroa River valley.

Regional gravity field (A) and the resulting residual gravity field of the Whataroa River valley (B). Black dots are gravity stations, white dots are weighted gravity stations used to determine the regional field. Alpine Fault (red line) (NZAFD). White lines represent river systems. Gravity data has been extrapolated. 
where $g_{s}(x, y)$ is the surface value at some $x$ and $y$ relative to the surface centre at 1389340 Easting, 5203307 Northing.

The fitted surface representing the regional gravity field over the Whataroa River valley shows an increasingly negative gravity trend towards the Southern Alps, and is interpreted to be the gravitational effect of a crustal root beneath the Southern Alps (Allis, 1986; Eberhart-Phillips and Bannister, 2002; Reilly, 1962; Stern, 1995; Woodward, 1979). The residual gravity anomaly map reveals significant structure within the study area, which can be used to describe the shallow sub-surface geometry beneath Whataroa River valley, particularly near the DFDP-2 drill site and Alpine Fault.

Features of interest revealed in the regional scale residual gravity map of the Whataroa River valley (Figure 3.11) include:

- A large residual gravity low (-9 to $-10 \mathrm{mGal}$ ) beneath the Whataroa floodplain, which is consistent with previous gravity surveys (Brikke, 2007; Davy, 2012).

- Large residual gravity highs ( $2 \mathrm{mGal})$ associated with the ranges on either side of the valley.

- The gravity low along the range front is defined by -3 to -4 mGal contour intervals, which show a strong elongation towards the entrance to the Whataroa River valley.

- There is no clear evidence of a western residual gravity low extending in the northwest direction of the floodplain.

\section{Local scale residual anomaly maps}

In order to describe the interesting features discovered in the study area, Figure 3.12 and Figure 3.13 show smaller scale residual gravity maps of the DFDP-2 drill site and Alpine Fault, respectively.

Features of interest revealed in Figure 3.12 include: 
- A large elongated residual gravity low defined by -3 to $-4 \mathrm{mGal}$ contour intervals next to the DFDP-2 drill site.

- A strong gravity trend in the -1 to $-3 \mathrm{mGal}$ range beneath the hillside adjacent to the DFDP-2 drill site, which becomes more negative towards the valley centre. The trend is defined by closely spaced contour lines (high gradient), indicating the presence of a steep density boundary beneath the base of the hillside.

Features of interest revealed in Figure 3.13 include:

- A strong gravity trend in the -1 to $-3 \mathrm{mGal}$ range beneath the NE rangefront, which becomes more negative toward the floodplain. The strong gravity trend does not appear to be as well-defined on the western range front.

- The strong gravity trend observed along the range front appears to extend SW towards the Whataroa River valley, where the gravity gradient is SE of the frontal thrust (main trace), indicating that there is a moderate or steeply dipping density boundary at depth. 


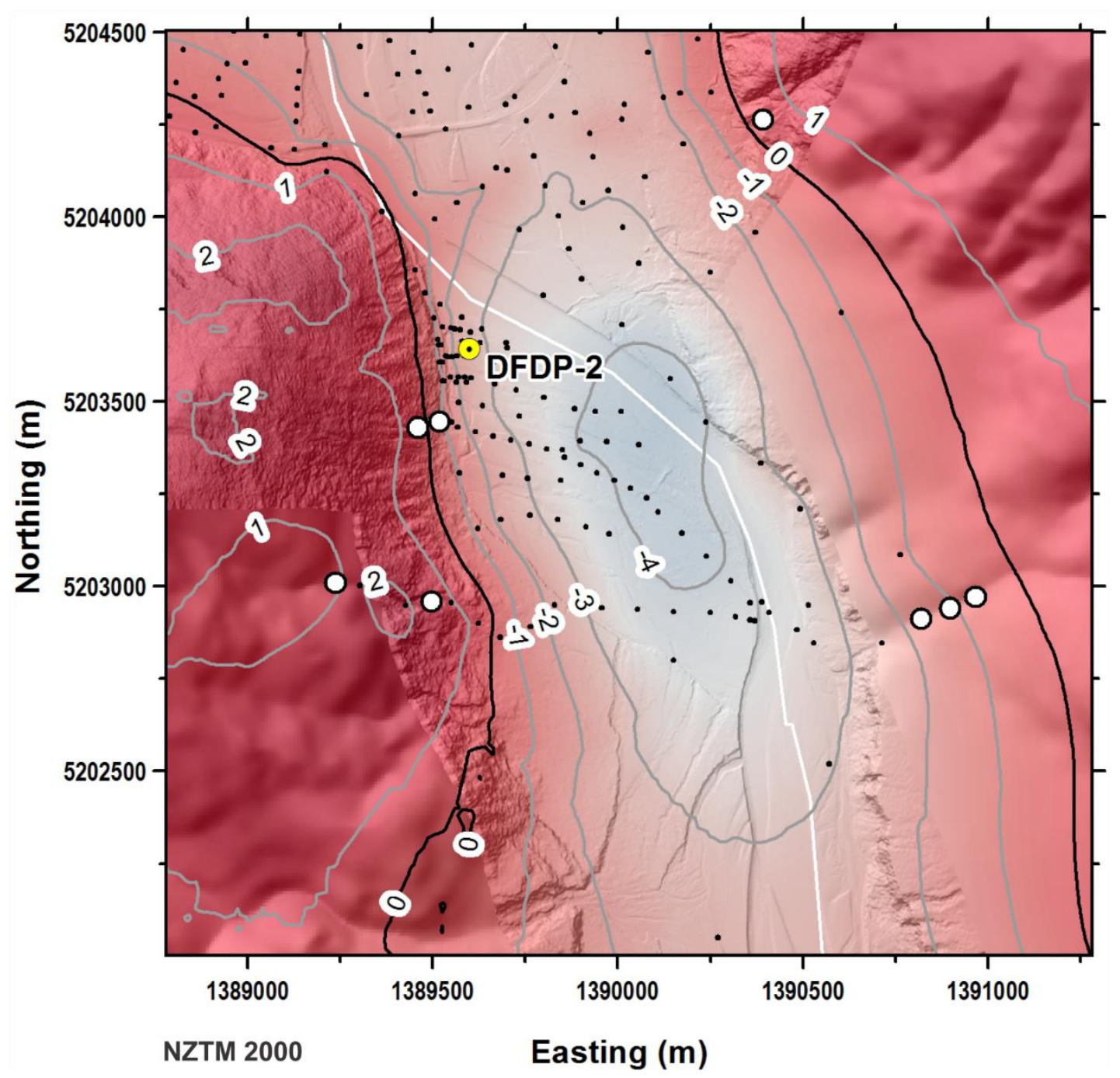

Figure 3.12: Residual anomaly map of the DFDP-2 drill site in the Whataroa River valley.

Black dots are gravity stations, white dots are weighted gravity stations. White line represents the trajectory of the Whataroa River. Gravity data has been extrapolated. 


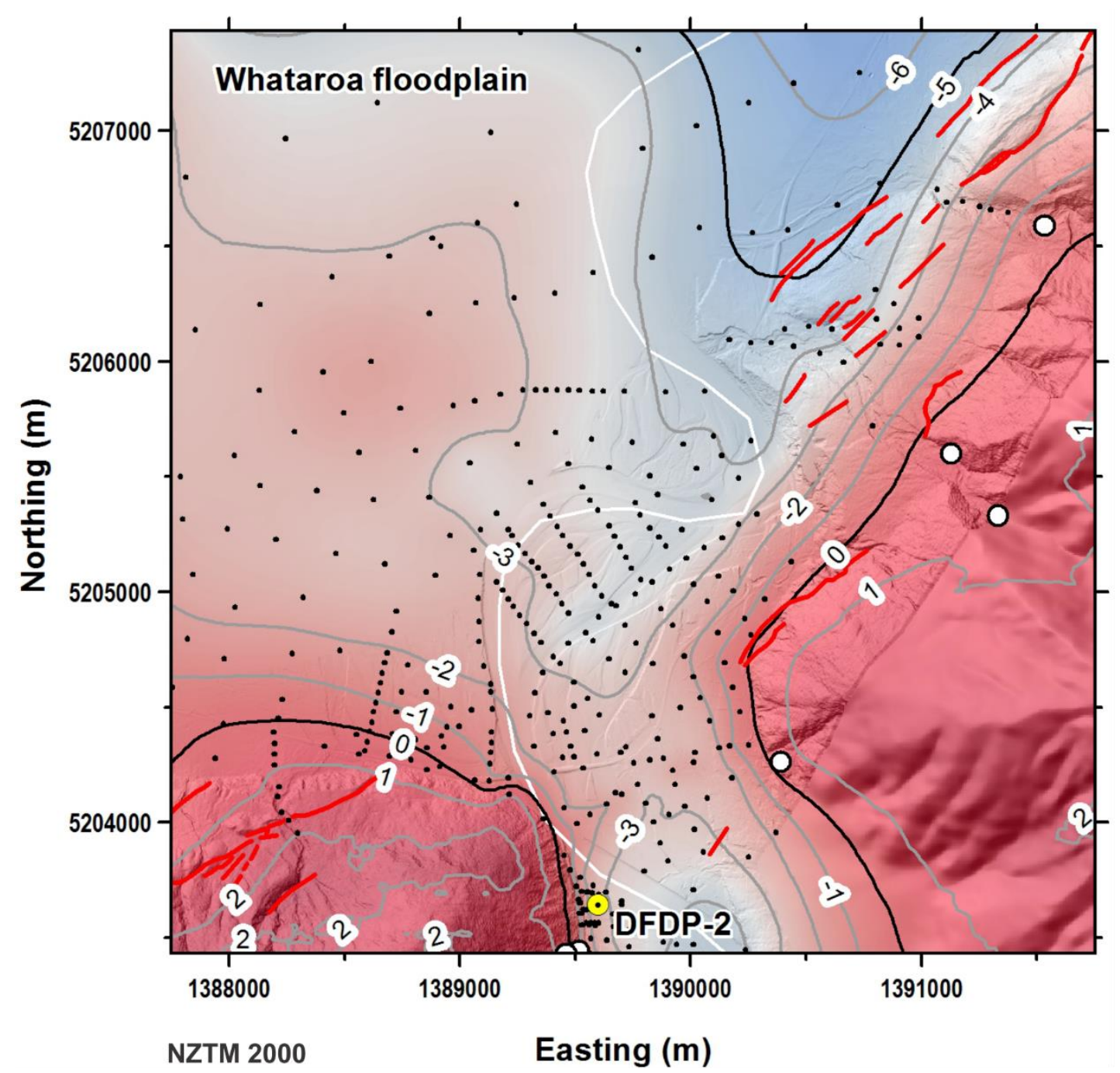

Figure 3.13: Residual anomaly map of the Alpine Fault at the entrance of the Whataroa River valley.

Black dots are gravity stations and white dots are weighted gravity stations. White line represents the trajectory of the Whataroa River. Red lines represent the mapped trace of the Alpine Fault provided by Barth et al. (2012). Gravity data has been extrapolated. 


\section{Chapter 4 Gravity models}

\subsection{Introduction}

This chapter presents 2-D sub-surface gravity models constructed from the results of the gravity survey over the Whataroa River valley. Gravity models are presented to explore the sub-surface geometry surrounding the DFDP-2 drill site. A set of profiles are then constructed that cross the nearby Alpine Fault. In addition, it is described how forward gravity models were used to design the survey around these targeted features.

\subsection{Gravity modelling}

The modelling process involves adjusting the geometry and density of sub-surface geologic units, to fit the calculated gravity signal with the observed residual gravity anomaly. Sediment thickness is constrained by direct observation at the DFDP-2 drill site (Cox et al., 2015; Sutherland et al., 2015), and to be zero if basement rock crops out at the surface. Seismic-reflection constraints on sediment thickness were not available and not used during this study. Based on data and discussion presented in Chapter 1, densities of $2.67 \mathrm{~g} / \mathrm{cc}$ and $2.1 \mathrm{~g} / \mathrm{cc}$ are assumed appropriate for bedrock and sediment respectively. Because Bouguer residual anomalies are modelled, the density of the 'air' layer is imposed to be $2.67 \mathrm{~g} / \mathrm{cc}$.

\subsection{Forward gravity models}

The following sections present 2-D forward gravity models of sub-surface geometry at the DFDP-2 drill site and Alpine Fault, and were constructed using the GM-SYS package in Oasis montaj developed by Geosoft ${ }^{\circledR}$, as described in Chapter 2. 


\subsubsection{DFDP-2 drill site}

The DFDP-2 drill site is located on a fluvial terrace $\sim 60 \mathrm{~m}$ from a steep hillslope (30$50^{\circ}$ ) (Figure 4.1). Before drilling commenced, geophysical models and slope projection into the sub-surface indicated a sediment thickness of $100 \pm 40 \mathrm{~m}$ at the drill site. However, the observed sediment thickness at DFDP-2 was $240 \mathrm{~m}$, which is more than double the value predicted from the projected angle of the adjacent hillside (Sutherland et al., 2015).

To explain how this is geologically possible, three alternative geometric hypotheses were considered before the gravity survey was undertaken:

1. The bedrock-sediment interface between the DFDP-2 drill site and the adjacent hillside is sub-vertical, interpreted as either a glacial U-shaped geometry or a fault (Figure 4.2; Model a).

2. The bedrock-sediment interface between the DFDP-2 drill site and the adjacent hillside is offset by a $\sim 40^{\circ}$ thrust fault that dips beneath the hillside (Figure 4.2; Model b).

3. The bedrock-sediment interface between the DFDP-2 drill site and the adjacent hillside is sub-horizontal, with sediment beneath the lower part of the hillside. This interpretation involves a low-angle thrust that is either a splay of the Alpine Fault, or related to slope instability (Figure 4.2; Model c). 


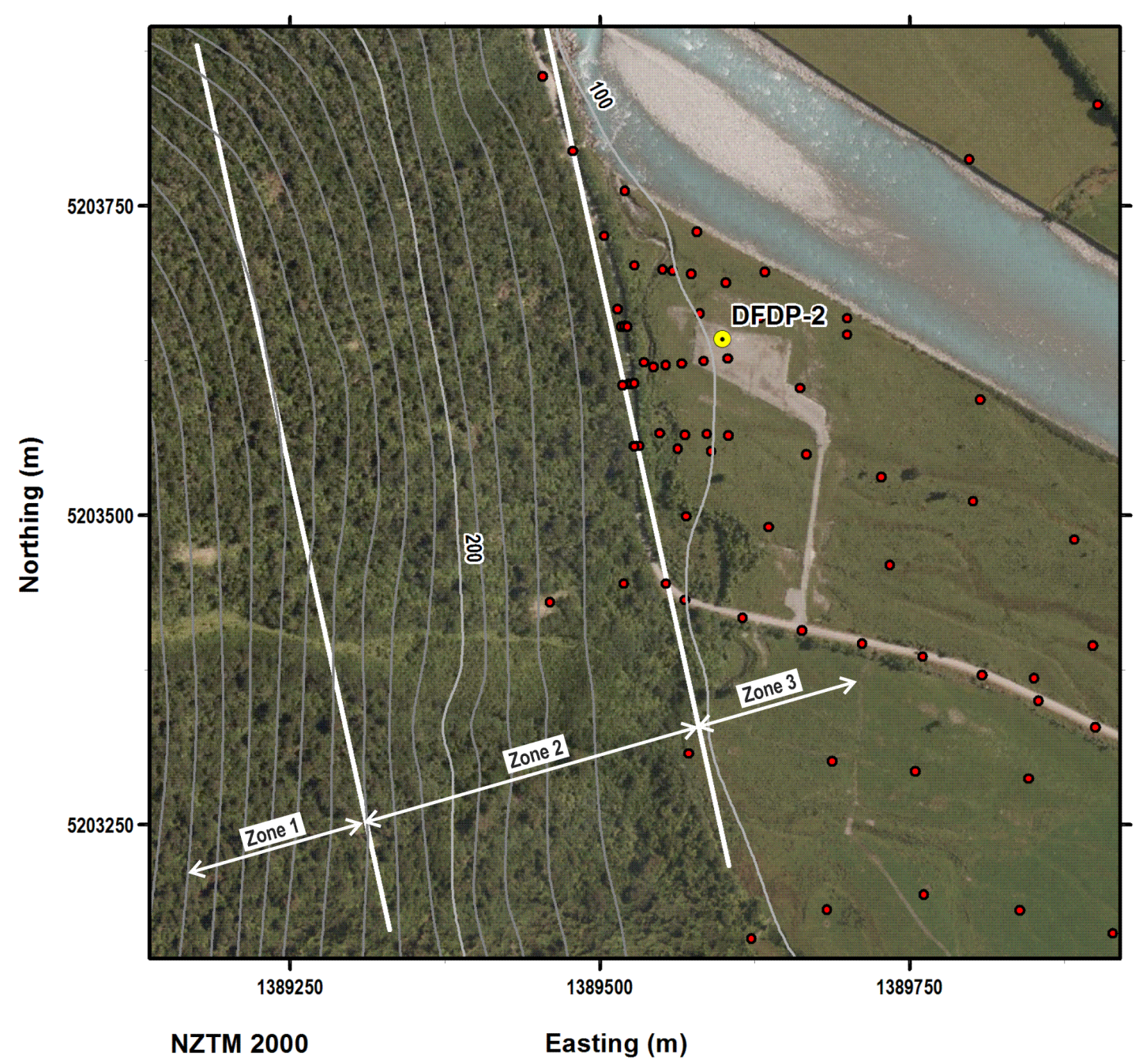

Figure 4.1: Aerial photograph of the DFDP-2 drill site.

Grey topography contours (20 m intervals) show the steep hillside adjacent to the DFDP-2 drill site. Survey Zones 1 to 3 shown in white where a dense set of gravity measurements (red dots) were established at the base of the hillside. Aerial photography sourced from Land Information New Zealand (LINZ).

\section{Survey design at the DFDP-2 drill site}

Figure 4.2 shows a synthesis of the calculated gravity signals for each geometric hypothesis described above. By comparing the calculated gravity signals based on the differing hypothetical geometries, it is possible to determine the most effective placement of gravity stations at the DFDP-2 drill site. 


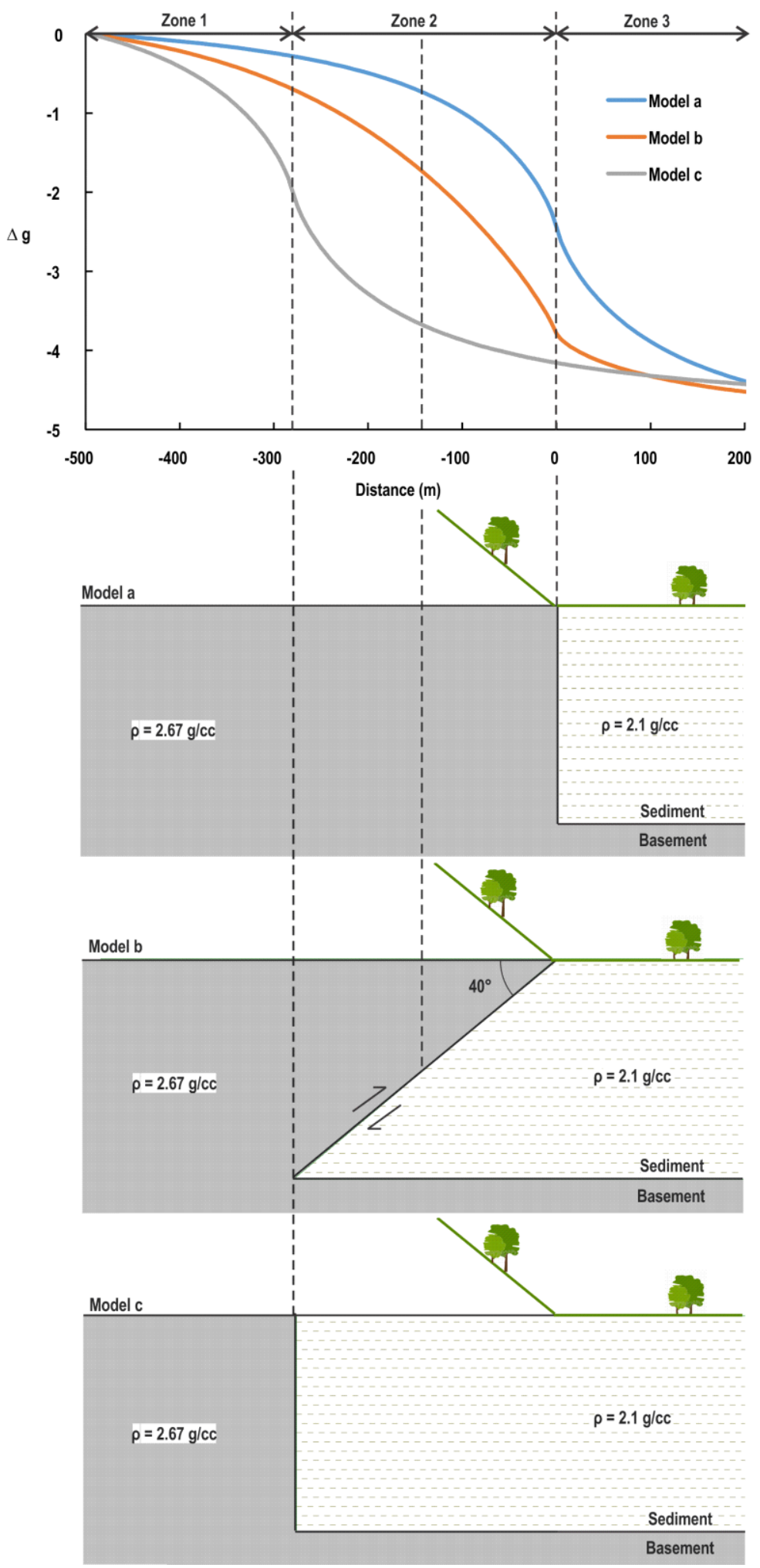

Figure 4.2: Forward gravity models.

Synthesis of the calculated gravity response (Top) for three forward gravity models (Bottom). Zones 1, 2 and 3 indicate survey areas of interest. Topography shown on models in green. All models can apply to the hillside adjacent to DFDP2 , and the range front adjacent to the Alpine Fault. 
As seen in Figure 4.2, there is a clear distinction between each calculated gravity signal across the profile, indicating that each hypothetical geometry has a unique gravity signature. The central area (Zone 2), is where there is the greatest difference in gravity between signals $(\Delta \mathrm{g})$, indicating Zone 2 is the most useful area to make gravity measurements. Unlike peripheral areas (Zone $1 \&$ Zone 3), where the calculated gravity signals are less distinguishable, measurements made in Zone 2 will ensure the observed gravity signal is clearly identifiable, thus falsifying the other two hypotheses. However, Zone 2 extends across the steep hillslope, which is covered in thick vegetation, making gravity surveying difficult or impossible (Figure 4.1). To address this problem, a plan was made to densify measurements at the base of the hillside, made accessible by a roadway shown in Figure 4.1. The calculated gravity signals between the hypothetical geometries are still distinguishable at the base of the hillside.

Figure 4.1 shows the measured gravity stations at the DFDP-2 survey site, where a dense coverage of gravity measurements (10-20 m site spacing) was achieved along the roadway at the base of the hillside with the addition of two sites located higher on the steep hillslope. These two sites were made accessible by a recent slip which is shown in the aerial photography (Figure 4.1).

The resulting 2-D gravity models of the DFDP-2 drill site constructed using projected gravity stations is presented in Section 4.4.1.

\subsubsection{Alpine Fault}

An additional aim of this project is to use the amalgamated gravity data to model the shallow structure of the Alpine Fault $(<500 \mathrm{~m})$, and define the location of the surface trace across the Whataroa River valley. The surface expression and shallow geometry of the Alpine Fault at the mouth of the Whataroa River valley is not well-defined due to post-glacial burial of the fault zone (Barth et al., 2012; Norris et al., 2012).

Based on the most recent measurements from the DFDP-2 borehole (Sutherland et al., 2015), a southeast dip of $30-60^{\circ}$ is estimated on the Alpine Fault at Whataroa. The same forward modelling approach used at the DFDP-2 drill site (Figure 4.2) can also be applied to the Alpine Fault, whereby the sediment-bedrock interface beneath the range front is either sub-vertical (Model a), dipping at an angle typical of a thrust fault (Model b), or sub-horizontal such that sediment protrudes under the range front (Model 
c). Just like the DFDP-2 drill site, the forward gravity models also predict a steep gravity gradient along the range front.

\section{Survey design across the Alpine Fault}

By applying the same technique used at the DFDP-2 drill site, the calculated gravity signals based on the differing hypothetical geometries across the Alpine Fault are compared, and the most effective placement of gravity stations determined.

Figure 4.3 shows an aerial photograph of the range front and mapped surface trace of the Alpine Fault in the study area. As seen in Figure 4.3, a dense coverage of gravity measurements (50-100 $\mathrm{m}$ site spacing) was achieved within the central area (Zone 2). The resulting 2-D gravity models constructed using observed residual anomalies projected along profile lines are presented in Section 4.4.2.

\subsection{Whataroa gravity models}

Two-dimensional models of the sub-surface geometry surrounding the DFDP-2 drill site and Alpine Fault are compared with the new observations below. The fit of the calculated gravity signal to the observed gravity observations is quantified as the Root Mean Square Error (RMSE, or 'Error'). 


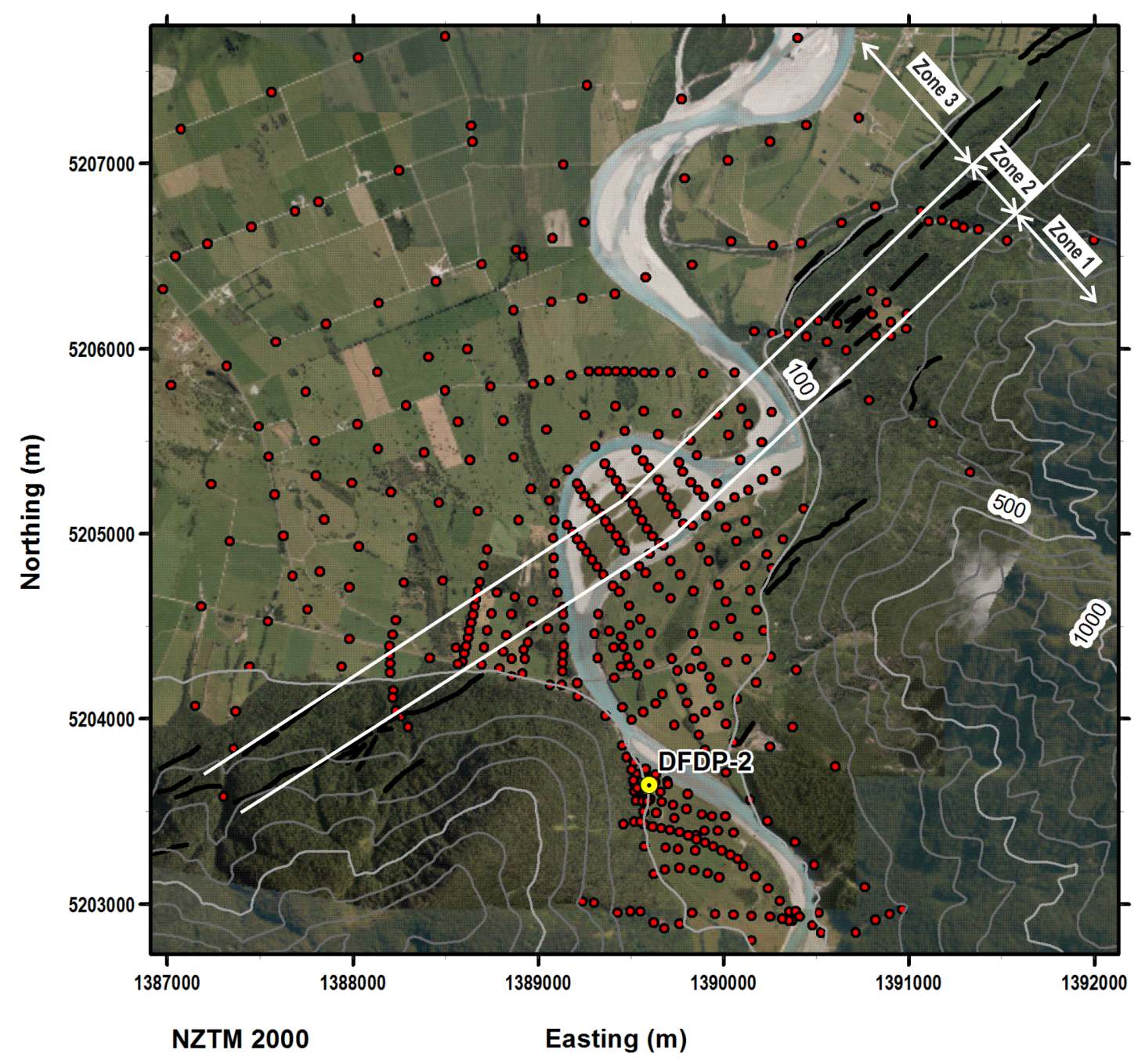

Figure 4.3: Aerial photograph of the study area.

Grey topography contours (100 m intervals) show the steep range front orientated approximately perpendicular to the mapped surface trace of the Alpine Fault (black lines). Survey Zones 1 to 3 shown in white. A dense coverage of gravity measurements (red dots) was established through Zone 2. Aerial photography sourced from Land Information New Zealand (LINZ). Fault trace lineaments from Barth et al. (2012).

\subsubsection{DFDP-2 gravity models}

Profile 1 with an azimuth of $085^{\circ}$ is orientated perpendicular to the steep gravity gradient at the hillside, as shown in Figure 4.4. 


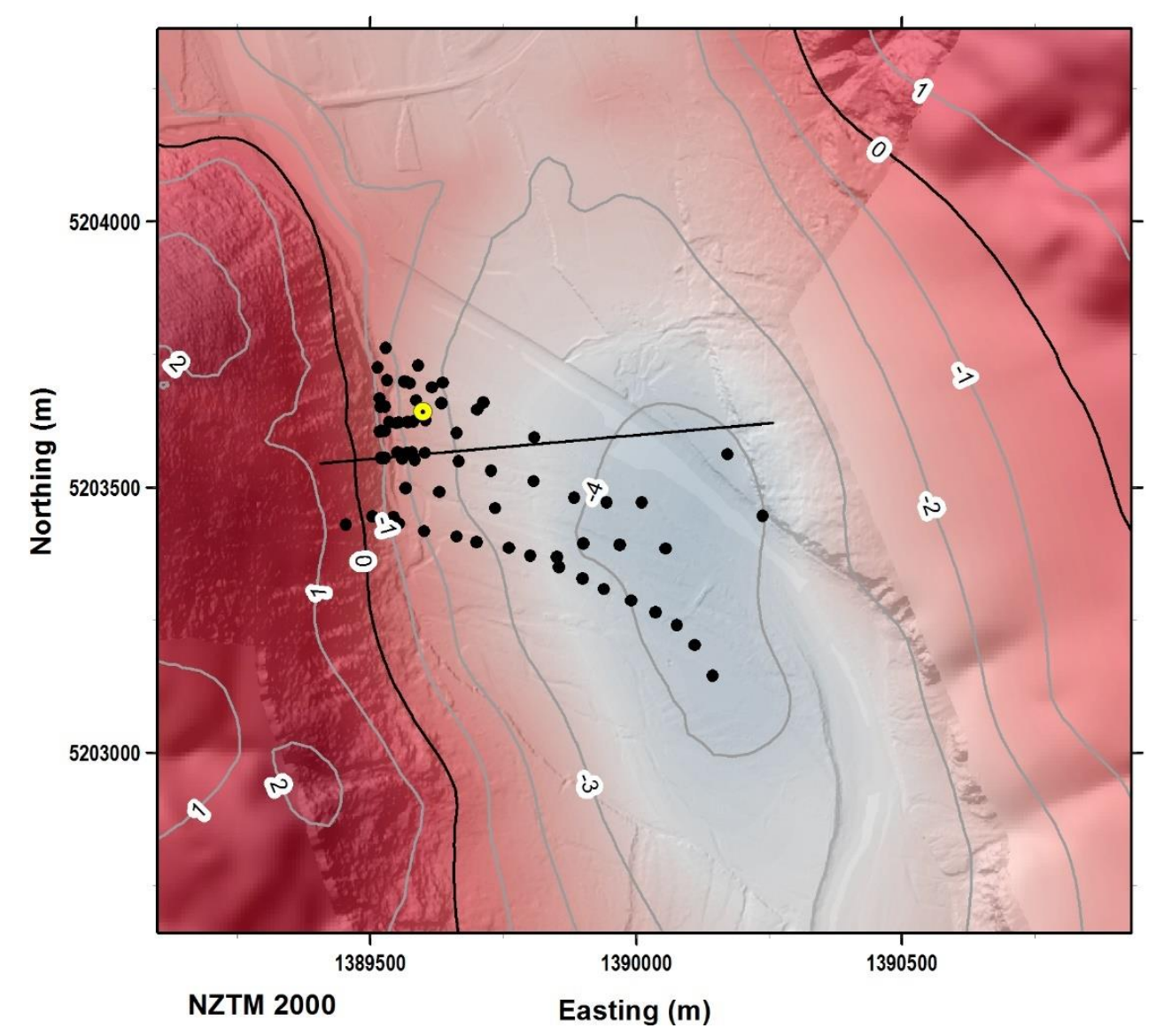

Figure 4.4: Residual gravity map of the DFDP-2 drill site showing Profile 1. Profile 1 (black line) is orientated perpendicular to the steep gravity gradient observed at the base of the hillside. Gravity stations (black dots) and the DFDP-2 drill site (yellow dot) are projected onto the profile.

Sediment thickness at the DFDP-2 drill site is constrained to $240 \mathrm{~m}$ based on direct observation (Sutherland et al., 2015), providing a constraint for this profile. Basement rock is assumed fixed to the base of the hillside.

Figure 4.5 shows a 2-D model (Model 1A) for Profile 1. 


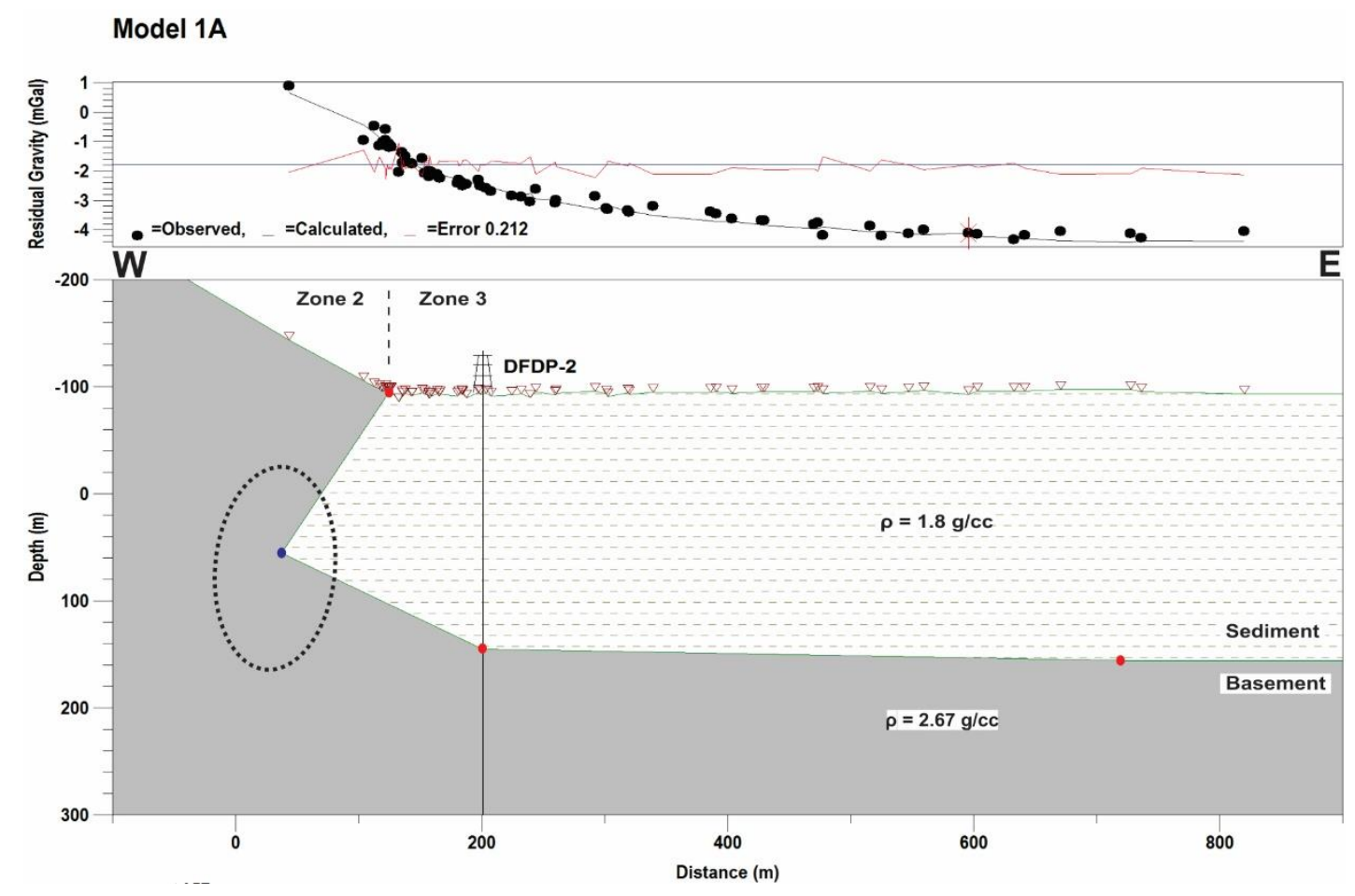

Figure 4.5: Gravity Model 1A for Profile 1 at the DFDP-2 drill site.

Top: observed gravity (black circles), tie point (red star), calculated gravity (black line), and RMSE of the fit (red line). Bottom: projected gravity stations (inverted triangles) extending along the profile. Red dots represent fixed constraints. Blue dot represents structurally inverted point with a confidence ellipse that was estimated by interactively moving the point until the RMSE was considered unacceptable. Zones refer to survey areas identified using forward models.

In order for the calculated signal to fit the observed gravity at the most western station on the hillside (located in Zone 2), a density of $1.8 \mathrm{~g} / \mathrm{cc}$ is required for the sediment. This unreasonably low value is discussed below.

The simplest possible model was constructed with just one additional sub-surface point (blue dot) located between the base of the hillside and the observed bedrock in the DFDP-2 drill hole. The inversion mode of GM-SYS was used to find the best fitting location of this point. The structurally inverted point suggests a thrust fault may exist under the hillside, resembling pre-survey forward model (b) (Figure 4.2). Structural inversion and its relative uncertainty is discussed in Section 4.5.

Figure 4.6 shows a second 2-D model (Model 1B) for Profile 1. 


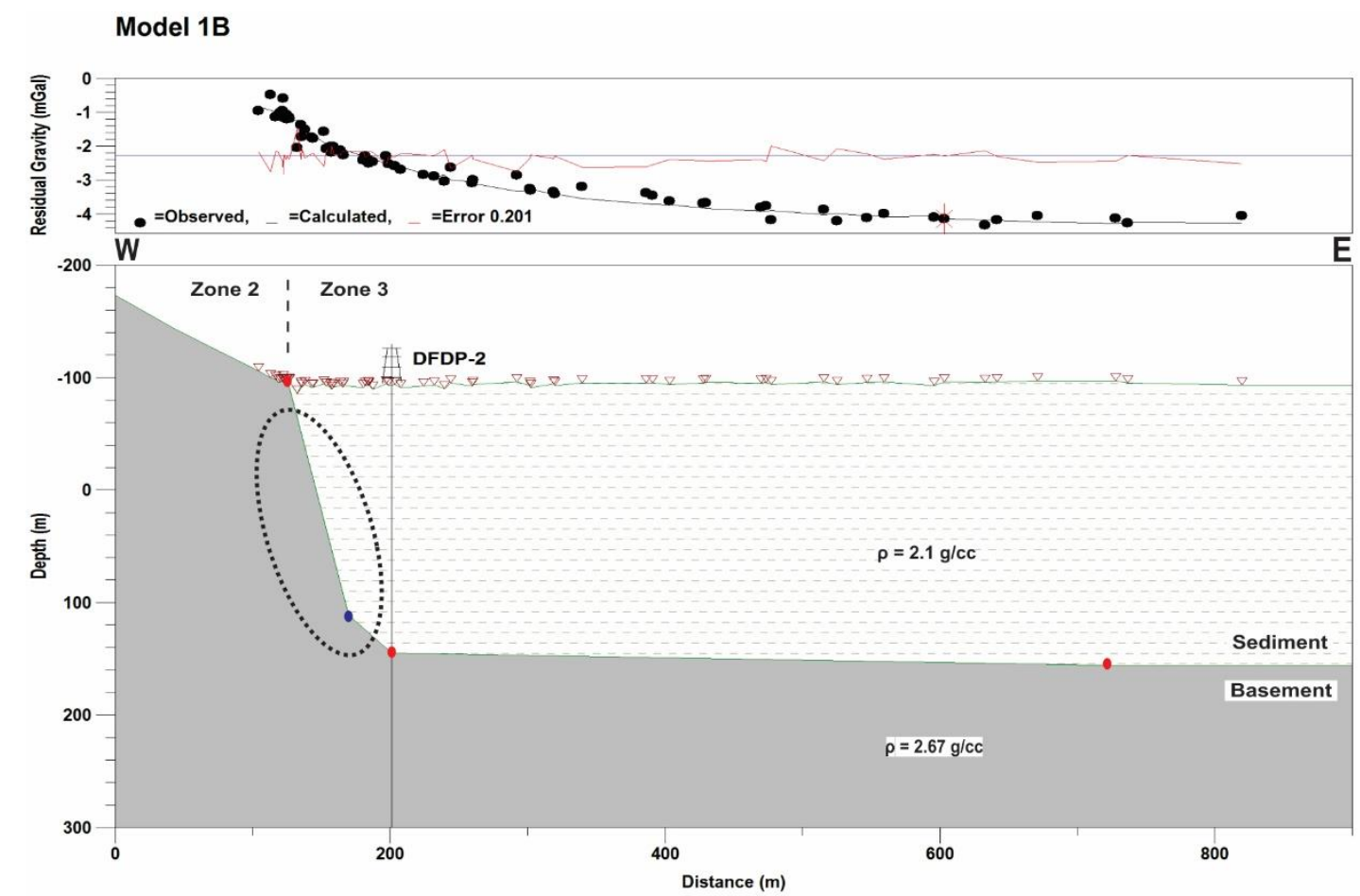

Figure 4.6: Gravity Model 1B for Profile 1 at the DFDP-2 drill site.

Top: observed gravity (black circles), tie point (red star), calculated gravity (black line), and RMSE of the fit (red line). Bottom: projected gravity stations (inverted triangles) extending along the profile. Red dots represent fixed constraints. Blue dot represents structurally inverted point with confidence ellipse (Section 4.5). Note that the western most station in survey Zone 2 has been removed.

Sediment density has been increased to a value that is more realistic for the Whataroa valley $(2.1 \mathrm{~g} / \mathrm{cc})$; however, this model requires that the most western gravity station be removed, since this results in a poor fit (exclusion might be justified by survey difficulties on the steep hillside). The new RMS error for the fit is reduced to $0.20 \mathrm{mGal}$. The structurally inverted point (blue dot) suggests a sub-vertical bedrocksediment interface may exist under the hillside, resembling the calculated signal produced by pre-survey forward model (a) (Figure 4.2).

Structural inversion and the error estimation for the optimised point (blue dot) in Models 1A and 1B is discussed in Section 4.5. 


\subsubsection{Alpine Fault gravity models}

Figure 4.7 shows gravity Profiles 2, 3, 4 and 5 extending across the mapped surface trace of the Alpine Fault in the study area. All profiles are orientated approximately perpendicular to the steep gravity gradient observed near the range front.

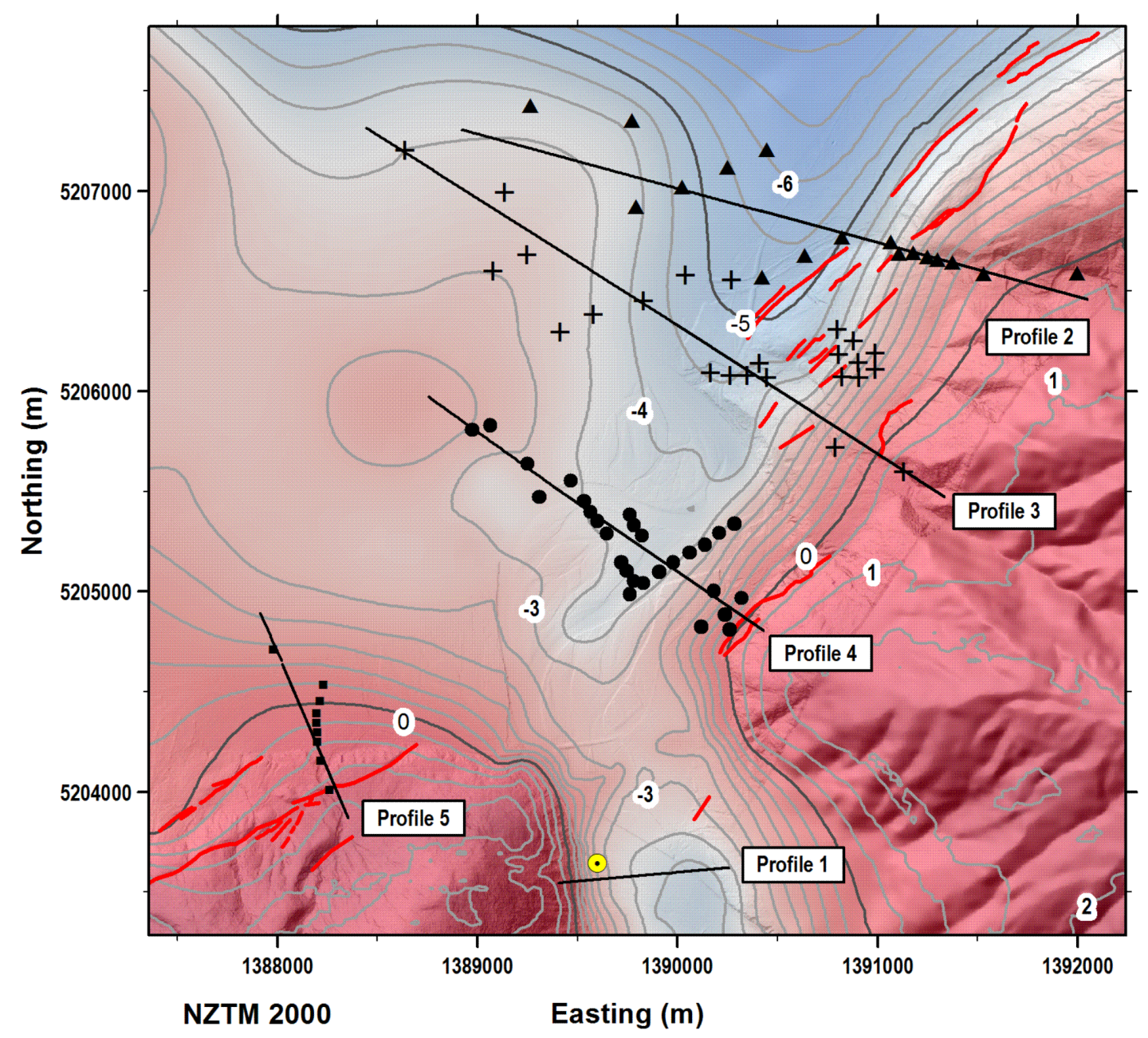

Figure 4.7: Residual gravity map showing all five gravity profiles.

Black symbols represent gravity stations projected to each profile (black lines). Profile 2 (triangles), Profile 3 (crosses), Profile 4 (circles) and Profile 5 (squares). Yellow dot (DFDP-2) and Profile 1 shown for reference. Mapped surface trace of the Alpine Fault (red lines) from Barth et al. (2012). Note the steep gravity gradient observed near the range front.

Sediment thickness is poorly constrained in this part of the study area, leaving only inferences to be made. Based on the modelling of Profile 1, a bulk density of $2.1 \mathrm{~g} / \mathrm{cc}$ is used for the sediment, and $2.67 \mathrm{~g} / \mathrm{cc}$ for basement rock. The surface trace of the 
Alpine Fault mapped by Barth et al. (2012) provides a valuable constraint for the profiles. Basement rock is assumed to be fixed to the base of the range front.

Figure 4.8 shows a 2-D model (Model 2) for Profile 2.

Model 2

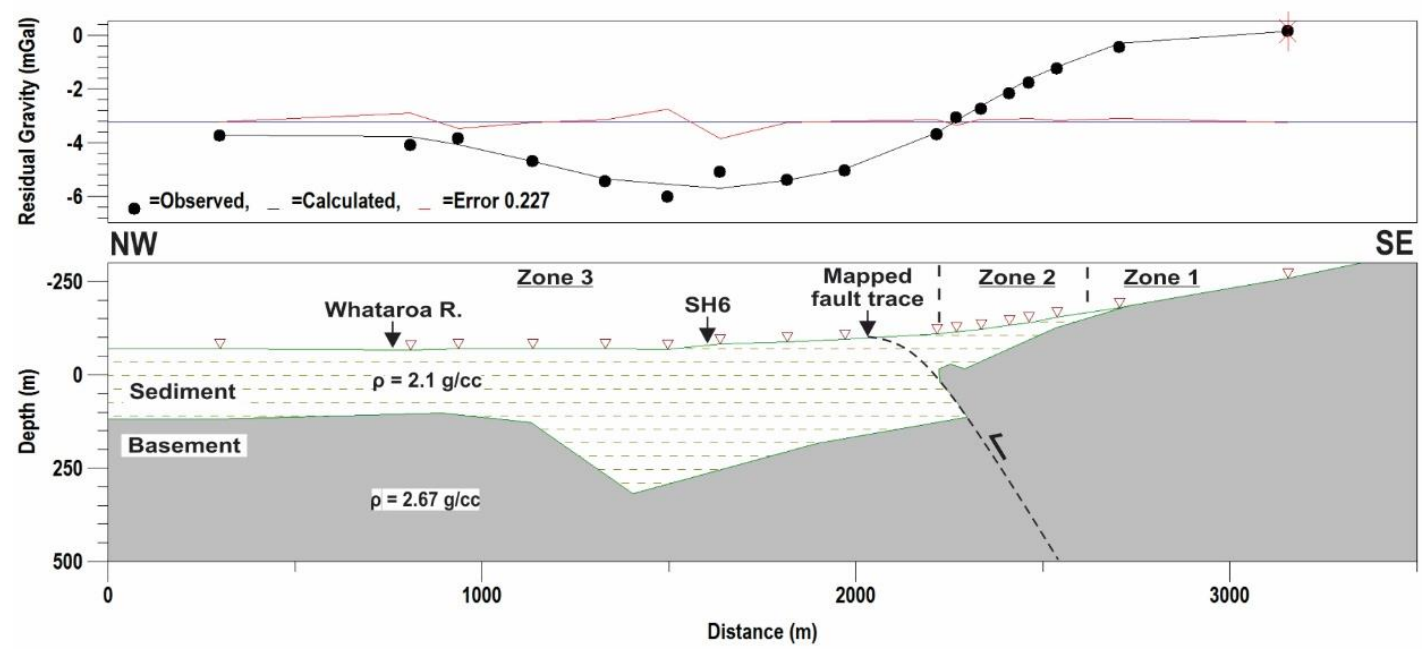

Figure 4.8: Gravity Model 2 for Profile 2 across the Alpine Fault.

Top: observed gravity (black circles), tie point (red star), calculated gravity (black line), and RMSE of the fit (red line). Bottom: projected gravity stations (inverted triangles) extending along the profile. The profile intersects the Whataroa River and State Highway 6 (SH6).

The RMS error for Model 2 is reasonable $(0.23 \mathrm{mGal})$. Increased error in the centre of the model is likely due to a station projection issue caused by a change in the gravity gradient relative to the azimuth of the profile (Figure 4.7). The steep gravity gradient observed along the range front (Zone 2) is inferred to be caused by the main thrust plane of the Alpine Fault, which is dipping moderately southeast. The fault plane is shown over-thrusting sediment in what is inferred to be a former glacial channel with a sediment thickness of $\sim 350 \mathrm{~m}$ at its deepest point. Projection to the surface requires a near-surface decrease in dip, but the fault plane agrees well with the mapped surface trace of the Alpine Fault, identified by Barth et al. (2012) as a thrust fault lineament.

Figure 4.9 shows a 2-D model (Model 3) for Profile 3. 
Model 3

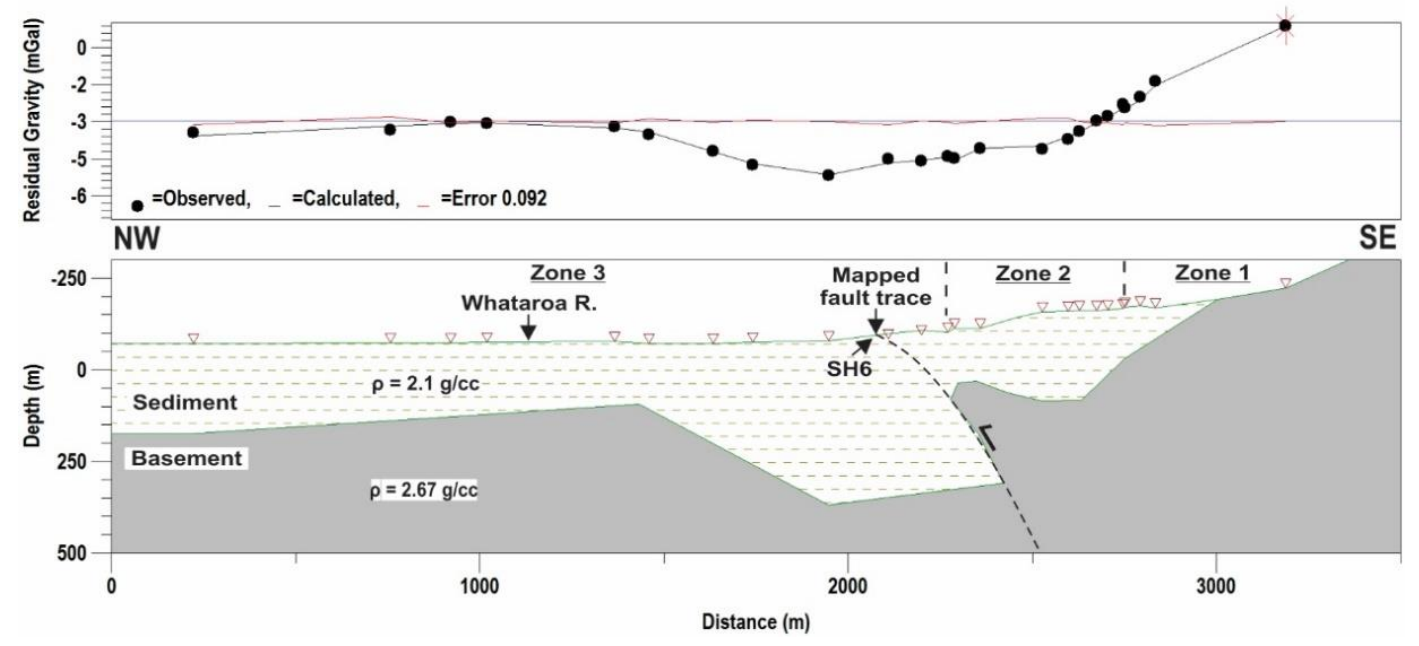

Figure 4.9: Gravity Model 3 for Profile 3 across the Alpine Fault.

Top: observed gravity (black circles), tie point (red star), calculated gravity (black line), and RMSE of the fit (red line). Bottom: projected gravity stations (inverted triangles) extending along the profile. The profile intersects the Whataroa River and State Highway 6 (SH6).

The sub-surface structure in Model 3 correlates well with Model 2. There is a steady increase in the amplitude of the observed gravity signal near the centre of the profile (Zone 2), inferred to be a continuation (NE to SW) of the main thrust plane of the Alpine Fault. The inferred glacial channel is $\sim 50 \mathrm{~m}$ deeper than Model 2 at its deepest point. Model 3 is also consistent with the thrust lineament mapped by Barth et al. (2012).

Figure 4.10 shows a 2-D model (Model 4) for Profile 4. 


\section{Model 4}

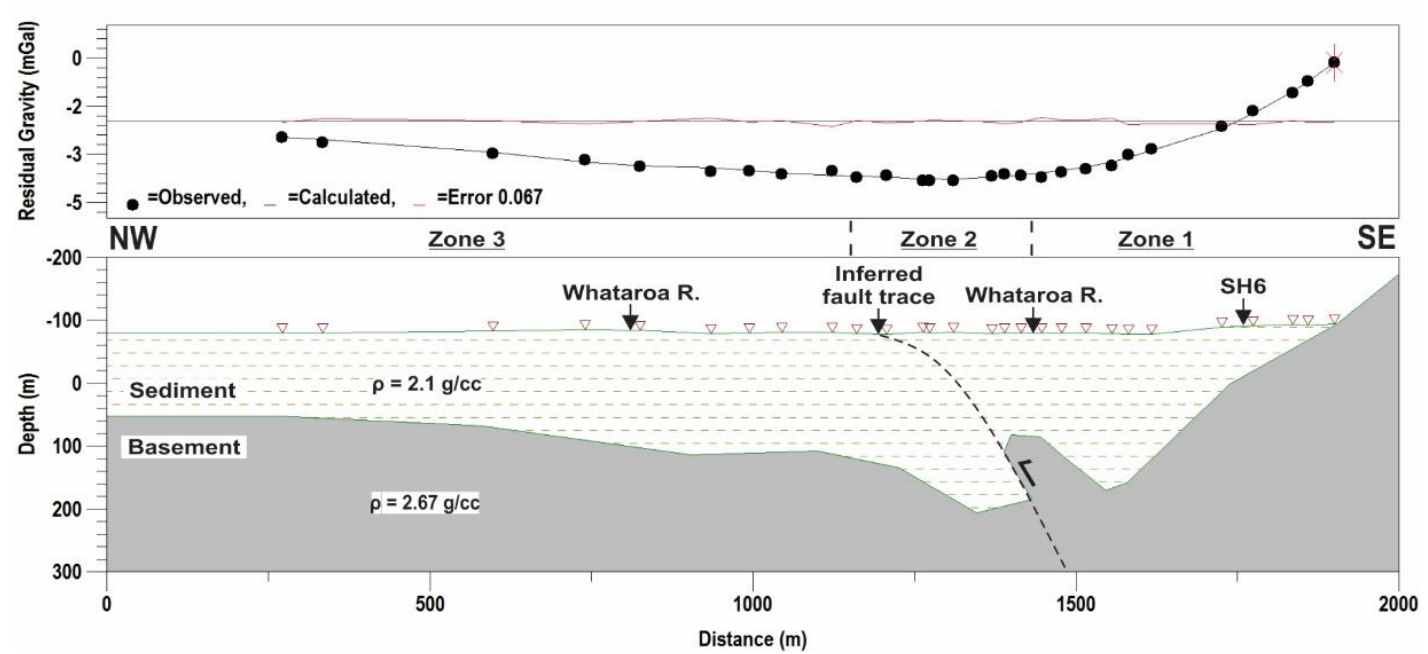

Figure 4.10: Gravity Model 4 for Profile 4 across the Alpine Fault.

Top: observed gravity (black circles), tie point (red star), calculated gravity (black line), and RMSE of the fit (red line). Bottom: projected gravity stations (inverted triangles) extending along the profile. The profile intersects the Whataroa River and State Highway 6 (SH6).

Model 4 correlates well spatially with Models 2 and 3. However, unlike Models 2 and 3, no surface fault trace constraint is mapped. Therefore, based on the interpretation of Models 2 and 3, the observed increase in the gravity signal near the centre of the profile is inferred to be a continuation (NE to $\mathrm{SW}$ ) of the main thrust plane of the Alpine Fault.

Figure 4.11 shows a 2-D model (Model 5) for Profile 5.

Model 5 contains little evidence of faulting. Based on a very small change in the slope angle of the bedrock-sediment interface produced by the model, and a projection of the mapped surface trace, the Alpine Fault is inferred to project to the surface with a moderately steep $\operatorname{dip}\left(\sim 60^{\circ}\right)$ to the southeast. 
Model 5

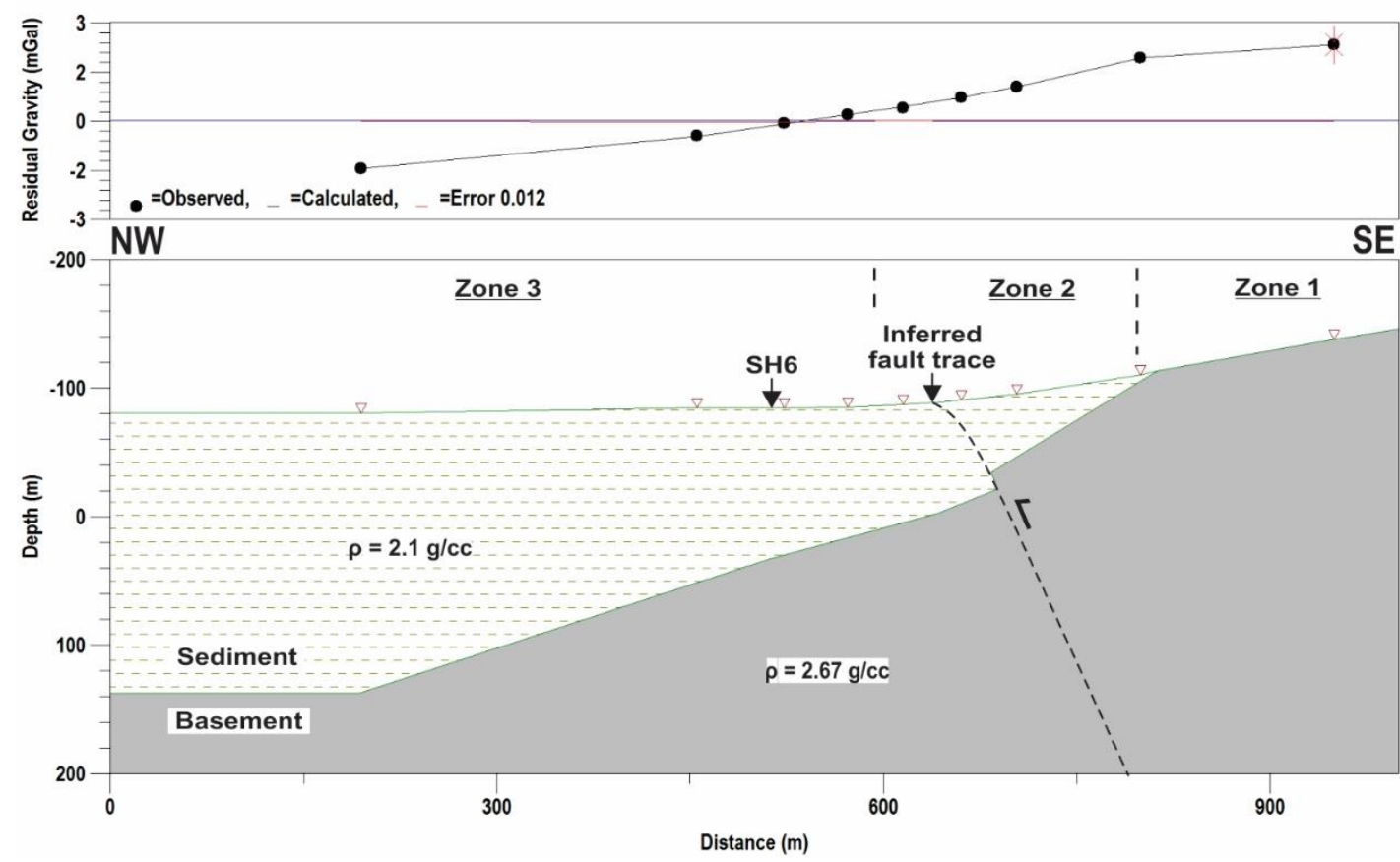

Figure 4.11: Gravity Model 5 for Profile 5 across the Alpine Fault.

Top: observed gravity (black circles), tie point (red star), calculated gravity (black line), and RMSE of the fit (red line). Bottom: projected gravity stations (inverted triangles) extending along the profile. The profile intersects State Highway 6 (SH6).

Based on the geometry of all four Models of the Alpine Fault presented above, the following inference is made about the location of the surface fault trace across the Whataroa River valley (Figure 4.12). 


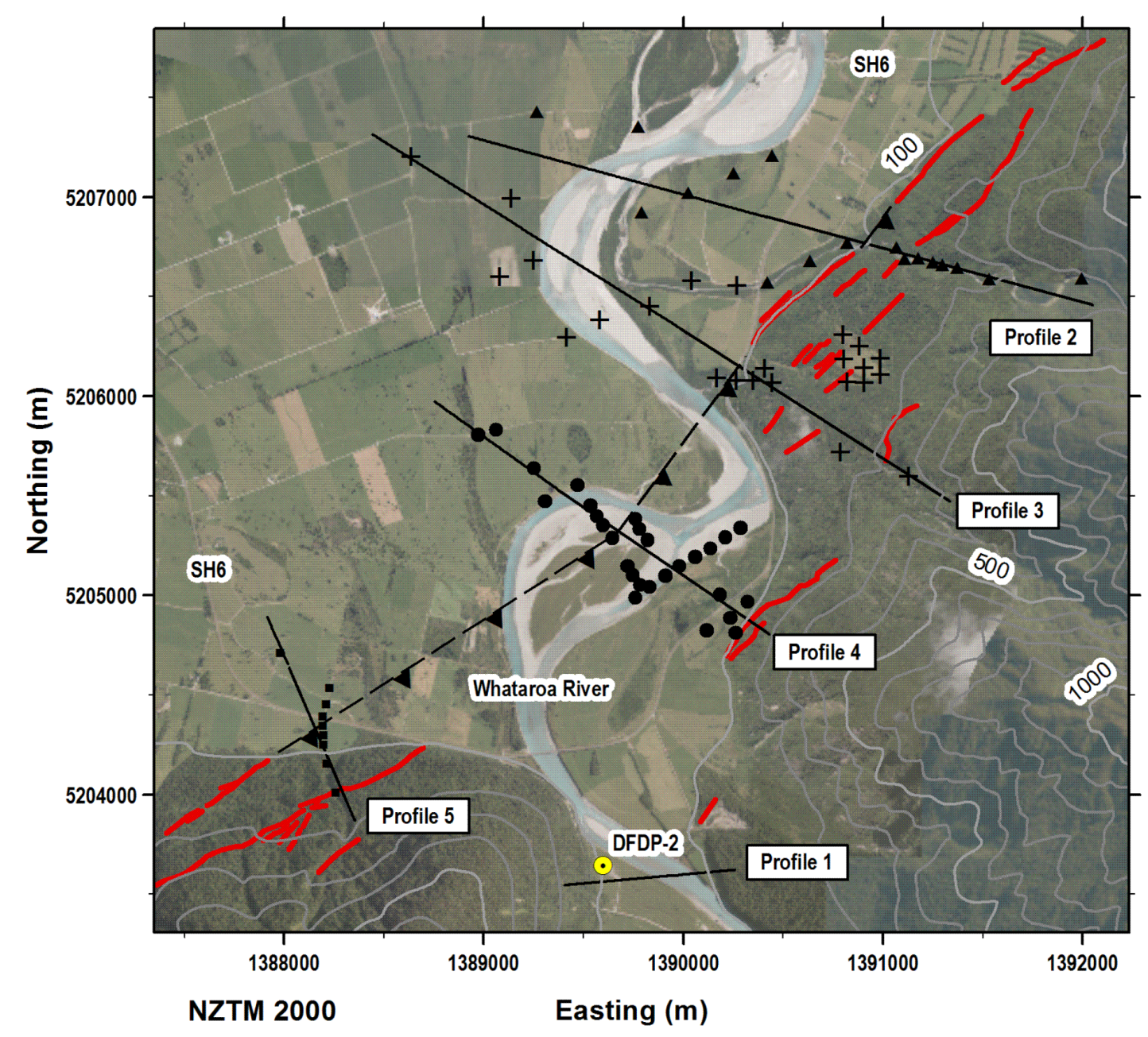

Figure 4.12: Inferred location of the Alpine Fault surface trace across the Whataroa River valley.

The inferred surface trace of the Alpine Fault (black line) intersects Profiles 2 to 5 based on the results of Models 2 to 5 and correlates well with the surface trace (red lines) mapped by Barth et al. (2012). Aerial photography from Land Information New Zealand (LINZ).

\subsection{Gravity structural inversion and uncertainty}

An inversion algorithm built into GM-SYS was used for Models 1A and 1B. A single point located between two structural constraints (hillside, DFDP-2B) is allowed to vary in the xy-plane to minimise misfit between the calculated and observed gravity. Multiple iterations were made until the inversion point could not be improved. The inversion process was then restarted with different starting points. The final result was found to be robust in both models. 
A confidence region (error ellipse) was estimated by manually moving the optimized point until the visual fit to the data was considered unreasonably poor. The confidence region corresponds approximately to a contour of fit (RMSE $=0.35 \mathrm{mGal}$ ). These alternative versions of Model 1A are shown in Figure 4.13.

Figure 4.14 shows similar sensitivity analysis for the inversion results for Model 1B on Profile 1. 


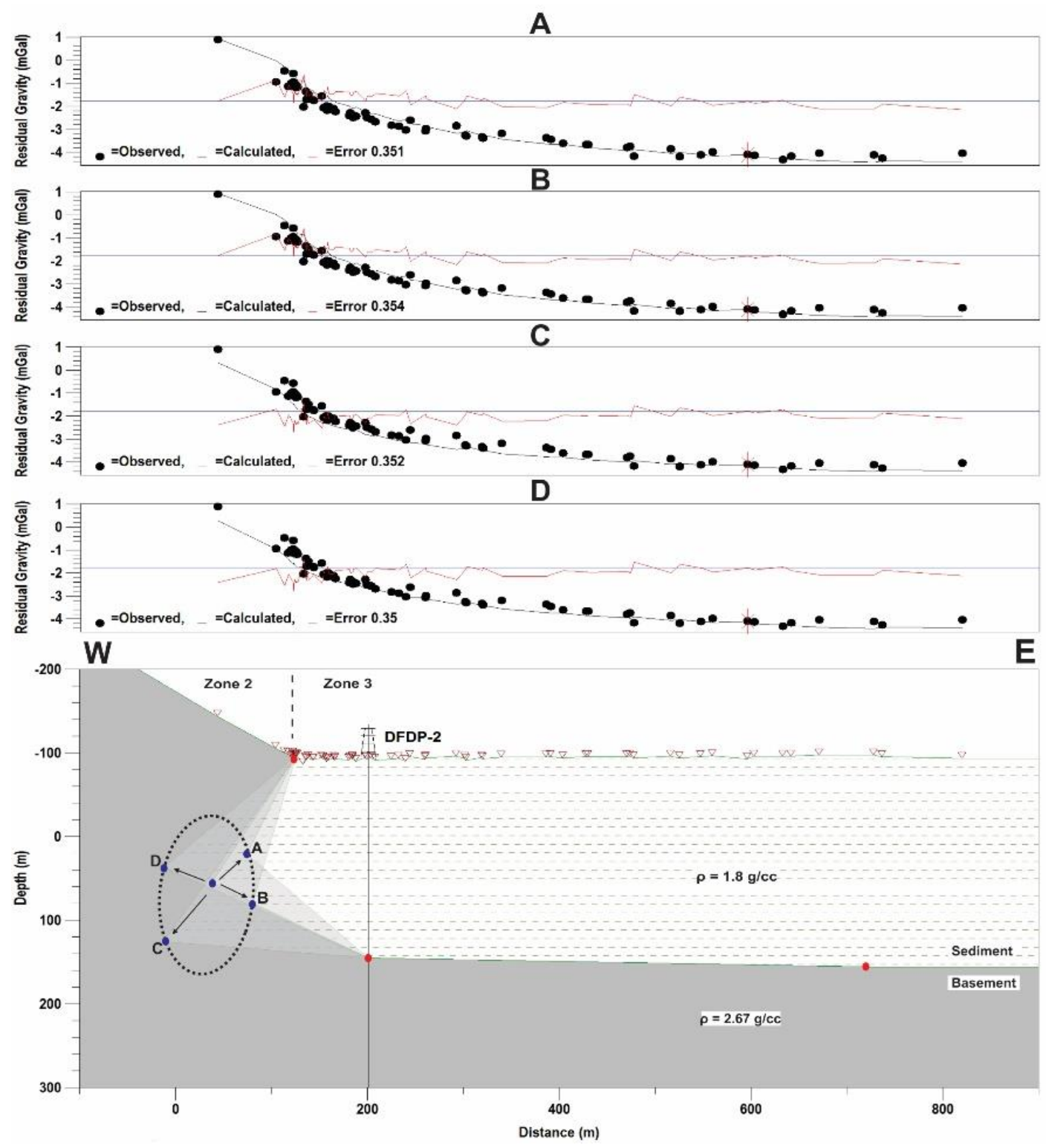

Figure 4.13: Model 1A structural inversion and uncertainty.

Top: Observed and calculated gravity response to points A, B, C and D. Bottom: The optimised point (near centre of ellipse) is manually shifted to locations A, B, $\mathrm{C}$ and $\mathrm{D}$ in the $\mathrm{xy}-$ plane to estimate a margin of error. 


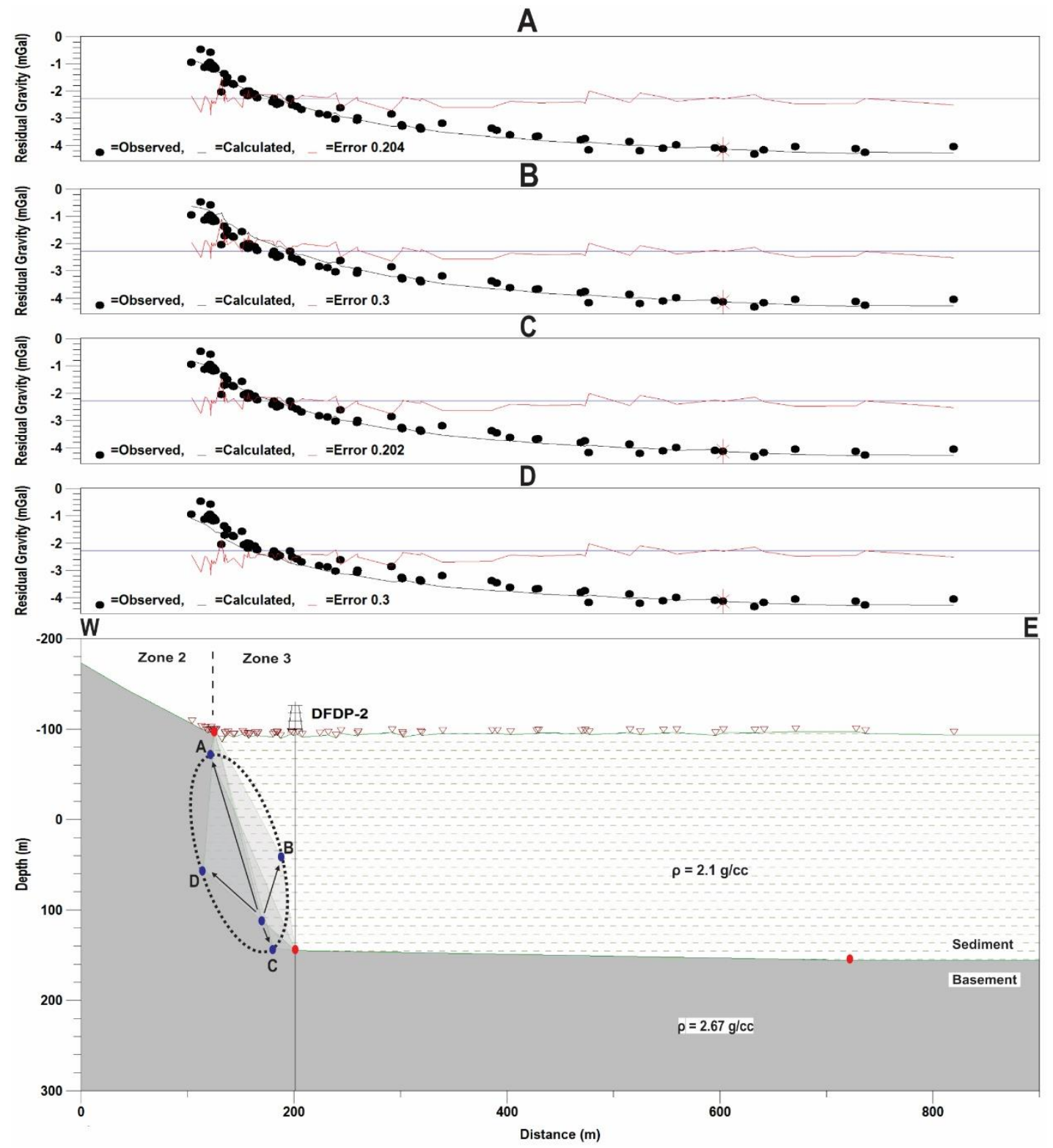

Figure 4.14: Model 1B structural inversion and uncertainty.

Top: Observed and calculated gravity response to points A, B, C and D. Bottom: The optimised point (near bottom of ellipse) is manually shifted to locations A, B, $\mathrm{C}$ and $\mathrm{D}$ in the $\mathrm{xy}$-plane to estimate a margin of error. 


\section{Chapter 5 Discussion and conclusions}

\subsection{Discussion}

\subsubsection{Gravity maps}

The effects of extensive erosion and faulting in the Whataroa River valley is observable in the Bouguer gravity and residual gravity maps presented in Section 3.5. Below is discussion of interesting features identified in Figures 3.9 to 3.13.

\section{Offset erosional features}

A prominent gravity low beneath the Whataroa floodplain originally recognised by Brikke (2007) and later by Davy (2012) indicates the presence of a lower density material, and hence, structural low beneath the floodplain. This feature, and a steep gravity gradient refined by Davy (2012) and by this study, has previously been inferred to be a large kettle hole carved during the Waimea glaciation ( 140 ka), dextrally offset by $\sim 3.5 \mathrm{~km}$ from the entrance to the Whataroa River valley, suggesting a horizontal displacement rate of $25 \mathrm{~mm} / \mathrm{yr}$ on the central Alpine Fault at Whataroa (Brikke, 2007). While this estimate agrees with other estimates of Quaternary horizontal displacement rates on the Alpine Fault in South Westland (Sutherland et al., 2006; Sutherland and Norris, 1995), it must be taken with caution given the sense of motion and segmentation of the Alpine Fault across the Whataroa River valley (Barth et al., 2012). Wellconstrained dated offsets are required to draw such a conclusion.

In addition to the large offset gravity low beneath the Whataroa floodplain, this study has defined a dextrally offset glacial channel at the entrance to the Whataroa River valley. Given that the best estimates of Quaternary horizontal-slip rates on the central Alpine Fault range between 20-30 mm/yr (Barth et al., 2013; Cooper and Norris, 1994; Norris and Cooper, 1997; Norris and Cooper, 2001; Sutherland et al., 2006; Sutherland 
and Norris, 1995; Wright, 1998), we would expect a dextral channel offset of between 340-510 m, assuming an LGM channel age of 17 kyr (Barrows et al., 2013). Using gravity data and surface topography, Davy et al. (2013) measured a channel offset of $372 \pm 159 \mathrm{~m}$ at Whataroa, and estimated a horizontal displacement rate of $20 \pm 9 \mathrm{~mm} / \mathrm{yr}$, assuming a channel age of $19 \pm 1$ kyr. However, the uncertainties associated with this technique are significant (Davy, 2012; Davy et al., 2013).

No obvious small-scale $(340-510 \mathrm{~m})$ horizontal offset is observable in the new gravity maps. This study shows that the Whataroa glacier turned to the northeast and followed the trace of the Alpine Fault, which complicates the determination of an offset. Improved techniques for measuring well-constrained ages and distances of offset subsurface features, accompanied with a joint interpretation with other geophysical methods (e.g. seismic-reflection data) are required to estimate both a reliable horizontaland vertical-displacement rate for the Alpine Fault at Whataroa.

\section{Local gravity gradients}

The new gravity maps reveal a high gravity gradient SE of the mapped frontal thrust of the Alpine Fault (main trace), inferred to be a moderate to steeply dipping density boundary at depth, suggesting the main thrust fault plane shallows in the near surface. Additionally, the gravity maps reveal a strong gravity trend along the hillside adjacent to the DFDP-2 drill site, inferred to be a steeply dipping density boundary buried beneath the hillside.

The sub-surface geometry of the Alpine Fault and DFDP-2 drill site based on the results of the gravity models is discussed in more detail in Section 5.1.2.

\section{Regional gravity gradient}

Reduction of the regional gravity field reveals a large regional gravity gradient decreasing towards the southeast, probably associated with the South Westland Basin in the northwest (Davy et al., 2013), and the crustal root beneath the Southern Alps (Allis, 1986; Eberhart-Phillips and Bannister, 2002; Reilly, 1962; Stern, 1995; Woodward, 1979). Subtraction of the regional gravity field from the Bouguer gravity data appears to have successfully removed the large southeast regional gravity gradient,

revealing significant short-wavelength structure in the study area, including a previously unknown gravity anomaly near the DFDP-2 drill site (discussed below). 
Residual gravity highs ( $2 \mathrm{mGal}$ ) associated with ranges on either side of the Whataroa valley may suggest the density used for terrain corrections was too high, but this cannot explain all of the variability. It is possible that sites used to fit the regional field were too close to the valley fill. Overall, the regional-residual separation appears to have successfully defined target features to a reasonable level of accuracy, and local DC-shift corrections were applied to individual profiles, as explained in Chapter 4.

Additional measurements with a good spatial coverage across the ranges surrounding the study area are required to improve the measurement of the regional gravity field.

\section{Whataroa valley erosional features}

After removal of the regional gravity field, a well-defined residual gravity low (-4 mGal) was observed near the DFDP-2 drill site. Based on initial interpretations, the gravity low is inferred to be the result of cyclic ice advance and subsequent glacial erosion, likely during the Otiran LGM, between 26-17 ka (Barrows et al., 2013). Following glacial retreat on the West Coast from LGM limits $\sim 18 \mathrm{ka}$ (Almond et al., 2001; Barrell et al., 2013; Newnham et al., 2003; Putnam et al., 2013; Shulmeister et al., 2005; Vandergoes and Fitzsimons, 2003; Williams, 1996), ice is inferred to have receded over the Alpine Fault at Whataroa 16.3-14.8 ka, based on evidence from South Westland (Sutherland and Norris, 1995).

The inferred timing of ice retreat across the Alpine Fault at Whataroa is consistent with the depositional age of lacustrine sediments (16.35-15.8 ka) observed in the DFDP2 drill core $\sim 1 \mathrm{~km}$ south of the mapped fault trace (Cox et al., 2015; Sutherland et al., 2015). This implies that the residual gravity low observed beneath the DFDP-2 drill site is the remnants of a glacial over-deepening carved during ice advance, that was subsequently filled with pro-glacial lake sediments during ice retreat and melting up the Whataroa River valley.

Cox et al. (2015) imply that the lake sediments sampled in DFDP-2 may correlate to the oldest lake sediments in Lakes Wahapo and Rotokino, suggesting a substantial $\left(\sim 100 \mathrm{~km}^{2}\right)$ pro-glacial lake once extended across the Whataroa floodplain. The evolution of this large ice-marginal lake likely involved a combination of dam types, and evolved through a sequence of different lake/dam configurations (Carrivick and Tweed, 2013). 
A detailed history of ice advance and retreat in the Whataroa River valley, including a comprehensive interpretation of the lake sediments sampled in the DFDP-2 drill hole, will greatly improve our understanding of the interesting features identified by this study.

\subsubsection{Sub-surface geometry}

\section{DFDP-2 drill site}

Two-dimensional gravity models of the sub-surface geometry beneath the hillside adjacent to the DFDP-2 drill site reveal either a reverse dipping bedrock-sediment interface, based on a sediment density of $1.8 \mathrm{~g} / \mathrm{cc}$ (Model 1A; Figure 4.5), or a subvertical bedrock-sediment interface, based on a sediment density of $2.1 \mathrm{~g} / \mathrm{cc}$ (Model 1B; Figure 4.6).

Based on provisional interpretations of sediments sampled in the DFDP-2 borehole (Cox et al., 2015; Sutherland et al., 2015), which includes lake silts between 60 and 200 $\mathrm{m}$, and assuming the porosity of the lake silts follow the same trend as the Taranaki mudstone compaction curve (Funnell et al., 1996), it is plausible to have a very low sediment density of $1.8 \mathrm{~g} / \mathrm{cc}$ beneath the drill site. For example, if we take the quoted surface porosity (54\%) and the compaction constant (2000 m) of Taranaki mud and apply those values to the lake silts, we can calculate a porosity range between 60 and $200 \mathrm{~m}$ depth using equation 5.1 (Funnell et al., 1996):

$$
\phi=\phi_{0} \exp \left(\frac{-z}{d}\right)
$$

where $\phi$ is porosity, $\mathrm{z}$ is depth in meters, $\phi_{0}$ is the initial surface porosity (54\%), and $d$ is the compaction constant $(2000 \mathrm{~m})$.

Assuming a grain density of $2.7 \mathrm{~g} / \mathrm{cc}$, the mean density of the lake silts between 60 and $200 \mathrm{~m}$ is $1.84 \pm 0.02 \mathrm{~g} / \mathrm{cc}$ (Figure 5.1). 


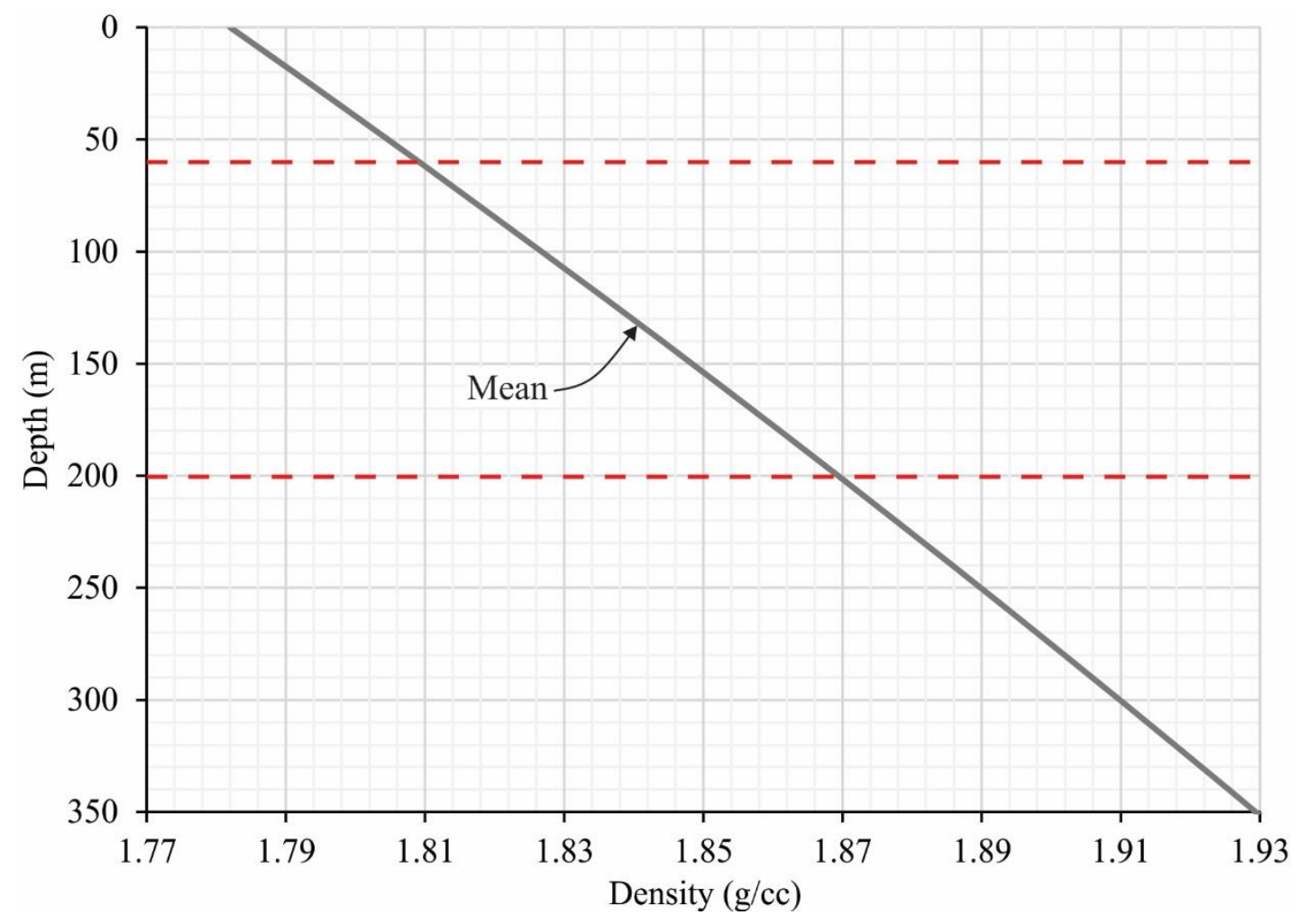

Figure 5.1: Calculated mean density of lake silts sampled in DFDP-2.

Depth range of the lake silts shown in red.

However, approximately $30 \%$ of sediment sampled in the DFDP-2 drill hole is gravel (Sutherland et al., 2015), introducing additional density to the lake silts, suggesting $2.1 \mathrm{~g} / \mathrm{cc}$ is a better estimate of the bulk density of sediment beneath the drill site.

Modelling of the bedrock-sediment interface using a sediment density of $1.8 \mathrm{~g} / \mathrm{cc}$ (Model 1A; Figure 4.5) fits the single gravity station (WDSS028) located high on the hillside within the preferred survey area (Zone 2), which has an estimated total uncertainty of $\pm 0.3 \mathrm{mGal}$ (see Appendix C; page 142). In addition, a reasonable error of $\pm 0.3 \mathrm{mGal}$ was estimated for the structurally inverted point in Model 1A (Figure 4.13), implying that even with a very low sediment density, Model $1 \mathrm{~A}$ is still a plausible model for the sub-surface geometry beneath the hillside.

While maintaining all fixed constraints of Model 1A, a misfit of gravity station WDSS028 was observed after increasing the sediment density to $2.1 \mathrm{~g} / \mathrm{cc}$. Subsequent removal of WDSS028 (Model 1B; Figure 4.6), and structural inversion of the optimised point beneath the hillside, yields a reasonable error of $\pm 0.2-0.3 \mathrm{mGal}$ for the model (Figure 4.14), implying Model1B is also plausible if the point on the hillside is removed. 
Based on these results, the bedrock-sediment interface beneath the hillside is either a thrust fault, possibly a splay of the Alpine Fault or large landslide, or a sub-vertical bedrocksediment interface, typical of U-shaped geomorphology, possibly the steep wall of the inferred over-deepening beneath the DFDP-2 drill site. A denser coverage of gravity stations is required on the hillside to demonstrate measurement repeatability and better define the sub-surface geometry near the DFDP-2 drill site. Improved GPS technologies capable of penetrating the thick vegetation on the hillside are essential for obtaining accurate height measurements of hillside gravity stations.

To suggest a possible mechanism to explain how a steep U-shaped glacial geomorphology may exist beneath the hillside, particularly in an area of extensive fluvial erosion (Herman and Braun, 2006; Hovius et al., 1997; Korup et al., 2004; Korup et al., 2005), rapid sedimentation recorded in the DFDP-2 sequence (Cox et al., 2015) may have filled the valley vertically and buttressed the valley walls before they had a chance to fail. This is a common observation at present-day Fox and Franz Josef glaciers, where steep valley walls protrude from the sediment.

It is important to note that either a thrust fault, or a steep valley wall has been defined only at the entrance of the Whataroa valley. Additional gravity measurements are required up-valley to delineate the extent of the observed gravity anomaly beneath the DFDP-2 drill site.

\section{Alpine Fault}

Based on data and discussion presented in Chapter 1, an assumed sediment density of 2.1 $\mathrm{g} / \mathrm{cc}$ was considered a reasonable value for 2-D gravity models of the sub-surface geometry beneath the range front. Comparison of Alpine Fault models (Section 4.4.2; Models 2 to 4) reveal a reverse dipping bedrock-sediment interface, inferred to be a moderate to steeply dipping density boundary at depth. The gravity gradient near the eastern range front provides a location where the basal contact of the sediment is offset. In order for the mapped frontal thrust to connect to the offset basal contact, a low-dip is required near the surface, consistent with previous studies of shallow Alpine Fault geometry (Cooper and Norris, 1994; Norris and Cooper, 1995). No significant evidence of faulting was observed in Model 5 located on the western range front, and no significant gravity gradient was observed in the gravity maps at this location, suggesting separate modes of faulting exist on either side of the valley entrance. 
Assuming a constant vertical displacement rate of $6 \pm 1 \mathrm{~mm} / \mathrm{yr}$ calculated in the Whataroa River valley (De Pascale and Davies, 2014), and assuming a glacial channel age of $17 \mathrm{kyr}$ (Barrows et al., 2013), we would expect a vertical offset of $102 \mathrm{~m}$ on the Alpine Fault at Whataroa. Two of the four Alpine Fault models (Models 2 and 4) suggest a vertical offset of $\sim 100$ m protrudes from the floor of the buried glacial channel.

A major limitation of the Alpine Fault models is a lack of independent geometrical constraints from seismic surveys. However, these preliminary models (seismic survey data will be available in future) are geologically reasonable, and fit well with the observed gravity signal across the range front.

\subsection{Future work}

The high-precision gravity data collected and processed during this study may be used for many future projects, including, but not limited to:

- Joint modelling with other geophysical data (e.g. seismic-reflection and magnetic data) and physical properties measurements (e.g. density of borehole sediments), allowing for a comprehensive joint interpretation of sub-surface structure near the Alpine Fault and DFDP-2 drill hole in the Whataroa River valley.

- Interpolation of sediment thickness determined by seismic-reflection methods and hence estimation of a sediment-volume beneath the Whataroa River valley, providing valuable insight into the erosional history of the valley.

- Constraints on the offset of sub-surface features by the Alpine Fault.

\subsection{Recommendations}

To make the amalgamation of existing and new gravity data as easy as possible, it is recommended that surveyors reproduce their raw datasets in a standardised manner, whereby spreadsheets are provided with required header information (e.g. Appendix C), similar to the SEG-Y (Society of Exploration Geophysics) standard used for seismic 
data. Such a standard will increase efficiency and prevent data from being lost or misinterpreted.

\subsection{Conclusions}

The collection of 466 high-precision $(0.015 \mathrm{mGal})$ gravity observations has allowed production of high-quality gravity anomaly maps at the DFDP-2 drill site and nearby Alpine Fault. Key findings of this study based on interpretation of those maps are listed below:

- A buried dextrally-offset glacial channel extending along the northeast range front, interpreted to be at least $350-450 \mathrm{~m}$ at its deepest point.

- Evidence of thrust faulting along the northeast range front based on interpretation of a well-defined steep gravity gradient.

- An inferred location of the near-surface trace of the Alpine Fault across the Whataroa River valley, consistent with structural lineaments mapped by Barth et al. (2012) along the range front.

- A large gravity low beneath the DFDP-2 drill site, interpreted to be a glacial over-deepening in the Whataroa River valley, consistent with lake sediments sampled in the DFDP-2 drill hole (Sutherland et al., 2015).

- A steep gravity gradient along the hillside adjacent to the DFDP-2 drill site, interpreted to be either a reverse fault, or a steep valley wall, depending on the density of the sediment assumed. 


\section{Appendix A Gravity Charts}




\begin{tabular}{|c|c|c|c|c|c|c|}
\hline Zone: & B & $\mathrm{C}$ & D & E & $\mathrm{F}$ & G \\
\hline $\mathrm{R}(\mathrm{m}): 2$ & 166 & 53.3 & 170 & 390 & 895 & 1530 \\
\hline $\mathrm{N}$ & 4 & 6 & 6 & 8 & 8 & 12 \\
\hline 1 & 0.5 & 1.9 & 3.3 & 7.6 & 11.5 & 24.9 \\
\hline 2 & 0.7 & 2.6 & 4.7 & 10.7 & 16.3 & 35.1 \\
\hline 3 & 0.8 & 3.2 & 5.8 & 13.1 & 19.9 & 43.3 \\
\hline 4 & 1.0 & 3.8 & 6.7 & 15.2 & 23.0 & 49.8 \\
\hline 5 & 1.1 & 4.2 & 7.5 & 17.0 & 25.7 & 55.6 \\
\hline 6 & 1.2 & 4.6 & 8.2 & 18.6 & 28.2 & 60.9 \\
\hline 7 & 1.3 & 5.0 & 8.9 & 20.1 & 30.4 & 65.8 \\
\hline 8 & 1.4 & 5.4 & 9.5 & 21.5 & 32.6 & 70.4 \\
\hline 9 & 1.5 & 5.7 & 10.1 & 22.9 & 34.5 & 74.7 \\
\hline 10 & 1.6 & 6.0 & 10.6 & 24.1 & 36.4 & 78.7 \\
\hline 20 & 2.4 & 8.7 & 15.1 & 34.2 & 51.6 & 111.6 \\
\hline 30 & 3.2 & 10.9 & 18.6 & 42.1 & 63.3 & 136.9 \\
\hline 40 & 3.9 & 12.9 & 21.7 & 48.8 & 73.2 & 158.3 \\
\hline 50 & 4.6 & 14.7 & 24.4 & 54.8 & 82.0 & 177.4 \\
\hline 60 & 5.3 & 16.5 & 26.9 & 60.2 & 90.0 & 194.7 \\
\hline 70 & 6.1 & 18.2 & 29.3 & 65.3 & 97.3 & 210.7 \\
\hline 80 & 6.9 & 19.9 & 31.5 & 70.1 & 104.2 & 225.6 \\
\hline 90 & 7.8 & 21.6 & 33.7 & 74.7 & 110.8 & 239.8 \\
\hline 100 & 8.7 & 23.4 & 35.7 & 79.1 & 117.0 & 253.2 \\
\hline
\end{tabular}

\section{Continued on next page}




\begin{tabular}{|c|c|c|c|c|c|c|}
\hline Zone: & $\mathrm{H}$ & I & $\mathbf{J}$ & $\mathrm{K}$ & $\mathrm{L}$ & $\mathrm{M}$ \\
\hline $\mathrm{R}(\mathrm{km}): 1.53$ & 2.61 & 4.47 & 6.65 & 9.9 & 14.7 & 21.9 \\
\hline $\mathrm{N}:$ & 12 & 12 & 16 & 16 & 16 & 16 \\
\hline 1 & 32 & 42 & 72 & 88 & 101 & 125 \\
\hline 2 & 46 & 60 & 101 & 124 & 148 & 182 \\
\hline 3 & 56 & 74 & 125 & 153 & 186 & 225 \\
\hline 4 & 65 & 85 & 144 & 176 & 213 & 262 \\
\hline 5 & 73 & 95 & 161 & 197 & 239 & 291 \\
\hline 6 & 80 & 104 & 176 & 216 & 261 & 319 \\
\hline 7 & 86 & 112 & 191 & 233 & 282 & 346 \\
\hline 8 & 92 & 120 & 204 & 249 & 303 & 370 \\
\hline 9 & 96 & 127 & 216 & 264 & 322 & 391 \\
\hline 10 & 103 & 134 & 228 & 278 & 338 & 413 \\
\hline 20 & 146 & 190 & 322 & 394 & 479 & 586 \\
\hline 30 & 179 & 233 & 396 & 483 & 587 & 717 \\
\hline 40 & 206 & 269 & 457 & 557 & 679 & 828 \\
\hline 50 & 231 & 301 & 511 & 624 & 759 & 926 \\
\hline 60 & 253 & 330 & 561 & 683 & 832 & 1015 \\
\hline 70 & 274 & 357 & 606 & 738 & 899 & 1097 \\
\hline 80 & 293 & 382 & 648 & 790 & 962 & 1173 \\
\hline 90 & 311 & 405 & 688 & 838 & 1020 & 1244 \\
\hline 100 & 328 & 427 & 726 & 884 & 1076 & 1312 \\
\hline
\end{tabular}

Table A.1: Hammer terrain correction chart.

Terrain corrections are shown for Hammer zones $\mathrm{B}$ to $\mathrm{M}$, in $\mu \mathrm{Gal}$, and per compartment. Note that $1 \mu \mathrm{Gal}=0.001 \mathrm{mGal}$. Inner and outer radii of the zones are listed in row R, in meters for zones B-G and in kilometres for zones H-M. The number of compartments within a zone are listed in row $\mathrm{N}$. The table lists the exact height differences that, assuming a density of $2670 \mathrm{~kg} / \mathrm{m}^{3}$, will produce the tabulated terrain effects (Milsom, 2003). 
MILLIGAL VALUES FOR LACOSTE \& ROMBERG, INC. MODEL G GRAVITI METFR IG- 519

\begin{tabular}{|c|c|c|c|c|c|}
\hline $\begin{array}{l}\text { COUNTER } \\
\text { READING* }\end{array}$ & $\begin{array}{l}\text { VALUE IN } \\
\text { MILLIGALS }\end{array}$ & $\begin{array}{l}\text { FACTOR FOR } \\
\text { INTERVAL. }\end{array}$ & $\begin{array}{l}\text { COUNTER } \\
\text { READING* }\end{array}$ & $\begin{array}{l}\text { VALUE IN } \\
\text { MILLIGALS }\end{array}$ & $\begin{array}{l}\text { FACTOR FOR } \\
\text { INTERVAL }\end{array}$ \\
\hline noo & 000.00 & 1.01235 & & & \\
\hline 100 & 101.24 & 1.01223 & 3600 & 3644.52 & 1.01326 \\
\hline 200 & 202.46 & 1.01213 & 3700 & 3745.85 & 1.01327 \\
\hline 300 & 303.67 & 1.01205 & 3800 & 3847.18 & 1.01330 \\
\hline 400 & 404.88 & 1.01199 & 3900 & 3948.51 & 1.01332 \\
\hline 500 & 506.08 & 1.01194 & 4000 & 4049.84 & 1.01334 \\
\hline 600 & 607.27 & 1.01192 & 4100 & 4151.17 & 1. C.1335 \\
\hline 700 & 708.46 & 1.01189 & 4200 & 4252.51 & 1.01336 \\
\hline $8 \cap 0$ & 8ก9. 65 & 1.01187 & 4300 & 4353.84 & 1.01336 \\
\hline $9 n 0$ & 910.84 & 1.01187 & 4400 & 4455.18 & 1.01334 \\
\hline 1000 & 1012.02 & 1.01187 & 4500 & 4556.51 & 1.01332 \\
\hline 1100 & 1113.21 & 1.01188 & 4600 & 4657.85 & 1.01329 \\
\hline 1200 & 1214.40 & 1.01189 & 4700 & 4759.17 & 1.01324 \\
\hline 1.300 & 1315.59 & 1.01191 & 4800 & 4860.50 & 1.01317 \\
\hline 1400 & 1416.78 & 1.01192 & 4900 & 4961.82 & 1.01307 \\
\hline 1500 & 1517.97 & 1.01196 & 5000 & 5063.12 & 1.01295 \\
\hline 1600 & 1619.17 & 1.01202 & 5100 & 5164.42 & 1.01284 \\
\hline 1700 & 1720.37 & 1.01207 & 5200 & 5265.70 & 1.01270 \\
\hline 1800 & 1821.58 & 1.01214 & 5300 & 5366.97 & 1.01254 \\
\hline 1900 . & 1922.79 & 1.01221 & 5400 & 5468.23 & 1.01236 \\
\hline 2000 & 2024.01 & 1.01228 & 5500 & 5569.46 & 1.01217 \\
\hline 2100 & 2125.24 & 1.01235 & 5600 & 5670.68 & 1.01194 \\
\hline 2200 & 2226.47 & 1.01243 & 5700 & 5771.87 & 1.01167 \\
\hline 2300 & 2327.72 & 1.01251 & 5800 & 5873.04 & 1.01140 \\
\hline 2400 & 2428.97 & 1.01260 & 5900 & 5974.18 & 1.01110 \\
\hline 2500 & 2530.23 & 1.01269 & 6000 & 6075.29 & 1.01081 \\
\hline 2600 & 2631.50 & 1.01276 & 6100 & 6176.37 & 1.01050 \\
\hline 2700 & 2732.77 & 1.01283 & 6200 & 6277.42 & 1.01019 \\
\hline 2800 & 2834.06 & 1.01289 & 6300 & 6300.44 & 1.00086 \\
\hline 2900 & 2935.35 & 1.01295 & 6400 & 6400.53 & 1.00953 \\
\hline 3000 & 3036.64 & 1.01301 & 6500 & 6500.48 & 1.00922 \\
\hline 3100 & 3137.94 & 1.01307 & 6600 & 6600.40 & 1.00882 \\
\hline 3200 & 3239.25 & 1.01312 & 6700 & 6700.28 & 1.00035 . \\
\hline 3300 & 3340.56 & 1.01317 & 6800 & $680 n .32$ & 1.00781 \\
\hline 3400 & 3441.88 & 1.01322 & 6900 & 6900.10 & 1.00722 \\
\hline 3500 & 3543.20 & 1.01324 & 7000 & 7000.82 & \\
\hline
\end{tabular}

Table A.2: Calibration table for a Lacoste \& Romberg model G-519 gravity meter. 
Appendix B Detailed Gravity Meter Technique 
The general procedure for taking a gravity measurement requires great care and patience. Firstly, to avoid problems with levelling the meter, it is essential to select a site that is as cemented as possible, such as exposed rock. In soft grassy areas, a spade is used to remove loose material and create a solid platform for the plate. The meter is then placed on the plate and levelled using both bubble levels and electronic levellers. The meter's internal beam is then released by turning the knurled arrestment knob, or clamp, counter-clockwise to its limit. The position of the beam is determined by assessing the crosshair in the microscope. Each meter model has a unique reading line, such as the G-model used in this study (reading line 2.2). To balance the beam, the left side of the crosshair is brought to the reading line by turning the nulling dial either left or right. For uniformity, it is essential to approach the reading line from the same direction, whereby each reading is made by approaching the reading line from left to right (turning clockwise). The slack in the gears and universal joint will cause an error if the reading line is not approached always from the same direction. The meter reading is then obtained from the counter and nulling dial, which is later converted to milligal using the meter's latest calibration table (Appendix A). Finally, the internal beam is stabilised by turning the knurled arrestment knob, or clamp, clockwise to its limit, and the meter is ready for transport to the next station. 


\section{Appendix C Gravity Data}




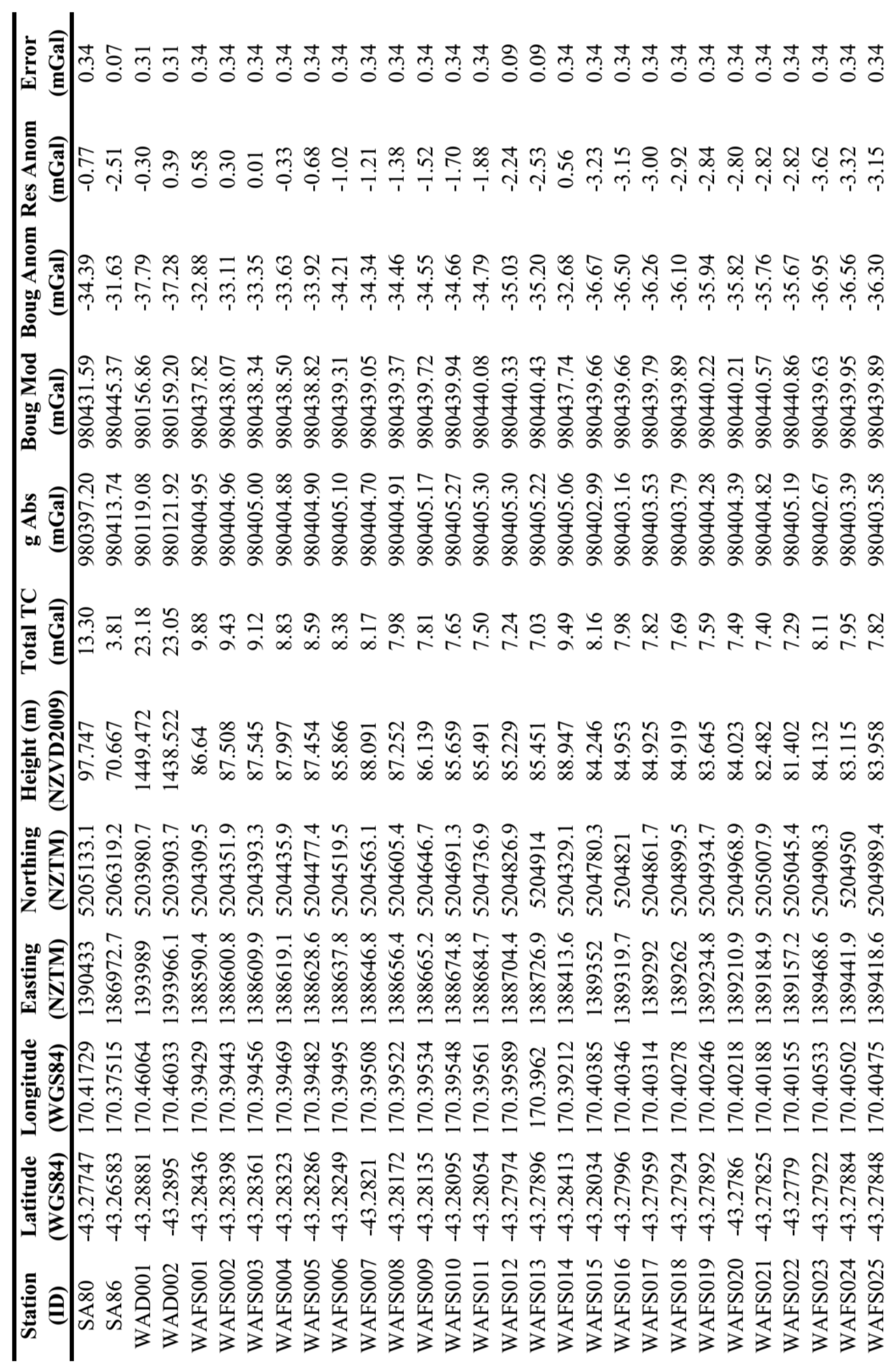

\section{Continued on next page}




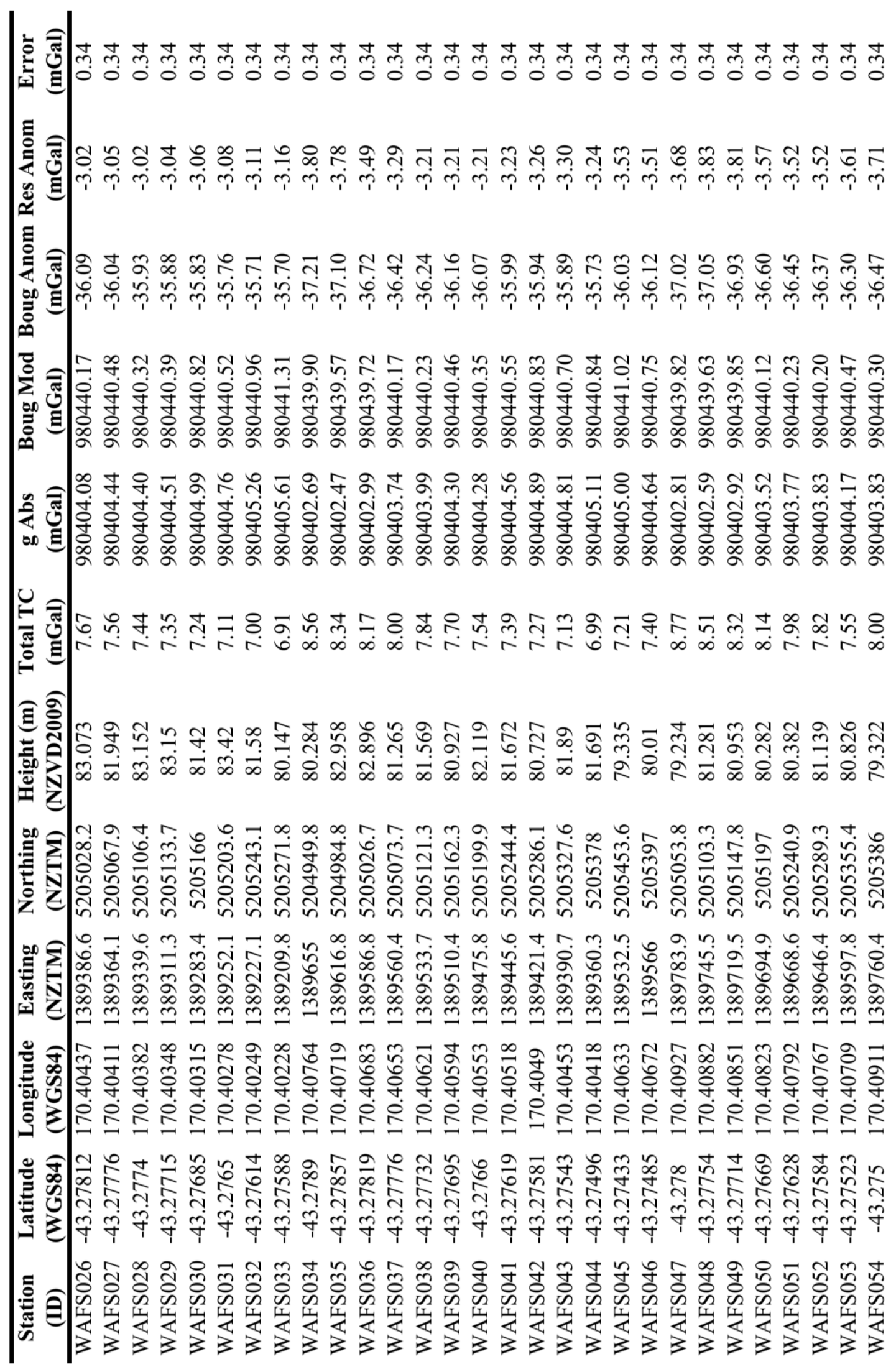

\section{Continued on next page}




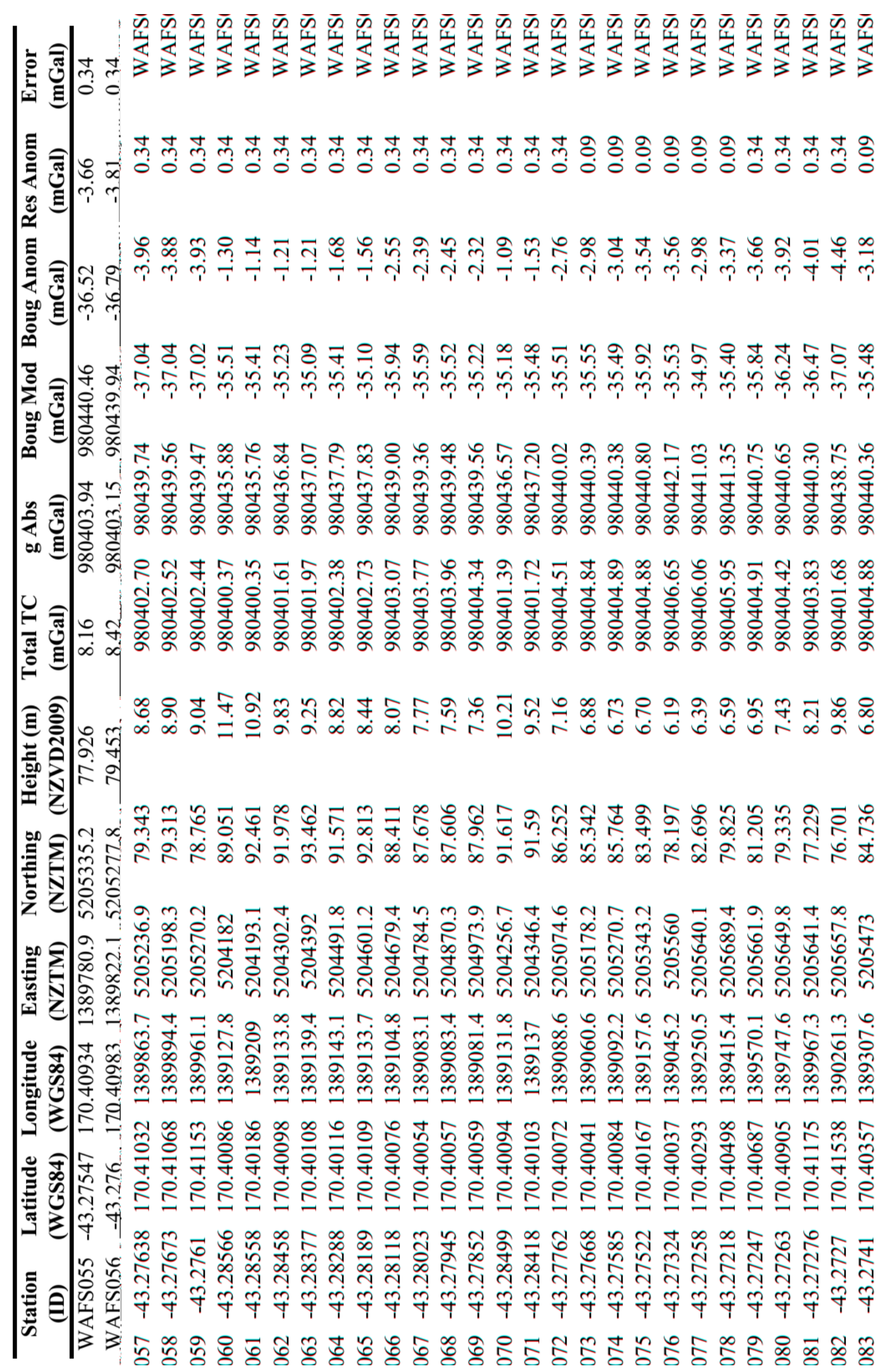

Continued on next page 


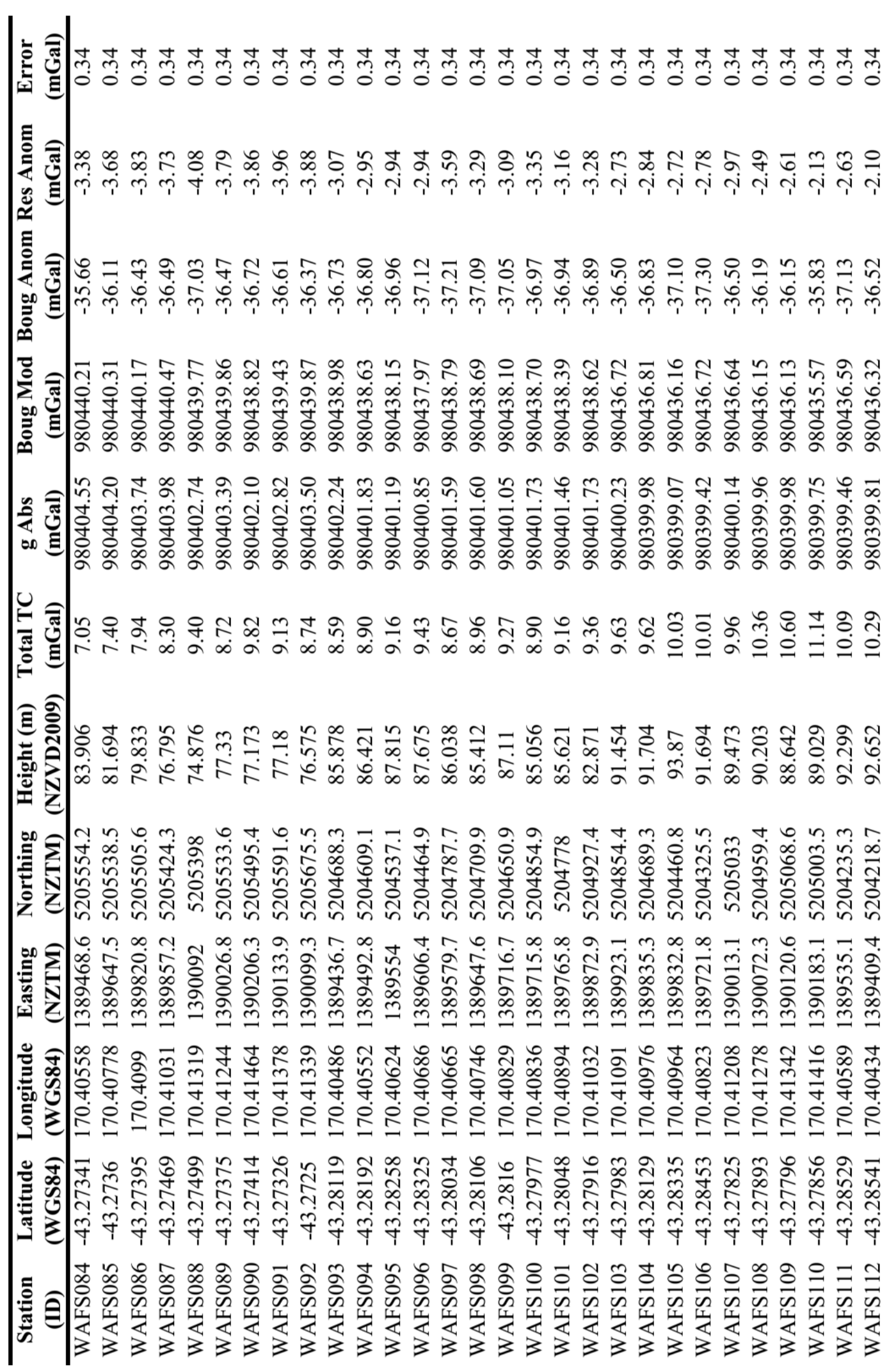

Continued on next page 


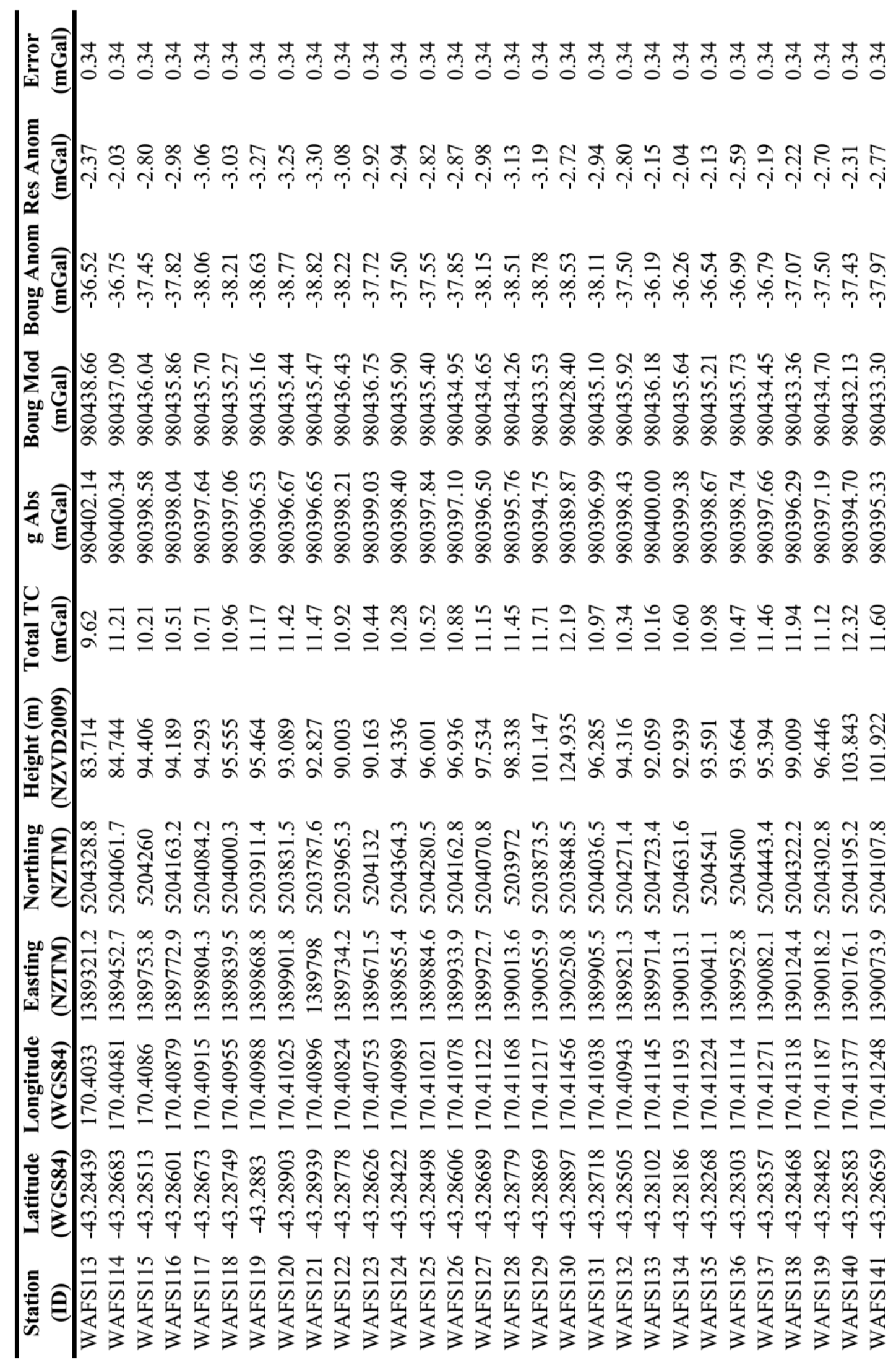

Continued on next page 


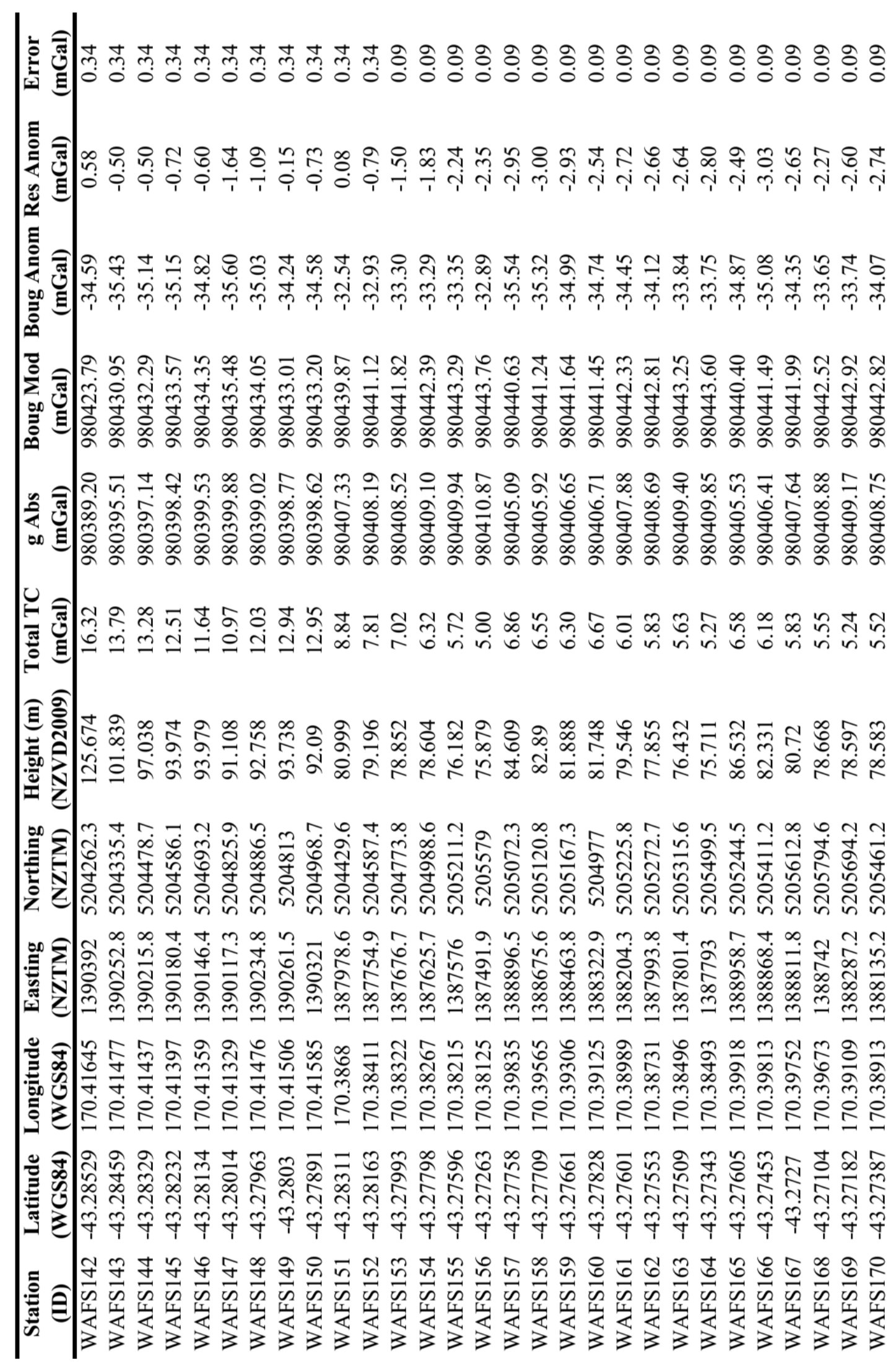

Continued on next page 


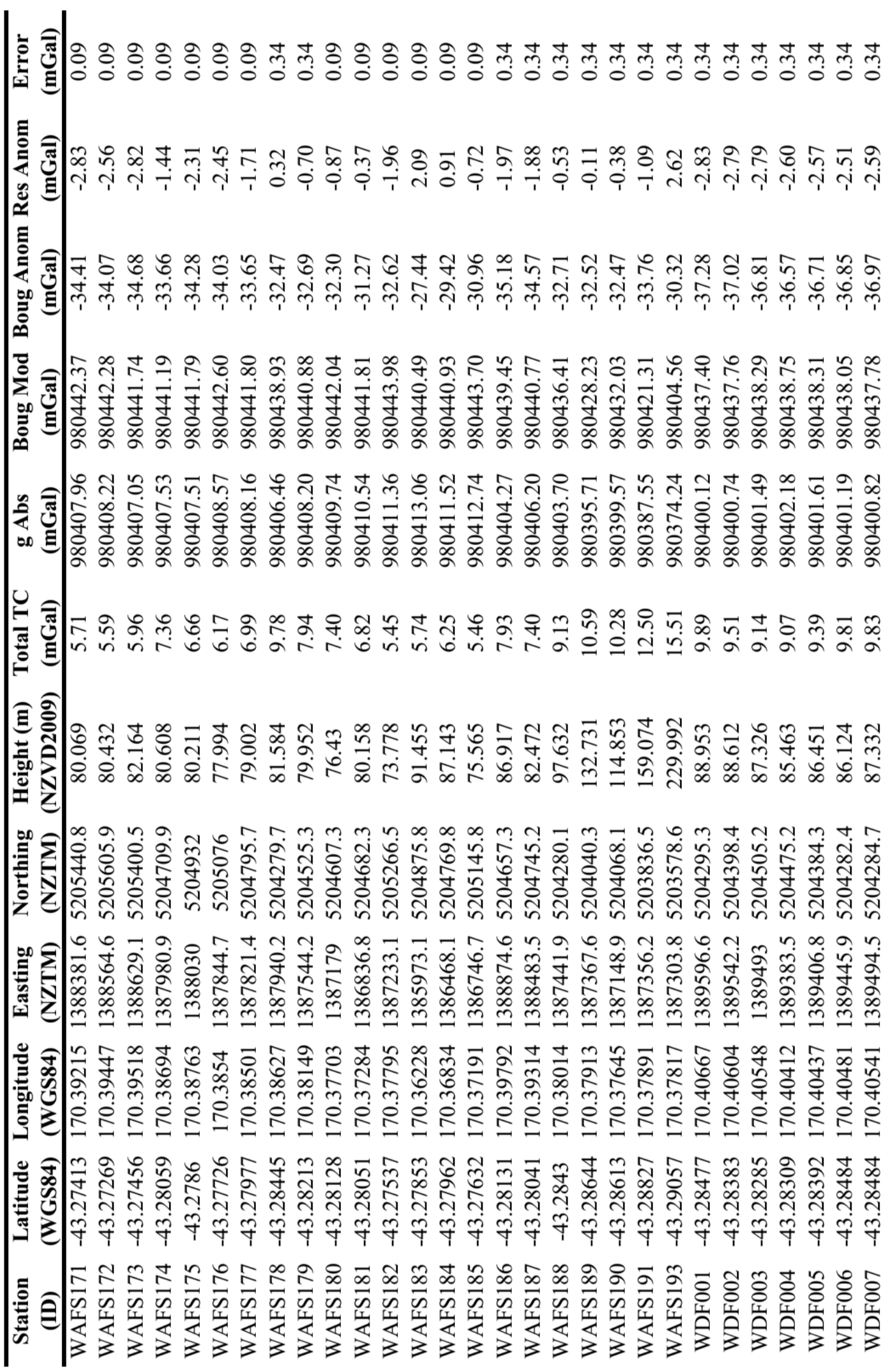

\section{Continued on next page}




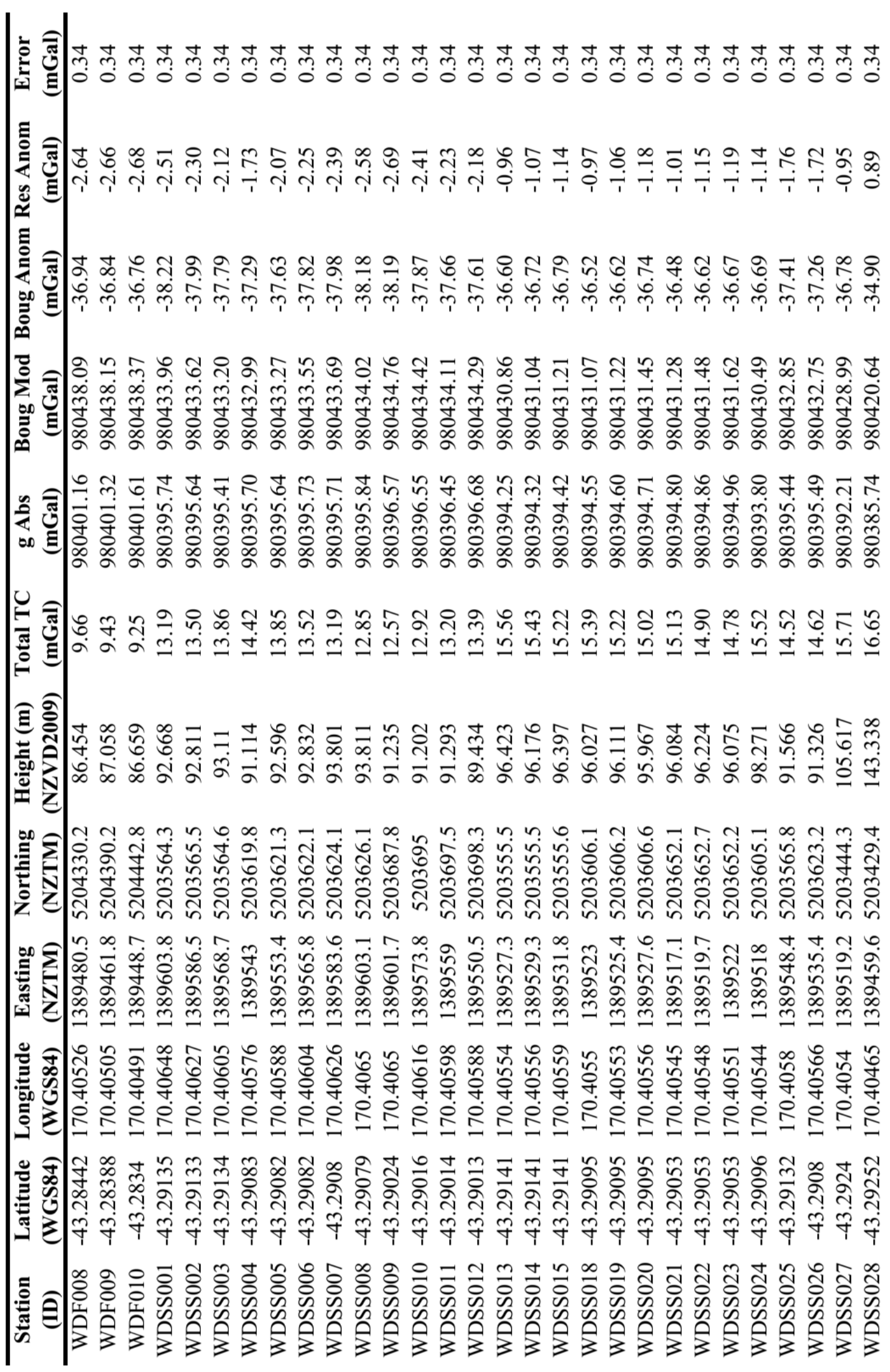

Continued on next page 


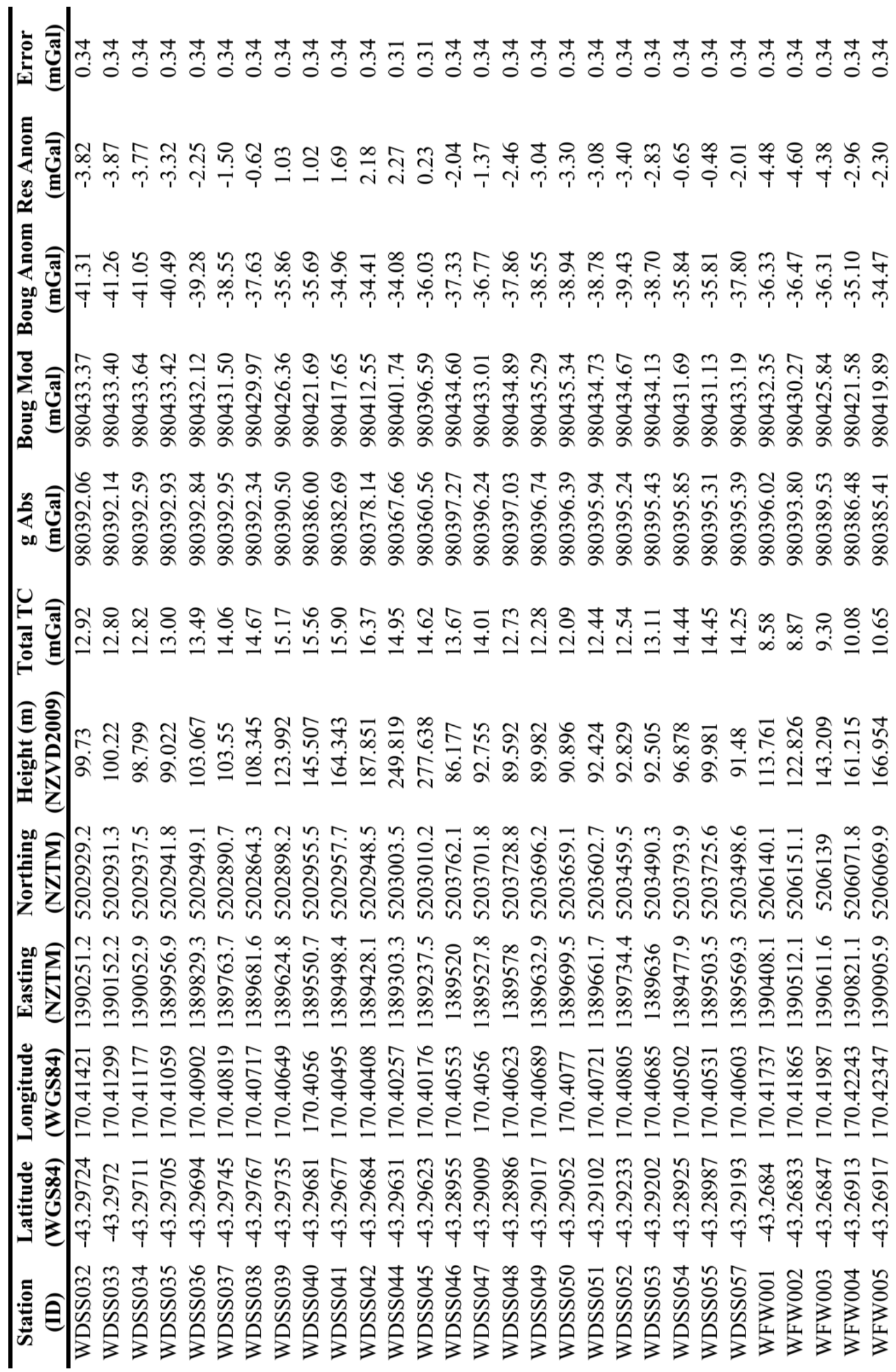

Continued on next page 


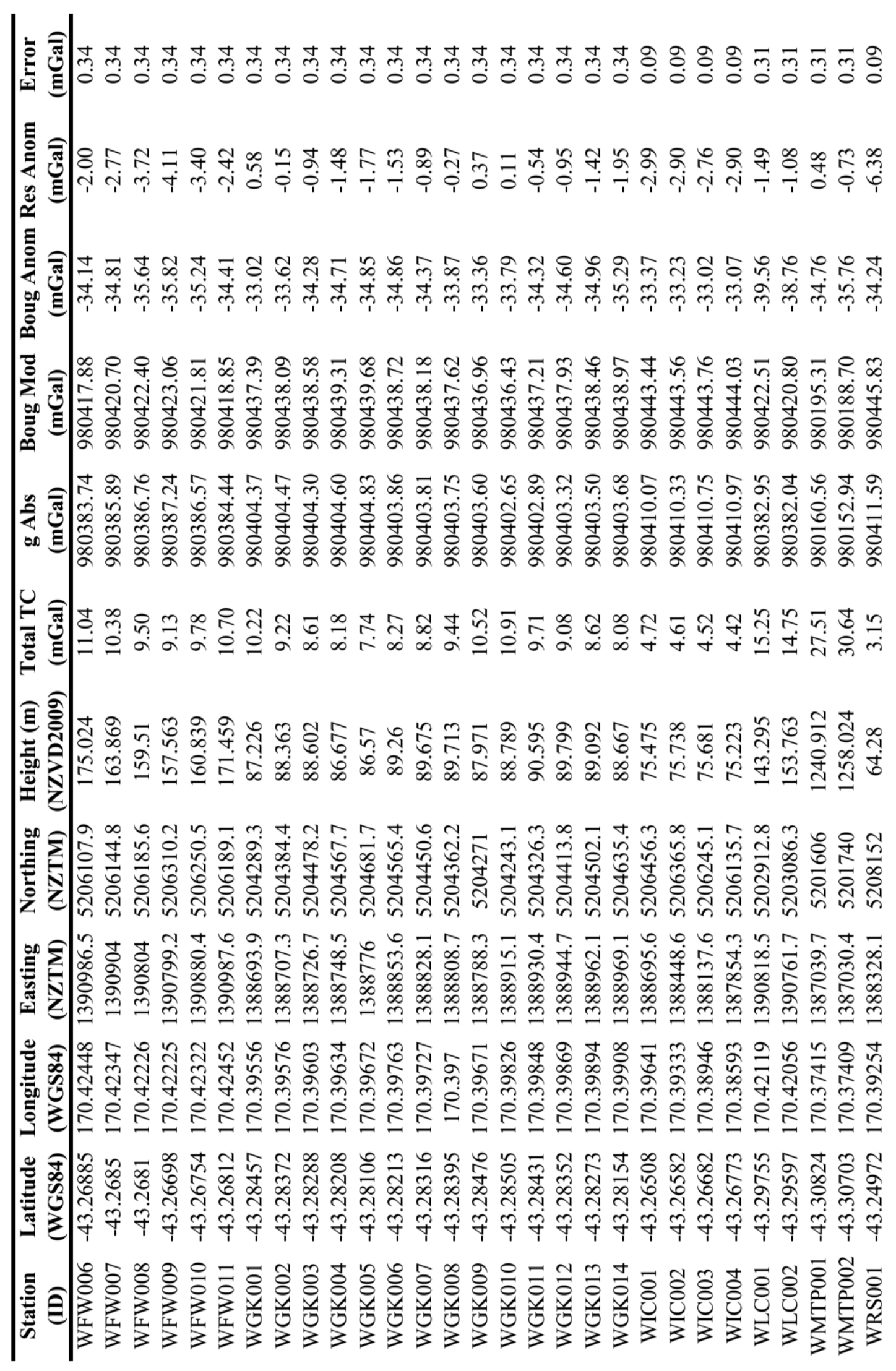

Continued on next page 


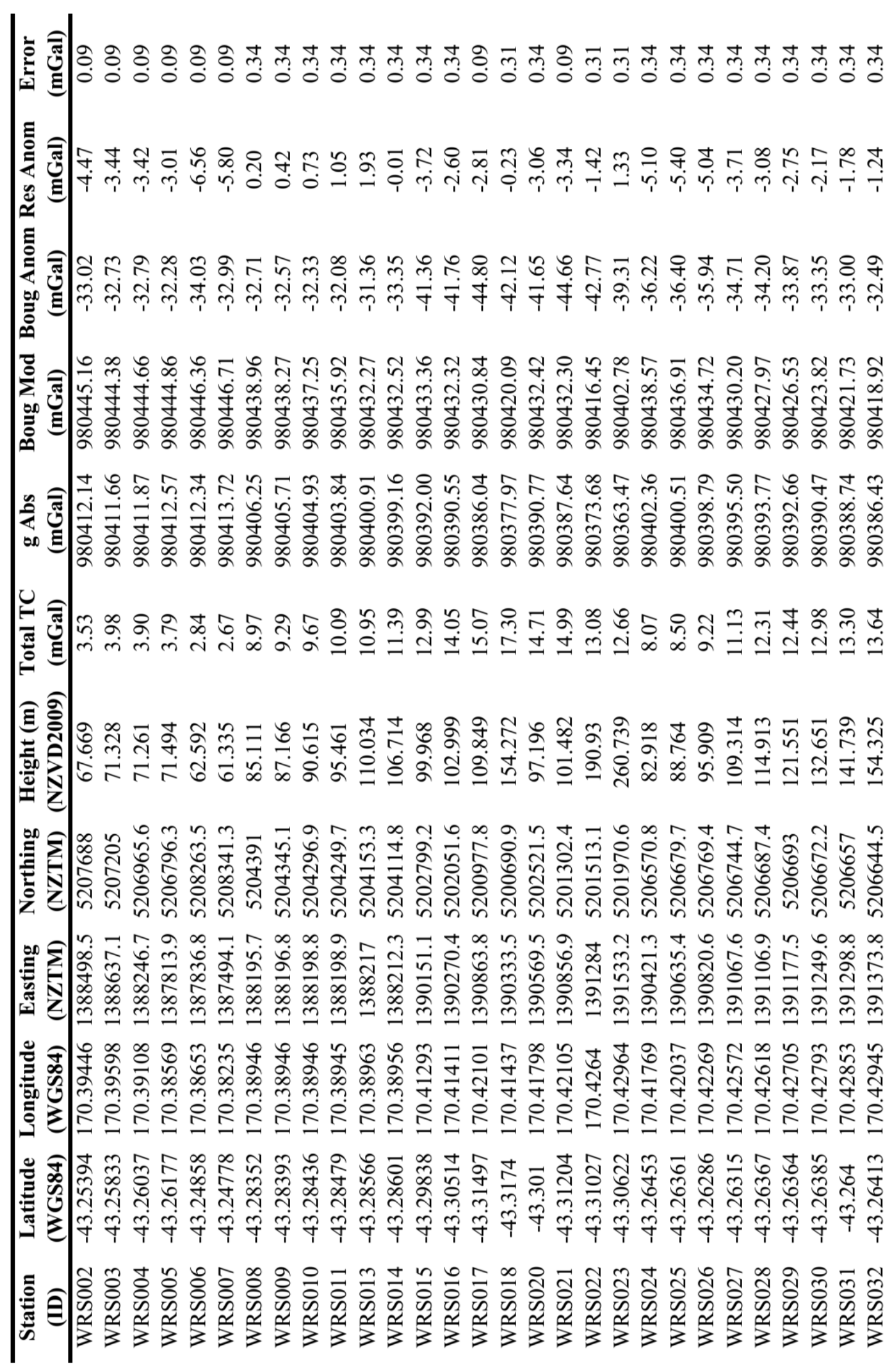

\section{Continued on next page}




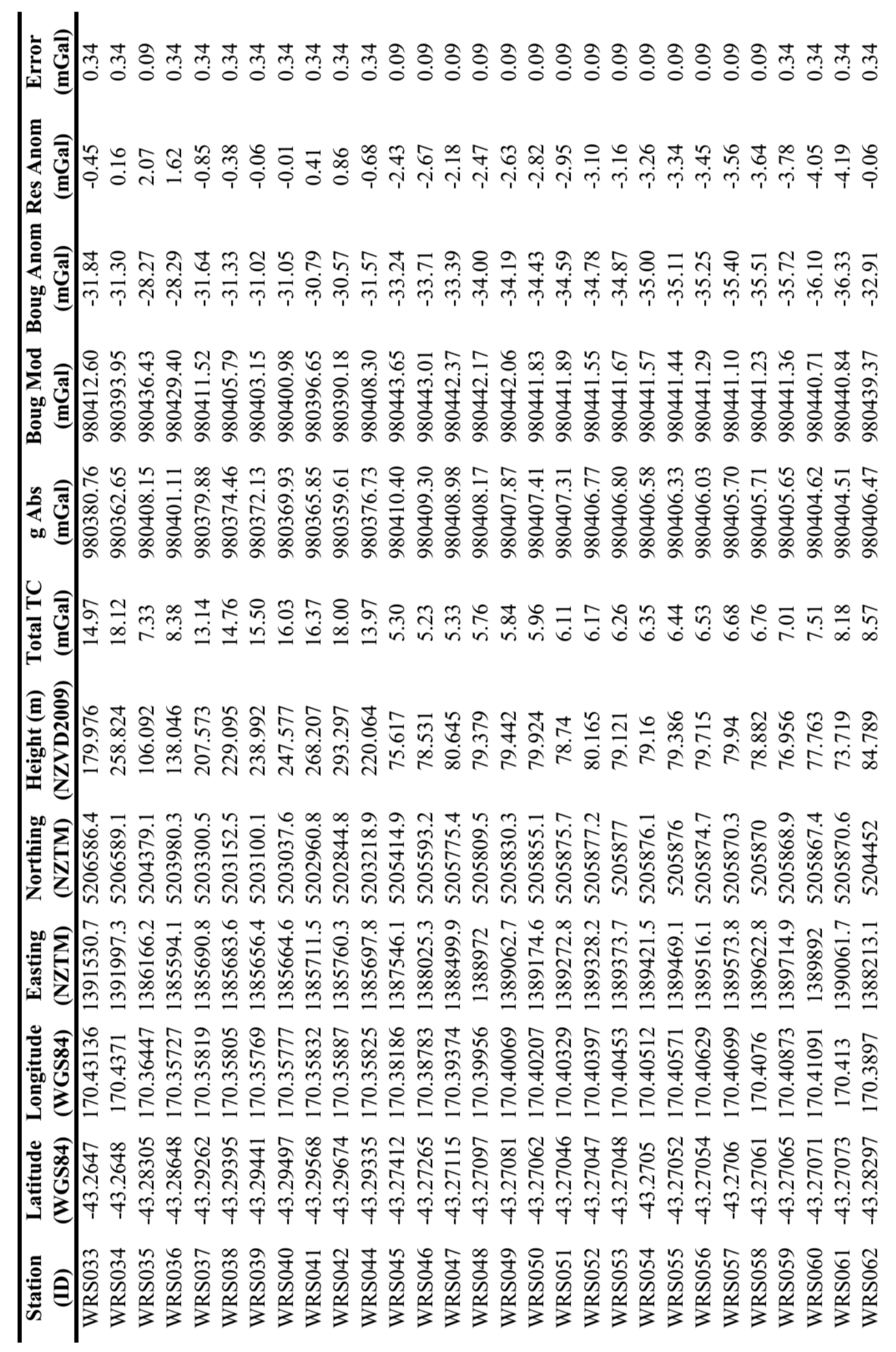

\section{Continued on next page}




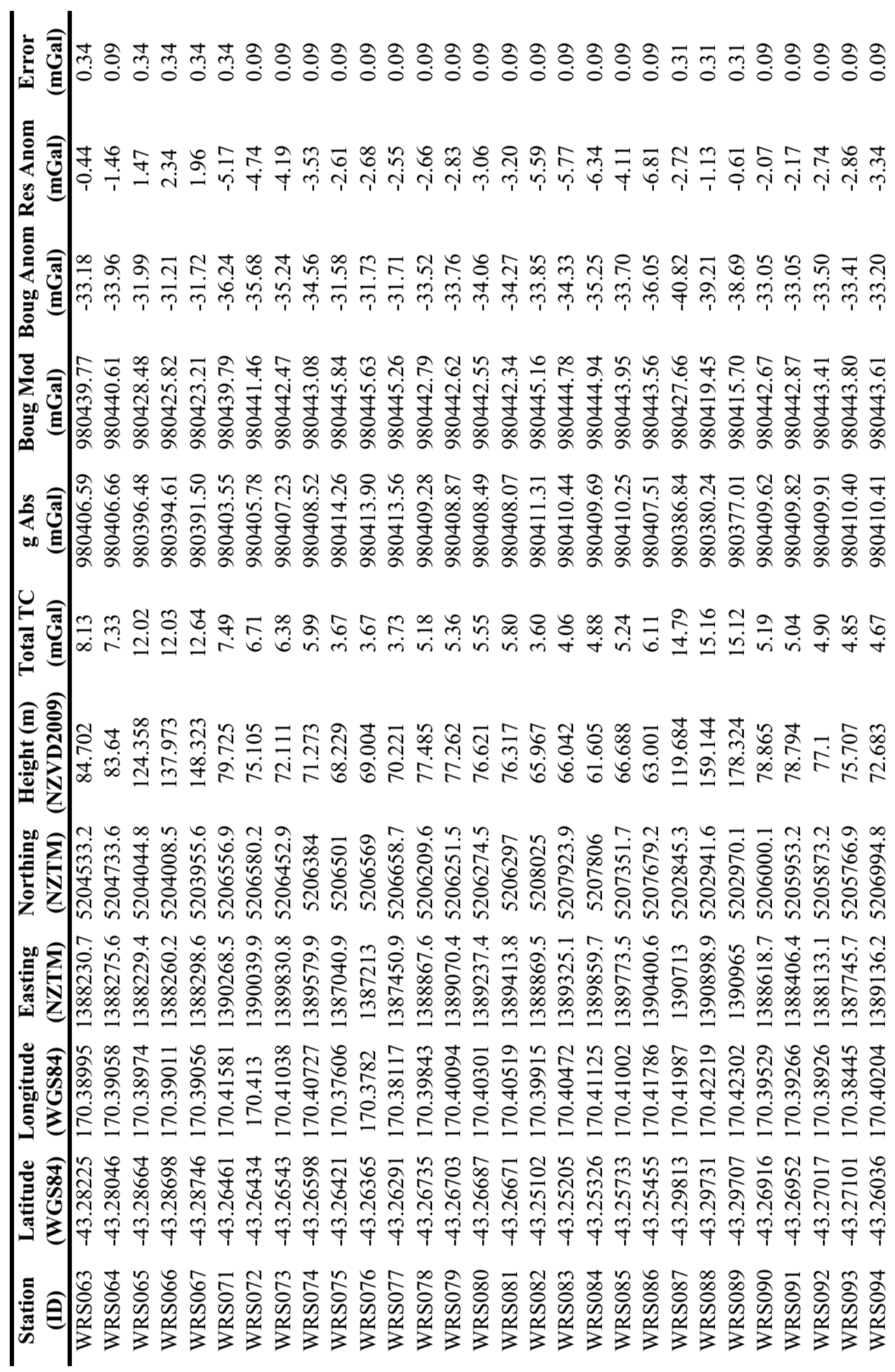

Continued on next page 


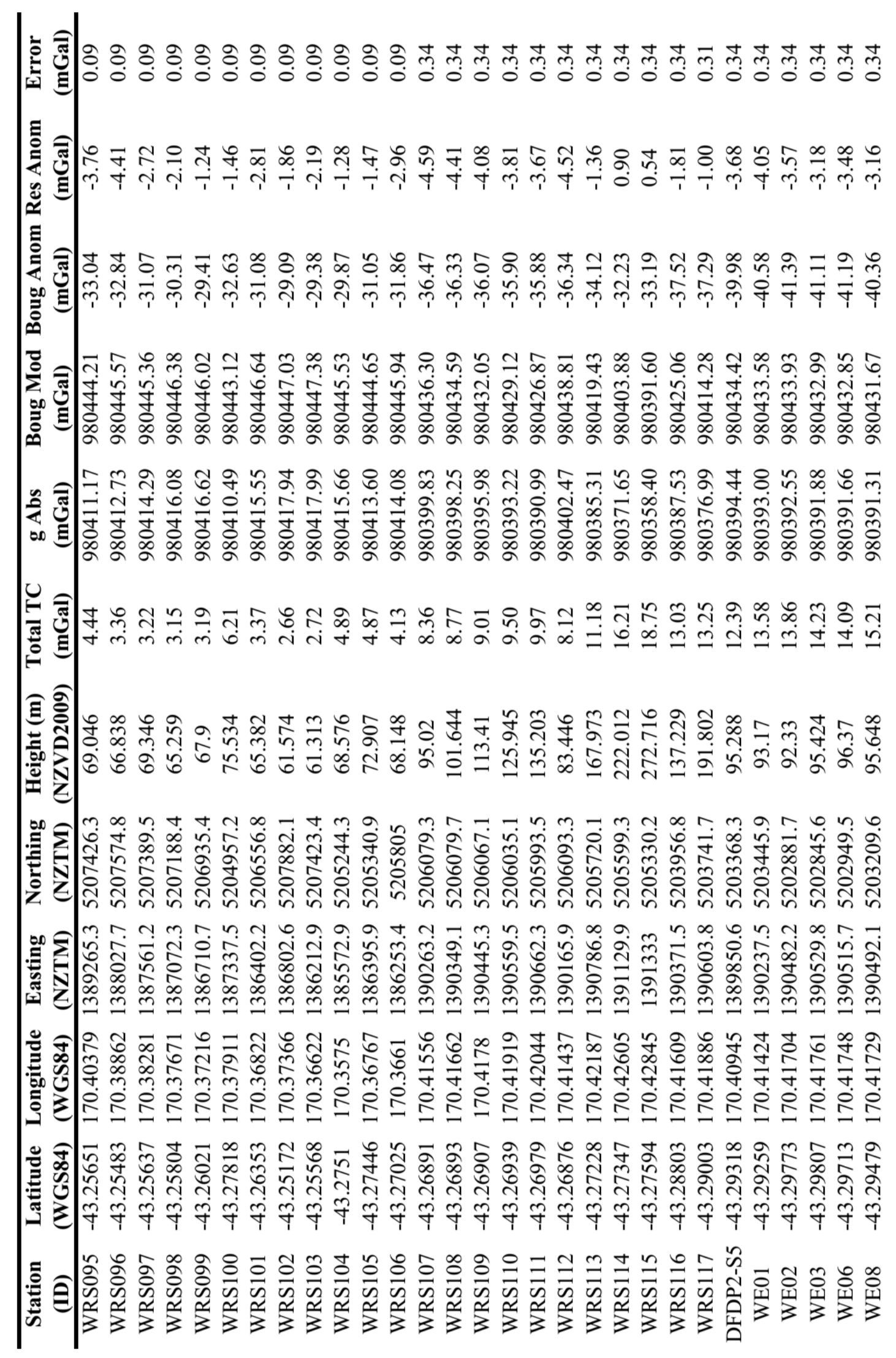

\section{Continued on next page}




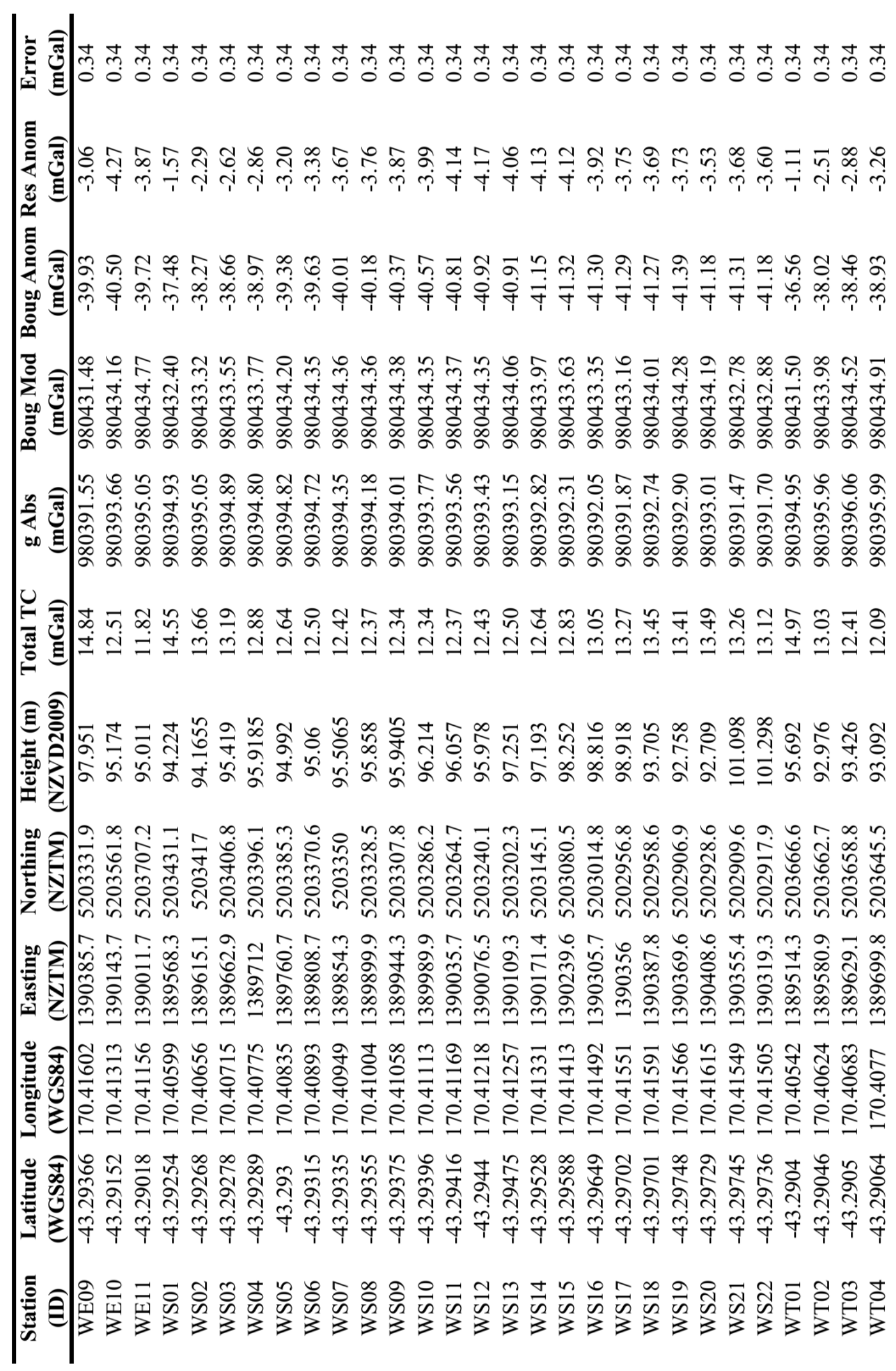

\section{Continued on next page}




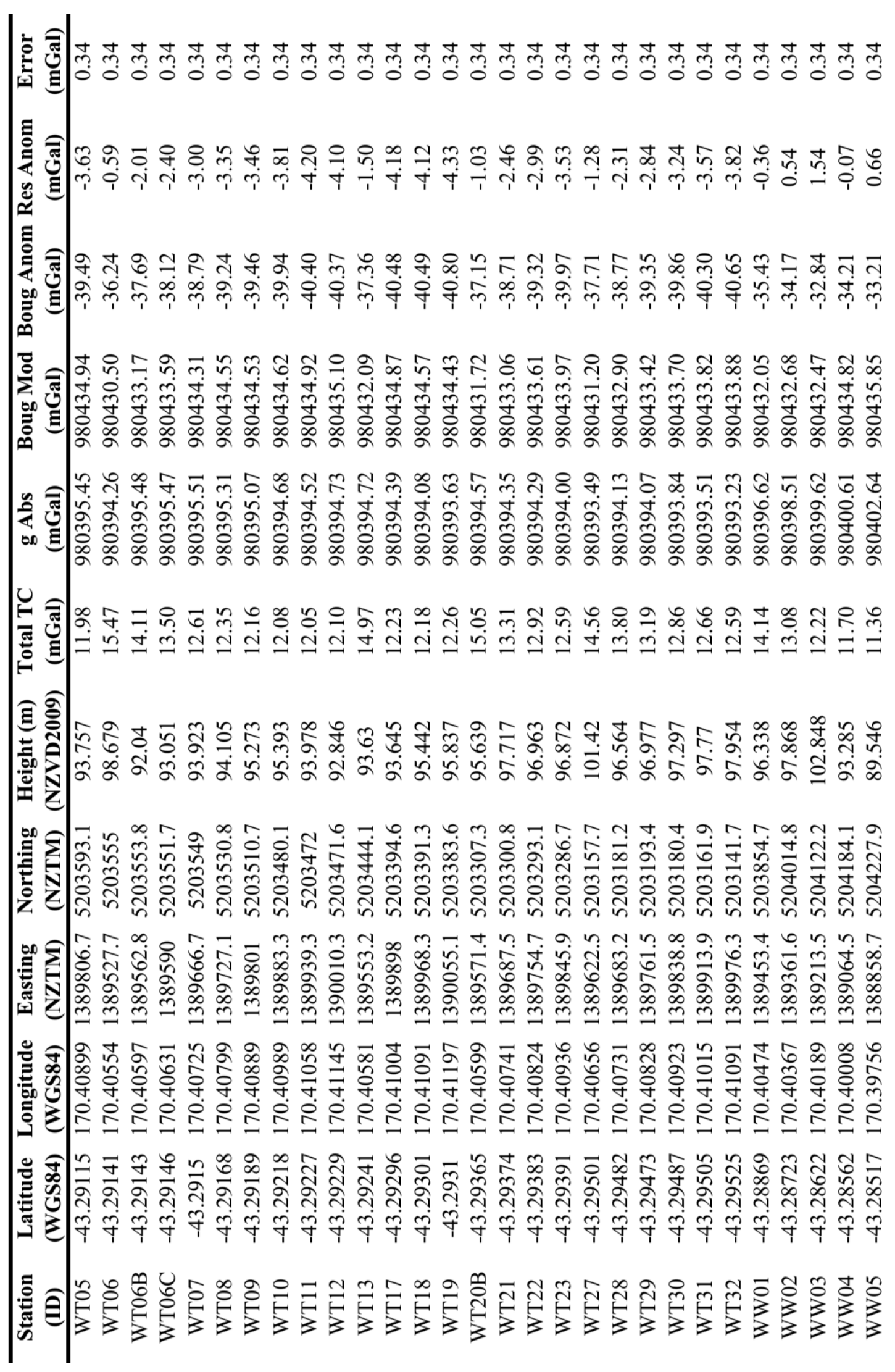

\section{Continued on next page}




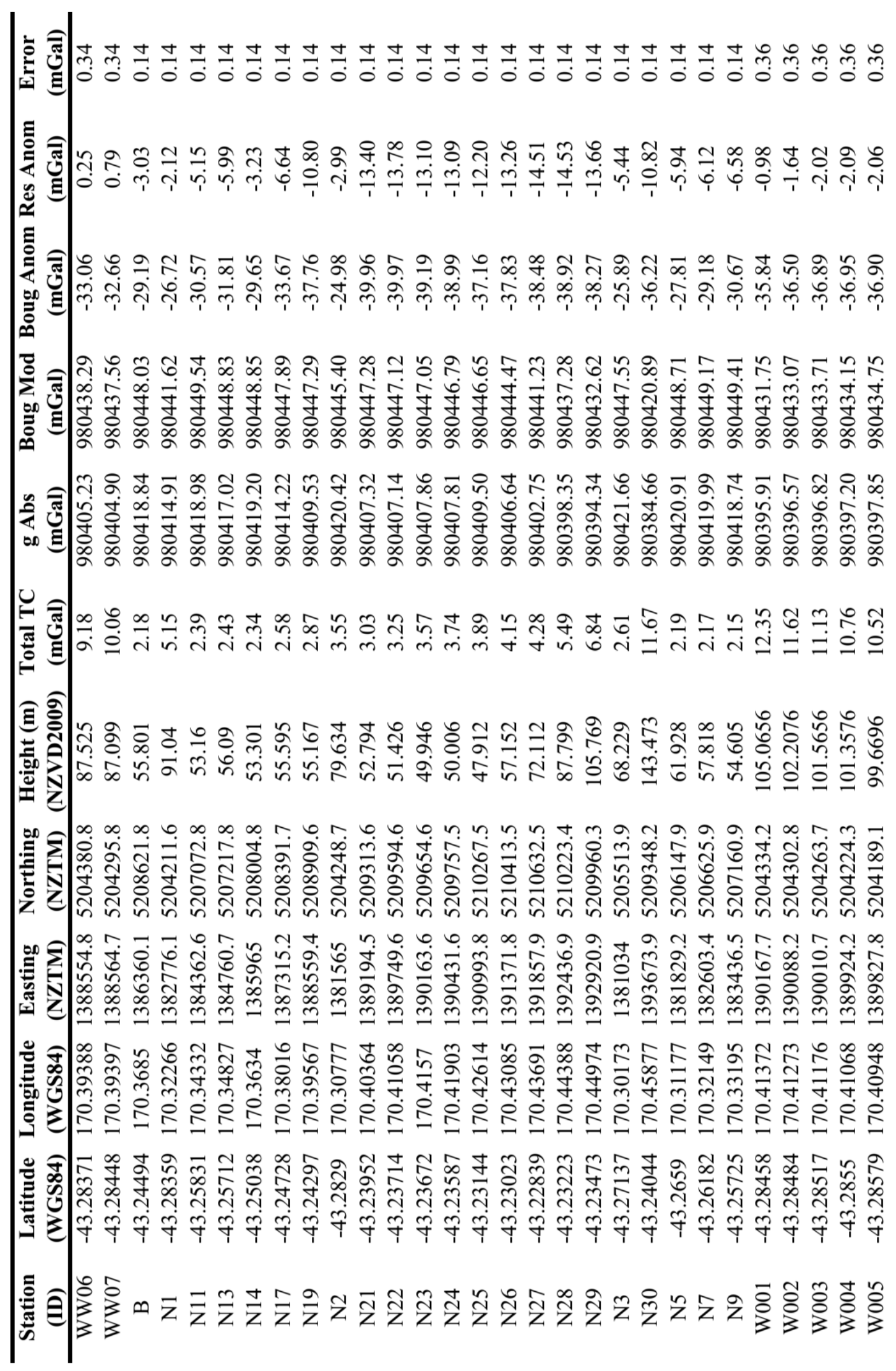

\section{Continued on next page}




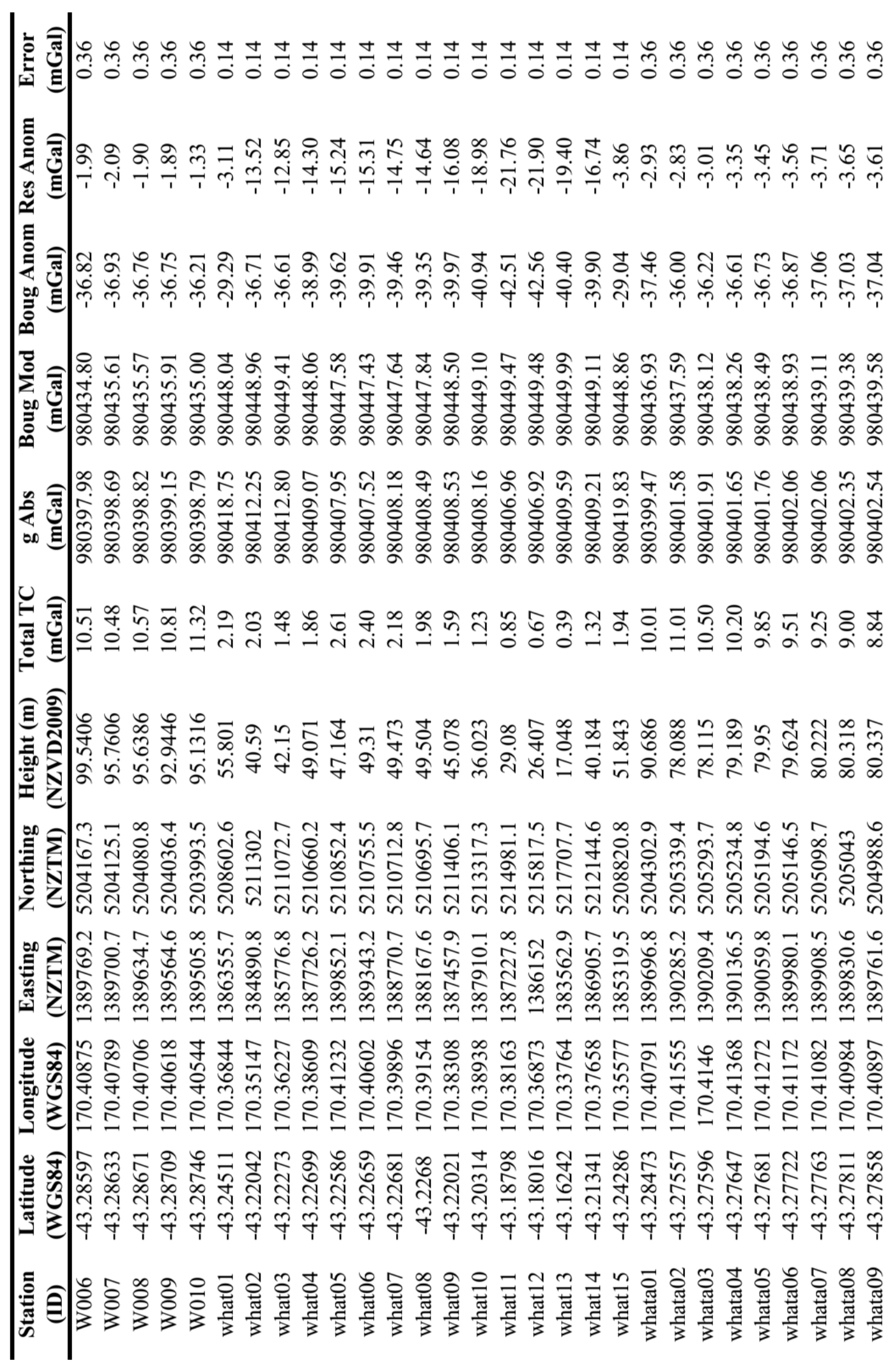

\section{Continued on next page}




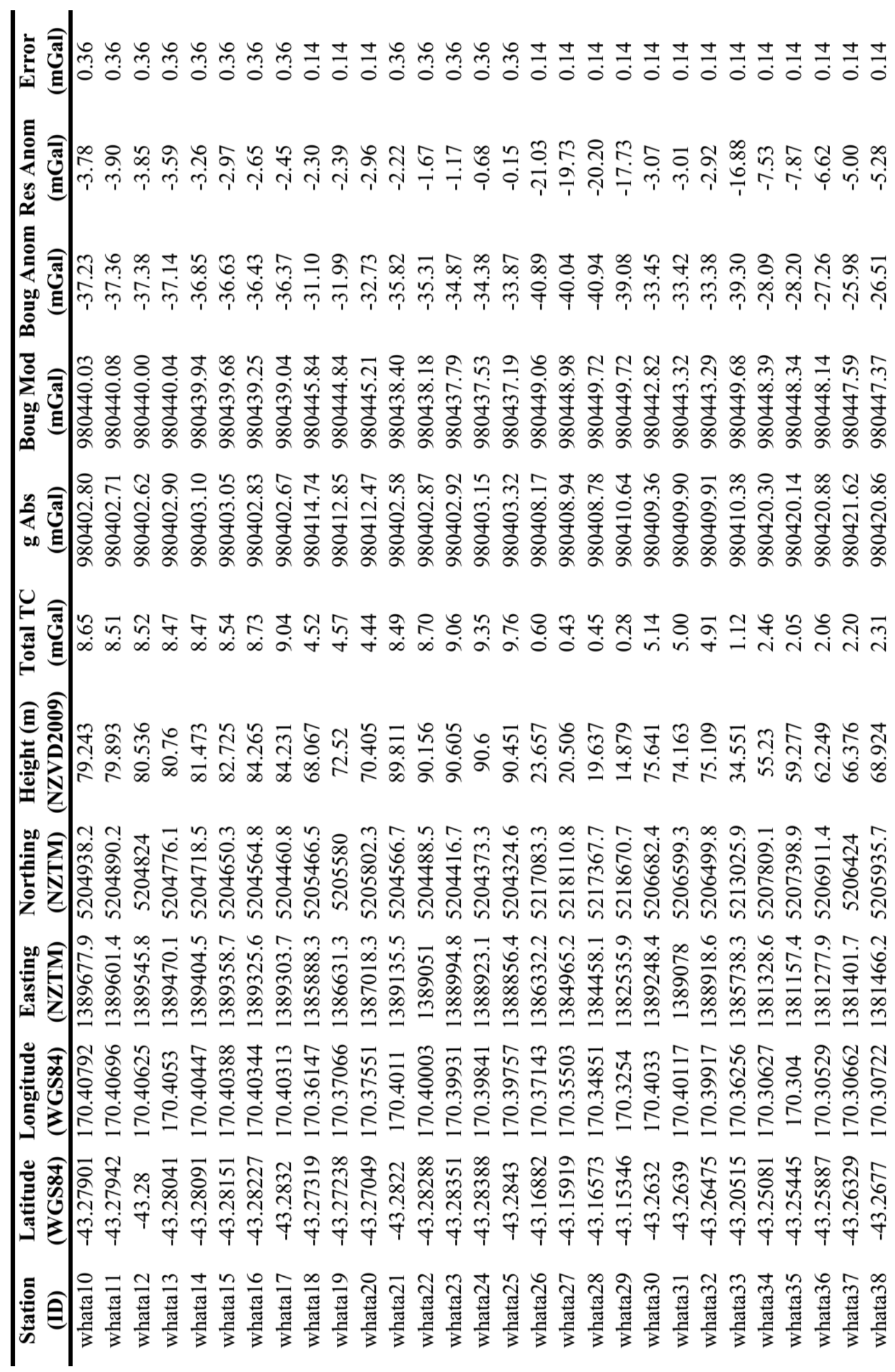

Continued on next page 


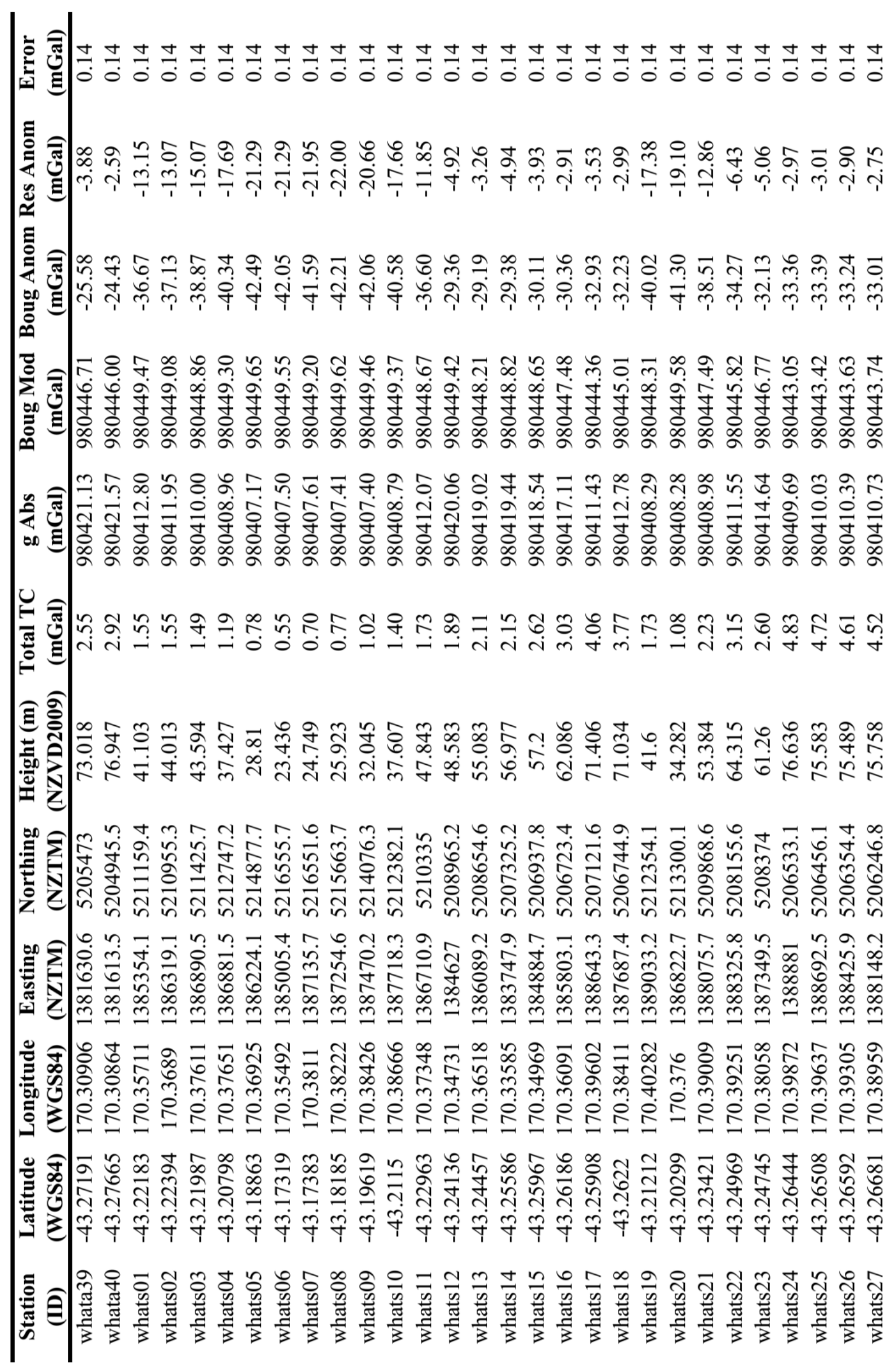

Continued on next page 


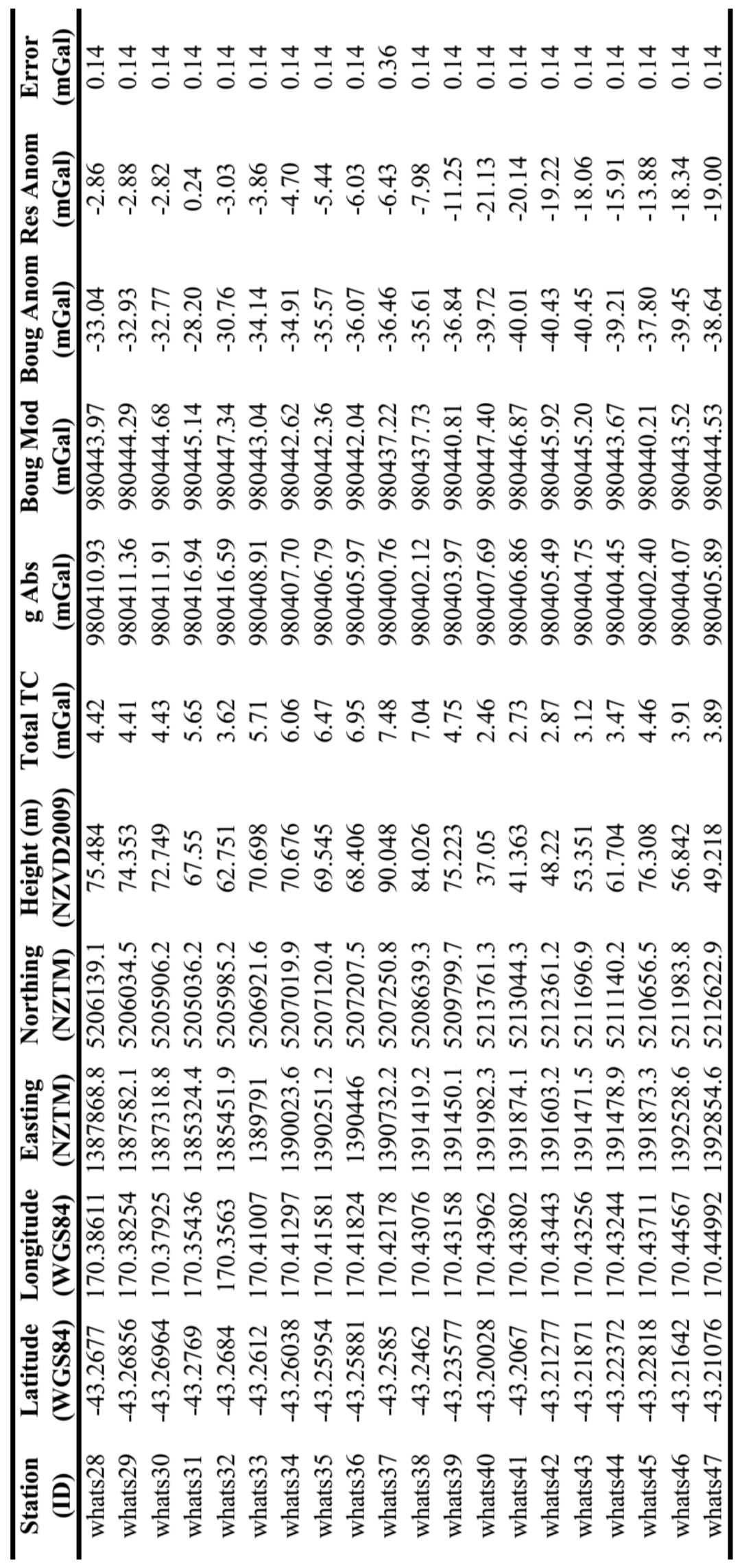

Table C.1: Gravity data collected during this study. 


\section{Appendix D Position survey data}




\begin{tabular}{|c|c|c|c|c|c|}
\hline Station & Latitude & Longitude & Horizontal error (m) & Height (WGS84) & Height error (m \\
\hline WAFS001 & -43.28436465 & 170.3942906 & 0.011 & 99.168 & 0.021 \\
\hline WAFS002 & -43.28398658 & 170.3944353 & 0.009 & 100.036 & 0.017 \\
\hline WAFS003 & -43.28361673 & 170.3945634 & 0.009 & 100.073 & 0.019 \\
\hline WAFS004 & -43.28323558 & 170.3946928 & 0.008 & 100.525 & 0.017 \\
\hline WAFS005 & -43.28286509 & 170.3948253 & 0.009 & 99.982 & 0.018 \\
\hline WAFS006 & -43.28248911 & 170.3949553 & 0.009 & 98.394 & 0.019 \\
\hline WAFS007 & -43.28209974 & 170.3950828 & 0.009 & 100.619 & 0.018 \\
\hline WAFS008 & -43.28172149 & 170.3952173 & 0.009 & 99.78 & 0.017 \\
\hline WAFS009 & -43.28135284 & 170.395341 & 0.008 & 98.667 & 0.015 \\
\hline WAFS010 & -43.28095364 & 170.3954762 & 0.009 & 98.187 & 0.016 \\
\hline WAFS011 & -43.28054678 & 170.3956159 & 0.01 & 98.019 & 0.019 \\
\hline WAFS012 & -43.27974247 & 170.3958934 & 0.01 & 97.757 & 0.016 \\
\hline WAFS013 & -43.27896547 & 170.3962039 & 0.01 & 97.979 & 0.016 \\
\hline WAFS014 & -43.28413846 & 170.3921211 & 0.01 & 101.475 & 0.014 \\
\hline WAFS015 & -43.28034291 & 170.4038486 & 0.01 & 96.774 & 0.01 \\
\hline WAFS016 & -43.27996766 & 170.4034658 & 0.01 & 97.481 & 0.01 \\
\hline WAFS017 & -43.27959447 & 170.4031409 & 0.01 & 97.453 & 0.01 \\
\hline WAFS018 & -43.27924563 & 170.4027859 & 0.01 & 97.447 & 0.01 \\
\hline WAFS019 & -43.27892111 & 170.4024641 & 0.009 & 96.173 & 0.01 \\
\hline WAFS020 & -43.27860715 & 170.4021828 & 0.009 & 96.551 & 0.011 \\
\hline WAFS021 & -43.27824921 & 170.4018783 & 0.009 & 95.01 & 0.011 \\
\hline WAFS022 & -43.27790397 & 170.4015511 & 0.009 & 93.93 & 0.011 \\
\hline WAFS023 & -43.27922401 & 170.4053333 & 0.008 & 96.66 & 0.011 \\
\hline WAFS024 & -43.27884164 & 170.4050202 & 0.008 & 95.643 & 0.011 \\
\hline WAFS025 & -43.278481 & 170.4047485 & 0.008 & 96.486 & 0.011 \\
\hline WAFS026 & -43.27812299 & 170.4043694 & 0.009 & 95.601 & 0.011 \\
\hline WAFS027 & -43.27775944 & 170.4041074 & 0.008 & 94.477 & 0.011 \\
\hline WAFS028 & -43.27740651 & 170.4038202 & 0.008 & 95.68 & 0.011 \\
\hline WAFS029 & -43.27715298 & 170.4034826 & 0.011 & 95.678 & 0.035 \\
\hline WAFS030 & -43.2768545 & 170.4031516 & 0.011 & 93.948 & 0.033 \\
\hline WAFS031 & -43.27650697 & 170.4027806 & 0.012 & 95.948 & 0.033 \\
\hline WAFS 032 & -43.27614521 & 170.4024871 & 0.012 & 94.108 & 0.032 \\
\hline WAFS033 & -43.27588216 & 170.4022854 & 0.012 & 92.675 & 0.031 \\
\hline WAFS034 & -43.27890281 & 170.4076436 & 0.008 & 92.812 & 0.01 \\
\hline WAFS035 & -43.27857783 & 170.4071872 & 0.009 & 95.486 & 0.011 \\
\hline WAFS036 & -43.27819266 & 170.4068338 & 0.009 & 95.424 & 0.011 \\
\hline WAFS037 & -43.27776249 & 170.4065262 & 0.009 & 93.793 & 0.011 \\
\hline WAFS038 & -43.27732648 & 170.4062153 & 0.008 & 94.097 & 0.01 \\
\hline WAFS039 & -43.27695135 & 170.405944 & 0.009 & 93.455 & 0.01 \\
\hline WAFS040 & -43.27660323 & 170.4055331 & 0.01 & 94.647 & 0.011 \\
\hline WAFS041 & -43.27619457 & 170.4051778 & 0.01 & 94.2 & 0.012 \\
\hline WAFS042 & -43.27581249 & 170.4048965 & 0.008 & 93.255 & 0.01 \\
\hline WAFS043 & -43.27543028 & 170.4045345 & 0.008 & 94.418 & 0.01 \\
\hline WAFS044 & -43.27496892 & 170.4041786 & 0.009 & 94.091 & 0.01 \\
\hline
\end{tabular}




\begin{tabular}{|c|c|c|c|c|c|}
\hline Station & Latitude & Longitude & Horizontal error $(\mathbf{m})$ & Height (WGS84) & Height error (m \\
\hline WAFS045 & -43.27433712 & 170.4063284 & 0.008 & 91.735 & 0.012 \\
\hline WAFS046 & -43.27485572 & 170.4067185 & 0.008 & 92.41 & 0.012 \\
\hline WAFS047 & -43.27800334 & 170.4092705 & 0.008 & 91.86 & 0.011 \\
\hline WAFS048 & -43.27754707 & 170.4088168 & 0.009 & 93.907 & 0.011 \\
\hline WAFS049 & -43.27714008 & 170.408513 & 0.008 & 93.579 & 0.011 \\
\hline WAFS050 & -43.27669065 & 170.4082289 & 0.008 & 92.81 & 0.011 \\
\hline WAFS051 & -43.27628852 & 170.4079218 & 0.008 & 92.91 & 0.011 \\
\hline WAFS052 & -43.27584699 & 170.4076671 & 0.008 & 93.667 & 0.01 \\
\hline WAFS053 & -43.27523865 & 170.4070946 & 0.008 & 93.354 & 0.011 \\
\hline WAFS054 & -43.27500827 & 170.4091084 & 0.009 & 91.948 & 0.009 \\
\hline WAFS055 & -43.27547113 & 170.4093408 & 0.008 & 90.552 & 0.008 \\
\hline WAFS056 & -43.27599908 & 170.4098265 & 0.009 & 92.079 & 0.009 \\
\hline WAFS057 & -43.27637896 & 170.4103231 & 0.009 & 91.969 & 0.009 \\
\hline WAFS058 & -43.27673452 & 170.4106855 & 0.008 & 91.939 & 0.008 \\
\hline WAFS059 & -43.27610655 & 170.411534 & 0.008 & 91.391 & 0.009 \\
\hline WDSS001 & -43.29135226 & 170.4064836 & 0.015 & 105.196 & 0.032 \\
\hline WDSS002 & -43.29133599 & 170.4062711 & 0.015 & 105.339 & 0.031 \\
\hline WDSS003 & -43.29133927 & 170.406051 & 0.014 & 105.638 & 0.029 \\
\hline WDSS004 & -43.2908354 & 170.4057563 & 0.014 & 103.642 & 0.028 \\
\hline WDSS005 & -43.29082486 & 170.4058851 & 0.013 & 105.124 & 0.026 \\
\hline WDSS006 & -43.29082096 & 170.4060375 & 0.013 & 105.36 & 0.026 \\
\hline WDSS007 & -43.29080843 & 170.4062576 & 0.013 & 106.329 & 0.025 \\
\hline WDSS008 & -43.29079589 & 170.4064986 & 0.013 & 106.339 & 0.024 \\
\hline WDSS009 & -43.29024005 & 170.4065046 & 0.012 & 103.763 & 0.023 \\
\hline WDSS010 & -43.29016777 & 170.4061637 & 0.011 & 103.73 & 0.021 \\
\hline WDSS011 & -43.29014151 & 170.4059826 & 0.012 & 103.821 & 0.022 \\
\hline WDSS012 & -43.29013168 & 170.4058785 & 0.011 & 101.962 & 0.019 \\
\hline WDSS013 & -43.29140928 & 170.4055381 & 0.028 & 108.951 & 0.028 \\
\hline WDSS014 & -43.29141036 & 170.4055623 & 0.03 & 108.704 & 0.039 \\
\hline WDSS015 & -43.29141025 & 170.405593 & 0.022 & 108.925 & 0.029 \\
\hline WDSS018 & -43.2909535 & 170.4055048 & 0.012 & 108.555 & 0.017 \\
\hline WDSS019 & -43.29095275 & 170.4055337 & 0.012 & 108.639 & 0.017 \\
\hline WDSS020 & -43.2909501 & 170.4055618 & 0.012 & 108.495 & 0.016 \\
\hline WDSS021 & -43.29053825 & 170.4054494 & 0.025 & 108.612 & 0.027 \\
\hline WDSS022 & -43.2905336 & 170.4054818 & 0.014 & 108.752 & 0.02 \\
\hline WDSS023 & -43.29053831 & 170.4055104 & 0.015 & 108.603 & 0.021 \\
\hline WDSS025 & -43.29132311 & 170.4058016 & 0.011 & 104.094 & 0.015 \\
\hline WDSS026 & -43.2908028 & 170.4056633 & 0.033 & 103.854 & 0.024 \\
\hline WRS001 & -43.24972661 & 170.3925371 & 0.01 & 76.562 & 0.012 \\
\hline WRS002 & -43.25394783 & 170.3944565 & 0.008 & 79.951 & 0.009 \\
\hline WRS003 & -43.258332 & 170.3959767 & 0.008 & 83.61 & 0.009 \\
\hline WRS004 & -43.26037544 & 170.39108 & 0.008 & 83.57 & 0.009 \\
\hline WRS005 & -43.26177654 & 170.3856879 & 0.009 & 83.803 & 0.013 \\
\hline WRS006 & -43.24858516 & 170.3865344 & 0.01 & 74.786 & 0.013 \\
\hline
\end{tabular}




\begin{tabular}{|c|c|c|c|c|c|}
\hline Station & Latitude & Longitude & Horizontal error (m) & Height (WGS84) & Height error ( \\
\hline WRS007 & -43.24778881 & 170.382347 & 0.009 & 73.529 & 0.01 \\
\hline WRS008 & -43.28352038 & 170.3894622 & 0.01 & 97.557 & 0.013 \\
\hline WRS009 & -43.28393393 & 170.3894582 & 0.009 & 99.612 & 0.01 \\
\hline WRS010 & -43.28436769 & 170.3894643 & 0.008 & 103.061 & 0.009 \\
\hline WRS011 & -43.28479289 & 170.3894473 & 0.007 & 107.907 & 0.008 \\
\hline WRS015 & -43.29838667 & 170.4129309 & 0.003 & 112.701 & 0.007 \\
\hline WRS016 & -43.30514504 & 170.4141158 & 0.006 & 115.732 & 0.008 \\
\hline WRS017 & -43.31497005 & 170.4210156 & 0.009 & 122.694 & 0.014 \\
\hline WRS018 & -43.31740264 & 170.4143738 & 0.017 & 167.117 & 0.021 \\
\hline WRS020 & -43.30100185 & 170.4179781 & 0.014 & 109.929 & 0.023 \\
\hline WRS021 & -43.31204757 & 170.421054 & 0.012 & 114.327 & 0.025 \\
\hline WRS022 & -43.31027141 & 170.4263961 & 0.026 & 203.858 & 0.038 \\
\hline WRS023 & -43.30622447 & 170.4296392 & 0.011 & 273.6 & 0.033 \\
\hline WRS024 & -43.26453518 & 170.4176956 & 0.013 & 95.424 & 0.018 \\
\hline WRS025 & -43.26361504 & 170.4203725 & 0.013 & 101.27 & 0.021 \\
\hline WRS026 & -43.26285962 & 170.4226863 & 0.02 & 108.415 & 0.035 \\
\hline WRS027 & -43.26314992 & 170.4257165 & 0.016 & 121.961 & 0.032 \\
\hline WRS028 & -43.26367639 & 170.4261787 & 0.015 & 127.56 & 0.043 \\
\hline WRS029 & -43.26364557 & 170.4270494 & 0.025 & 134.198 & 0.055 \\
\hline WRS030 & -43.26385272 & 170.4279301 & 0.02 & 145.298 & 0.038 \\
\hline WRS031 & -43.26400325 & 170.4285291 & 0.016 & 154.386 & 0.025 \\
\hline WRS032 & -43.26413611 & 170.4294477 & 0.017 & 166.972 & 0.037 \\
\hline WRS033 & -43.26470222 & 170.4313568 & 0.034 & 192.623 & 0.093 \\
\hline WRS034 & -43.26480683 & 170.4371021 & 0.024 & 271.471 & 0.033 \\
\hline WRS035 & -43.28305393 & 170.3644693 & 0.009 & 118.461 & 0.016 \\
\hline WRS036 & -43.28647932 & 170.3572698 & 0.009 & 150.345 & 0.016 \\
\hline WRS037 & -43.29262139 & 170.3581958 & 0.01 & 220.036 & 0.032 \\
\hline WRS038 & -43.29395095 & 170.3580497 & 0.029 & 241.558 & 0.069 \\
\hline WRS039 & -43.29441421 & 170.3576942 & 0.04 & 251.455 & 0.035 \\
\hline WRS040 & -43.29497832 & 170.3577704 & 0.02 & 260.04 & 0.046 \\
\hline WRS041 & -43.29568242 & 170.3583184 & 0.015 & 280.67 & 0.021 \\
\hline WRS042 & -43.29674024 & 170.3588735 & 0.064 & 305.843 & 0.137 \\
\hline WRS044 & -43.29335702 & 170.3582504 & 1.1 & 232.527 & 0.266 \\
\hline WRS045 & -43.27412766 & 170.3818591 & 0.015 & 87.926 & 0.023 \\
\hline WRS046 & -43.27265855 & 170.3878264 & 0.015 & 90.84 & 0.025 \\
\hline WRS047 & -43.27115299 & 170.3937389 & 0.015 & 93.045 & 0.023 \\
\hline WRS048 & -43.27097823 & 170.3995636 & 0.009 & 91.779 & 0.013 \\
\hline WRS049 & -43.27081698 & 170.4006883 & 0.009 & 91.842 & 0.013 \\
\hline WRS050 & -43.27062479 & 170.4020752 & 0.009 & 92.324 & 0.015 \\
\hline WRS051 & -43.27046702 & 170.4032929 & 0.009 & 91.14 & 0.016 \\
\hline WRS052 & -43.27046961 & 170.4039748 & 0.01 & 92.565 & 0.02 \\
\hline WRS053 & -43.27048345 & 170.4045347 & 0.008 & 91.521 & 0.017 \\
\hline WRS054 & -43.27050514 & 170.4051235 & 0.008 & 91.56 & 0.017 \\
\hline WRS055 & -43.27051928 & 170.4057087 & 0.01 & 91.786 & 0.019 \\
\hline
\end{tabular}




\begin{tabular}{|c|c|c|c|c|c|}
\hline Station & Latitude & Longitude & Horizontal error (m) & Height (WGS84) & Height error (m) \\
\hline WRS056 & -43.2705445 & 170.4062877 & 0.008 & 92.115 & 0.014 \\
\hline WRS057 & -43.27059983 & 170.4069958 & 0.008 & 92.34 & 0.014 \\
\hline WRS058 & -43.27061683 & 170.4075983 & 0.011 & 91.282 & 0.019 \\
\hline WRS059 & -43.27065206 & 170.4087319 & 0.012 & 89.462 & 0.019 \\
\hline WRS060 & -43.27071492 & 170.4109123 & 0.011 & 90.269 & 0.017 \\
\hline WRS061 & -43.27073355 & 170.4130015 & 0.022 & 86.225 & 0.034 \\
\hline WRS062 & -43.28297665 & 170.3897002 & 0.008 & 97.235 & 0.013 \\
\hline WRS063 & -43.28225159 & 170.3899473 & 0.009 & 97.148 & 0.013 \\
\hline WRS064 & -43.28046108 & 170.3905778 & 0.018 & 96.086 & 0.025 \\
\hline WAD001 & -43.28881498 & 170.4606411 & 0.009 & 1462.65 & 0.015 \\
\hline WAD002 & -43.28950085 & 170.4603303 & 0.009 & 1451.7 & 0.015 \\
\hline WDF001 & -43.28477034 & 170.406673 & 0.014 & 101.576 & 0.022 \\
\hline WDF002 & -43.28382751 & 170.4060426 & 0.012 & 101.235 & 0.017 \\
\hline WDF003 & -43.28285341 & 170.4054785 & 0.012 & 99.949 & 0.016 \\
\hline WDF004 & -43.28309275 & 170.4041181 & 0.013 & 98.086 & 0.016 \\
\hline WDF005 & -43.28391653 & 170.4043699 & 0.012 & 99.074 & 0.015 \\
\hline WDF006 & -43.28484416 & 170.404813 & 0.014 & 98.747 & 0.016 \\
\hline WDF007 & -43.28483707 & 170.4054118 & 0.012 & 99.955 & 0.015 \\
\hline WDF008 & -43.28442381 & 170.4052567 & 0.012 & 99.077 & 0.015 \\
\hline WDF009 & -43.28387921 & 170.4050497 & 0.011 & 99.681 & 0.014 \\
\hline WDF010 & -43.28340168 & 170.4049086 & 0.01 & 99.282 & 0.015 \\
\hline WFW001 & -43.26840127 & 170.4173683 & 0.007 & 126.362 & 0.016 \\
\hline WFW002 & -43.26833151 & 170.4186518 & 0.004 & 135.427 & 0.011 \\
\hline WFW003 & -43.26846822 & 170.419873 & 0.014 & 155.81 & 0.018 \\
\hline WFW004 & -43.26913057 & 170.4224262 & 0.011 & 173.816 & 0.013 \\
\hline WFW005 & -43.26917179 & 170.4234693 & 0.01 & 179.555 & 0.012 \\
\hline WFW006 & -43.26885205 & 170.4244763 & 0.011 & 187.625 & 0.013 \\
\hline WFW007 & -43.26849691 & 170.4234739 & 0.01 & 176.47 & 0.013 \\
\hline WFW008 & -43.26810248 & 170.4222582 & 0.01 & 172.111 & 0.012 \\
\hline WFW009 & -43.26697978 & 170.4222468 & 0.01 & 170.164 & 0.012 \\
\hline WFW010 & -43.2675395 & 170.4232242 & 0.01 & 173.44 & 0.014 \\
\hline WFW011 & -43.26812138 & 170.4245197 & 0.009 & 184.06 & 0.014 \\
\hline WGK001 & -43.28457184 & 170.3955563 & 0.017 & 99.849 & 0.057 \\
\hline WGK002 & -43.28372013 & 170.3957579 & 0.016 & 100.986 & 0.049 \\
\hline WGK003 & -43.28288112 & 170.3960323 & 0.015 & 101.225 & 0.029 \\
\hline WGK004 & -43.28208217 & 170.3963355 & 0.014 & 99.3 & 0.021 \\
\hline WGK005 & -43.28106449 & 170.3967178 & 0.013 & 99.193 & 0.017 \\
\hline WGK006 & -43.28213272 & 170.3976281 & 0.013 & 101.883 & 0.018 \\
\hline WGK007 & -43.28315794 & 170.3972702 & 0.013 & 102.298 & 0.016 \\
\hline WGK008 & -43.28394831 & 170.3969979 & 0.013 & 102.336 & 0.015 \\
\hline WGK009 & -43.28476268 & 170.3967114 & 0.01 & 100.594 & 0.014 \\
\hline WGK010 & -43.28504909 & 170.3982625 & 0.01 & 101.412 & 0.014 \\
\hline WGK011 & -43.28430511 & 170.3984828 & 0.01 & 103.218 & 0.014 \\
\hline WGK012 & -43.28352167 & 170.3986918 & 0.009 & 102.422 & 0.012 \\
\hline
\end{tabular}




\begin{tabular}{|c|c|c|c|c|c|}
\hline Station & Latitude & Longitude & Horizontal error (m) & Height (WGS84) & Height error (m) \\
\hline WGK013 & -43.28273246 & 170.3989398 & 0.009 & 101.715 & 0.013 \\
\hline WGK014 & -43.28153521 & 170.3990776 & 0.016 & 101.29 & 0.017 \\
\hline WIC001 & -43.26507893 & 170.3964086 & 0.008 & 87.97 & 0.01 \\
\hline WIC002 & -43.26582389 & 170.3933337 & 0.008 & 88.233 & 0.01 \\
\hline WIC003 & -43.26682229 & 170.3894592 & 0.008 & 88.085 & 0.011 \\
\hline WIC004 & -43.26772664 & 170.3859302 & 0.008 & 87.627 & 0.012 \\
\hline WLC001 & -43.29754669 & 170.4211937 & 0.033 & 156.123 & 0.051 \\
\hline WLC002 & -43.29597068 & 170.42056 & 0.052 & 166.591 & 0.067 \\
\hline WMTP001 & -43.30824237 & 170.3741494 & 0.008 & 1253.553 & 0.012 \\
\hline WMTP002 & -43.30703421 & 170.3740868 & 0.009 & 1270.665 & 0.013 \\
\hline WRS087 & -43.29812511 & 170.4198685 & 0.019 & 132.512 & 0.022 \\
\hline WRS088 & -43.29731024 & 170.4221941 & 0.14 & 171.972 & 0.111 \\
\hline WRS089 & -43.29707211 & 170.4230194 & 1.033 & 191.152 & 0.968 \\
\hline SA86 & -43.26582325 & 170.3751545 & 0.3 & 81.802 & 0.4 \\
\hline SA80 & -43.27746724 & 170.4172908 & 0.5 & 110.468 & 0.5 \\
\hline WAFS060 & -43.28565865 & 170.400857 & 0.1 & 101.674 & 0.5 \\
\hline WAFS061 & -43.28558135 & 170.4018621 & 0.3 & 105.084 & 0.9 \\
\hline WAFS062 & -43.2845767 & 170.4009778 & 0.5 & 104.601 & 1.7 \\
\hline WAFS063 & -43.28377299 & 170.4010806 & 0.6 & 106.085 & 1.5 \\
\hline WAFS064 & -43.28287568 & 170.4011644 & 0.2 & 104.194 & 0.6 \\
\hline WAFS065 & -43.28188868 & 170.4010908 & 0.3 & 105.436 & 1.3 \\
\hline WAFS066 & -43.28117762 & 170.4007645 & 0.3 & 101.034 & 1.2 \\
\hline WAFS067 & -43.28022585 & 170.4005387 & 0.2 & 100.301 & 0.8 \\
\hline WAFS068 & -43.27945445 & 170.4005743 & 0.1 & 100.229 & 0.4 \\
\hline WAFS069 & -43.27852216 & 170.4005898 & 0.2 & 100.585 & 0.5 \\
\hline WAFS070 & -43.28498757 & 170.4009357 & 0.5 & 104.24 & 1.9 \\
\hline WAFS071 & -43.28418245 & 170.401034 & 0.5 & 104.213 & 0.6 \\
\hline WAFS072 & -43.27761828 & 170.4007164 & 0.1 & 98.875 & 0.3 \\
\hline WAFS073 & -43.27667864 & 170.4004114 & 0.3 & 97.965 & 0.5 \\
\hline WAFS074 & -43.27585481 & 170.4008369 & 0.5 & 98.387 & 1.1 \\
\hline WAFS075 & -43.27522108 & 170.4016689 & 0.2 & 96.122 & 0.6 \\
\hline WAFS076 & -43.2732394 & 170.4003685 & 0.2 & 90.692 & 0.5 \\
\hline WAFS077 & -43.2725768 & 170.4029273 & 0.1 & 95.191 & 0.4 \\
\hline WAFS078 & -43.27217927 & 170.4049754 & 0.1 & 92.32 & 0.2 \\
\hline WAFS079 & -43.27246936 & 170.4068699 & 0.1 & 93.7 & 0.3 \\
\hline WAFS080 & -43.27262824 & 170.40905 & 0.1 & 91.936 & 0.2 \\
\hline WAFS081 & -43.27276462 & 170.4117509 & 0.1 & 89.83 & 0.2 \\
\hline WAFS082 & -43.27269953 & 170.4153768 & 0.1 & 89.302 & 0.1 \\
\hline WAFS083 & -43.27409557 & 170.4035658 & 0.1 & 97.231 & 0.3 \\
\hline WAFS084 & -43.27341056 & 170.4055786 & 0.2 & 96.401 & 0.3 \\
\hline WAFS085 & -43.27360129 & 170.4077753 & 0.1 & 94.189 & 0.1 \\
\hline WAFS086 & -43.27394552 & 170.4098957 & 0.1 & 92.434 & 0.1 \\
\hline WAFS087 & -43.27468737 & 170.4103136 & 0.2 & 89.396 & 0.3 \\
\hline WAFS088 & -43.27498944 & 170.4131933 & 0.2 & 87.477 & 0.2 \\
\hline
\end{tabular}




\begin{tabular}{|c|c|c|c|c|c|}
\hline Station & Latitude & Longitude & Horizontal error $(\mathbf{m})$ & Height (WGS84) & Height error (m) \\
\hline WAFS089 & -43.27375131 & 170.4124429 & 0.1 & 89.931 & 0.2 \\
\hline WAFS090 & -43.27414443 & 170.4146377 & 0.1 & 89.774 & 0.2 \\
\hline WAFS091 & -43.2732596 & 170.4137833 & 0.4 & 89.781 & 0.4 \\
\hline WAFS092 & -43.27249508 & 170.4133891 & 0.2 & 89.176 & 0.7 \\
\hline WAFS093 & -43.2811902 & 170.4048551 & 0.1 & 98.501 & 0.2 \\
\hline WAFS094 & -43.28191873 & 170.4055152 & 0.1 & 99.044 & 0.2 \\
\hline WAFS095 & -43.2825835 & 170.4062415 & 0.1 & 100.438 & 0.2 \\
\hline WAFS096 & -43.28324756 & 170.4068591 & 0.1 & 100.298 & 0.1 \\
\hline WAFS097 & -43.28033666 & 170.4066539 & 0.1 & 98.661 & 0.2 \\
\hline WAFS098 & -43.2810551 & 170.4074601 & 0.1 & 98.035 & 0.3 \\
\hline WAFS099 & -43.28160478 & 170.4082878 & 0.1 & 99.733 & 0.3 \\
\hline WAFS100 & -43.27976974 & 170.4083554 & 0.1 & 97.679 & 0.2 \\
\hline WAFS101 & -43.28047558 & 170.4089417 & 0.1 & 98.342 & 0.2 \\
\hline WAFS102 & -43.2791618 & 170.4103169 & 0.1 & 95.592 & 0.2 \\
\hline WAFS103 & -43.27983215 & 170.4109068 & 0.1 & 104.175 & 0.2 \\
\hline WAFS104 & -43.28129233 & 170.4097636 & 0.2 & 104.425 & 0.2 \\
\hline WAFS105 & -43.28334709 & 170.4096448 & 0.1 & 106.591 & 0.3 \\
\hline WAFS106 & -43.28453399 & 170.4082266 & 0.1 & 104.317 & 0.3 \\
\hline WAFS107 & -43.2782505 & 170.4120837 & 0.1 & 102.194 & 0.2 \\
\hline WAFS108 & -43.27892937 & 170.4127842 & 0.1 & 102.924 & 0.2 \\
\hline WAFS109 & -43.27796014 & 170.4134199 & 0.1 & 101.363 & 0.1 \\
\hline WAFS110 & -43.27856316 & 170.4141645 & 0.1 & 101.75 & 0.2 \\
\hline WAFS111 & -43.28529321 & 170.4058926 & 0.1 & 104.922 & 0.2 \\
\hline WAFS112 & -43.28540675 & 170.404339 & 0.1 & 105.275 & 0.2 \\
\hline WAFS113 & -43.28439162 & 170.4032957 & 0.5 & 96.337 & 0.5 \\
\hline WAFS114 & -43.28683122 & 170.4048124 & 0.5 & 97.367 & 0.6 \\
\hline WAFS115 & -43.28513196 & 170.4085951 & 0.2 & 107.127 & 0.3 \\
\hline WAFS116 & -43.28600748 & 170.4087938 & 0.1 & 106.91 & 0.2 \\
\hline WAFS117 & -43.2867275 & 170.4091496 & 0.1 & 107.014 & 0.4 \\
\hline WAFS118 & -43.28749204 & 170.4095511 & 0.1 & 108.276 & 0.3 \\
\hline WAFS119 & -43.28830003 & 170.4098785 & 0.3 & 108.185 & 0.6 \\
\hline WAFS 120 & -43.28902736 & 170.4102546 & 0.2 & 105.81 & 0.4 \\
\hline WAFS121 & -43.28939345 & 170.4089591 & 0.2 & 105.548 & 0.4 \\
\hline WAFS122 & -43.28777686 & 170.4082418 & 0.1 & 102.626 & 0.2 \\
\hline WAFS123 & -43.28625977 & 170.4075336 & 0.1 & 102.786 & 0.3 \\
\hline WAFS124 & -43.28422213 & 170.4098861 & 0.2 & 107.057 & 0.5 \\
\hline WAFS125 & -43.28498391 & 170.4102143 & 0.2 & 108.722 & 0.3 \\
\hline WAFS126 & -43.28605637 & 170.4107762 & 0.2 & 109.657 & 0.2 \\
\hline WAFS127 & -43.28689463 & 170.411219 & 0.3 & 110.255 & 0.2 \\
\hline WAFS128 & -43.28779499 & 170.4116846 & 0.2 & 111.059 & 0.2 \\
\hline WAFS129 & -43.28869233 & 170.412168 & 0.2 & 113.868 & 0.3 \\
\hline WAFS130 & -43.28897175 & 170.4145588 & 0.2 & 137.656 & 0.4 \\
\hline WAFS131 & -43.28718465 & 170.4103776 & 0.1 & 109.006 & 0.2 \\
\hline WAFS132 & -43.28504833 & 170.4094315 & 0.1 & 107.037 & 0.2 \\
\hline
\end{tabular}




\begin{tabular}{|c|c|c|c|c|c|}
\hline Station & Latitude & Longitude & Horizontal error (m) & Height (WGS84) & Height error (m) \\
\hline WAFS133 & -43.28102375 & 170.4114518 & 0.1 & 104.78 & 0.1 \\
\hline WAFS134 & -43.28186142 & 170.4119297 & 0.1 & 105.66 & 0.1 \\
\hline WAFS 135 & -43.28268419 & 170.4122401 & 0.1 & 106.312 & 0.2 \\
\hline WAFS136 & -43.28302832 & 170.4111372 & 0.1 & 106.385 & 0.2 \\
\hline WAFS 137 & -43.28357391 & 170.4127081 & 0.1 & 108.115 & 0.1 \\
\hline WAFS138 & -43.28467514 & 170.4131822 & 0.1 & 111.73 & 0.1 \\
\hline WAFS 139 & -43.2848201 & 170.4118677 & 0.1 & 109.167 & 0.2 \\
\hline WAFS140 & -43.28583221 & 170.4137701 & 0.2 & 116.564 & 0.4 \\
\hline WAFS141 & -43.28659046 & 170.4124785 & 0.2 & 114.643 & 0.4 \\
\hline WAFS142 & -43.28528885 & 170.4164542 & 1 & 138.395 & 0.9 \\
\hline WAFS143 & -43.28459302 & 170.4147687 & 0.5 & 114.56 & 0.5 \\
\hline WAFS144 & -43.28329328 & 170.4143681 & 0.3 & 109.759 & 0.5 \\
\hline WAFS145 & -43.28231742 & 170.4139732 & 0.2 & 106.695 & 0.7 \\
\hline WAFS146 & -43.28134461 & 170.4135944 & 0.1 & 106.7 & 0.2 \\
\hline WAFS147 & -43.28014286 & 170.4132877 & 0.1 & 103.829 & 0.2 \\
\hline WAFS148 & -43.27963059 & 170.4147568 & 0.1 & 105.479 & 0.2 \\
\hline WAFS149 & -43.28029908 & 170.4150581 & 0.1 & 106.459 & 0.2 \\
\hline WAFS 150 & -43.27891453 & 170.41585 & 0.1 & 104.811 & 0.2 \\
\hline WAFS151 & -43.2831086 & 170.3868024 & 0.1 & 93.54 & 0.1 \\
\hline WAFS152 & -43.28162578 & 170.3841088 & 0.1 & 91.737 & 0.1 \\
\hline WAFS153 & -43.27992759 & 170.383218 & 0.1 & 91.393 & 0.1 \\
\hline WAFS154 & -43.27798079 & 170.3826739 & 0.4 & 91.145 & 0.6 \\
\hline WAFS155 & -43.27596468 & 170.3821476 & 0.1 & 88.723 & 0.4 \\
\hline WAFS156 & -43.2726324 & 170.3812542 & 0.3 & 88.283 & 0.7 \\
\hline WAFS 157 & -43.27758484 & 170.3983505 & 0.1 & 97.232 & 0.1 \\
\hline WAFS 158 & -43.27708635 & 170.3956506 & 0.1 & 95.513 & 0.1 \\
\hline WAFS 159 & -43.2766091 & 170.3930603 & 0.2 & 94.511 & 0.2 \\
\hline WAFS 160 & -43.27828149 & 170.3912528 & 0.2 & 94.289 & 0.3 \\
\hline WAFS161 & -43.27601028 & 170.3898882 & 0.1 & 92.087 & 0.1 \\
\hline WAFS162 & -43.27552849 & 170.3873145 & 0.1 & 90.396 & 0.2 \\
\hline WAFS163 & -43.27508896 & 170.384962 & 0.2 & 88.973 & 0.3 \\
\hline WAFS 164 & -43.27343184 & 170.3849303 & 0.1 & 88.115 & 0.2 \\
\hline WAFS165 & -43.27605316 & 170.3991834 & 0.3 & 99.155 & 0.5 \\
\hline WAFS166 & -43.27452849 & 170.3981346 & 0.1 & 94.826 & 0.2 \\
\hline WAFS 167 & -43.27269926 & 170.3975161 & 0.1 & 93.215 & 0.2 \\
\hline WAFS168 & -43.27104409 & 170.3967262 & 0.1 & 91.163 & 0.2 \\
\hline WAFS 169 & -43.27182017 & 170.3910885 & 0.1 & 91.001 & 0.2 \\
\hline WAFS170 & -43.2738733 & 170.3891283 & 0.1 & 90.987 & 0.2 \\
\hline WAFS171 & -43.27412559 & 170.3921538 & 0.1 & 92.564 & 0.2 \\
\hline WAFS 172 & -43.27269173 & 170.3944698 & 0.2 & 92.927 & 0.2 \\
\hline WAFS 173 & -43.27455814 & 170.3951846 & 0.1 & 94.659 & 0.1 \\
\hline WAFS174 & -43.28058811 & 170.3869385 & 0.1 & 93.149 & 0.2 \\
\hline WAFS 175 & -43.27860352 & 170.387629 & 0.1 & 92.752 & 0.2 \\
\hline WAFS 176 & -43.27725659 & 170.3854037 & 0.1 & 90.535 & 0.1 \\
\hline
\end{tabular}




\begin{tabular}{|c|c|c|c|c|c|}
\hline Station & Latitude & Longitude & Horizontal error (m) & Height (WGS84) & Height error (m) \\
\hline WAFS177 & -43.27977076 & 170.3850083 & 0.1 & 91.543 & 0.1 \\
\hline WAFS178 & -43.2844461 & 170.3862718 & 0.1 & 94.125 & 0.3 \\
\hline WAFS179 & -43.2821255 & 170.3814911 & 0.3 & 92.493 & 0.4 \\
\hline WAFS180 & -43.28128492 & 170.3770261 & 0.4 & 88.971 & 0.5 \\
\hline WAFS181 & -43.28051288 & 170.3728421 & 0.2 & 92.622 & 0.3 \\
\hline WAFS182 & -43.27537064 & 170.3779478 & 0.1 & 86.319 & 0.2 \\
\hline WAFS183 & -43.27852763 & 170.362284 & 0.1 & 103.919 & 0.3 \\
\hline WAFS184 & -43.27962166 & 170.3683365 & 0.1 & 99.607 & 0.2 \\
\hline WAFS185 & -43.27631876 & 170.3719128 & 0.1 & 88.029 & 0.2 \\
\hline WAFS186 & -43.28131196 & 170.3979219 & 0.1 & 99.54 & 0.2 \\
\hline WAFS187 & -43.28041129 & 170.393141 & 0.1 & 95.095 & 0.1 \\
\hline WAFS188 & -43.28430241 & 170.3801367 & 0.3 & 110.173 & 0.3 \\
\hline WAFS189 & -43.28643818 & 170.3791291 & 0.2 & 145.272 & 0.2 \\
\hline WAFS190 & -43.28612639 & 170.3764475 & 0.3 & 127.394 & 0.3 \\
\hline WAFS191 & -43.28826845 & 170.3789104 & 1.2 & 171.615 & 1.4 \\
\hline WAFS193 & -43.29057281 & 170.3781651 & 0.6 & 242.533 & 1.7 \\
\hline WDSS024 & -43.29095724 & 170.4054409 & 0.9 & 110.894 & 0.9 \\
\hline WDSS027 & -43.29240407 & 170.4053951 & 0.4 & 118.381 & 0.6 \\
\hline WDSS028 & -43.29252081 & 170.4046546 & 0.2 & 156.102 & 0.4 \\
\hline WDSS032 & -43.29724157 & 170.4142121 & 0.1 & 112.558 & 0.1 \\
\hline WDSS033 & -43.29719542 & 170.4129944 & 0.1 & 113.048 & 0.1 \\
\hline WDSS034 & -43.29711119 & 170.4117738 & 0.1 & 111.627 & 0.1 \\
\hline WDSS035 & -43.29704652 & 170.4105935 & 0.1 & 111.85 & 0.1 \\
\hline WDSS036 & -43.29694464 & 170.4090241 & 0.1 & 115.895 & 0.2 \\
\hline WDSS037 & -43.29745177 & 170.408194 & 0.1 & 116.314 & 0.1 \\
\hline WDSS038 & -43.29766662 & 170.4071731 & 0.1 & 121.109 & 0.2 \\
\hline WDSS039 & -43.29734559 & 170.4064864 & 1.4 & 136.756 & 1.8 \\
\hline WDSS040 & -43.29680965 & 170.4055954 & 1.1 & 158.271 & 1.1 \\
\hline WDSS041 & -43.2967748 & 170.4049525 & 1 & 177.107 & 1 \\
\hline WDSS042 & -43.29683847 & 170.4040833 & 1.8 & 200.615 & 1.9 \\
\hline WDSS044 & -43.2963086 & 170.4025666 & 1.3 & 262.583 & 1.7 \\
\hline WDSS045 & -43.29623016 & 170.4017588 & 0.5 & 290.402 & 0.8 \\
\hline WDSS046 & -43.2895452 & 170.4055257 & 0.9 & 98.8 & 0.9 \\
\hline WDSS047 & -43.29008988 & 170.4055991 & 0.5 & 105.378 & 0.7 \\
\hline WDSS048 & -43.28986112 & 170.4062279 & 0.2 & 102.215 & 0.6 \\
\hline WDSS049 & -43.29016942 & 170.4068907 & 0.1 & 102.605 & 0.2 \\
\hline WDSS050 & -43.29052195 & 170.4076976 & 0.1 & 103.519 & 0.1 \\
\hline WDSS051 & -43.29101883 & 170.4072108 & 0.1 & 105.047 & 0.2 \\
\hline WDSS052 & -43.292327 & 170.4080511 & 0.3 & 105.593 & 0.4 \\
\hline WDSS053 & -43.29202271 & 170.4068503 & 0.5 & 105.269 & 0.5 \\
\hline WDSS054 & -43.28924775 & 170.4050197 & 0.7 & 109.501 & 1 \\
\hline WDSS055 & -43.28986913 & 170.405309 & 0.8 & 112.604 & 1.6 \\
\hline WDSS056 & -43.29186 & 170.4055981 & 1.3 & 110.974 & 2.6 \\
\hline WDSS057 & -43.29192903 & 170.4060325 & 0.1 & 104.244 & 0.3 \\
\hline
\end{tabular}




\begin{tabular}{|c|c|c|c|c|c|}
\hline Station & Latitude & Longitude & Horizontal error (m) & Height (WGS84) & Height error (m) \\
\hline WRS013 & -43.28566068 & 170.3896313 & 0.3 & 122.575 & 0.6 \\
\hline WRS014 & -43.28600623 & 170.3895591 & 0.4 & 119.255 & 1.3 \\
\hline WRS065 & -43.28664076 & 170.3897421 & 0.7 & 136.899 & 0.9 \\
\hline WRS066 & -43.28697534 & 170.3901078 & 0.5 & 150.514 & 0.9 \\
\hline WRS067 & -43.28746239 & 170.3905599 & 0.5 & 160.864 & 1 \\
\hline WRS071 & -43.26461386 & 170.4158078 & 0.1 & 92.326 & 0.2 \\
\hline WRS072 & -43.26433986 & 170.4130035 & 0.1 & 87.706 & 0.2 \\
\hline WRS073 & -43.26542737 & 170.4103805 & 0.1 & 84.712 & 0.2 \\
\hline WRS074 & -43.26597666 & 170.4072659 & 0.1 & 83.768 & 0.3 \\
\hline WRS075 & -43.26421132 & 170.376059 & 0.1 & 80.633 & 0.2 \\
\hline WRS076 & -43.26364825 & 170.3782026 & 0.1 & 81.408 & 0.3 \\
\hline WRS077 & -43.26290813 & 170.3811654 & 0.6 & 82.625 & 0.6 \\
\hline WRS078 & -43.26734644 & 170.3984311 & 0.2 & 89.98 & 0.3 \\
\hline WRS079 & -43.26702671 & 170.400944 & 0.2 & 89.757 & 0.2 \\
\hline WRS080 & -43.26686659 & 170.4030078 & 0.1 & 89.116 & 0.2 \\
\hline WRS081 & -43.2667131 & 170.4051886 & 0.2 & 88.812 & 0.3 \\
\hline WRS082 & -43.25101641 & 170.3991503 & 0.1 & 78.344 & 0.2 \\
\hline WRS083 & -43.25205339 & 170.4047182 & 0.1 & 78.419 & 0.4 \\
\hline WRS084 & -43.25326351 & 170.4112531 & 0.1 & 74.086 & 0.3 \\
\hline WRS085 & -43.25732568 & 170.4100182 & 0.1 & 79.169 & 0.2 \\
\hline WRS086 & -43.25455413 & 170.4178611 & 0.1 & 75.482 & 0.2 \\
\hline WRS087 & -43.29810703 & 170.419916 & 1.3 & 134.972 & 1.6 \\
\hline WRS088 & -43.29730604 & 170.4222028 & 2.1 & 175.946 & 1.5 \\
\hline WRS089 & -43.29725803 & 170.4229735 & 13.1 & 211.362 & 9.2 \\
\hline WRS090 & -43.2691612 & 170.395287 & 0.2 & 91.36 & 0.4 \\
\hline WRS091 & -43.26952335 & 170.3926555 & 0.1 & 91.289 & 0.2 \\
\hline WRS092 & -43.27016594 & 170.3892608 & 0.1 & 89.504 & 0.3 \\
\hline WRS093 & -43.27101321 & 170.3844509 & 0.2 & 88.111 & 0.4 \\
\hline WRS094 & -43.26035836 & 170.4020388 & 0.4 & 85.178 & 1.7 \\
\hline WRS095 & -43.2565128 & 170.4037918 & 0.3 & 81.423 & 0.6 \\
\hline WRS096 & -43.25483067 & 170.3886178 & 0.3 & 79.127 & 0.8 \\
\hline WRS097 & -43.25636613 & 170.3828053 & 0.2 & 81.635 & 0.6 \\
\hline WRS098 & -43.25803724 & 170.3767106 & 0.1 & 77.548 & 0.3 \\
\hline WRS099 & -43.26021048 & 170.3721627 & 0.3 & 80.227 & 0.8 \\
\hline WRS100 & -43.27818182 & 170.3791126 & 0.1 & 88.075 & 0.1 \\
\hline WRS101 & -43.26352823 & 170.3682187 & 0.2 & 77.709 & 0.2 \\
\hline WRS102 & -43.25172099 & 170.3736602 & 0.1 & 73.787 & 0.2 \\
\hline WRS103 & -43.25567996 & 170.3662246 & 0.2 & 73.526 & 0.3 \\
\hline WRS104 & -43.27509882 & 170.3575006 & 0.2 & 80.97 & 0.3 \\
\hline WRS105 & -43.27446372 & 170.3676697 & 0.2 & 85.234 & 0.3 \\
\hline WRS106 & -43.27024925 & 170.3660954 & 0.2 & 80.475 & 0.3 \\
\hline WRS107 & -43.26890785 & 170.4155613 & 0.4 & 107.621 & 0.5 \\
\hline WRS108 & -43.26892813 & 170.4166187 & 0.2 & 114.245 & 0.2 \\
\hline WRS109 & -43.26906851 & 170.4177985 & 0.5 & 126.011 & 0.5 \\
\hline
\end{tabular}




\begin{tabular}{|c|c|c|c|c|c|}
\hline Station & Latitude & Longitude & Horizontal error (m) & Height (WGS84) & Height error (m) \\
\hline WRS110 & -43.26938789 & 170.4191912 & 1.2 & 138.546 & 1.3 \\
\hline WRS111 & -43.2697909 & 170.4204413 & 0.5 & 147.804 & 0.4 \\
\hline WRS112 & -43.26875509 & 170.4143686 & 0.1 & 96.047 & 0.1 \\
\hline WRS113 & -43.27228482 & 170.4218696 & 0.3 & 180.574 & 0.5 \\
\hline WRS114 & -43.27346705 & 170.4260479 & 0.6 & 234.754 & 1.5 \\
\hline WRS115 & -43.27594418 & 170.4284465 & 0.1 & 285.59 & 0.4 \\
\hline WRS116 & -43.28803113 & 170.4160862 & 0.5 & 149.95 & 1.5 \\
\hline WRS117 & -43.29003043 & 170.4188648 & 1.1 & 204.523 & 1.4 \\
\hline DFDP2-S5 & -43.29317979 & 170.409447 & 0.4 & 108.116 & 0.6 \\
\hline WE01 & -43.29258946 & 170.4142411 & 1.1 & 105.998 & 1.1 \\
\hline WE02 & -43.29773298 & 170.4170399 & 0.6 & 105.158 & 0.5 \\
\hline WE03 & -43.29807064 & 170.4176115 & 0.6 & 108.252 & 0.5 \\
\hline WE06 & -43.29713241 & 170.4174773 & 0.6 & 109.198 & 0.8 \\
\hline WE08 & -43.29478668 & 170.4172869 & 0.7 & 108.476 & 0.7 \\
\hline WE09 & -43.29365685 & 170.4160222 & 0.7 & 110.779 & 0.7 \\
\hline WE10 & -43.29152104 & 170.4131307 & 0.5 & 107.895 & 0.9 \\
\hline WE11 & -43.29017675 & 170.4115598 & 0.9 & 107.732 & 1.8 \\
\hline WS01 & -43.29253649 & 170.4059947 & 0.4 & 106.988 & 0.5 \\
\hline WS02 & -43.29267576 & 170.4065647 & 0.4 & 106.9295 & 0.6 \\
\hline WS03 & -43.29278131 & 170.4071498 & 0.4 & 108.183 & 0.5 \\
\hline WS04 & -43.29289088 & 170.4077511 & 0.3 & 108.6825 & 0.4 \\
\hline WS05 & -43.29300214 & 170.4083467 & 0.3 & 107.756 & 0.4 \\
\hline WS06 & -43.29314795 & 170.4089311 & 0.3 & 107.888 & 0.4 \\
\hline WS07 & -43.29334579 & 170.4094856 & 0.3 & 108.3345 & 0.4 \\
\hline WS08 & -43.29355181 & 170.4100387 & 0.3 & 108.686 & 0.5 \\
\hline WS09 & -43.29375071 & 170.4105775 & 0.3 & 108.7685 & 0.4 \\
\hline WS10 & -43.29395731 & 170.4111314 & 0.3 & 109.042 & 0.4 \\
\hline WS11 & -43.29416305 & 170.4116865 & 0.5 & 108.885 & 0.7 \\
\hline WS12 & -43.29439594 & 170.4121794 & 0.4 & 108.806 & 0.5 \\
\hline WS13 & -43.2947452 & 170.4125693 & 0.8 & 110.079 & 1.1 \\
\hline WS14 & -43.2952773 & 170.4133127 & 1.2 & 110.021 & 1.6 \\
\hline WS15 & -43.29587701 & 170.4141271 & 0.6 & 111.08 & 0.9 \\
\hline WS16 & -43.2964865 & 170.4149168 & 0.6 & 111.644 & 1.1 \\
\hline WS17 & -43.29702275 & 170.4155138 & 0.6 & 111.746 & 1.2 \\
\hline WS18 & -43.29701472 & 170.4159059 & 0.4 & 106.533 & 0.7 \\
\hline WS19 & -43.29747523 & 170.4156629 & 0.8 & 105.586 & 1.4 \\
\hline WS20 & -43.29729063 & 170.4161508 & 0.7 & 105.537 & 1.2 \\
\hline WS21 & -43.29744709 & 170.4154886 & 0.2 & 113.926 & 0.2 \\
\hline WS22 & -43.29736232 & 170.4150476 & 0.5 & 114.126 & 0.6 \\
\hline WT01 & -43.29040311 & 170.4054197 & 1 & 108.315 & 0.9 \\
\hline WT02 & -43.29045608 & 170.4062378 & 0.4 & 105.599 & 0.5 \\
\hline WT03 & -43.29050465 & 170.4068306 & 0.1 & 106.049 & 0.1 \\
\hline WT04 & -43.29064455 & 170.4076963 & 0.1 & 105.715 & 0.1 \\
\hline WT05 & -43.29114541 & 170.4089924 & 0.5 & 106.478 & 0.5 \\
\hline
\end{tabular}




\begin{tabular}{|c|c|c|c|c|c|}
\hline Station & Latitude & Longitude & Horizontal error (m) & Height (WGS84) & Height error (m) \\
\hline WT06 & -43.29141016 & 170.4055416 & 0.6 & 111.302 & 0.5 \\
\hline WT06B & -43.29143125 & 170.4059735 & 0.2 & 104.663 & 0.2 \\
\hline WT06C & -43.29145746 & 170.4063078 & 0.4 & 105.674 & 0.5 \\
\hline WT07 & -43.29150312 & 170.4072517 & 0.4 & 106.546 & 0.5 \\
\hline WT08 & -43.29168354 & 170.4079883 & 0.4 & 106.869 & 0.6 \\
\hline WT09 & -43.29188527 & 170.4088909 & 0.3 & 108.101 & 0.5 \\
\hline WT10 & -43.29218378 & 170.4098926 & 0.3 & 108.221 & 0.5 \\
\hline WT11 & -43.29227163 & 170.4105788 & 0.4 & 106.806 & 0.8 \\
\hline WT12 & -43.29229482 & 170.4114531 & 0.4 & 105.674 & 0.6 \\
\hline WT13 & -43.29241482 & 170.4058134 & 6.8 & 106.394 & 0.8 \\
\hline WT17 & -43.29295697 & 170.4100407 & 0.3 & 106.473 & 0.6 \\
\hline WT18 & -43.29300624 & 170.4109052 & 0.3 & 108.27 & 0.6 \\
\hline WT19 & -43.29309892 & 170.4119711 & 0.3 & 108.665 & 0.6 \\
\hline WT20B & -43.29365065 & 170.4059857 & 0.5 & 108.403 & 0.7 \\
\hline WT21 & -43.29374178 & 170.4074122 & 0.4 & 110.481 & 0.5 \\
\hline WT22 & -43.29382996 & 170.4082372 & 0.4 & 109.727 & 0.5 \\
\hline WT23 & -43.29391234 & 170.4093578 & 0.4 & 109.7 & 0.5 \\
\hline WT27 & -43.29501059 & 170.406557 & 0.4 & 114.184 & 0.6 \\
\hline WT28 & -43.29481644 & 170.407314 & 0.5 & 109.328 & 0.5 \\
\hline WT29 & -43.2947284 & 170.4082831 & 0.2 & 109.741 & 0.3 \\
\hline WT30 & -43.29486643 & 170.40923 & 0.1 & 110.125 & 0.1 \\
\hline WT31 & -43.29505428 & 170.410148 & 0.1 & 110.598 & 0.1 \\
\hline WT32 & -43.29525312 & 170.4109087 & 0.1 & 110.782 & 0.1 \\
\hline WW01 & -43.28869355 & 170.4047416 & 0.7 & 108.961 & 0.6 \\
\hline WW02 & -43.28722806 & 170.403673 & 1.1 & 110.491 & 0.9 \\
\hline WW03 & -43.28622001 & 170.4018905 & 1.2 & 115.471 & 1.6 \\
\hline WW04 & -43.28562171 & 170.4000784 & 0.3 & 105.908 & 0.5 \\
\hline WW05 & -43.28517021 & 170.3975616 & 0.3 & 102.169 & 0.5 \\
\hline WW06 & -43.2837095 & 170.393878 & 0.3 & 100.148 & 0.5 \\
\hline WW07 & -43.28447706 & 170.3939674 & 0.4 & 99.722 & 0.5 \\
\hline
\end{tabular}

Table D.1: Site survey GPS data. 
Appendix E Gsolve Data 


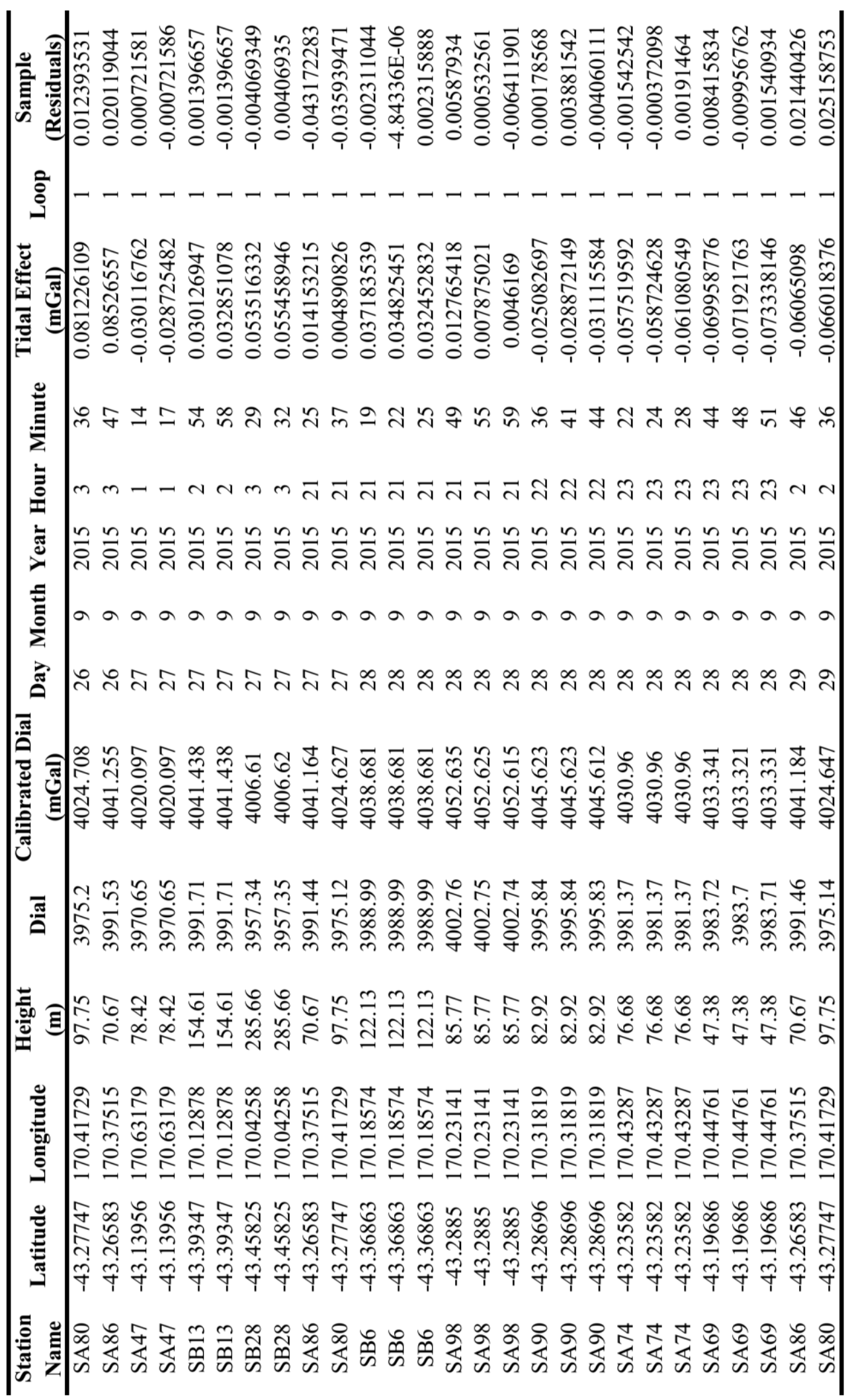

Table E.1: Survey measurements processed using Gsolve for 10 absolute gravity reference stations of the New Zealand gravity network.

Note that time has been converted to UTC. 


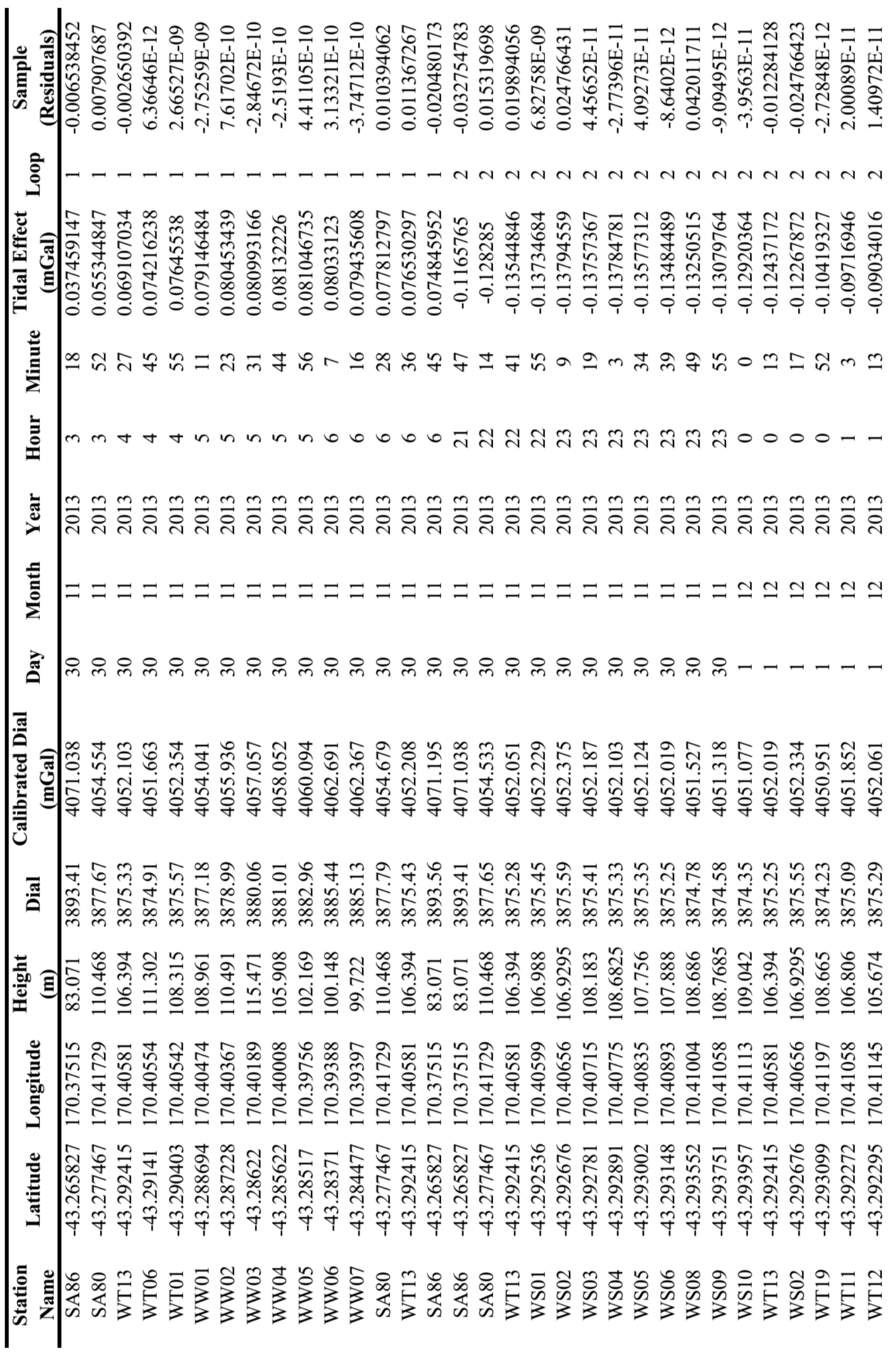

Continued on next page 


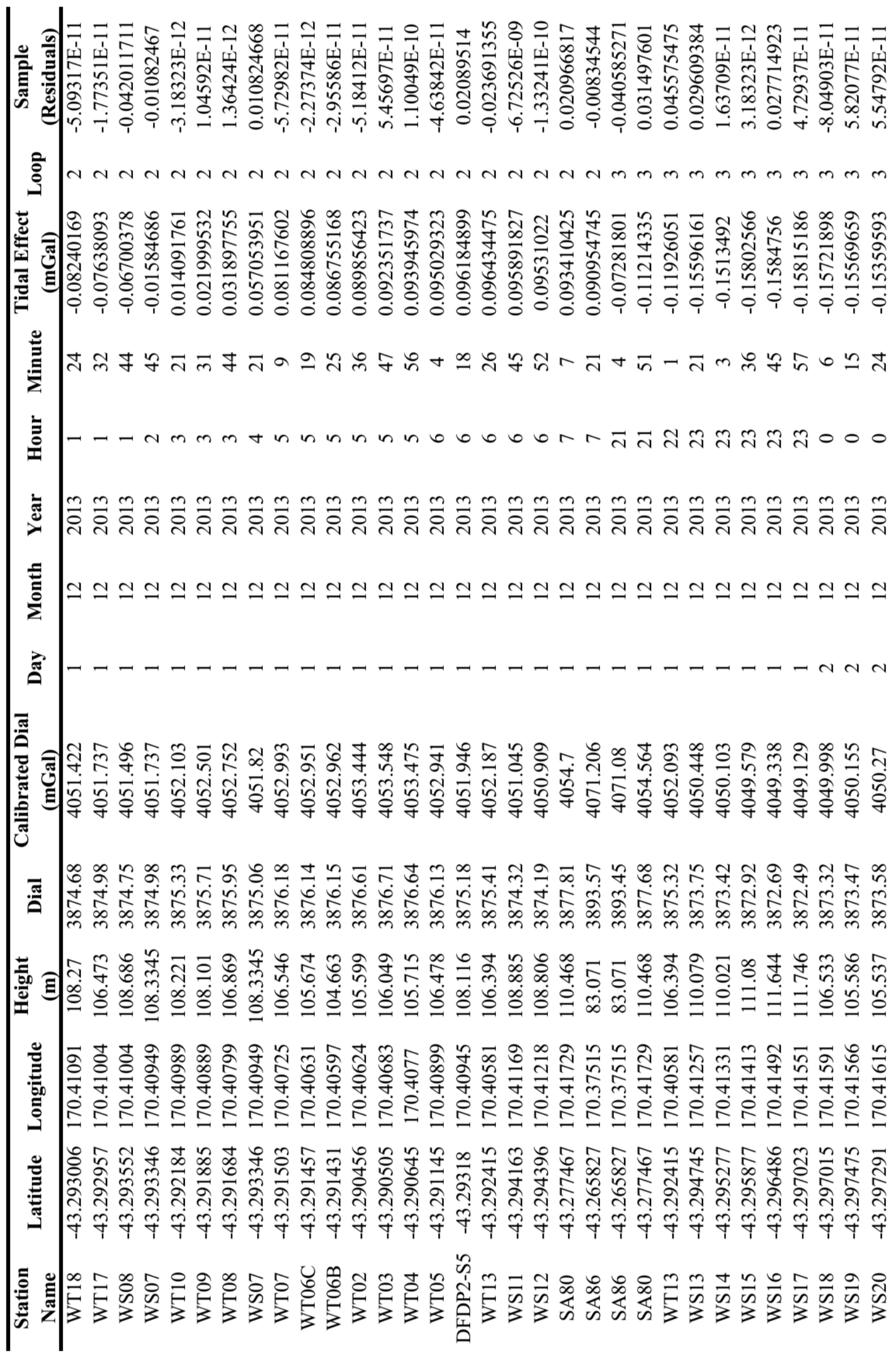

\section{Continued on next page}




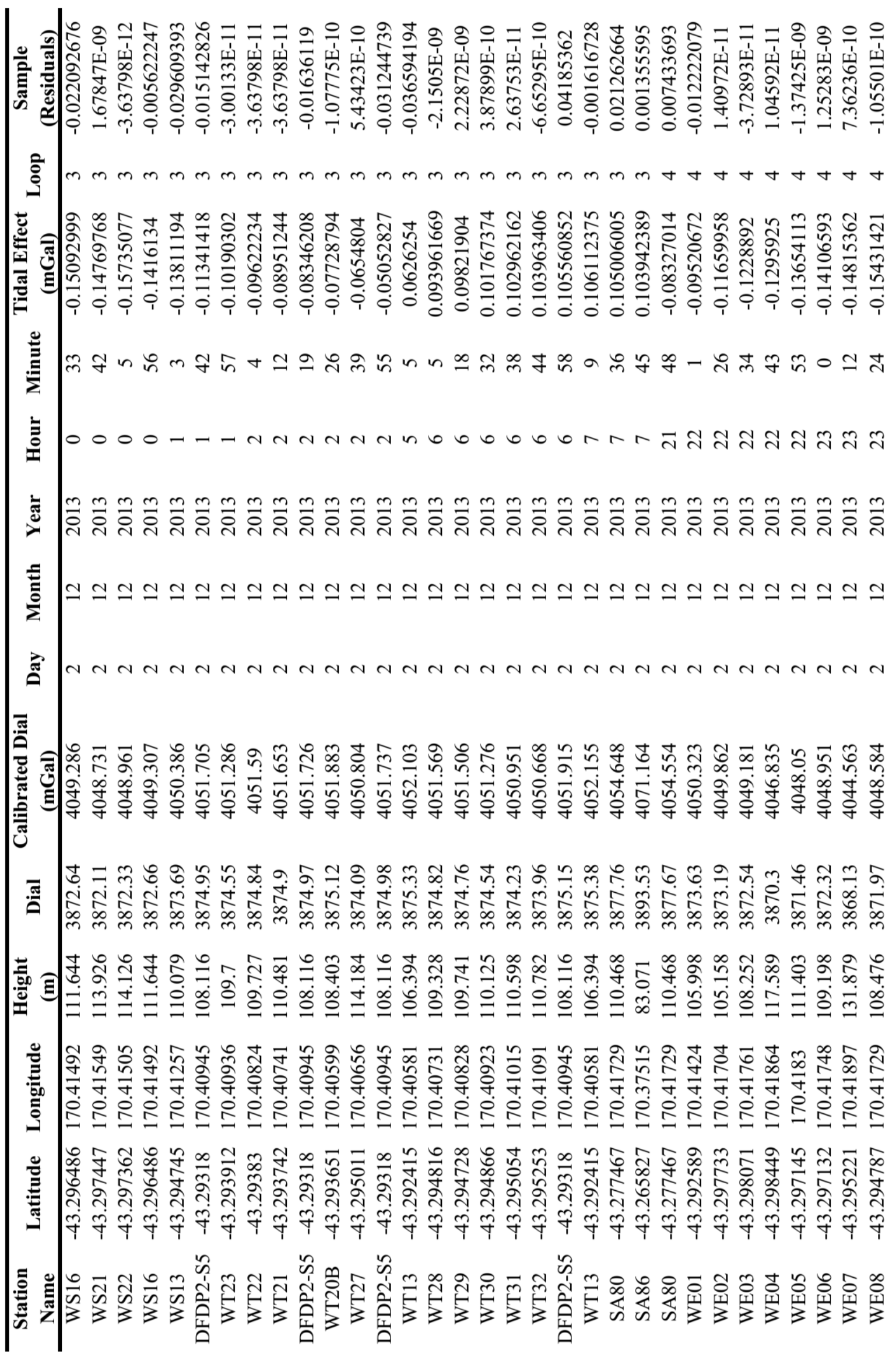

Continued on next page 


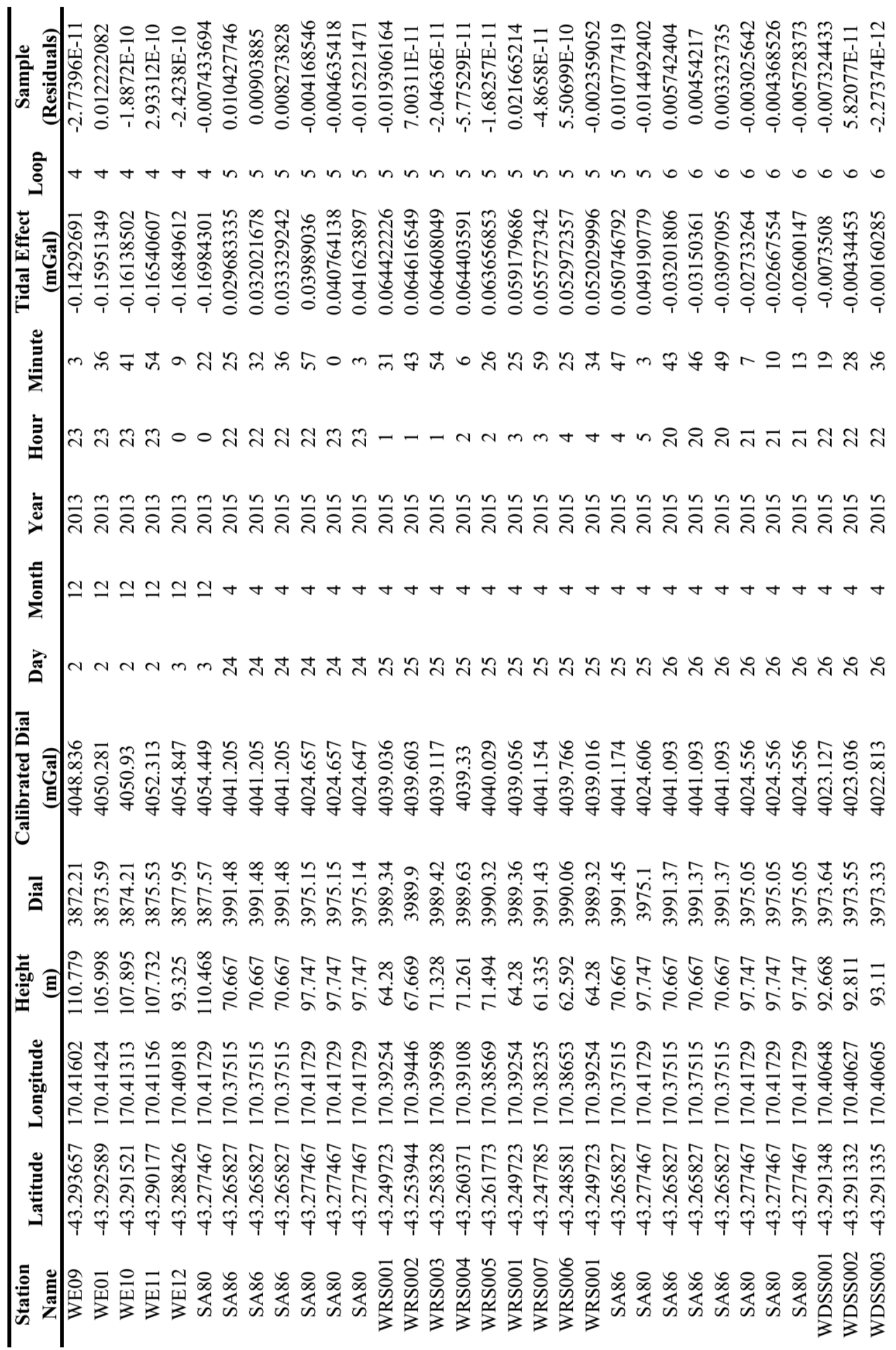

\section{Continued on next page}




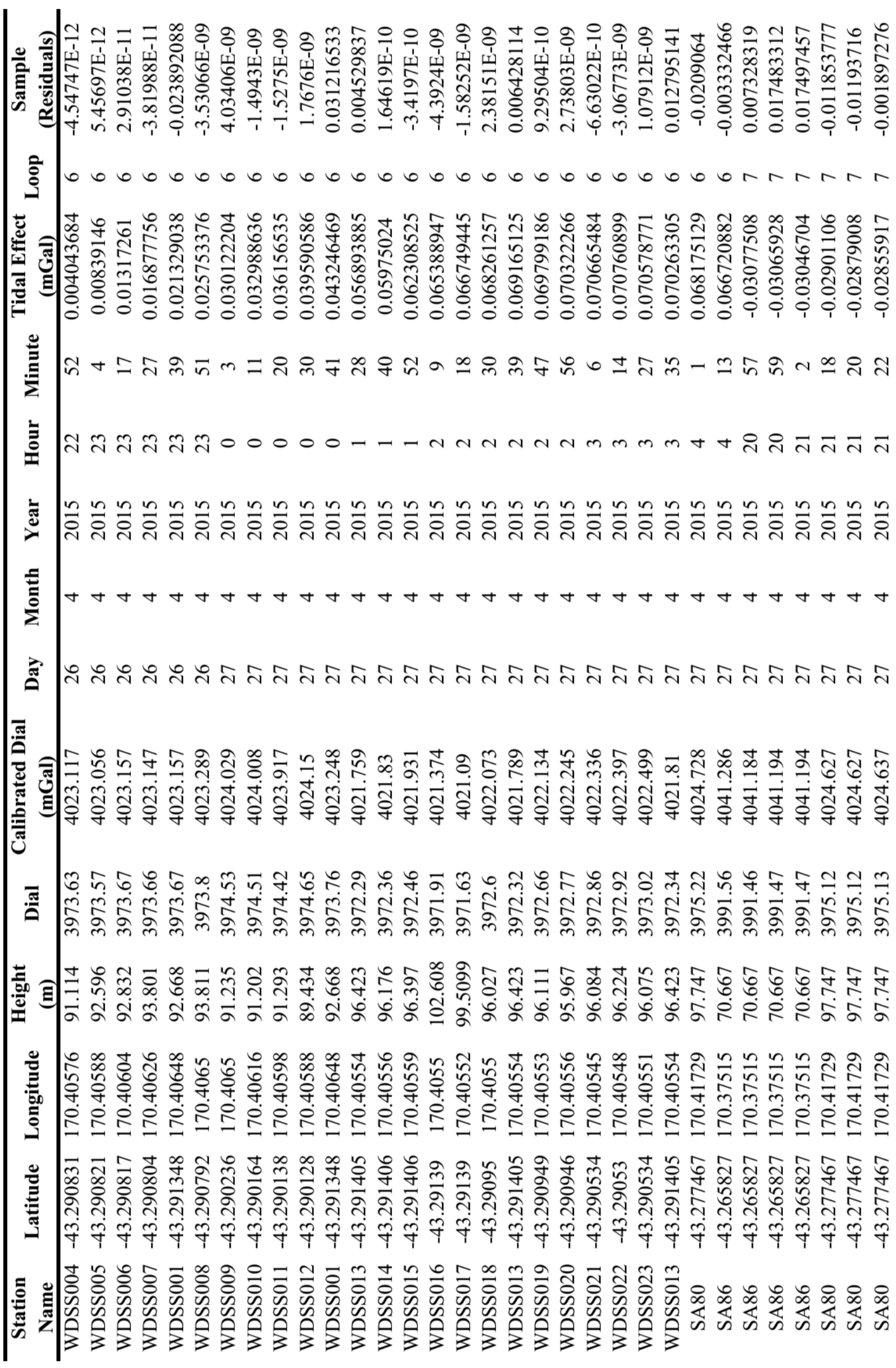

\section{Continued on next page}




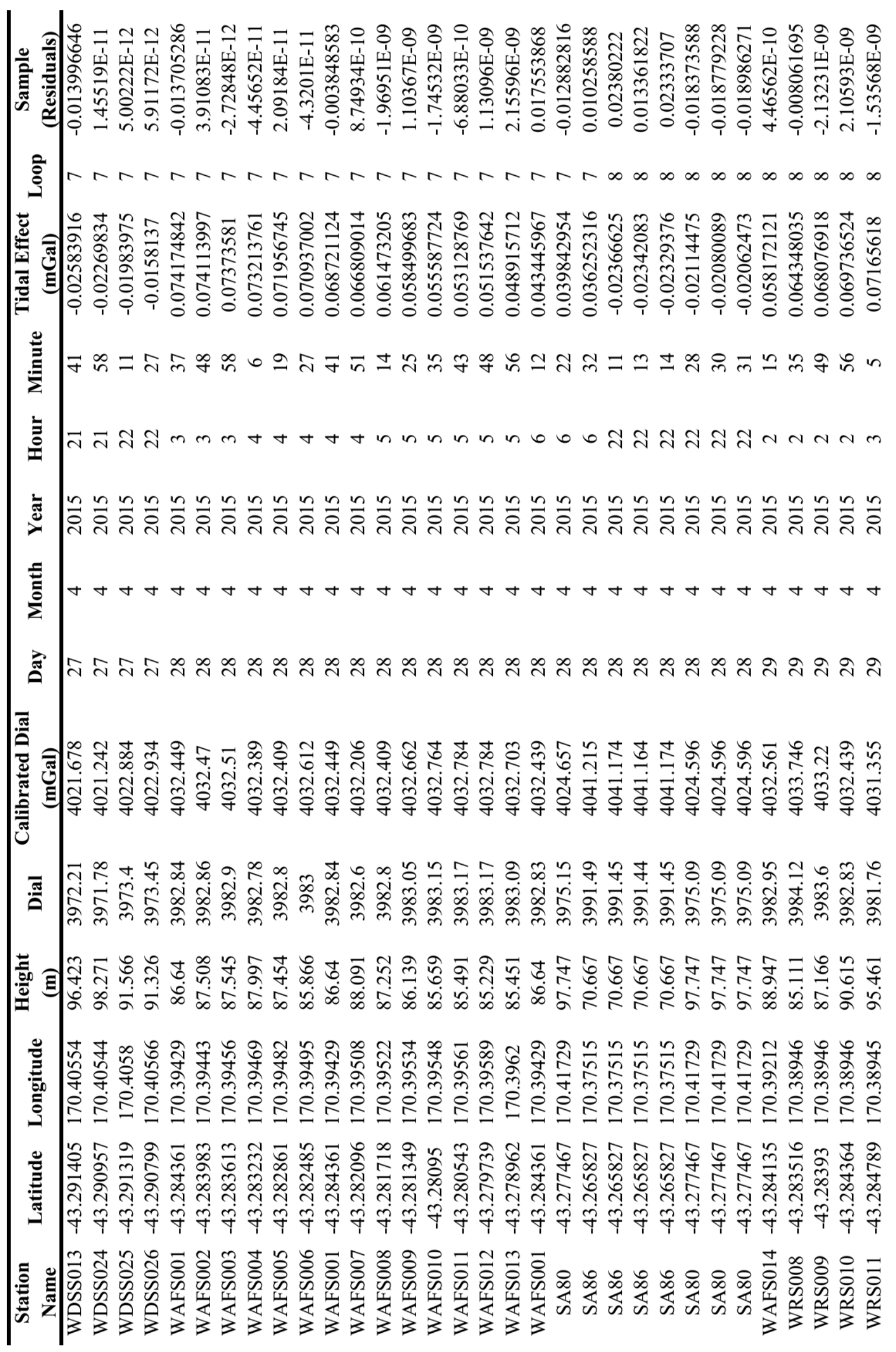

\section{Continued on next page}




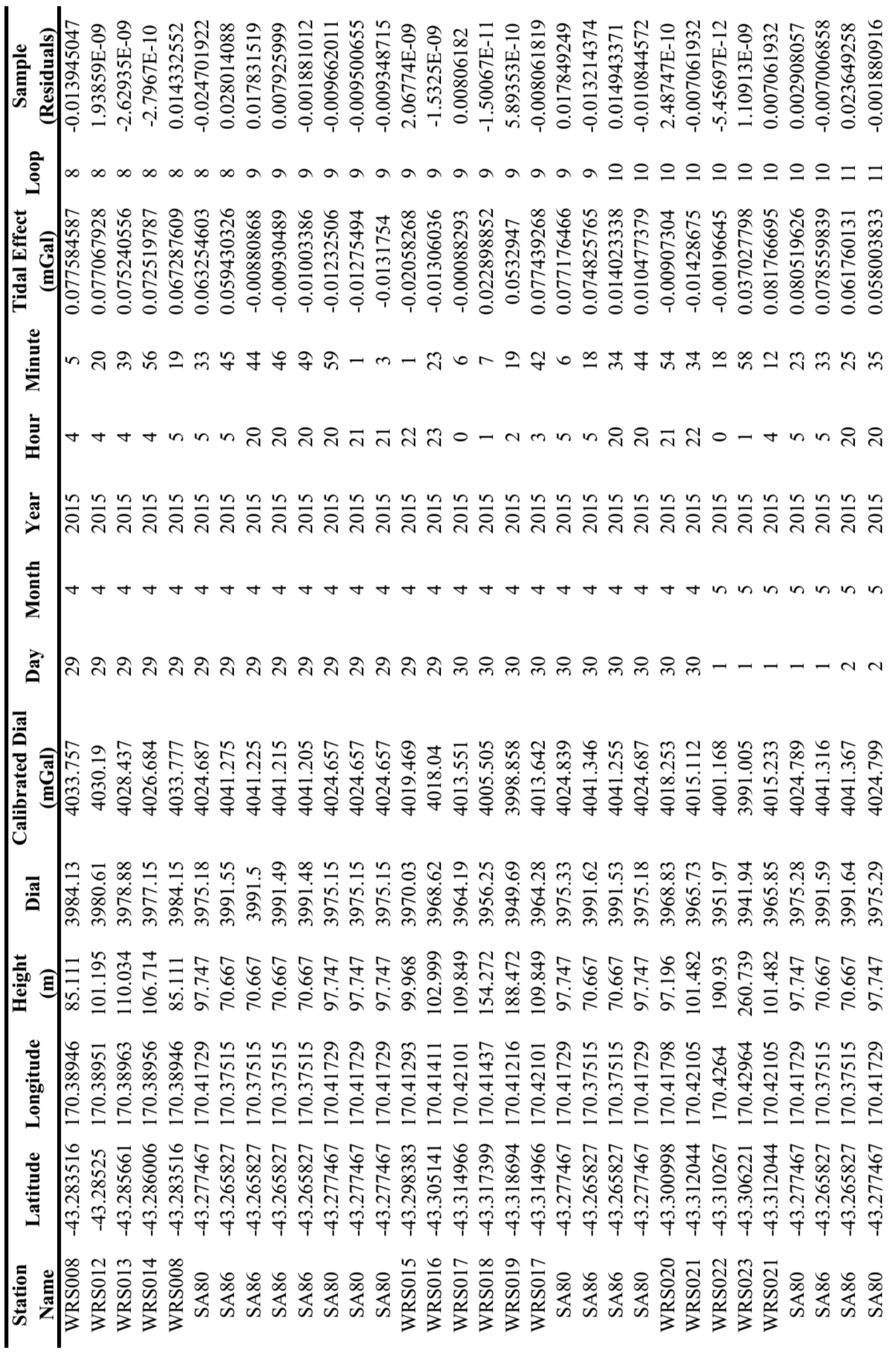

Continued on next page 


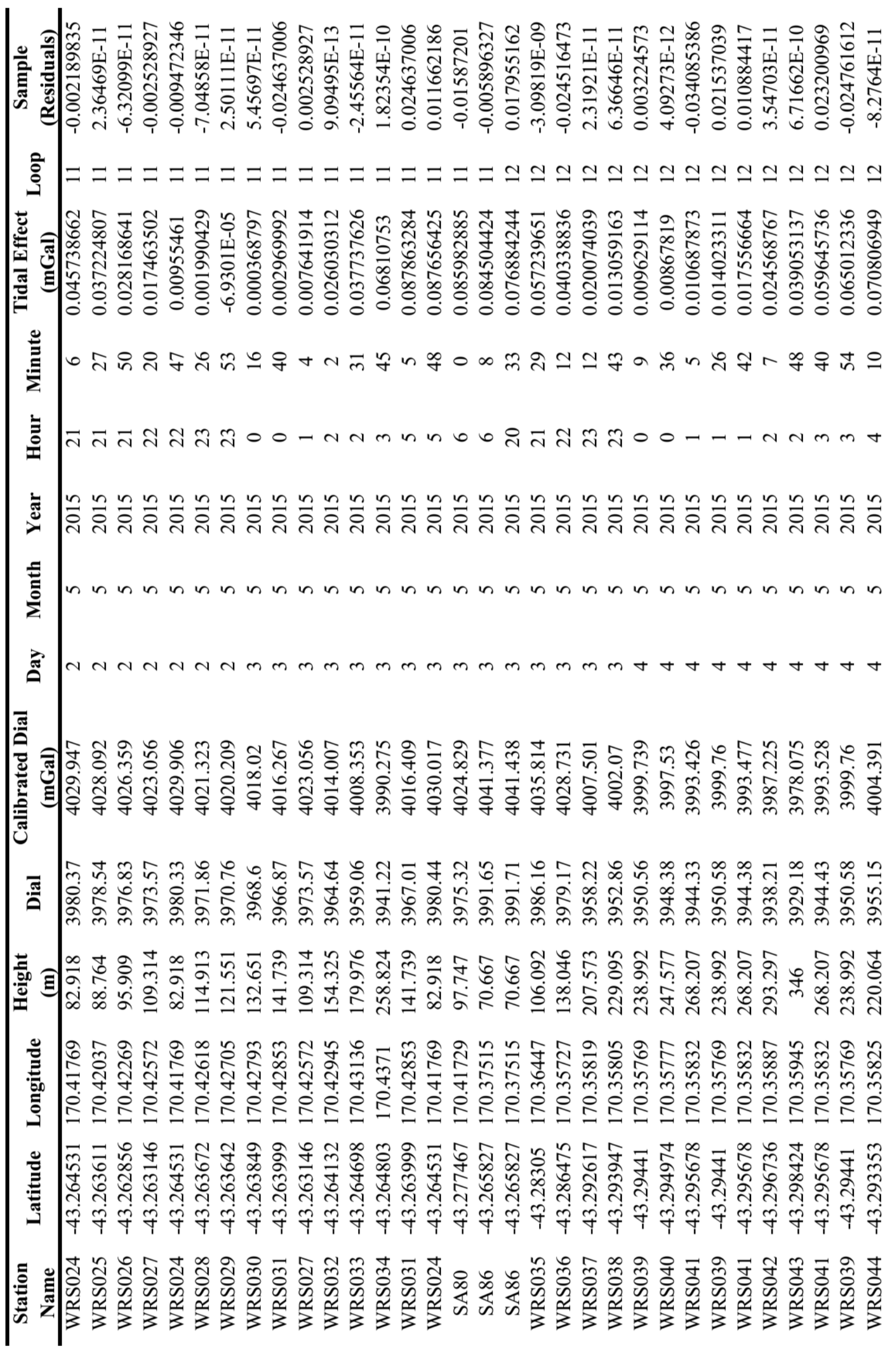

\section{Continued on next page}




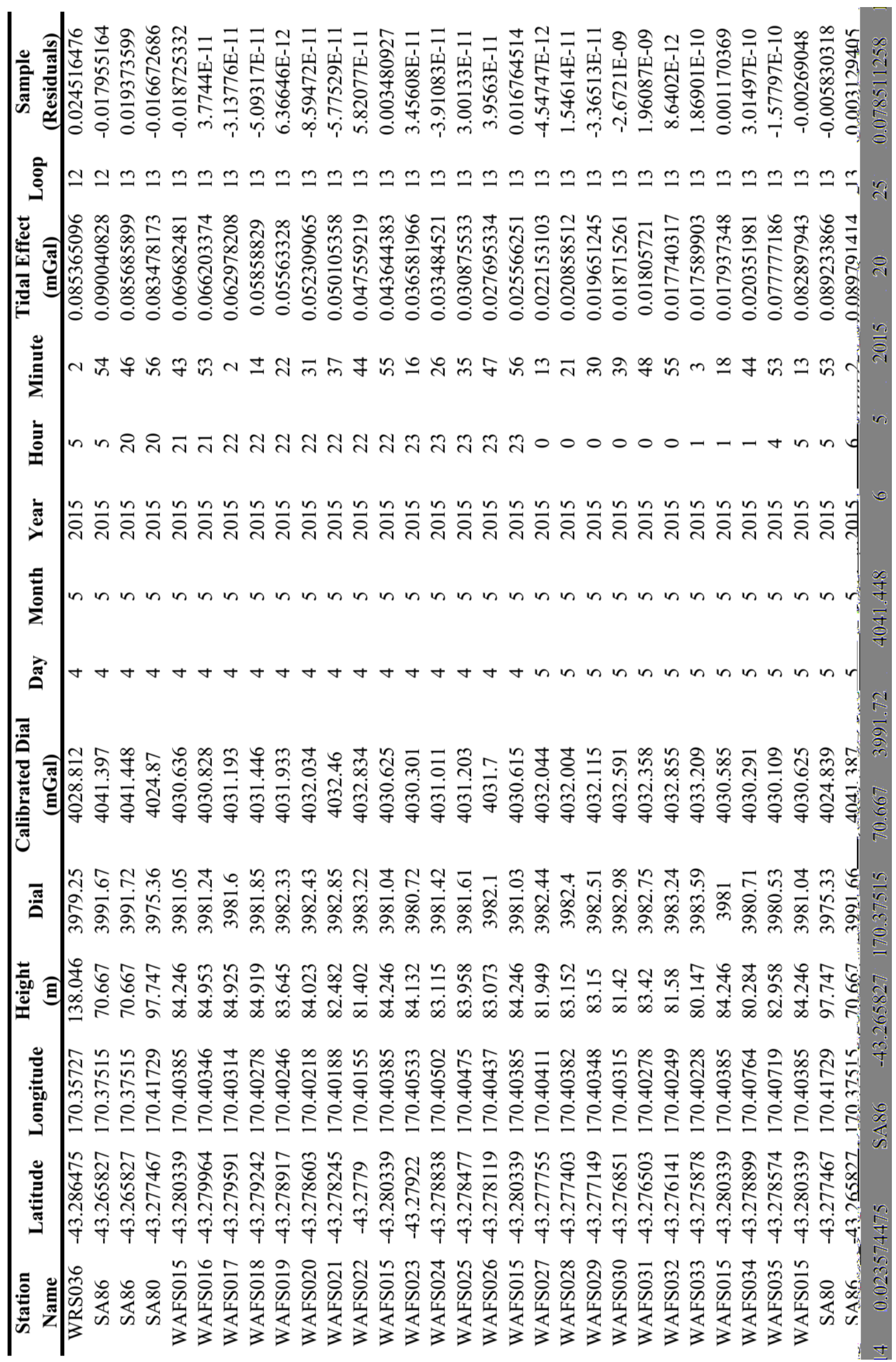

\section{Continued on next page}




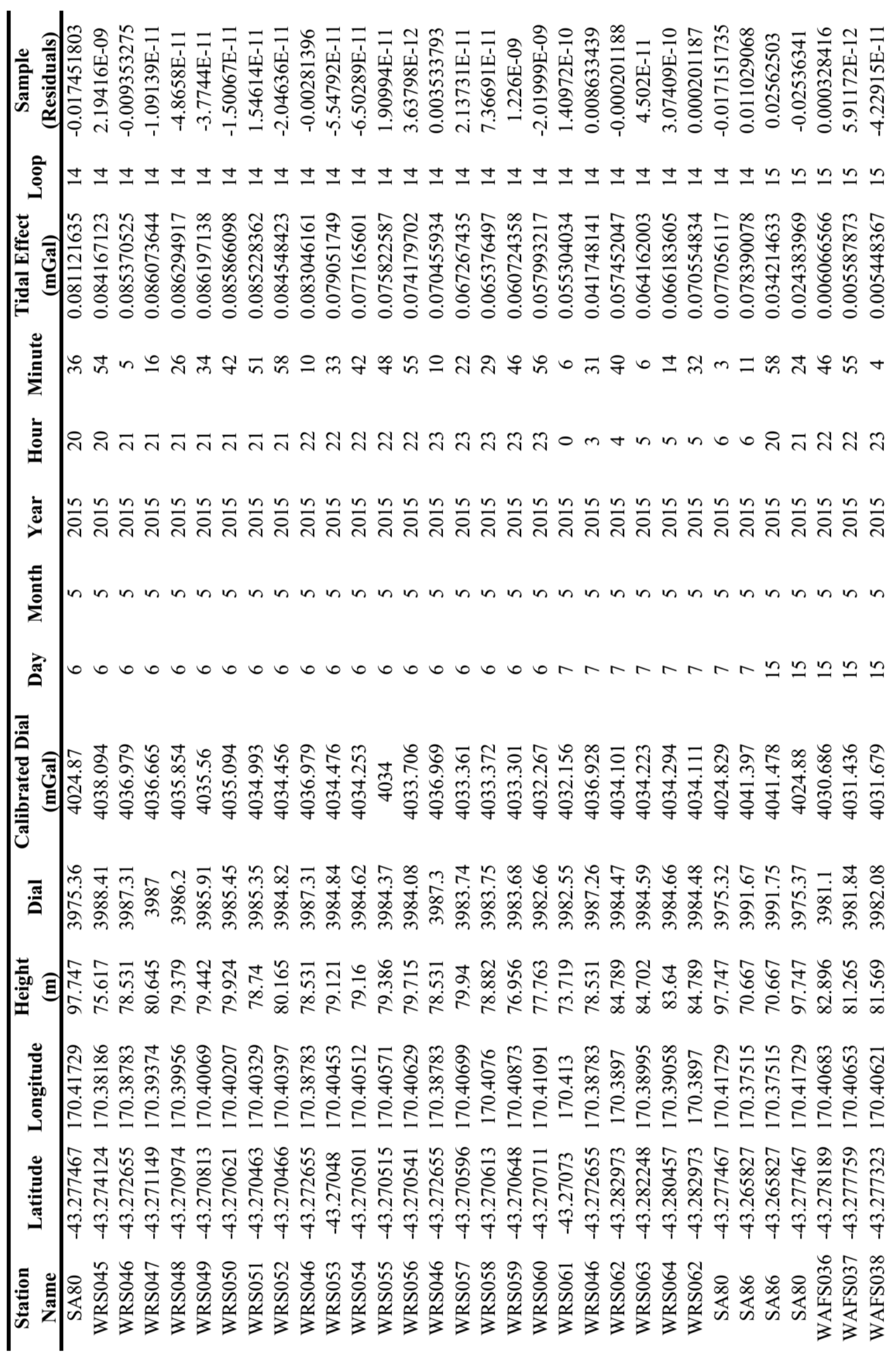

\section{Continued on next page}




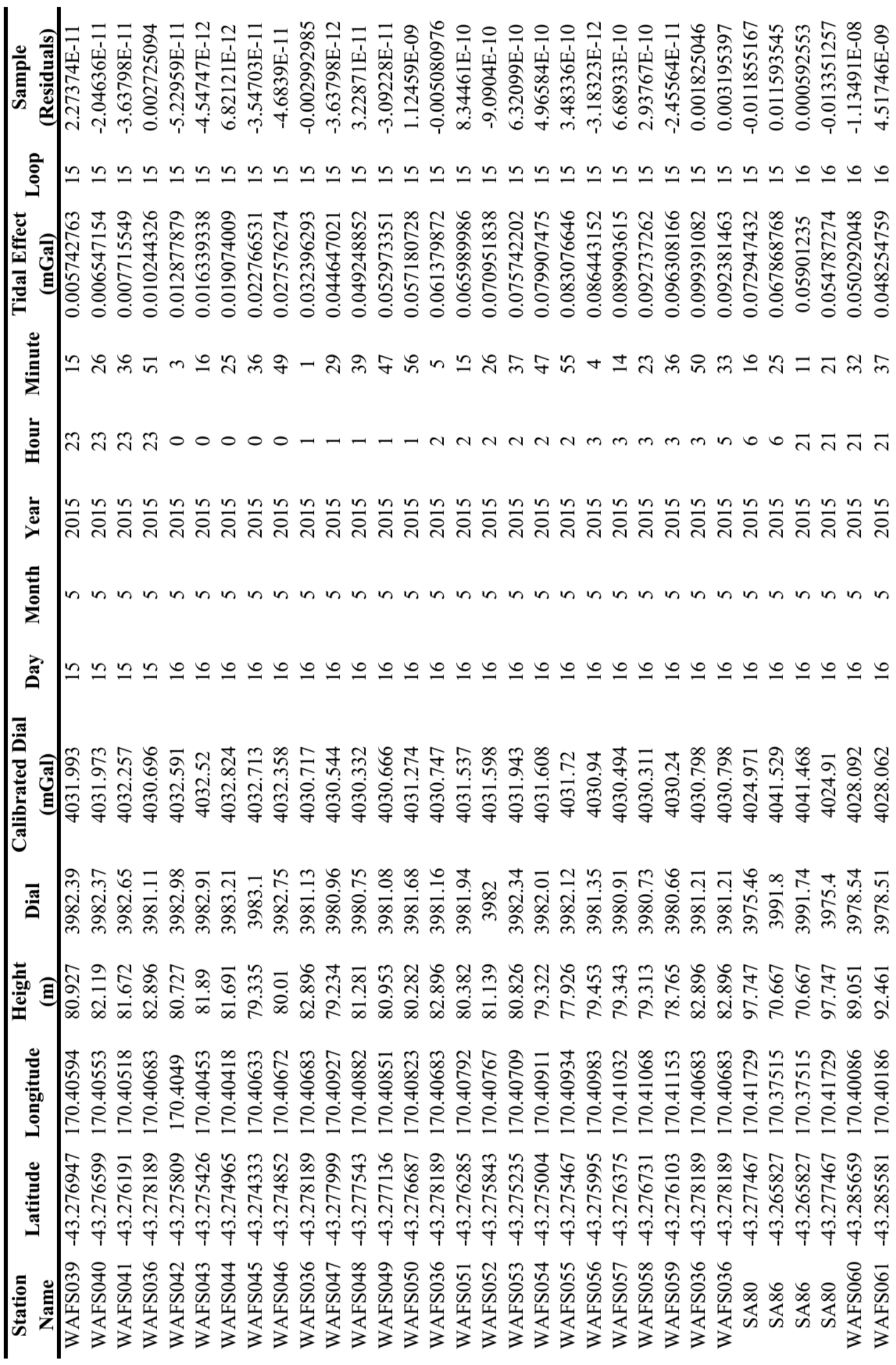

\section{Continued on next page}




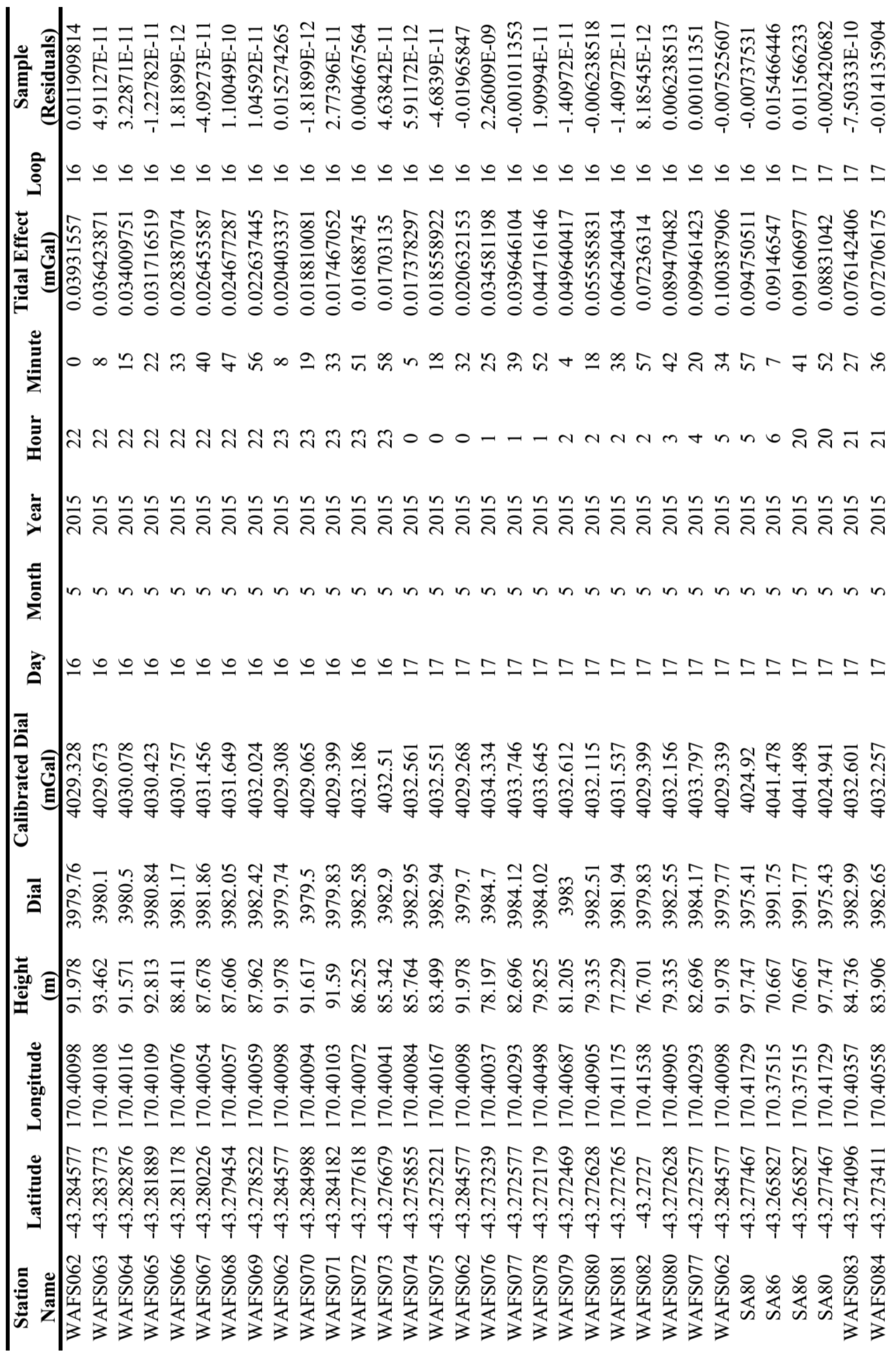

\section{Continued on next page}




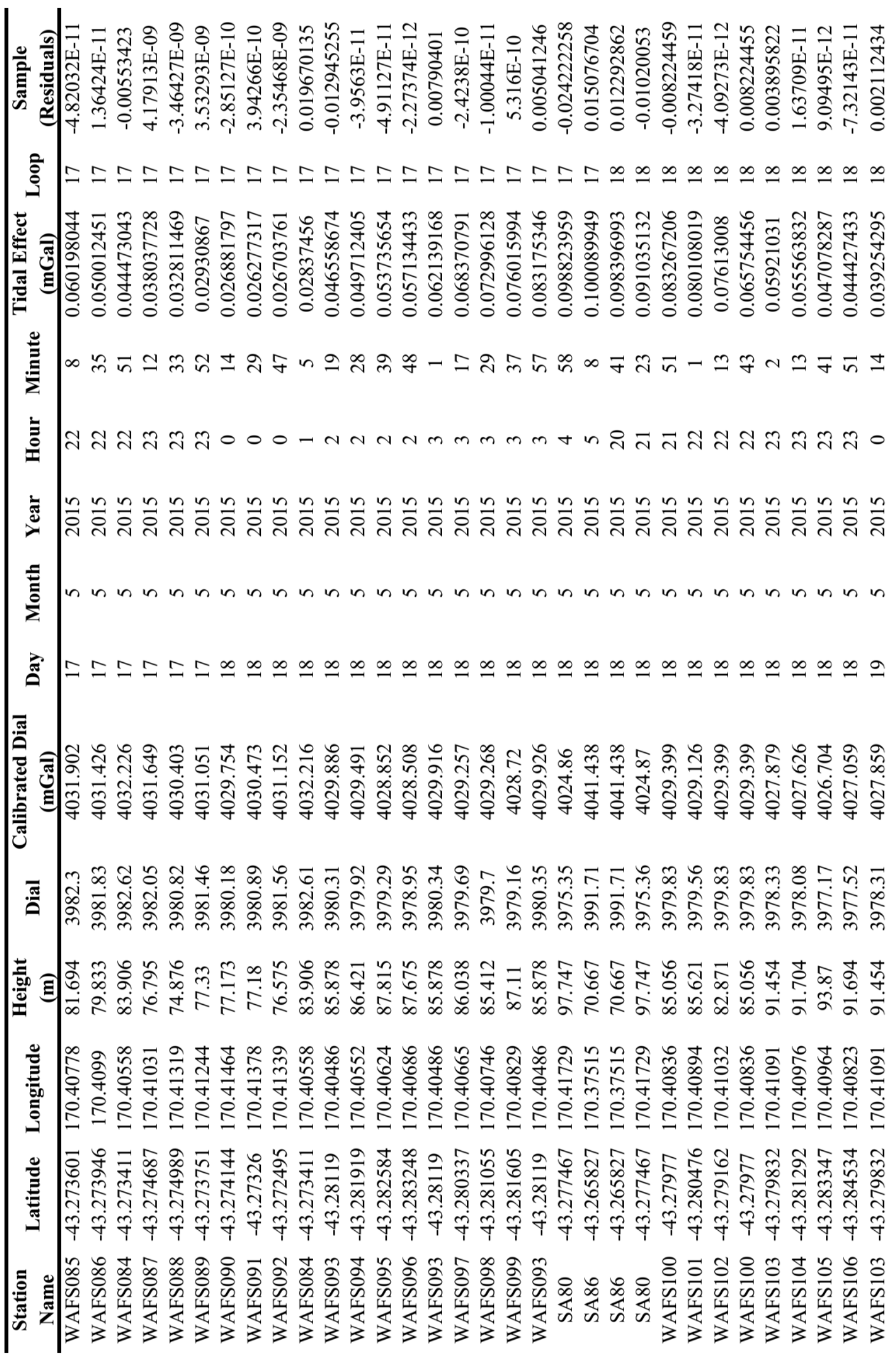

\section{Continued on next page}




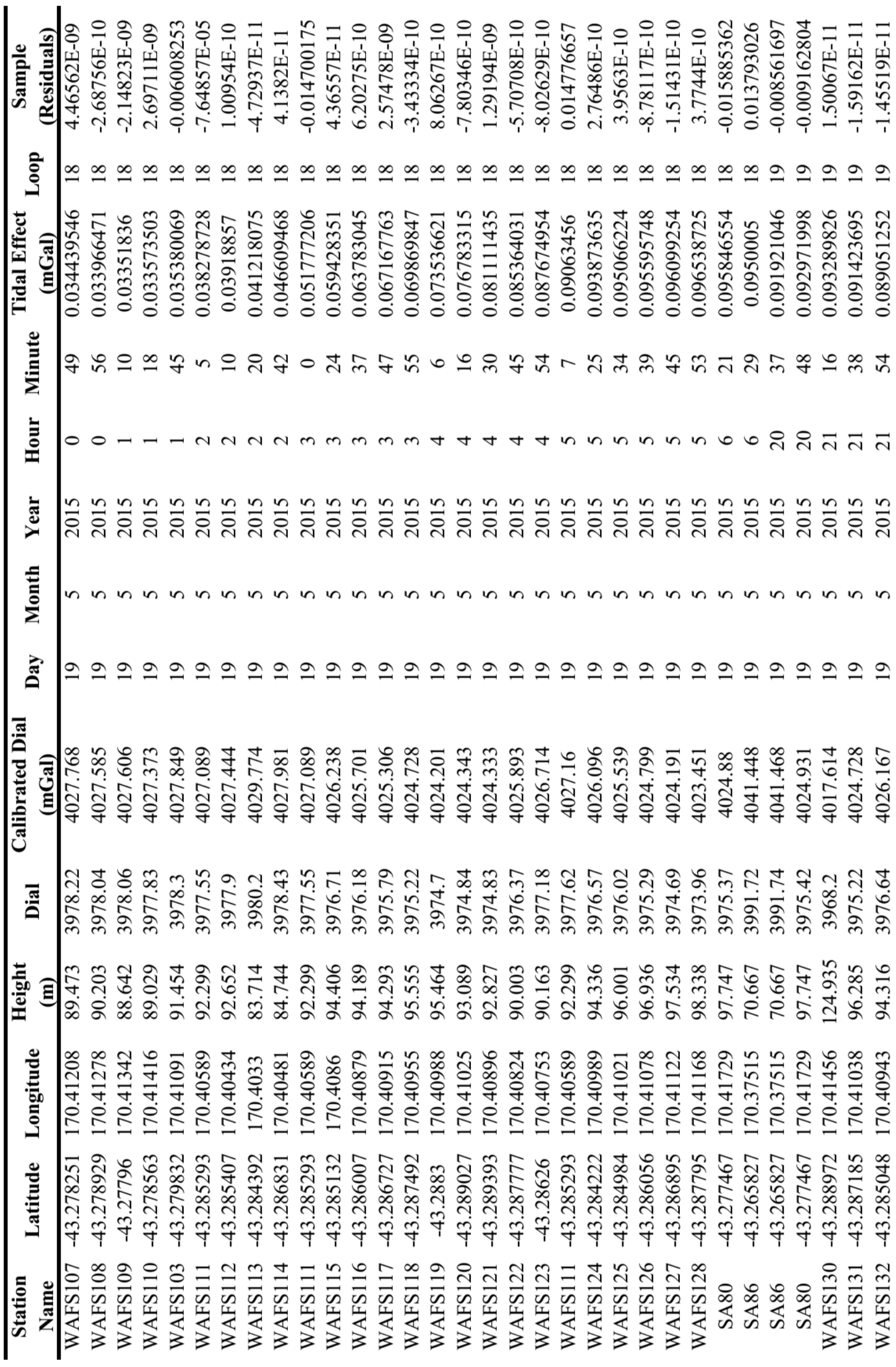

\section{Continued on next page}




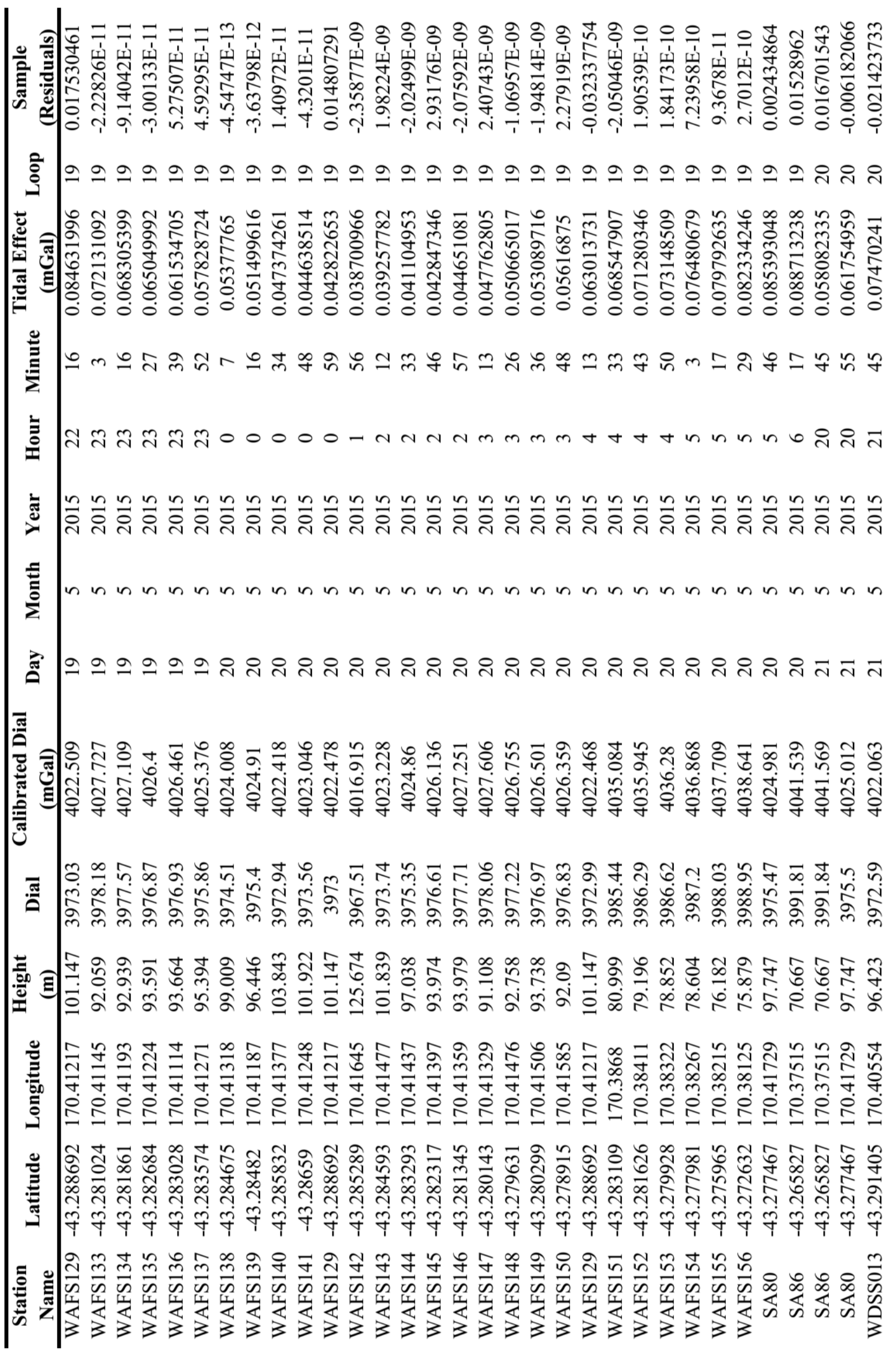

\section{Continued on next page}




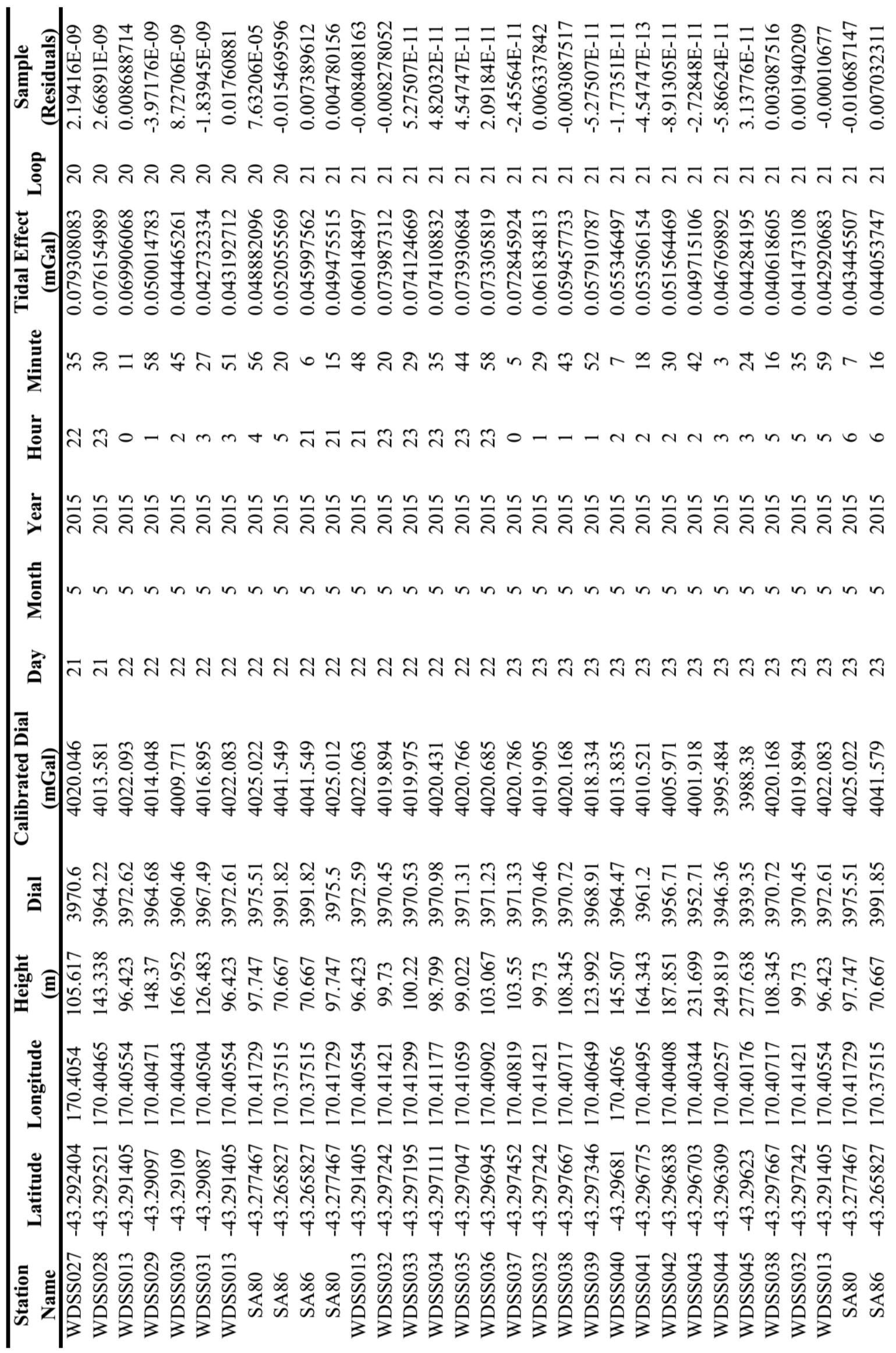

\section{Continued on next page}




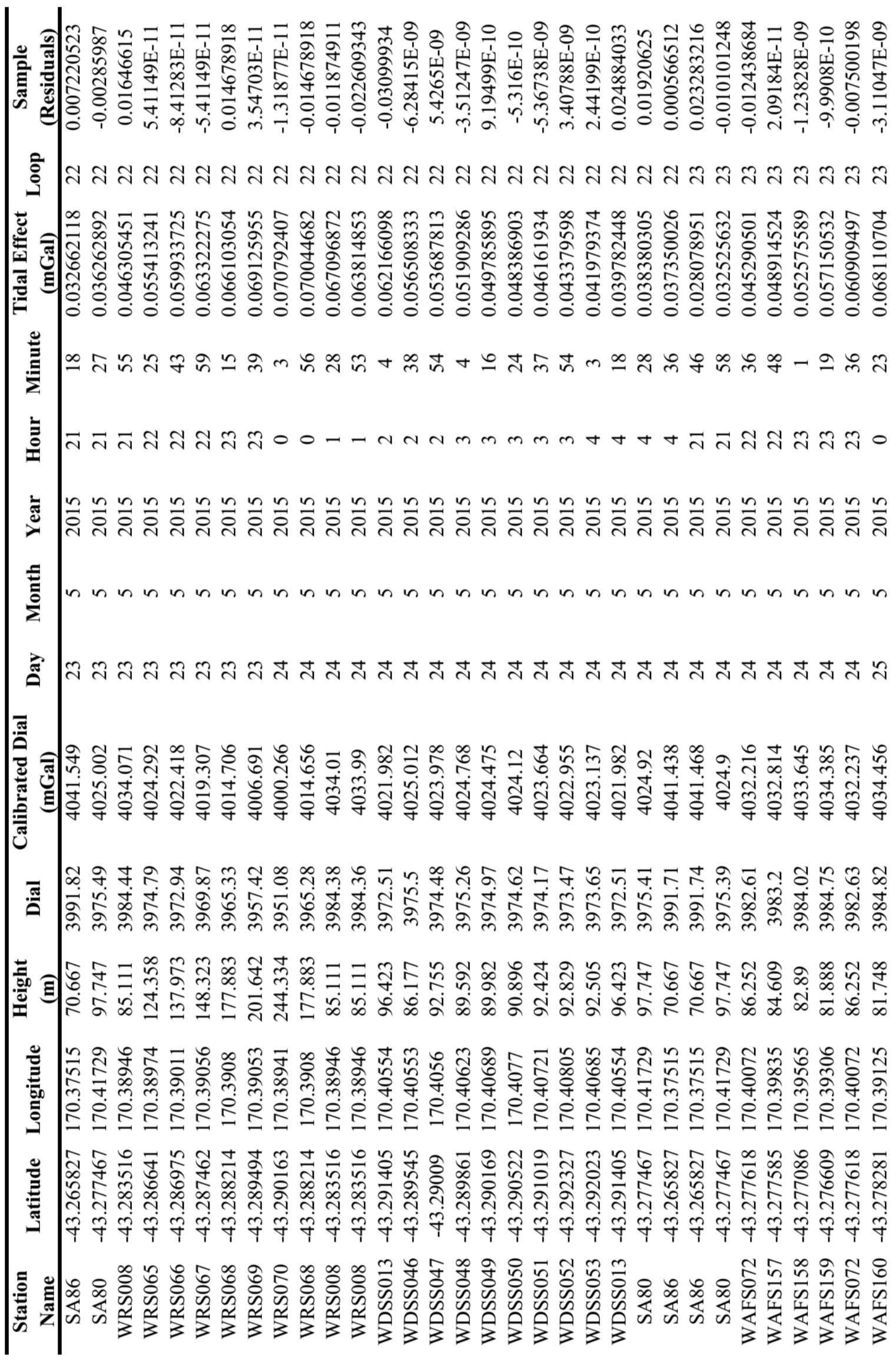

\section{Continued on next page}




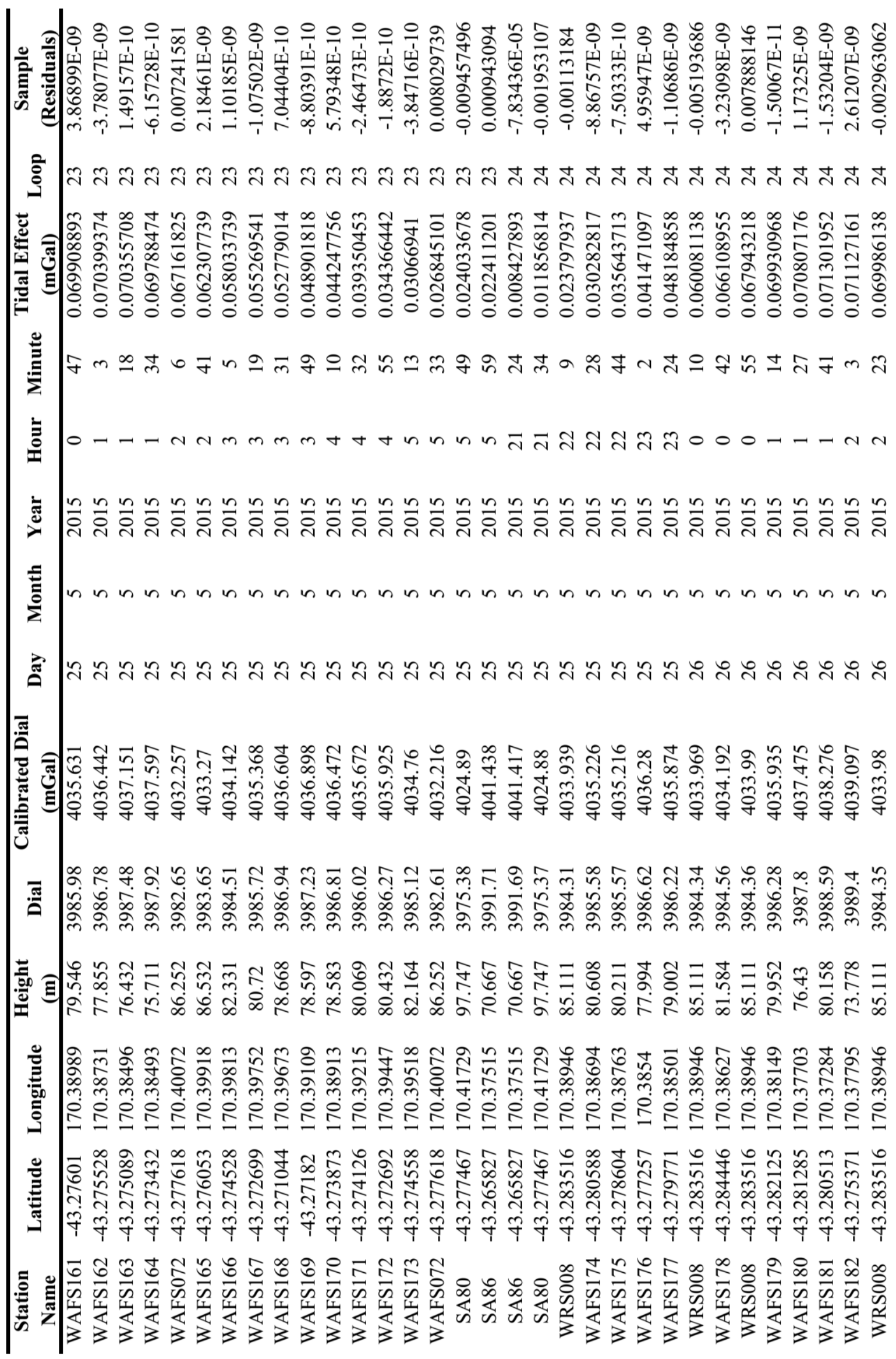

\section{Continued on next page}




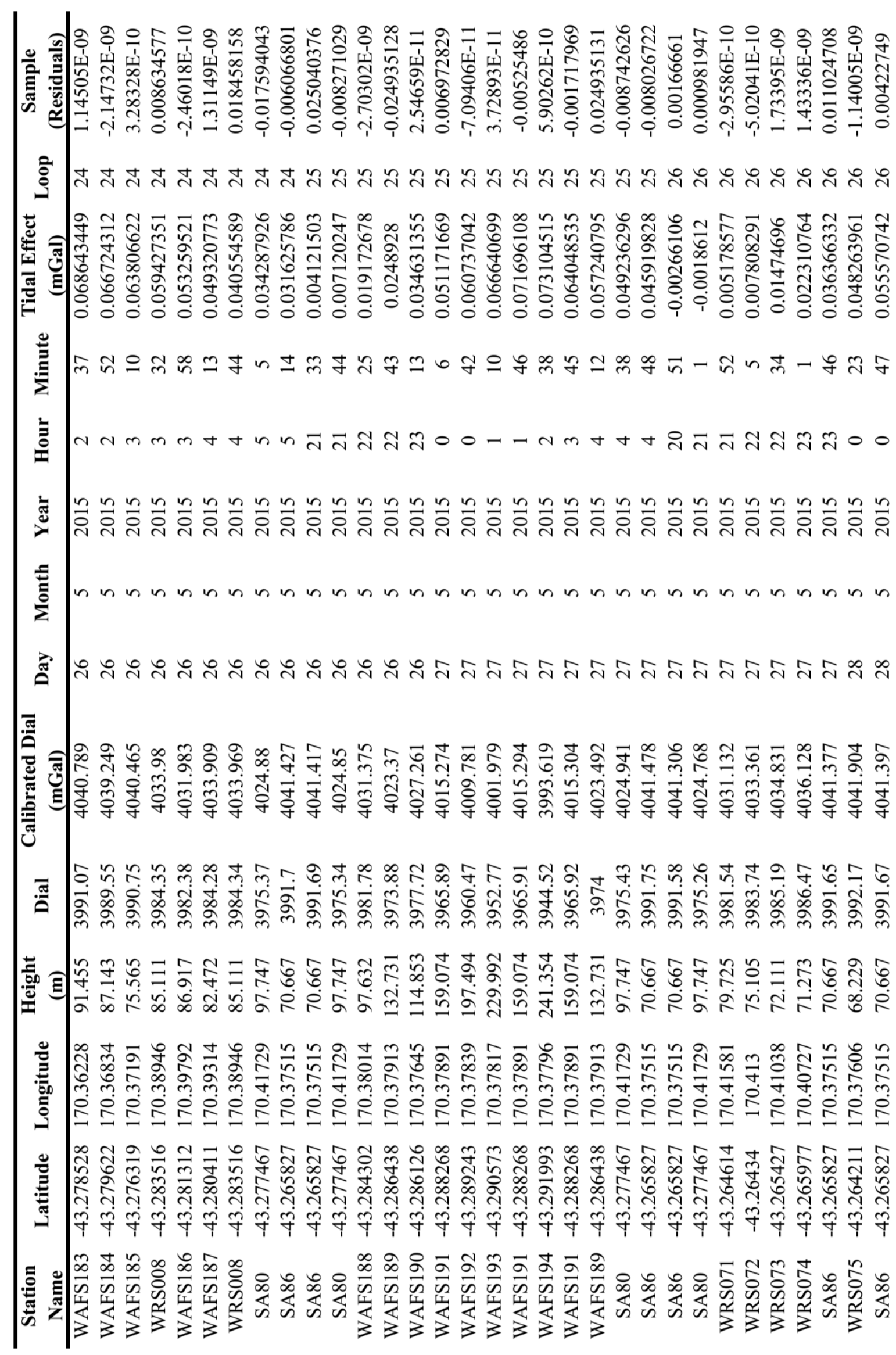

Continued on next page 


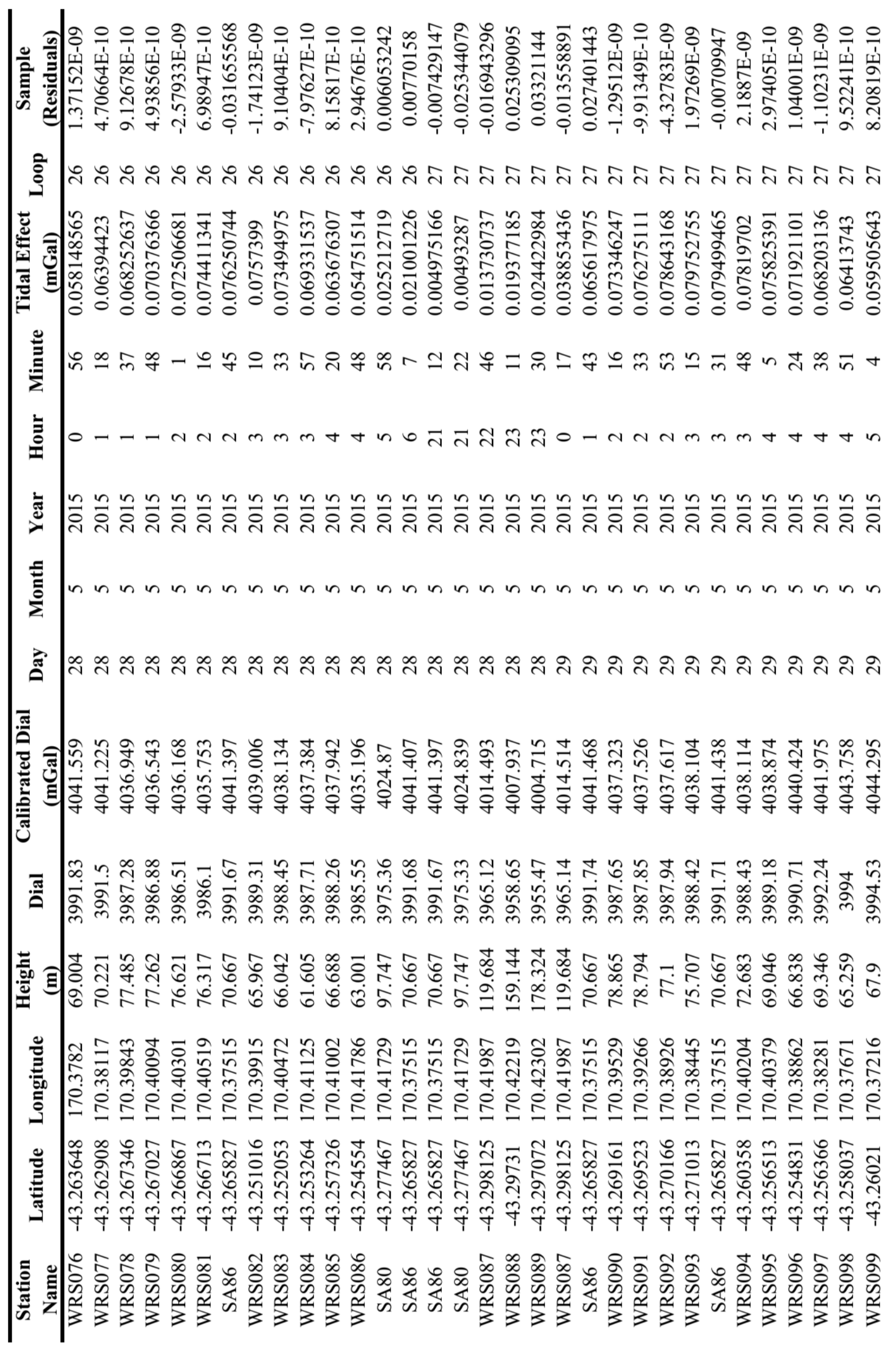

\section{Continued on next page}




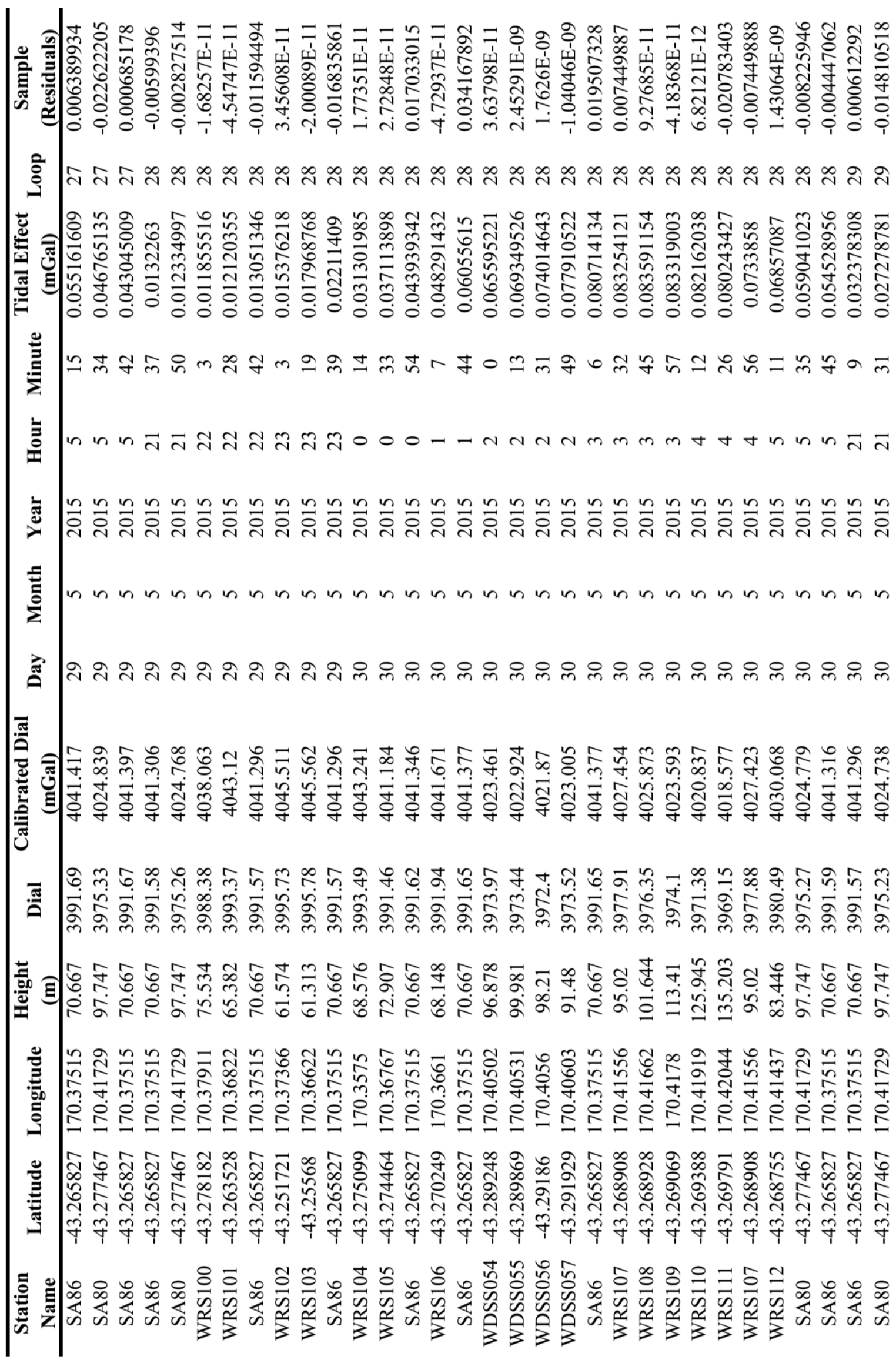

\section{Continued on next page}




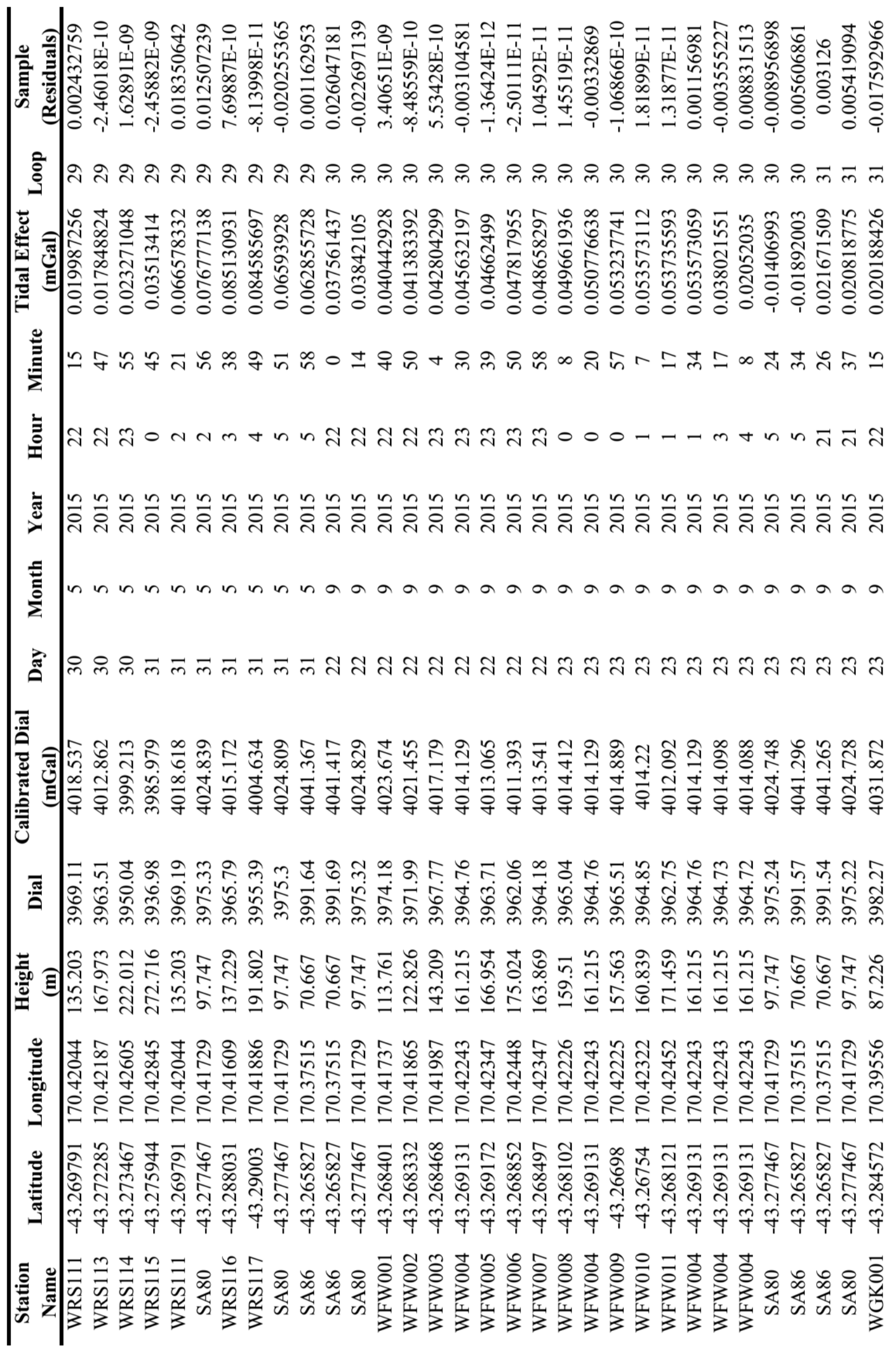

\section{Continued on next page}




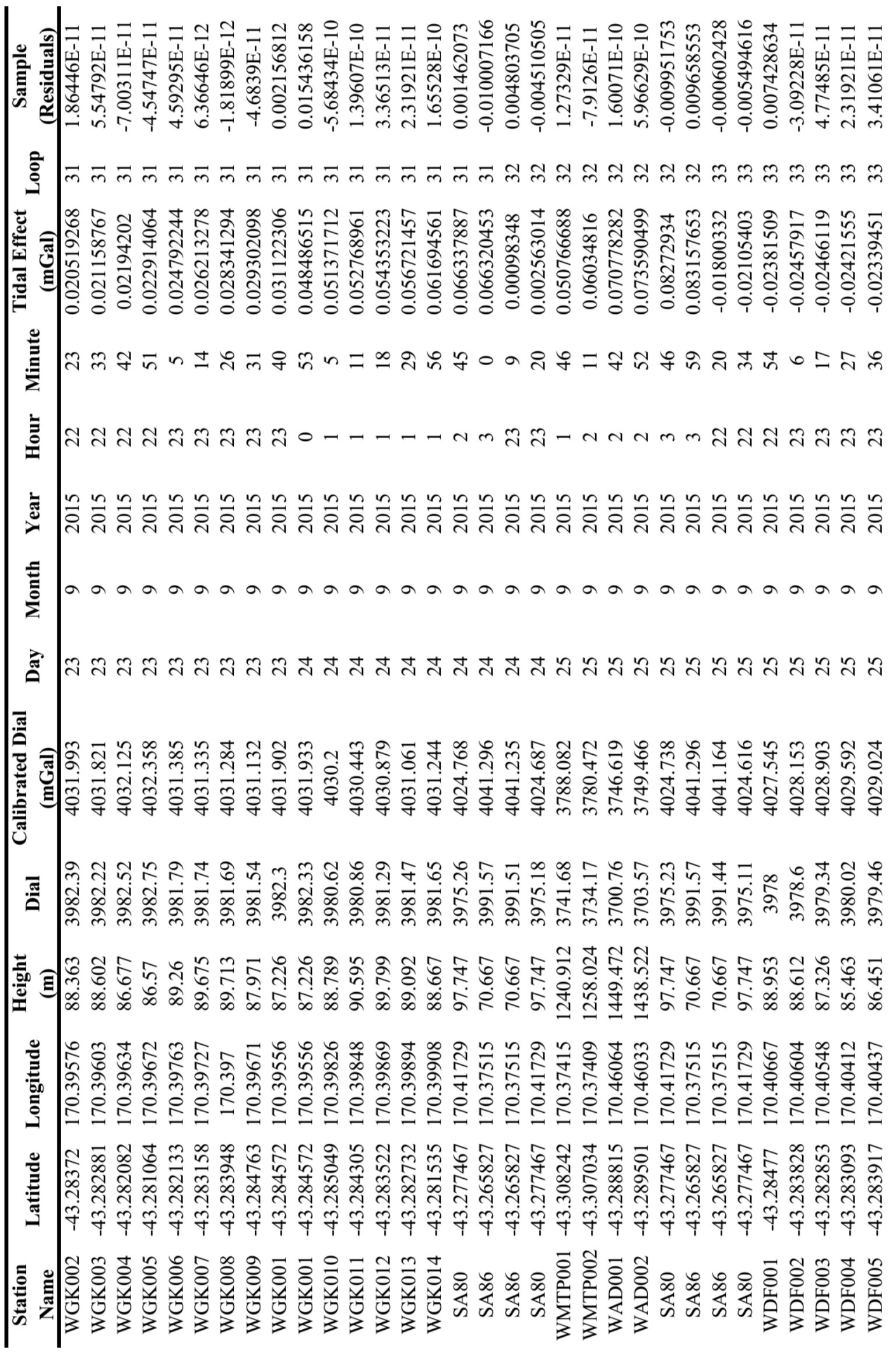

\section{Continued on next page}




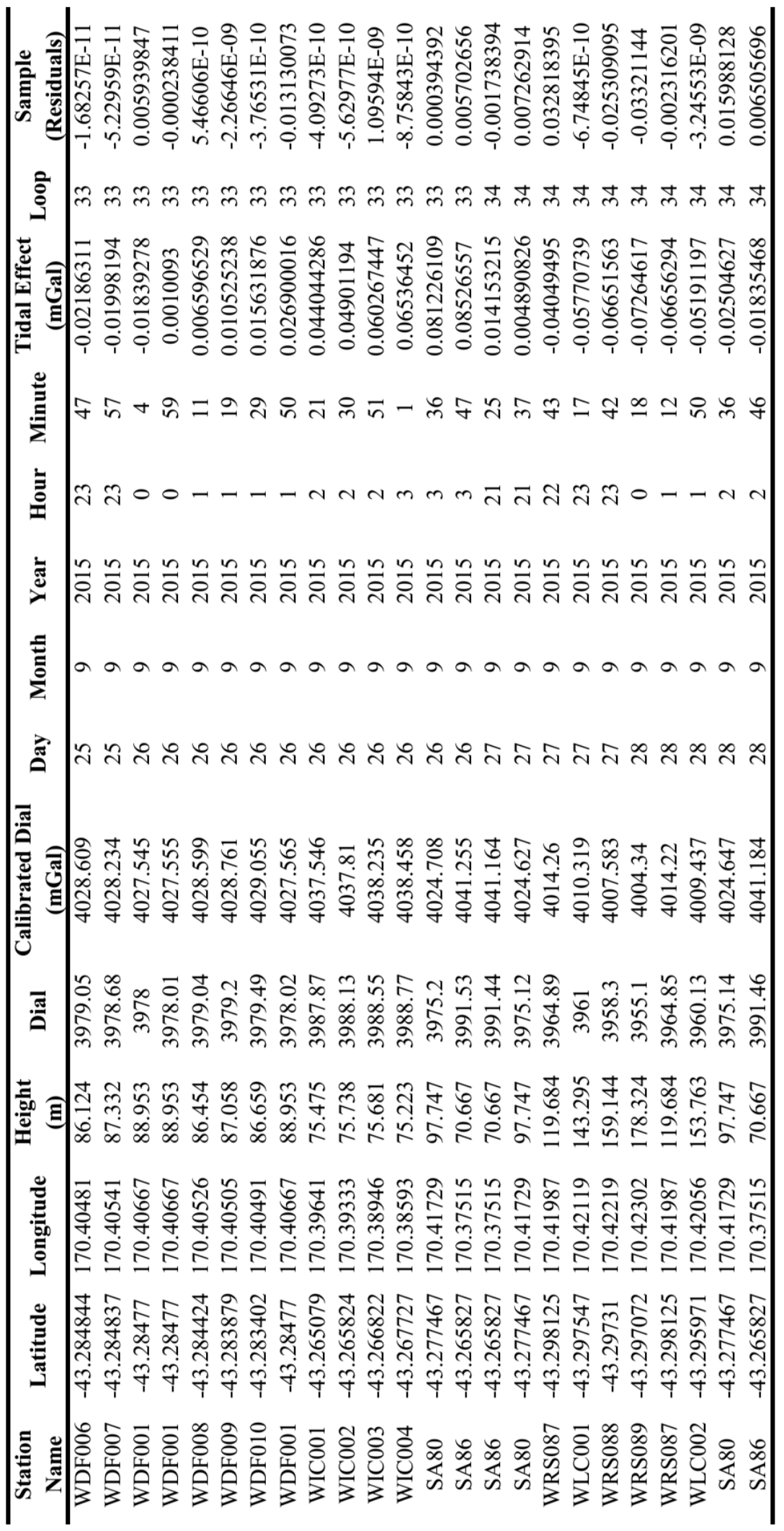

Table E.2: Survey measurements processed using Gsolve for the entire gravity survey.

Note that time has been converted to UTC. 

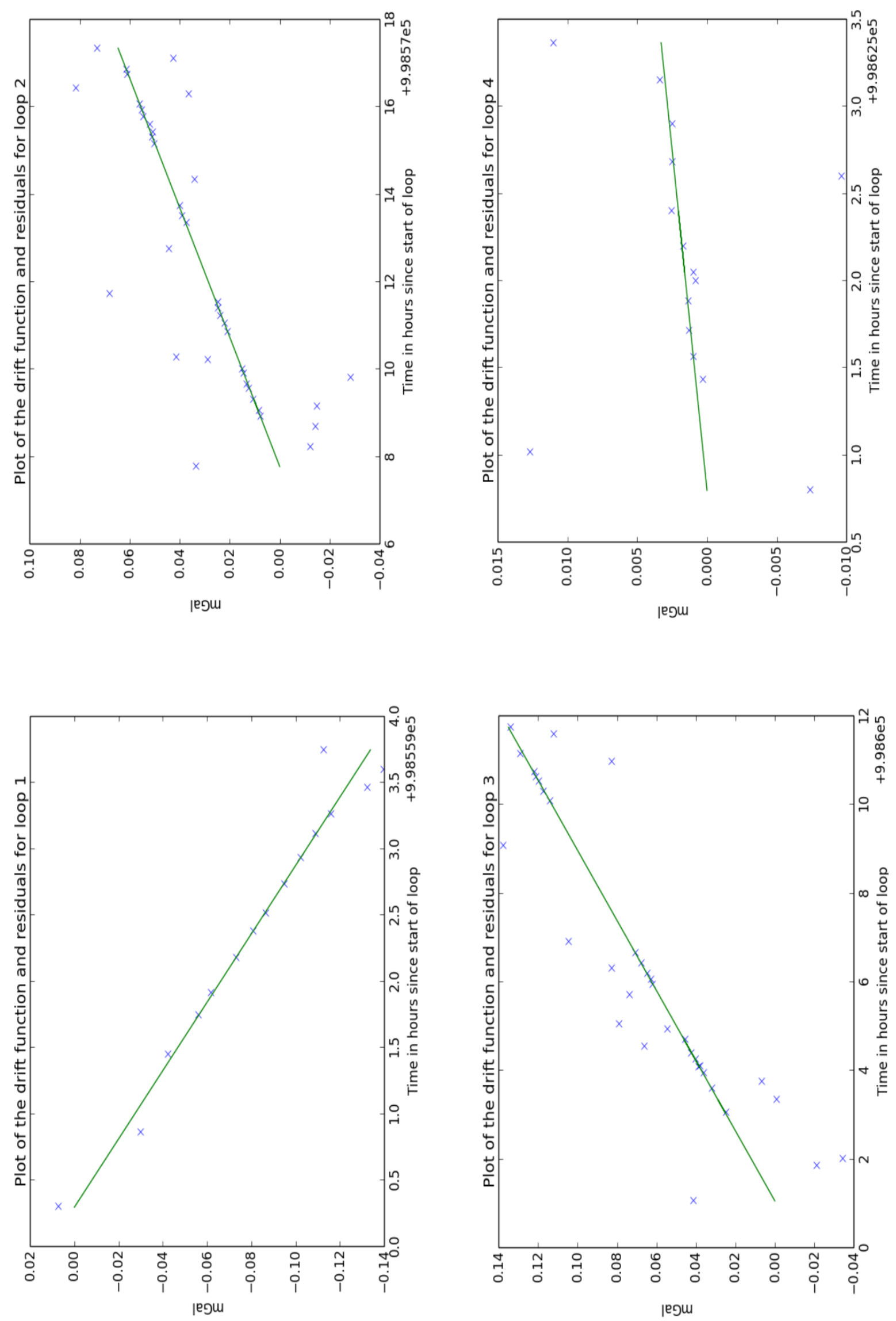

Continued on next page 

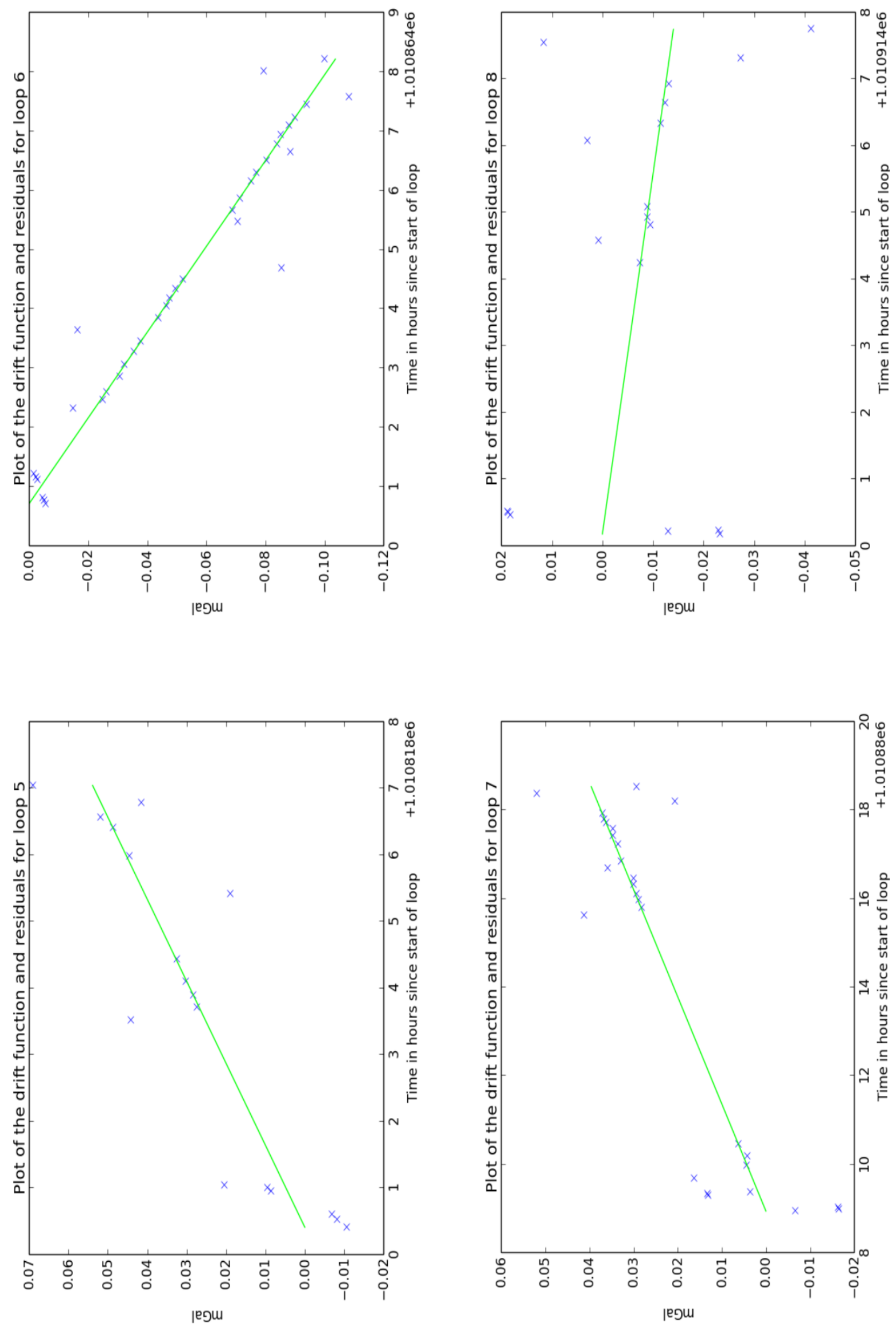

\section{Continued on next page}



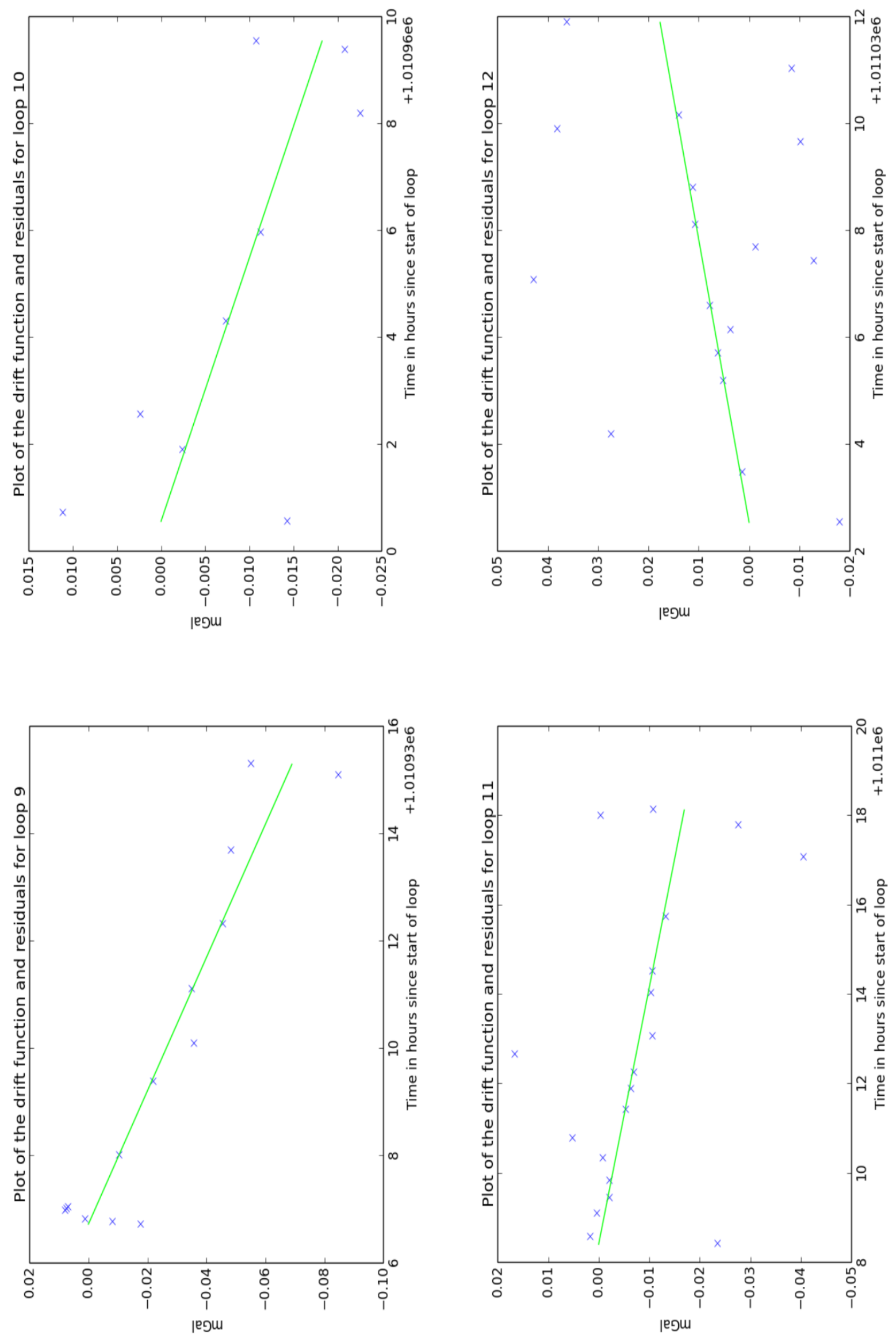

Continued on next page 

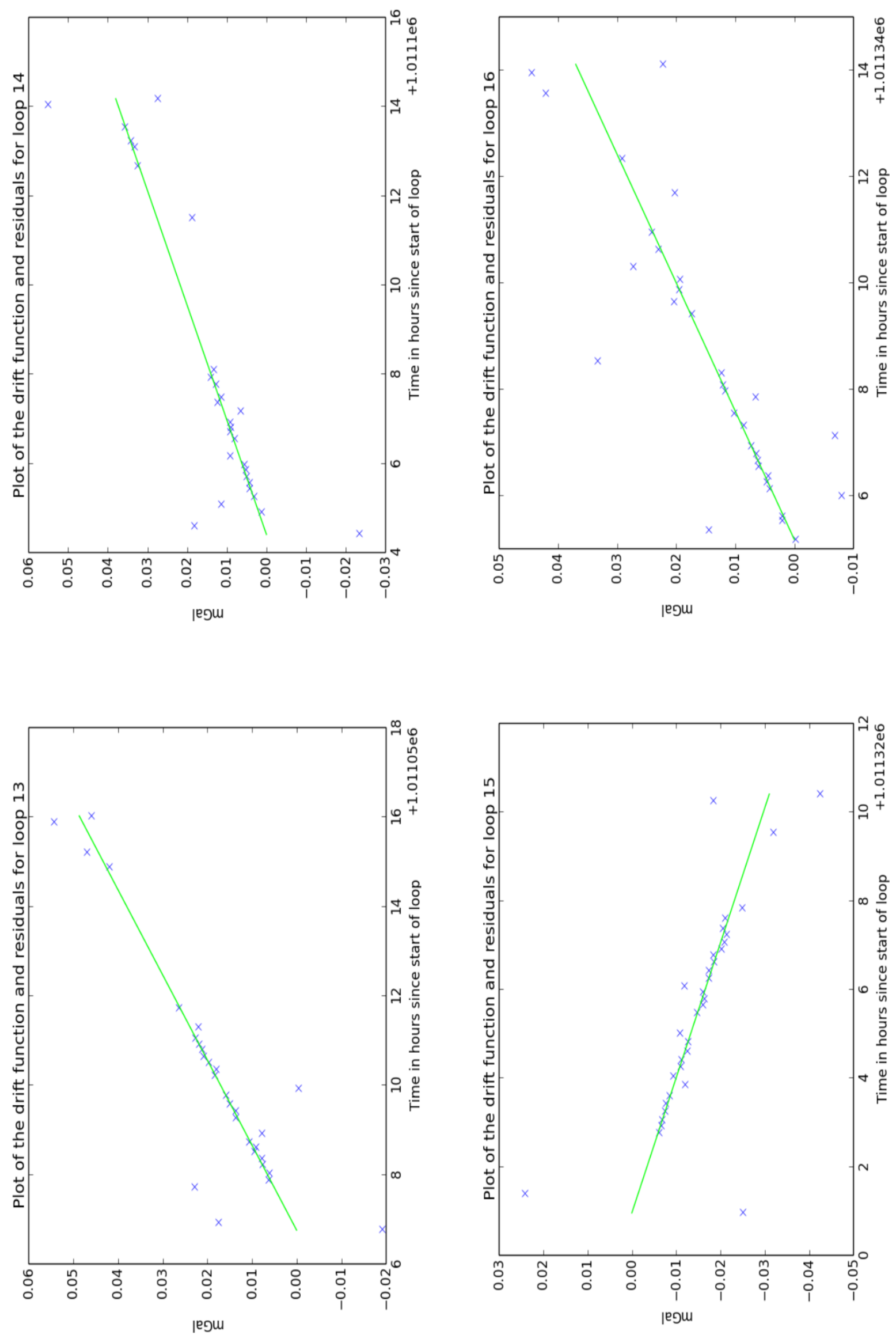

\section{Continued on next page}



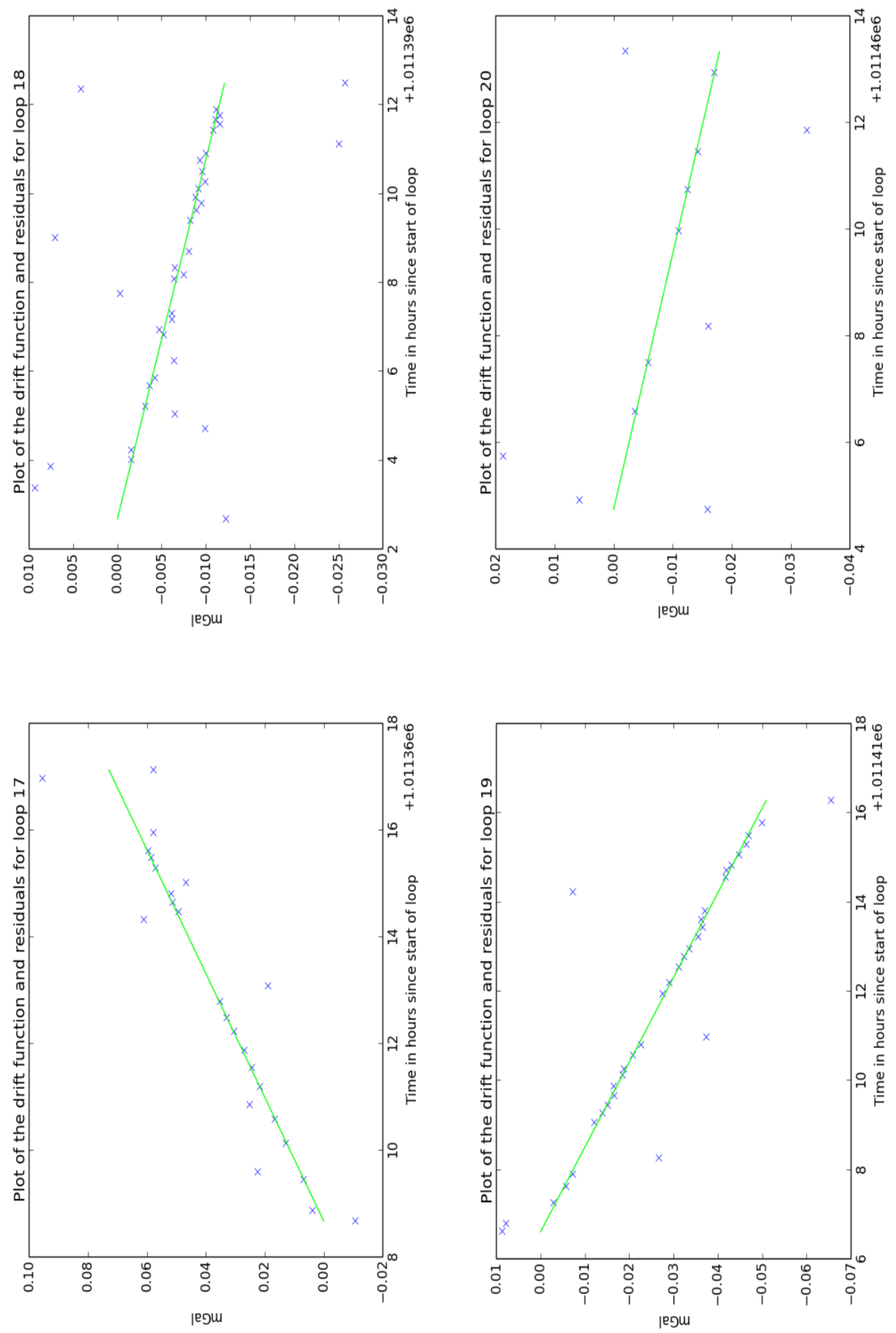

Continued on next page 

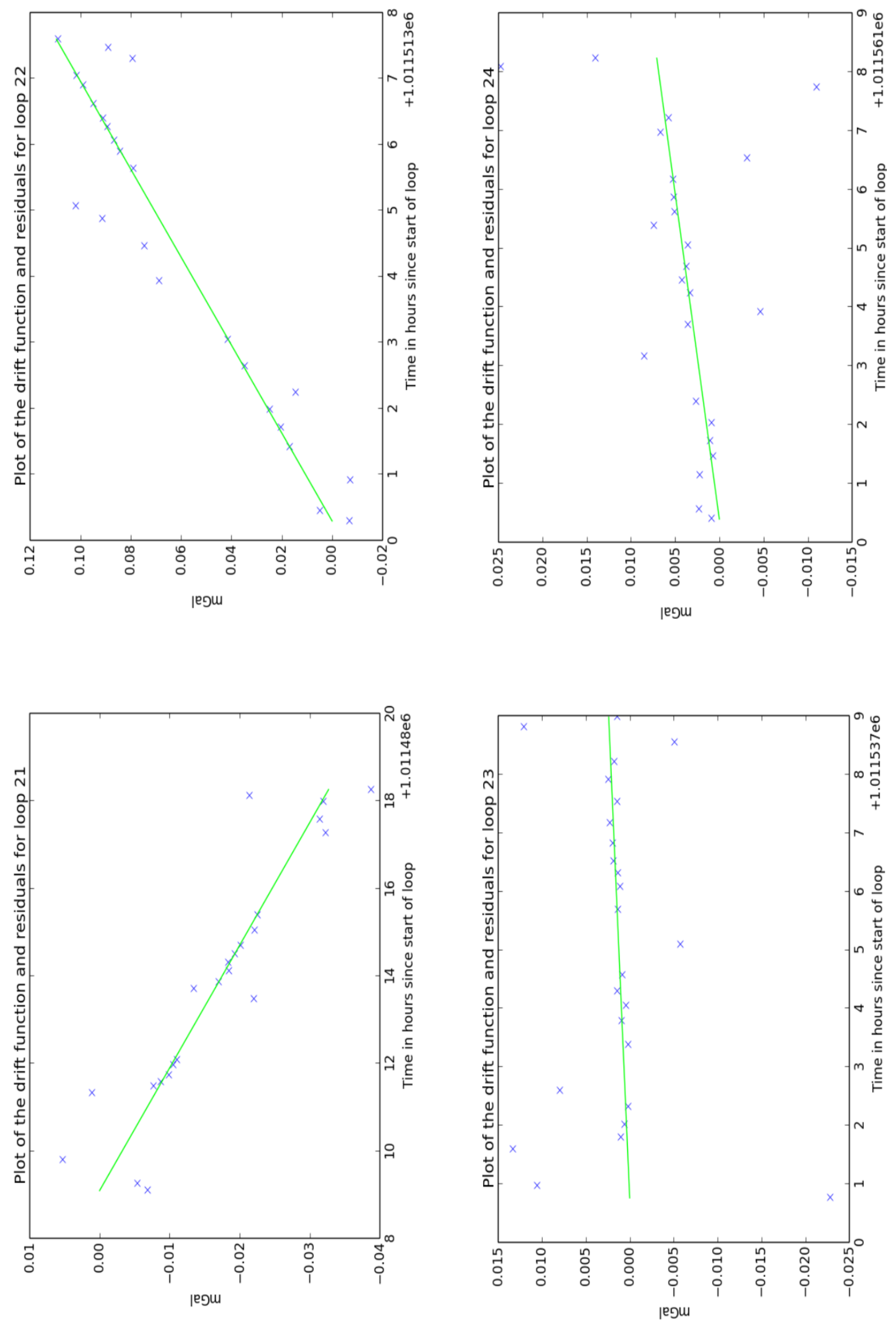

Continued on next page 

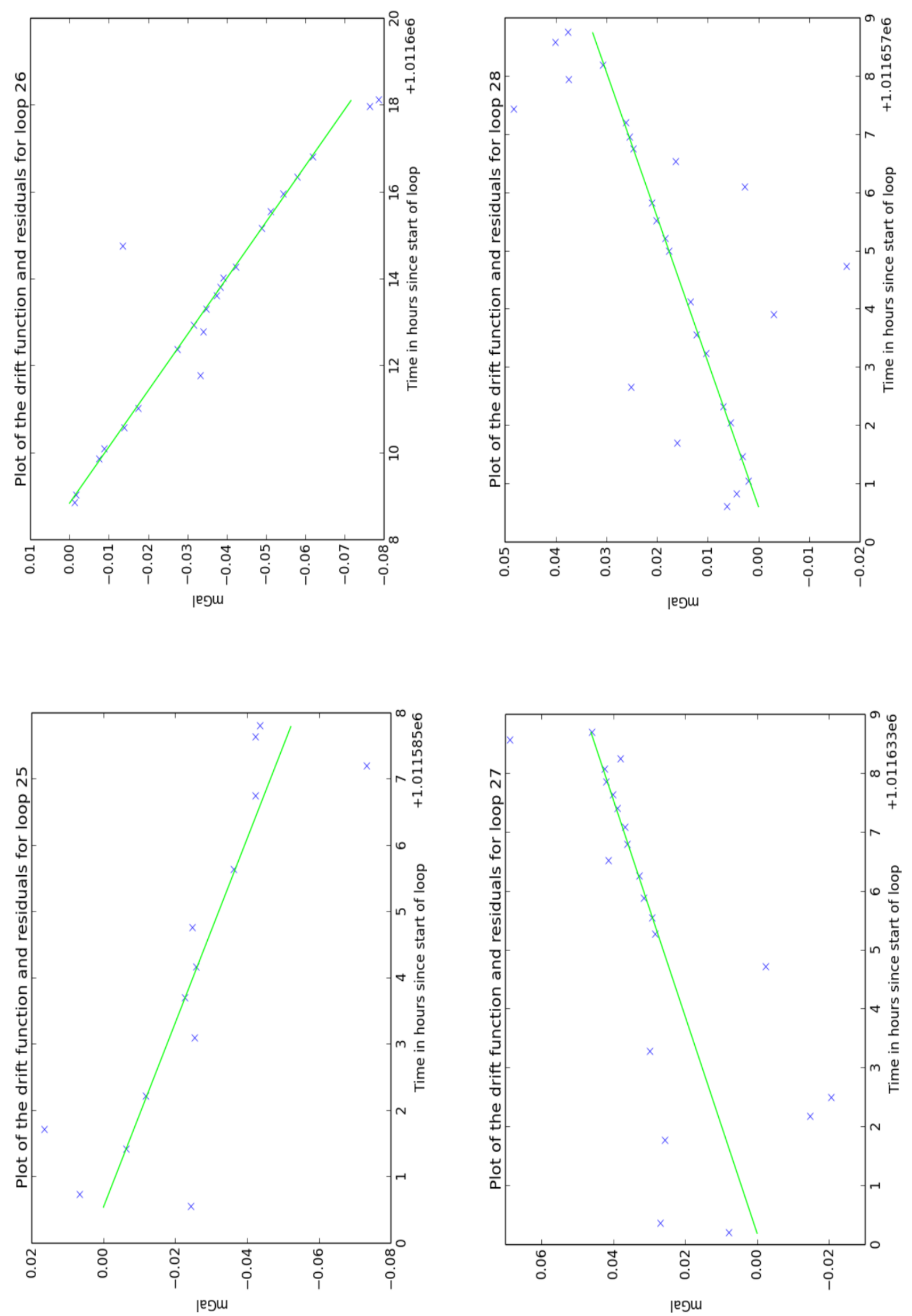

Continued on next page 
APPENDIX E: GSOLVE DATA
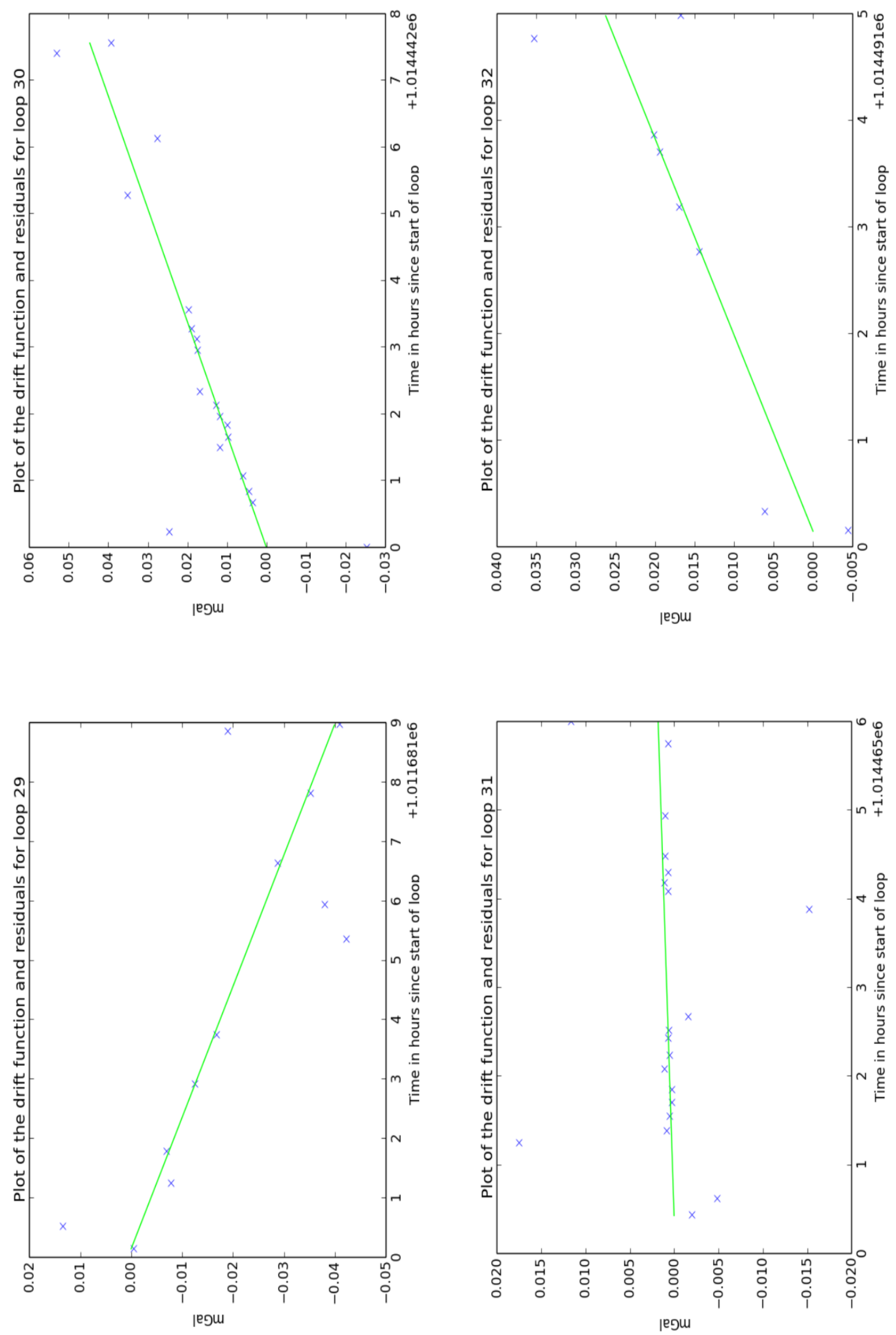

\section{Continued on next page}



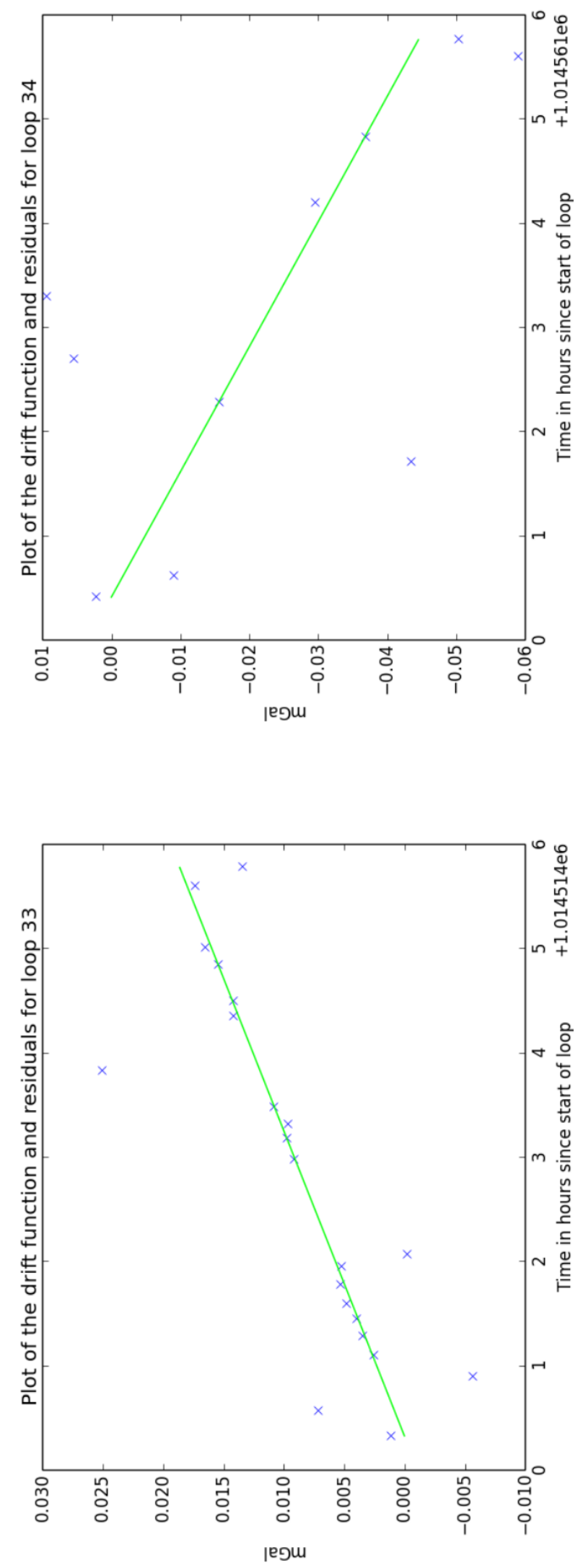

Figure E.1: Drift curves for all 34 survey loops produced using Gsolve. 


\section{Bibliography}

Adams, C., 1979, Age and origin of the Southern Alps: Royal Society of New Zealand Bulletin, v. 18, p. 73-78.

Adams, C., 1981, Uplift rates and thermal structure in the Alpine fault zone and Alpine schists, Southern Alps, New Zealand: Geological Society, London, Special Publications, v. 9, no. 1, p. 211-222.

Adams, C., Barley, M., Maas, R., and Doyle, M., 2002, Provenance of Permian-Triassic volcaniclastic sedimentary terranes in New Zealand: evidence from their radiogenic isotope characteristics and detrital mineral age patterns: New Zealand Journal of Geology and Geophysics, v. 45, no. 2, p. 221-242.

Adams, J., 1980a, Contemporary uplift and erosion of the Southern Alps, New Zealand: Geological Society of America Bulletin, v. 91, no. 1 Part II, p. 1-114.

Adams, J., 1980b, Paleoseismicity of the Alpine fault seismic gap, New Zealand: Geology, v. 8, no. 2, p. 72-76.

Allis, R. G., 1986, Mode of crustal shortening adjacent to the Alpine Fault, New Zealand: Tectonics, v. 5, no. 1, p. 15-32.

Alloway, B. V., Lowe, D. J., Barrell, D. J., Newnham, R. M., Almond, P. C., Augustinus, P. C., Bertler, N. A., Carter, L., Litchfield, N. J., and McGlone, M. S., 2007, Towards a climate event stratigraphy for New Zealand over the past 30000 years (NZ-INTIMATE project): Journal of Quaternary Science, v. 22, no. 1, p. $9-35$.

Almond, P., Duncan, R., Tonkin, P., Alloway, B., Barrell, D., Berryman, K., McSaveney, M., and Read, S., 2000, Catastrophic aggradation following the last Alpine Fault earthquake: Preliminary results from the Whataroa floodplain, South Westland, New Zealand, 9th Australia-New Zealand Geomorphology Group (ANZGG) Conference, Programme: Geomorphology Wanaka, p. 1.

Almond, P., Moar, N., and Lian, O., 2001, Reinterpretation of the glacial chronology of South Westland, New Zealand: New Zealand Journal of Geology and Geophysics, v. 44, no. 1, p. 1-15.

Almond, P. C., Barrell, D., Hyatt, O., Rother, H., Shulmeister, J., and Vandergoes, M., 2007, Quaternary geomorphology, stratigraphy, and paleoclimate of the central Southern Alps, South Island, Lincoln University. 
Anderson, B., Lawson, W., and Owens, I., 2008, Response of Franz Josef Glacier Ka Roimata o Hine Hukatere to climate change: Global and Planetary Change, v. 63, no. 1, p. 23-30.

Anderson, B., and Mackintosh, A., 2006, Temperature change is the major driver of late-glacial and Holocene glacier fluctuations in New Zealand: Geology, v. 34, no. 2, p. 121-124.

Anderson, H., Eberhart-Phillips, D., McEvilly, T., Wu, F., and Uhrhammer, R., 1997, Southern Alps passive seismic experiment: Institute of Geological and Nuclear Sciences Ltd., Lower Hutt, 0478095902.

Anderson, H., and Webb, T., 1994, New Zealand seismicity: patterns revealed by the upgraded National Seismograph Network: New Zealand journal of geology and geophysics, v. 37, no. 4, p. 477-493.

Barnes, P. M., 2009, Postglacial (after $20 \mathrm{ka}$ ) dextral slip rate of the offshore Alpine fault, New Zealand: Geology, v. 37, no. 1, p. 3-6.

Barnes, P. M., Sutherland, R., Davy, B., and Delteil, J., 2001, Rapid creation and destruction of sedimentary basins on mature strike-slip faults: an example from the offshore Alpine Fault, New Zealand: Journal of structural geology, v. 23, no. 11 , p. $1727-1739$.

Barnes, P. M., Sutherland, R., and Delteil, J., 2005, Strike-slip structure and sedimentary basins of the southern Alpine Fault, Fiordland, New Zealand: Geological Society of America Bulletin, v. 117, no. 3-4, p. 411-435.

Barrell, D. J., Almond, P. C., Vandergoes, M. J., Lowe, D. J., Newnham, R. M., and members, I., 2013, A composite pollen-based stratotype for inter-regional evaluation of climatic events in New Zealand over the past 30,000 years (NZINTIMATE project): Quaternary Science Reviews, v. 74, p. 4-20.

Barrell, D. J. A., 2011, Chapter 75 - Quaternary Glaciers of New Zealand, in Jürgen Ehlers, P. L. G., and Philip, D. H., eds., Developments in Quaternary Sciences, Volume Volume 15, Elsevier, p. 1047-1064.

Barrows, T. T., Almond, P., Rose, R., Fifield, L. K., Mills, S. C., and Tims, S. G., 2013, Late Pleistocene glacial stratigraphy of the Kumara-Moana region, west coast of South Island, New Zealand: Quaternary Science Reviews, v. 74, p. 139-159.

Barrows, T. T., Hope, G. S., Prentice, M. L., Fifield, L. K., and Tims, S. G., 2011, Late Pleistocene glaciation of the Mt Giluwe volcano, Papua New Guinea: Quaternary Science Reviews, v. 30, no. 19, p. 2676-2689.

Barrows, T. T., and Juggins, S., 2005, Sea-surface temperatures around the Australian margin and Indian Ocean during the Last Glacial Maximum: Quaternary Science Reviews, v. 24, no. 7, p. 1017-1047. 
Barrows, T. T., Juggins, S., De Deckker, P., Calvo, E., and Pelejero, C., 2007, Longterm sea surface temperature and climate change in the Australian-New Zealand region: Paleoceanography, v. 22, no. 2.

Barth, N., Kulhanek, D., Beu, A., Murray-Wallace, C., Hayward, B., Mildenhall, D., and Lee, D. E., 2013, New c. 270 kyr strike-slip and uplift rates for the southern Alpine Fault and implications for the New Zealand plate boundary: Journal of Structural Geology, v. 64, p. 39-52.

Barth, N. C., Toy, V. G., Langridge, R. M., and Norris, R. J., 2012, Scale dependence of oblique plate-boundary partitioning: New insights from LiDAR, central Alpine fault, New Zealand: Lithosphere, v. 4, no. 5, p. 435-448.

Batt, G. E., 2001, The approach to steady-state thermochronological distribution following orogenic development in the Southern Alps of New Zealand: American Journal of Science, v. 301, no. 4-5, p. 374-384.

Beaumont, C., Kamp, P. J. J., Hamilton, J., and Fullsack, P., 1996, The continental collision zone, South Island, New Zealand: Comparison of geodynamical models and observations: Journal of Geophysical Research: Solid Earth, v. 101, no. B2, p. 3333-3359.

Beavan, J., Denys, P., Denham, M., Hager, B., Herring, T., and Molnar, P., 2010, Distribution of present-day vertical deformation across the Southern Alps, New Zealand, from 10 years of GPS data: Geophysical Research Letters, v. 37, no. 16.

Beavan, J., Ellis, S., Wallace, L., and Denys, P., 2007, Kinematic constraints from GPS on oblique convergence of the Pacific and Australian plates, central South Island, New Zealand: A Continental Plate Boundary: Tectonics at South Island, New Zealand, p. 75-94.

Beavan, J., Moore, M., Pearson, C., Henderson, M., Parsons, B., Bourne, S., England, P., Walcott, D., Blick, G., Darby, D., and Hodgkinson, K., 1999, Crustal deformation during 1994-1998 due to oblique continental collision in the central Southern Alps, New Zealand, and implications for seismic potential of the Alpine fault: Journal of Geophysical Research: Solid Earth, v. 104, no. B11, p. $25233-25255$.

Beavan, J., Tregoning, P., Bevis, M., Kato, T., and Meertens, C., 2002, Motion and rigidity of the Pacific Plate and implications for plate boundary deformation: Journal of Geophysical Research: Solid Earth, v. 107, no. B10.

Beck, A. E., 1981, Physical principles of exploration methods: an introductory text for geology and geophysics students.

Beggs, J., Challis, G., and Cook, R., 1990, Basement geology of the Campbell Plateau: implications for correlation of the Campbell Magnetic Anomaly System: New Zealand journal of geology and geophysics, v. 33, no. 3, p. 401-404. 
Berryman, K., Beanland, S., Cooper, A., Cutten, H., Norris, R., and Wood, P., 1992, The Alpine Fault, New Zealand: variation in Quaternary structural style and geomorphic expression: Annales tectonicae, v. 6, no. Suppl, p. 126-163.

Biasi, G. P., Langridge, R. M., Berryman, K. R., Clark, K. J., and Cochran, U. A., 2015, Maximum-Likelihood Recurrence Parameters and Conditional Probability of a Ground-Rupturing Earthquake on the Southern Alpine Fault, South Island, New Zealand: Bulletin of the Seismological Society of America, v. 105, no. 1, p. 94106.

Boese, C., Jacobs, K., Smith, E., Stern, T., and Townend, J., 2014, Background and delayed-triggered swarms in the central Southern Alps, South Island, New Zealand: Geochemistry, Geophysics, Geosystems, v. 15, no. 4, p. 945-964.

Boese, C., Townend, J., Smith, E., and Stern, T., 2012, Microseismicity and stress in the vicinity of the Alpine Fault, central Southern Alps, New Zealand: Journal of Geophysical Research: Solid Earth, v. 117, no. B2.

Bourguignon, S., Bannister, S., Henderson, C. M., Townend, J., and Zhang, H., 2015, Structural heterogeneity of the midcrust adjacent to the central Alpine Fault, New Zealand: Inferences from seismic tomography and seismicity between Harihari and Ross: Geochemistry, Geophysics, Geosystems, v. 16, no. 4, p. 1017-1043.

Bourguignon, S., Savage, M., and Stern, T., 2007a, Crustal thickness and Pn anisotropy beneath the Southern Alps oblique collision, New Zealand: A Continental Plate Boundary: Tectonics at South Island, New Zealand, p. 115-122.

Bourguignon, S., Stern, T. A., and Savage, M. K., 2007b, Crust and mantle thickening beneath the southern portion of the Southern Alps, New Zealand: Geophysical Journal International, v. 168, no. 2, p. 681-690.

Bradshaw, J. D., 1989, Cretaceous geotectonic patterns in the New Zealand region: Tectonics, v. 8, no. 4, p. 803-820.

Brikke, N., 2007, Seismic velocity structure of the shallow part of the Alpine fault and gravity study of the basement features in the Whataroa River flood plain, Central Westland, South Island [Post Graduate Diploma PGD]: Victoria University of Wellington.

Brocher, T. M., 2005, Empirical relations between elastic wavespeeds and density in the Earth's crust: Bulletin of the Seismological Society of America, v. 95, no. 6, p. 2081-2092.

Burger, H. R., Sheehan, A. F., and Jones, C. H., 2006, Introduction to applied geophysics: Exploring the shallow subsurface, WW Norton.

Carrivick, J. L., and Tweed, F. S., 2013, Proglacial lakes: character, behaviour and geological importance: Quaternary Science Reviews, v. 78, p. 34-52. 
Chamberlain, C. J., Shelly, D. R., Townend, J., and Stern, T. A., 2014, Low-frequency earthquakes reveal punctuated slow slip on the deep extent of the Alpine Fault, New Zealand: Geochemistry, Geophysics, Geosystems, v. 15, no. 7, p. 29842999.

Christensen, N. I., and Okaya, D. A., 2007, Compressional and shear wave velocities in South Island, New Zealand rocks and their application to the interpretation of seismological models of the New Zealand crust: A Continental Plate Boundary: Tectonics at South Island, New Zealand, p. 123-155.

Cook, S. J., and Swift, D. A., 2012, Subglacial basins: Their origin and importance in glacial systems and landscapes: Earth-Science Reviews, v. 115, no. 4, p. 332372.

Cooper, A., 1980, Retrograde alteration of chromian kyanite in metachert and amphibolite whiteschist from the Southern Alps, New Zealand, with implications for uplift on the Alpine Fault: Contributions to mineralogy and petrology, v. 75, no. 2, p. 153-164.

Cooper, A. F., and Norris, R. J., 1994, Anatomy, structural evolution, and slip rate of a plate-boundary thrust: The Alpine fault at Gaunt Creek, Westland, New Zealand: Geological Society of America Bulletin, v. 106, no. 5, p. 627-633.

Cooper, A. F., and Norris, R. J., 1995, Displacement on the Alpine Fault at Haast River, South Westland, New Zealand: New Zealand Journal of Geology and Geophysics, v. 38, no. 4, p. 509-514.

Cooper, R., 1989, New Zealand tectonostratigraphic terranes and panbiogeography: New Zealand journal of zoology, v. 16, no. 4, p. 699-712.

Cooper, R., and Tulloch, A., 1992, Early Palaeozoic terranes in New Zealand and their relationship to the Lachlan Fold Belt: Tectonophysics, v. 214, no. 1, p. 129-144.

Cotton, C. A., Coastal history of southern Westland and northern Fiordland, in Proceedings Transactions of the Royal Society of New Zealand1956, Volume 83 , p. $483-488$.

Cox, S., Howarth, J. D., Upton, P., Sutherland, R., Langridge, R., and Barth, N., Quaternary geology of the DFDP-2 drill holes, Alpine Fault, New Zealand, in Proceedings AGU Fall Meeting Abstracts, San Francisco, California, USA: Muscone, 2015.

Cox, S. C., and Barrell, D. J. A., 2007, Geology of the Aoraki area, Institute of Geological and Nuclear Sciences 1: 250000 geological Map 15: Lower Hutt, New Zealand (GNS Science), v. 1 sheet +71 p.

Cox, S. C., Sims, A., Sutherland, R., and Science, G. N. S., 2013, Whataroa groundwater surveys, Westland, New Zealand: GNS Science.

Cox, S. C., and Sutherland, R., 2007, Regional Geological Framework of South Island, New Zealand, and its Significance for Understanding the Active Plate 
Boundary, A Continental Plate Boundary: Tectonics at South Island, New Zealand, American Geophysical Union, p. 19-46.

Davey, F., Henyey, T., Kleffmann, S., Melhuish, A., Okaya, D., Stern, T., Woodward, D., and Transect, S. I. G., 1995, Crustal reflections from the Alpine fault zone, south Island, New Zealand.

Davey, F. J., 2010, Crustal seismic reflection profile across the alpine fault and coastal plain at Whataroa, South Island: New Zealand Journal of Geology and Geophysics, v. 53, no. 4, p. 359-368.

Davey, F. J., Eberhart-Phillips, D., Kohler, M. D., Bannister, S., Caldwell, G., Henrys, S., Scherwath, M., Stern, T., and Van Avendonk, H., 2007, Geophysical Structure of the Southern Alps Orogen, South Island, New Zealand, A Continental Plate Boundary: Tectonics at South Island, New Zealand, American Geophysical Union, p. 47-72.

Davey, F. J., Henyey, T., Holbrook, W. S., Okaya, D., Stern, T. A., Melhuish, A., Henrys, S., Anderson, H., Eberhart-Phillips, D., McEvilly, T., Uhrhammer, R., Wu, F., Jiracek, G. R., Wannamaker, P. E., Caldwell, G., and Christensen, N., 1998, Preliminary results from a geophysical study across a modern, continentcontinent collisional plate boundary - the Southern Alps, New Zealand: Tectonophysics, v. 288, no. 1-4, p. 221-235.

Davies, T. R., and Smart, C., 2007, Obstruction of subglacial conduits by bedload sediment-implications for alpine glacier motion: Journal of Hydrology (New Zealand), v. 46, no. 2, p. 51.

Davies, T. R., Smart, C. C., and Turnbull, J. M., 2003, Water and sediment outbursts from advanced Franz Josef glacier, New Zealand: Earth Surface Processes and Landforms, v. 28, no. 10, p. 1081-1096.

Davy, R., 2012, Glaciotectonic processes associated with the central Alpine Fault: a gravity study of the central West Coast, South Island, New Zealand [Master of Science MSc]: Victoria University of Wellington.

Davy, R., Stern, T., and Townend, J., 2013, Gravity analysis of glaciotectonic processes, central Alpine Fault, South Island, New Zealand: New Zealand Journal of Geology and Geophysics, v. 56, no. 2, p. 100-108.

De Pascale, G., and Davies, T., Plate boundary behaviour, recent uplift, and seismic hazard along the Central Alpine Fault near the Whataroa River, South Island, New Zealand, in Proceedings AGU Fall Meeting Abstracts, San Francisco, California, USA: Muscone 2014, Volume 1, p. 06.

De Pascale, G. P., 2014, Neotectonics and Paleoseismology of the Central Alpine Fault, New Zealand: Unpublished manuscript, University of Canterbury, Christchurch, New Zealand.

DeMets, C., Gordon, R. G., and Argus, D. F., 2010, Geologically current plate motions: Geophysical Journal International, v. 181, no. 1, p. 1-80. 
Douglass, D., Singer, B., Kaplan, M., Mickelson, D., and Caffee, M., 2006, Cosmogenic nuclide surface exposure dating of boulders on last-glacial and late-glacial moraines, Lago Buenos Aires, Argentina: interpretive strategies and paleoclimate implications: Quaternary Geochronology, v. 1, no. 1, p. 43-58.

Eberhart-Phillips, D., Reyners, M., Bannister, S., Chadwick, M., and Ellis, S., 2010, Establishing a versatile 3-D seismic velocity model for New Zealand: Seismological Research Letters, v. 81, no. 6, p. 992-1000.

Eberhart-Phillips, D., 1995, Examination of seismicity in the central Alpine fault region, South Island, New Zealand: New Zealand journal of geology and geophysics, v. 38, no. 4, p. 571-578.

Eberhart-Phillips, D., and Bannister, S., 2002, Three-dimensional crustal structure in the Southern Alps region of New Zealand from inversion of local earthquake and active source data: Journal of Geophysical Research: Solid Earth, v. 107, no. B10.

Evans, D. J., Shulmeister, J., and Hyatt, O., 2010, Sedimentology of latero-frontal moraines and fans on the west coast of South Island, New Zealand: Quaternary Science Reviews, v. 29, no. 27, p. 3790-3811.

Fitzharris, B., Hay, J., and Jones, P., 1992, Behaviour of New Zealand glaciers and atmospheric circulation changes over the past 130 years: The Holocene, v. 2, no. 2 , p. $97-106$.

Fitzsimons, S. J., and Veit, H., 2001, Geology and geomorphology of the European Alps and the Southern Alps of New Zealand: A comparison: Mountain Research and Development, v. 21, no. 4, p. 340-349.

Funnell, R., Chapman, D., Allis, R., and Armstrong, P., 1996, Thermal state of the Taranaki Basin, New Zealand: Journal of Geophysical Research: Solid Earth, v. 101, no. B11, p. 25197-25215.

Gaina, C., Müller, D. R., Royer, J. Y., Stock, J., Hardebeck, J., and Symonds, P., 1998, The tectonic history of the Tasman Sea: a puzzle with 13 pieces: Journal of Geophysical Research: Solid Earth, v. 103, no. B6, p. 12413-12433.

Gardner, G., Gardner, L., and Gregory, A., 1974, Formation velocity and density-the diagnostic basics for stratigraphic traps: Geophysics, v. 39, no. 6, p. 770-780.

Gerkens, J. C. A., 1989, Foundation of exploration geophysics, Amsterdam, New York, NY, U.S.A., Elsevier Science distributor, U.S. \& Canada.

Glomb, V., Buske, S., Kovacs, A., and Gorman, A., Seismic site characterization for the Deep-Fault-Drilling-Project Alpine Fault, in Proceedings EGU General Assembly Conference Abstracts2013, Volume 15, p. 243.

Golledge, N. R., Mackintosh, A. N., Anderson, B. M., Buckley, K. M., Doughty, A. M., Barrell, D. J. A., Denton, G. H., Vandergoes, M. J., Andersen, B. G., and Schaefer, J. M., 2012, Last Glacial Maximum climate in New Zealand inferred 
from a modelled Southern Alps icefield: Quaternary Science Reviews, v. 46, p. $30-45$.

Grapes, R., and Watanabe, T., 1992, Metamorphism and uplift of Alpine schist in the Franz Josef-Fox Glacier area of the Southern Alps, New Zealand: Journal of metamorphic geology, v. 10, no. 2, p. 171-180.

Grapes, R., and Watanabe, T., 1994, Mineral composition variation in Alpine Schist, Southern Alps, New Zealand: implications for recrystallization and exhumation: Island Arc, v. 3, no. 3, p. 163-181.

Griffiths, G. A., 1979, High sediment yields from major rivers of the western Southern Alps, New Zealand.

Griffiths, G. A., 1981, Some suspended sediment yields from South Island catchments, New Zealand: JAWRA Journal of the American Water Resources Association, v. 17 , no. 4 , p. $662-671$.

Griffiths, G. A., and McSaveney, M., 1986, Sedimentation and river containment on Waitangitaona alluvial fan-South Westland, New Zealand: Zeitschrift für Geomorphologie, NF, p. 215-230.

Hammer, S., 1939, Terrain corrections for gravimeter stations: Geophysics, v. 4, no. 3, p. 184-194.

Hanson, C. R., Norris, R. J., and Cooper, A. F., 1990, Regional fracture patterns east of the Alpine Fault between the Fox and Franz Josef glaciers, Westland, New Zealand: New Zealand Journal of Geology and Geophysics, v. 33, no. 4, p. 617622.

Hatherton, T., 1980, Shallow seismicity in New Zealand 1956-75: Journal of the Royal Society of New Zealand, v. 10, no. 1, p. 19-25.

Hatherton, T., and Leopard, A. E., 1964, The densities of New Zealand rocks: New Zealand Journal of Geology and Geophysics, v. 7, no. 3, p. 605-625.

Henderson, R. D., and Thompson, S. M., 1999, Extreme rainfalls in the Southern alps of New Zealand: Journal of Hydrology, v. 38, no. 2, p. 309-330.

Henrys, S., Woodward, D., Okaya, D., and Yu, J., 2004, Mapping the Moho beneath the Southern Alps continent-continent collision, New Zealand, using wideangle reflections: Geophysical research letters, v. 31, no. 17.

Herman, F., and Braun, J., 2006, Fluvial response to horizontal shortening and glaciations: a study in the Southern Alps of New Zealand: Journal of Geophysical Research: Earth Surface, v. 111, no. F1.

Herman, F., and Braun, J., 2008, Evolution of the glacial landscape of the Southern Alps of New Zealand: Insights from a glacial erosion model: Journal of Geophysical Research: Earth Surface, v. 113, no. F2. 
Herman, F., Braun, J., and Dunlap, W. J., 2007, Tectonomorphic scenarios in the Southern Alps of New Zealand: Journal of Geophysical Research: Solid Earth, v. 112 , no. B4, p. 1-25.

Herman, F., Rhodes, E. J., Braun, J., and Heiniger, L., 2010, Uniform erosion rates and relief amplitude during glacial cycles in the Southern Alps of New Zealand, as revealed from OSL-thermochronology: Earth and Planetary Science Letters, v. 297, no. 1-2, p. 183-189.

Heusser, L. E., and Van de Geer, G., 1994, Direct correlation of terrestrial and marine paleoclimatic records from four glacial-interglacial cycles-DSDP Site 594 Southwest Pacific: Quaternary Science Reviews, v. 13, no. 3, p. 273-282.

Hicks, D. M., McSaveney, M., and Chinn, T., 1990, Sedimentation in proglacial Ivory Lake, Southern Alps, New Zealand: Arctic and Alpine Research, p. 26-42.

Hicks, M. D., Hill, J., and Shankar, U., 1996, Variation of suspended sediment yields around New Zealand: the relative importance of rainfall and geology: IAHS publication, p. 149-156.

Hinze, W. J., 2003, Bouguer reduction density, why 2.67?: Geophysics, v. 68, no. 5, p. 1559-1560.

Hinze, W. J., Aiken, C., Brozena, J., Coakley, B., Dater, D., Flanagan, G., Forsberg, R., Hildenbrand, T., Keller, G. R., and Kellogg, J., 2005, New standards for reducing gravity data: The North American gravity database: Geophysics, v. 70, no. 4 , p. J25-J32.

Holm, D. K., Norris, R. J., and Craw, D., 1989, Brittle and ductile deformation in a zone of rapid uplift: Central Southern Alps, New Zealand: Tectonics, v. 8, no. 2, p. 153-168.

Hovius, N., Stark, C. P., and Allen, P. A., 1997, Sediment flux from a mountain belt derived by landslide mapping: Geology, v. 25, no. 3, p. 231-234.

Howarth, J. D., Fitzsimons, S. J., Norris, R. J., and Jacobsen, G. E., 2012, Lake sediments record cycles of sediment flux driven by large earthquakes on the Alpine fault, New Zealand: Geology, v. 40, no. 12, p. 1091-1094.

Hull, A., and Berryman, K., 1986, Holocene tectonism in the region of the Alpine fault at Lake McKerrow, Fiordland, New Zealand: Recent crustal movements of the Pacific region, v. 24, p. 317-331.

Kääb, A., and Haeberli, W., 2001, Evolution of a high-mountain thermokarst lake in the Swiss Alps: Arctic, Antarctic, and Alpine Research, p. 385-390.

Kamp, P. J., 1986, The mid-Cenozoic Challenger Rift System of western New Zealand and its implications for the age of Alpine fault inception: Geological Society of America Bulletin, v. 97, no. 3, p. 255-281. 
Kamp, P. J., and Tippett, J. M., 1993, Dynamics of Pacific plate crust in the South Island (New Zealand) zone of oblique continent-continent convergence: Journal of Geophysical Research: Solid Earth (1978-2012), v. 98, no. B9, p. 1610516118.

Kamp, P. J. J., Green, P. F., and Tippett, J. M., 1992, Tectonic architecture of the mountain front-foreland basin transition, South Island, New Zealand, assessed by fission track analysis: Tectonics, v. 11, no. 1, p. 98-113.

Kearey, P., Brooks, M., and Hill, I., 2013, An introduction to geophysical exploration, John Wiley \& Sons.

Kleffmann, S., 1999, Crustal Structure Studies of a Transpressional Plate Boundary: The Central South Island of New Zealand: a Thesis Submitted to the Victoria University of Wellington in Fulfilment of the Requirements for the Degree of Doctor of Philosophy in Geophysics: Victoria University of Wellington.

Kleffmann, S., Davey, F., Melhuish, A., Okaya, D., Stern, T., and Team, S., 1998, Crustal structure in the central South Island, New Zealand, from the Lake Pukaki seismic experiment: New Zealand Journal of Geology and Geophysics, v. 41, no. 1, p. 39-49.

Koons, P., 1989, The topographic evolution of collisional mountain belts; a numerical look at the Southern Alps, New Zealand: American journal of science, v. 289, no. 9, p. 1041-1069.

Koons, P., 1995, Modeling the topographic evolution of collisional belts: Annual Review of Earth and Planetary Sciences, v. 23, p. 375-408.

Koons, P. O., 1987, Some thermal and mechanical consequences of rapid uplift: an example from the Southern Alps, New Zealand: Earth and Planetary Science Letters, v. 86, no. 2-4, p. 307-319.

Koons, P. O., 1990, Two-sided orogen: Collision and erosion from the sandbox to the Southern Alps, New Zealand, Geology, Volume 18, p. 679-682.

Korup, O., 2002, Recent research on landslide dams-a literature review with special attention to New Zealand: Progress in Physical Geography, v. 26, no. 2, p. 206235 .

Korup, O., McSaveney, M. J., and Davies, T. R., 2004, Sediment generation and delivery from large historic landslides in the Southern Alps, New Zealand: Geomorphology, v. 61, no. 1, p. 189-207.

Korup, O., Schmidt, J., and McSaveney, M. J., 2005, Regional relief characteristics and denudation pattern of the western Southern Alps, New Zealand: Geomorphology, v. 71, no. 3, p. 402-423.

Korup, O., Strom, A. L., and Weidinger, J. T., 2006, Fluvial response to large rockslope failures: Examples from the Himalayas, the Tien Shan, and the Southern Alps in New Zealand: Geomorphology, v. 78, no. 1, p. 3-21. 
Korup, O., and Tweed, F., 2007, Ice, moraine, and landslide dams in mountainous terrain: Quaternary Science Reviews, v. 26, no. 25, p. 3406-3422.

Kovacs, A., 2011, Geophysical characterisation of the Alpine Fault throughout and beneath Whataroa Valley, Haast River and Turnbull River, Westland, New Zealand: Unpublished manuscript, University of Otago, Dunedin, New Zealand.

Kovacs, A., Gorman, A., Lay, V., and Buske, S., Seismic and gravity investigations of the shallow (upper $1 \mathrm{~km}$ ) hanging wall of the Alpine Fault in the vicinity of the Whataroa River, New Zealand, in Proceedings AGU Fall Meeting Abstracts, San Francisco, California, USA: Muscone 2013, Volume 1, p. 2613.

Laird, M., and Bradshaw, J., 2004, The break-up of a long-term relationship: the Cretaceous separation of New Zealand from Gondwana: Gondwana Research, v. 7, no. 1, p. 273-286.

Langridge, R., Villamor, P., Basili, R., Almond, P., Martinez-Diaz, J., and Canora, C., 2010, Revised slip rates for the Alpine fault at Inchbonnie: Implications for plate boundary kinematics of South Island, New Zealand: Lithosphere, v. 2, no. 3, p. 139-152.

Langridge, R. M., Ries, W. F., Farrier, T., Barth, N. C., Khajavi, N., and De Pascale, G. P., 2014, Developing sub 5-m LiDAR DEMs for forested sections of the Alpine and Hope faults, South Island, New Zealand: Implications for structural interpretations: Journal of Structural Geology, v. 64, p. 53-66.

Lay, V., Buske, S., Kovacs, A., Gorman, A., and Bannister, S., Advanced Seismic Imaging Techniques Characterize the Alpine Fault at Whataroa (New Zealand), in Proceedings AGU Fall Meeting Abstracts, San Francisco, California, USA: Muscone, 2015, Volume 1, p. 2429.

Leitner, B., Eberhart-Phillips, D., Anderson, H., and Nabelek, J. L., 2001, A focused look at the Alpine fault, New Zealand: Seismicity, focal mechanisms, and stress observations: Journal of Geophysical Research: Solid Earth, v. 106, no. B2, p. 2193-2220.

Lemieux-Dudon, B., Blayo, E., Petit, J.-R., Waelbroeck, C., Svensson, A., Ritz, C., Barnola, J.-M., Narcisi, B. M., and Parrenin, F., 2010, Consistent dating for Antarctic and Greenland ice cores: Quaternary Science Reviews, v. 29, no. 1, p. 8-20.

Litchfield, N., Van Dissen, R., Sutherland, R., Barnes, P., Cox, S., Norris, R., Beavan, R., Langridge, R., Villamor, P., and Berryman, K., 2014, A model of active faulting in New Zealand: New Zealand Journal of Geology and Geophysics, v. 57, no. 1, p. 32-56.

Little, T. A., Cox, S., Vry, J. K., and Batt, G., 2005, Variations in exhumation level and uplift rate along the oblique-slip Alpine fault, central Southern Alps, New Zealand: Geological Society of America Bulletin, v. 117, no. 5-6, p. 707-723. 
Little, T. A., Holcombe, R. J., and Ilg, B. R., 2002, Ductile fabrics in the zone of active oblique convergence near the Alpine Fault, New Zealand: identifying the neotectonic overprint: Journal of Structural Geology, v. 24, no. 1, p. 193-217.

Longman, I., 1959, Formulas for computing the tidal accelerations due to the moon and the sun: Journal of Geophysical Research, v. 64, no. 12, p. 2351-2355.

Ludwig, W. J., Nafe, J. E., and Drake, C. L., 1970, Seismic refraction: The sea, v. 4, no. Part 1, p. 53-84.

Lukas, S., 2011, Ice-cored moraines, Encyclopedia of Snow, Ice and Glaciers, Springer, p. 616-619.

Mattauer, M., 1986, Intracontinental subduction, crust-mantle décollement and crustalstacking wedge in the Himalayas and other collision belts: Geological Society, London, Special Publications, v. 19, no. 1, p. 37-50.

Matte, P., Tapponnier, P., Arnaud, N., Bourjot, L., Avouac, J., Vidal, P., Qing, L., Yusheng, P., and Yi, W., 1996, Tectonics of Western Tibet, between the Tarim and the Indus: Earth and Planetary Science Letters, v. 142, no. 3, p. 311-330.

McCubbine, J., Tontini, F., Stagpoole, V., and Smith, E., 2016, Gsolve, A Python computer program with a graphical user interface to reduce relative gravity survey measurements to absolute gravity values: Unpublished manuscript, Victoria University of Wellington/GNS Science, Wellington, New Zealand.

McCulloch, R., Fogwill, C., Sugden, D. E., Bentley, M. J., and Kubik, P., 2005, Chronology of the last glaciation in central Strait of Magellan and Bahía Inútil, southernmost South America: Geografiska Annaler: Series A, Physical Geography, v. 87, no. 2, p. 289-312.

McSaveney, M., 2002, The next great west coast earthquake, Thepra: Earth Movements, Volume 19, New Zealand. Ministry of Civil Defense, p. 36-41.

Meyer, B., Tapponnier, P., Bourjot, L., Metivier, F., Gaudemer, Y., Peltzer, G., Shunmin, G., and Zhitai, C., 1998, Crustal thickening in Gansu-Qinghai, lithospheric mantle subduction, and oblique, strike-slip controlled growth of the Tibet plateau: Geophysical Journal International, v. 135, no. 1, p. 1-47.

Milsom, J., 2003, Field Geophysics, John Wiley and Sons Ltd., Chichester, The Geological Field Guide Series

Mohr, P. J., Taylor, B. N., and Newell, D. B., 2012, CODATA Recommended Values of the Fundamental Physical Constants: 2010a): Journal of Physical and Chemical Reference Data, v. 41, no. 4, p. 043109.

Mortimer, N., 2000, Metamorphic discontinuities in orogenic belts: example of the garnet-biotite-albite zone in the Otago Schist, New Zealand: International journal of earth sciences, v. 89, no. 2, p. 295-306. 
Mortimer, N., 2004, New Zealand's geological foundations: Gondwana Research, v. 7, no. 1, p. 261-272.

Mortimer, N., 2005, PETLAB: New Zealand's rock and geoanalytical database: Geological Society of New Zealand Newsletter, v. 136, p. 27-31.

Muir, R., Ireland, T., Weaver, S., Bradshaw, J., Evans, J., Eby, G., and Shelley, D., 1998, Geochronology and geochemistry of a Mesozoic magmatic arc system, Fiordland, New Zealand: Journal of the Geological Society, v. 155, no. 6, p. 1037-1053.

Münker, C., and Cooper, R., 1999, The Cambrian arc complex of the Takaka Terrane, New Zealand: an integrated stratigraphical, paleontological and geochemical approach: New Zealand Journal of Geology and Geophysics, v. 42, no. 3, p. 415-445.

Münker, C., and Crawford, A. J., 2000, Cambrian arc evolution along the SE Gondwana active margin: a synthesis from Tasmania-New Zealand-Australia-Antarctica correlations: Tectonics, v. 19, no. 3, p. 415-432.

Nafe, J. E., and Drake, C. L., 1963, Physical properties of marine sediments: The Sea, John Wiley \& Sons, New York, v. 3, p. 794-815.

Nathan, S., Anderson, H. J., Cook, R. A., Herzer, R., Hoskins, R., Raine, J., and Smale, D., 1986, Cretaceous and Cenozoic sedimentary basins of the West Coast region, South Island, New Zealand, Science Information Pub. Centre, DSIR, for the New Zealand Geological Survey.

Nelson, C. S., Cooke, P. J., Hendy, C. H., and Cuthbertson, A. M., 1993, Oceanographic and climatic changes over the past 160,000 years at Deep Sea Drilling Project Site 594 off southeastern New Zealand, southwest Pacific Ocean: Paleoceanography, v. 8 , no. 4 , p. 435-458.

Newnham, R. M., Eden, D. N., Lowe, D. J., and Hendy, C. H., 2003, Rerewhakaaitu Tephra, a land-sea marker for the Last Termination in New Zealand, with implications for global climate change: Quaternary Science Reviews, v. 22, no. 2, p. 289-308.

Nibourel, L., Herman, F., Cox, S. C., Beyssac, O., and Lavé, J., 2015, Provenance analysis using Raman spectroscopy of carbonaceous material: A case study in the Southern Alps of New Zealand: Journal of Geophysical Research: Earth Surface, v. 120, no. 10, p. 2056-2079.

Norris, R., Cooper, A., Toy, V., Read, S., and Easterbrook, L., Three-dimensional structure of the Alpine Fault zone in the region around the Waitangi-taona and Whataroa Rivers, in Proceedings Geosciences 2012 conference, Hamilton, New Zealand: The University of Waikato, 2012.

Norris, R. J., and Cooper, A. F., 1995, Origin of small-scale segmentation and transpressional thrusting along the Alpine fault, New Zealand: Geological Society of America Bulletin, v. 107, no. 2, p. 231-240. 
Norris, R. J., and Cooper, A. F., 1997, Erosional control on the structural evolution of a transpressional thrust complex on the Alpine Fault, New Zealand: Journal of Structural Geology, v. 19, no. 10, p. 1323-1342.

Norris, R. J., and Cooper, A. F., 2001, Late Quaternary slip rates and slip partitioning on the Alpine Fault, New Zealand: Journal of Structural Geology, v. 23, no. 2, p. 507-520.

Norris, R. J., and Cooper, A. F., 2003, Very high strains recorded in mylonites along the Alpine Fault, New Zealand: implications for the deep structure of plate boundary faults: Journal of Structural Geology, v. 25, no. 12, p. 2141-2157.

Norris, R. J., and Cooper, A. F., 2007, The Alpine Fault, New Zealand: Surface Geology and Field Relationships: A Continental Plate Boundary: Tectonics at South Island, New Zealand, p. 157-175.

Norris, R. J., Koons, P. O., and Cooper, A. F., 1990, The obliquely-convergent plate boundary in the South Island of New Zealand: implications for ancient collision zones: Journal of Structural Geology, v. 12, no. 5, p. 715-725.

Northwest Geophysical Associates, I., 2004, GM-SYS Gravity/Magnetic Modeling Software: User's Guide, Version 4.9.

O'Keefe, B., 2008, Microseismicity of the central Alpine Fault region: New Zealand [M. Sc. thesis]: Wellington, New Zealand, University of Victoria.

Okaya, D., Stern, T., Davey, F., Henrys, S., and Cox, S., 2007, Continent-Continent Collision at the Pacific/Indo-Australian Plate Boundary: Background, Motivation, and Principal Results, A Continental Plate Boundary: Tectonics at South Island, New Zealand, 1-18 p.:

Petersen, T., Gledhill, K., Chadwick, M., Gale, N. H., and Ristau, J., 2011, The New Zealand national seismograph network: Seismological Research Letters, v. 82, no. 1, p. 9-20.

Petit, J.-R., Jouzel, J., Raynaud, D., Barkov, N. I., Barnola, J.-M., Basile, I., Bender, M., Chappellaz, J., Davis, M., and Delaygue, G., 1999, Climate and atmospheric history of the past 420,000 years from the Vostok ice core, Antarctica: Nature, v. 399 , no. 6735 , p. $429-436$.

Purdie, H., Brook, M., and Fuller, I., 2008, Seasonal variation in ablation and surface velocity on a temperate maritime glacier: Fox Glacier, New Zealand: Arctic, Antarctic, and Alpine Research, v. 40, no. 1, p. 140-147.

Putnam, A. E., Denton, G. H., Schaefer, J. M., Barrell, D. J., Andersen, B. G., Finkel, R. C., Schwartz, R., Doughty, A. M., Kaplan, M. R., and Schlüchter, C., 2010, Glacier advance in southern middle-latitudes during the Antarctic Cold Reversal: Nature Geoscience, v. 3, no. 10, p. 700-704.

Putnam, A. E., Schaefer, J. M., Denton, G. H., Barrell, D. J., Birkel, S. D., Andersen, B. G., Kaplan, M. R., Finkel, R. C., Schwartz, R., and Doughty, A. M., 2013, 
the last glacial maximum at $44 \mathrm{~S}$ documented by a 10 Be moraine chronology at Lake Ohau, Southern Alps of New Zealand: Quaternary Science Reviews, v. 62, p. 114-141.

Reed, J., 1964, Mylonites, cataclasites, and associated rocks along the Alpine fault, South Island, New Zealand: New Zealand journal of geology and geophysics, v. 7 , no. 4 , p. 645-684.

Reilly, W., 1962, Gravity and crustal thickness in New Zealand: New Zealand journal of geology and geophysics, v. 5, no. 2, p. 228-233.

Reilly, W., and Whiteford, C., 1979, Bouguer and isostatic anomalies, South Island: Gravity Map of New Zealand.

Reilly, W. I., 1970, Adjustment of gravity meter observations: New Zealand Journal of Geology and Geophysics, v. 13, no. 3, p. 697-702.

Reilly, W. I., 1972, New Zealand gravity map series: New Zealand Journal of Geology and Geophysics, v. 15, no. 1, p. 3-15.

Reyners, M., 1988, Reservoir-induced seismicity at lake Pukaki, New Zealand: Geophysical Journal International, v. 93, no. 1, p. 127-135.

Reyners, M., 1989, New Zealand seismicity 1964-87: an interpretation: New Zealand journal of geology and geophysics, v. 32, no. 3, p. 307-315.

Robertson, E. I., 1960, The New Zealand Provisional Gravity System, Geophysics Division Report No 27 +Appendix, DSIR, Wellington.

Robertson, E. I., and Reilly, W. I., 1960, The New Zealand Primary Gravity Network: New Zealand Journal of Geology and Geophysics, v. 3, no. 1, p. 41-68.

Roser, B., and Korsch, R., 1999, Geochemical characterization, evolution and source of a Mesozoic accretionary wedge: the Torlesse terrane, New Zealand: Geological Magazine, v. 136, no. 05, p. 493-512.

Roser, B., Mortimer, N., Turnbull, I., and Landis, C., 1993, Geology and geochemistry of the Caples Terrane, Otago, New Zealand: compositional variations near a Permo-Triassic arc margin: R F, p. 3-19.

Scherwath, M., Stein, S., Davey, F. D., and Davies, R., 2006, Three-dimensional lithospheric deformation and gravity anomalies associated with oblique continental collision in South Island, New Zealand: Geophysical Journal International, v. 167, no. 2, p. 906-916.

Scherwath, M., Stern, T., Davey, F., Okaya, D., Holbrook, W. S., Davies, R., and Kleffmann, S., 2003, Lithospheric structure across oblique continental collision in New Zealand from wide-angle P wave modeling: Journal of Geophysical Research: Solid Earth, v. 108, no. B12. 
Schleicher, A. M., Sutherland, R., Townend, J., Toy, V. G., and van der Pluijm, B. A., 2015, Clay mineral formation and fabric development in the DFDP-1B borehole, central Alpine Fault, New Zealand: New Zealand Journal of Geology and Geophysics, v. 58, no. 1, p. 13-21.

Schubert, G., 2015, Treatise on geophysics, Elsevier.

Shulmeister, J., Davies, T. R., Evans, D. J., Hyatt, O. M., and Tovar, D. S., 2009, Catastrophic landslides, glacier behaviour and moraine formation-A view from an active plate margin: Quaternary Science Reviews, v. 28, no. 11, p. 10851096.

Shulmeister, J., Fink, D., and Augustinus, P. C., 2005, A cosmogenic nuclide chronology of the last glacial transition in North-West Nelson, New Zealandnew insights in Southern Hemisphere climate forcing during the last deglaciation: Earth and Planetary Science Letters, v. 233, no. 3, p. 455-466.

Shulmeister, J., Goodwin, I., Renwick, J., Harle, K., Armand, L., McGlone, M. S., Cook, E., Dodson, J., Hesse, P. P., Mayewski, P., and Curran, M., 2004, The Southern Hemisphere westerlies in the Australasian sector over the last glacial cycle: a synthesis: Quaternary International, v. 118-119, no. 0, p. 23-53.

Sibson, R., 1977, Fault rocks and fault mechanisms: Journal of the Geological Society, v. 133, no. 3 , p. 191-213.

Sibson, R., White, S., and Atkinson, B., 1979, Fault rock distribution and structure within the Alpine Fault Zone: a preliminary account: The Origin of the Southern Alps, v. 18, p. 55-65.

Sibson, R., White, S., and Atkinson, B., 1981, Structure and distribution of fault rocks in the Alpine Fault Zone, New Zealand: Geological Society, London, Special Publications, v. 9, no. 1, p. 197-210.

Simpson, G. D., Cooper, A. F., and Norris, R. J., 1994, Late quaternary evolution of the Alpine fault zone at Paringa, South Westland, New Zealand: New Zealand journal of geology and geophysics, v. 37, no. 1, p. 49-58.

Sircombe, K. N., and Kamp, P. J., 1998, The South Westland Basin: seismic stratigraphy, basin geometry and evolution of a foreland basin within the Southern Alps collision zone, New Zealand: Tectonophysics, v. 300, no. 1, p. 359-387.

Smart, G., 1971, Petroleum report series PR528: Harihari-1.

Smart, G., 1972, Petroleum report series PR529: Waihoi-1.

Smith, E. G., Stern, T., and O'Brien, B., 1995, A seismic velocity profile across the central South Island, New Zealand, from explosion data: New Zealand journal of geology and geophysics, v. 38, no. 4, p. 565-570. 
Stagpoole, V., 2013, Description of the data in the GNS gravity database: GNS Science science internal report.

Stern, T., 1979, Regional and residual gravity fields, central North Island, New Zealand: New Zealand journal of geology and geophysics, v. 22, no. 4, p. 479485.

Stern, T., and McBride, J., 1998, Seismic exploration of continental strike-slip zones: Tectonophysics, v. 286, no. 1, p. 63-78.

Stern, T., Molnar, P., Okaya, D., and Eberhart-Phillips, D., 2000, Teleseismic P wave delays and modes of shortening the mantle lithosphere beneath South Island, New Zealand: Journal of Geophysical Research: Solid Earth, v. 105, no. B9, p. 21615-21631.

Stern, T., Okaya, D., Kleffmann, S., Scherwath, M., Henrys, S., and Davey, F., 2007, Geophysical exploration and dynamics of the Alpine fault zone: A Continental Plate Boundary: Tectonics at South Island, New Zealand, p. 207-233.

Stern, T. A., 1995, Gravity anomalies and crustal loading at and adjacent to the Alpine Fault, New Zealand: New Zealand Journal of Geology and Geophysics, v. 38, no. 4 , p. 593-600.

Suggate, R., 1990, Late pliocene and quaternary glaciations of New Zealand: Quaternary science reviews, v. 9, no. 2, p. 175-197.

Suggate, R. P., and Almond, P. C., 2005, The Last Glacial Maximum (LGM) in western South Island, New Zealand: implications for the global LGM and MIS 2: Quaternary Science Reviews, v. 24, no. 16-17, p. 1923-1940.

Sutherland, R., 1995, The Australia-Pacific boundary and Cenozoic plate motions in the SW Pacific: Some constraints from Geosat data: Tectonics, v. 14, no. 4, p. 819-831.

Sutherland, R., 1996, Transpressional development of the Australia-Pacific boundary through southern South Island, New Zealand: Constraints from MiocenePliocene sediments, Waiho-1 borehole, South Westland: New Zealand journal of geology and geophysics, v. 39, no. 2, p. 251-264.

Sutherland, R., 1999a, Basement geology and tectonic development of the greater New Zealand region: an interpretation from regional magnetic data: Tectonophysics, v. 308, no. 3, p. 341-362.

Sutherland, R., 1999b, Cenozoic bending of New Zealand basement terranes and Alpine Fault displacement: A brief review: New Zealand Journal of Geology and Geophysics, v. 42, no. 2, p. 295-301.

Sutherland, R., Berryman, K., and Norris, R., 2006, Quaternary slip rate and geomorphology of the Alpine fault: Implications for kinematics and seismic hazard in southwest New Zealand: Geological Society of America Bulletin, v. 118 , no. 3-4, p. 464-474. 
Sutherland, R., Davey, F., and Beavan, J., 2000, Plate boundary deformation in South Island, New Zealand, is related to inherited lithospheric structure: Earth and Planetary Science Letters, v. 177, no. 3, p. 141-151.

Sutherland, R., Eberhart-Phillips, D., Harris, R., Stern, T., Beavan, J., Ellis, S., Henrys, S., Cox, S., Norris, R., and Berryman, K., 2007, Do great earthquakes occur on the Alpine Fault in central South Island, New Zealand?: A Continental Plate Boundary: Tectonics at South Island, New Zealand, p. 235-251.

Sutherland, R., Gurnis, M., Kamp, P. J., and House, M. A., 2009, Regional exhumation history of brittle crust during subduction initiation, Fiordland, southwest New Zealand, and implications for thermochronologic sampling and analysis strategies: Geosphere, v. 5, no. 5, p. 409-425.

Sutherland, R., and Norris, R. J., 1995, Late Quaternary displacement rate, paleoseismicity, and geomorphic evolution of the Alpine Fault: Evidence from Hokuri Creek, South Westland, New Zealand: New Zealand Journal of Geology and Geophysics, v. 38, no. 4, p. 419-430.

Sutherland, R., Townend, J., Toy, V., Allen, M., Baratin, L., Barth, N., Beacroft., Benson, 1., Boese, C., Boles, A., Boulton, C., Capova, 1., Carpenter, B., Celerier, B., Chamberlain, C., Conze, R., Cooper, A., Coussens, J., Coutts, A., Cox, S., Craw, L., Doan, M., Eccles, J., Faulkner, D., Grieve, J., Grochowski, J., Gulley, A., Henry, G., Howarth, J., Jacobs, K., Jeppson, T., Kato, N., Keys, S., Kirilova, M., Kometani, Y., Kovacs, A., Langridge, R., Lin, W., Little, T., Mallyon, D., Mariani, B., Marx, R., Massiot, C., Mathewson, L., Melosh, B., Menzies, C., Moore, J., Morales, L., Morgan, C., Mori, H., Niemeijera, A., Nishikawa, O., Nitsch, O., Paris Cavailhès, J., Pooley, B., Prior, D., Pyne, A., Sauer, K., Savage, M., Schleicher, A., Schmitt, D., Shigematsu, N., Taylor-Offord, S., Tobin, H., Upton, P., Valdez, R., Weaver, K., Wiersberg, T., Williams J., Yeo, S., and Zimmer, M., 2015, Deep Fault Driling Project (DFDP), Alpine Fault Boreholes DFDP-2A and DFDP-2B Technical Completion Report: GNS Science.

Sutherland, R., Toy, V. G., Townend, J., Cox, S. C., Eccles, J. D., Faulkner, D. R., Prior, D. J., Norris, R. J., Mariani, E., Boulton, C., Carpenter, B. M., Menzies, C. D., Little, T. A., Hasting, M., De Pascale, G. P., Langridge, R. M., Scott, H. R., Lindroos, Z. R., Fleming, B., and Kopf, A. J., 2012, Drilling reveals fluid control on architecture and rupture of the Alpine fault, New Zealand: Geology, v. 40 , no. 12 , p. $1143-1146$.

Talwani, M., Worzel, J. L., and Landisman, M., 1959, Rapid gravity computations for two-dimensional bodies with application to the Mendocino submarine fracture zone: Journal of Geophysical Research, v. 64, no. 1, p. 49-59.

Telford, W. M., Geldart, L. P., and Sheriff, R. E., 1990, Applied geophysics, Cambridge university press.

Thurber, C. H., Roecker, S. W., Townend, J., Bannister, S. C., Guo, B., Rawles, C., and Feenstra, J. P., Crustal Structure and Seismicity along the Central Alpine Fault: 
Results from the WIZARD Array, in Proceedings AGU Fall Meeting Abstracts, San Francisco, California, USA: Muscone, 2015.

Tippett, J. M., and Kamp, P. J., 1993, Fission track analysis of the late Cenozoic vertical kinematics of continental Pacific crust, South Island, New Zealand: Journal of Geophysical Research: Solid Earth (1978-2012), v. 98, no. B9, p. 16119-16148.

Tippett, J. M., and Kamp, P. J., 1995, Geomorphic evolution of the Southern Alps, New Zealand: Earth Surface Processes and Landforms, v. 20, no. 2, p. 177-192.

Tovar, D. S., Shulmeister, J., and Davies, T., 2008, Evidence for a landslide origin of New Zealand's Waiho Loop moraine: Nature Geoscience, v. 1, no. 8, p. 524526.

Townend, J., 2009, Drilling, Sampling, and Monitoring the Alpine Fault: Deep Fault Drilling Project-Alpine Fault, New Zealand; Franz Josef, New Zealand, 2228 March 2009: Eos, Transactions American Geophysical Union, v. 90, no. 36, p. 312-312.

Townend, J., Sutherland, R., and Toy, V., 2009, Deep Fault Drilling Project, Alpine Fault, New Zealand: Scientific Drilling, no. 8, Sept 2009.

Townend, J., Sutherland, R., Toy, V. G., Eccles, J. D., Boulton, C., Cox, S. C., and McNamara, D., 2013, Late-interseismic state of a continental plate-bounding fault: Petrophysical results from DFDP-1 wireline logging and core analysis, Alpine Fault, New Zealand: Geochemistry, Geophysics, Geosystems, v. 14, no. 9, p. 3801-3820.

Toy, V. G., Boulton, C. J., Sutherland, R., Townend, J., Norris, R. J., Little, T. A., Prior, D. J., Mariani, E., Faulkner, D., and Menzies, C. D., 2015, Fault rock lithologies and architecture of the central Alpine fault, New Zealand, revealed by DFDP-1 drilling: Lithosphere, v. 7, no. 2, p. 155-173.

Toy, V. G., Prior, D. J., and Norris, R. J., 2008, Quartz fabrics in the Alpine Fault mylonites: Influence of pre-existing preferred orientations on fabric development during progressive uplift: Journal of Structural Geology, v. 30, no. 5, p. 602-621.

Tulloch, A., 1988, Batholiths, plutons, and suites: nomenclature for granitoid rocks of Westland-Nelson, New Zealand: New Zealand journal of geology and geophysics, v. 31, no. 4, p. 505-509.

Tulloch, A., and Kimbrough, D., 1989, The Paparoa metamorphic core complex, New Zealand: cretaceous extension associated with fragmeotation of the pacific margin of Gondwana: Tectonics, v. 8, no. 6, p. 1217-1234.

Turnbull, I., Allibone, A., and Jongens, R., 2010, Geology of the Fiordland area: Institute of Geological and Nuclear Sciences, v. 1, no. 250, p. 000.

Turnbull, I. M., and Allibone, A., 2003, Geology of the Murihiku area, GNS Science. 
Turney, C., Roberts, R., De Jonge, N., Prior, C., Wilmshurst, J., McGlone, M., and Cooper, J., 2007, Redating the advance of the New Zealand Franz Josef Glacier during the Last Termination: evidence for asynchronous climate change: Quaternary Science Reviews, v. 26, no. 25, p. 3037-3042.

Tweed, F., 2011, Ice-Dammed Lakes, Encyclopedia of Snow, Ice and Glaciers, Springer, p. 619-621.

Van Avendonk, H. J. A., Holbrook, W. S., Okaya, D., Austin, J. K., Davey, F., and Stern, T., 2004, Continental crust compression; a seismic refraction study of South Island geophysical transect; I, South Island, New Zealand. : Journal of Geophysical Research, v. 109, no. B6, p. 1-16.

Vandergoes, M. J., and Fitzsimons, S. J., 2003, The last glacial-interglacial transition (LGIT) in south westland, New Zealand: paleoecological insight into midlatitude southern hemisphere climate change: Quaternary Science Reviews, v. 22 , no. 14 , p. 1461-1476.

Vandergoes, M. J., Hogg, A. G., Lowe, D. J., Newnham, R. M., Denton, G. H., Southon, J., Barrell, D. J., Wilson, C. J., McGlone, M. S., and Allan, A. S., 2013a, A revised age for the Kawakawa/Oruanui tephra, a key marker for the Last Glacial Maximum in New Zealand: Quaternary Science Reviews, v. 74, p. 195-201.

Vandergoes, M. J., Newnham, R. M., Denton, G. H., Blaauw, M., and Barrell, D. J., 2013b, The anatomy of Last Glacial Maximum climate variations in south Westland, New Zealand, derived from pollen records: Quaternary Science Reviews, v. 74, p. 215-229.

Vandergoes, M. J., Newnham, R. M., Preusser, F., Hendy, C. H., Lowell, T. V., Fitzsimons, S. J., Hogg, A. G., Kasper, H. U., and Schlüchter, C., 2005, Regional insolation forcing of late Quaternary climate change in the Southern Hemisphere: Nature, v. 436, no. 7048, p. 242-245.

Waight, T. E., Weaver, S., Ireland, T., Maas, R., Muir, R., and Shelley, D., 1997, Field characteristics, petrography, and geochronology of the Hohonu Batholith and the adjacent Granite Hill complex, North Westland, New Zealand: New Zealand journal of geology and geophysics, v. 40, no. 1, p. 1-17.

Walcott, R., 1998, Modes of oblique compression: Late Cenozoic tectonics of the South Island of New Zealand: Reviews of Geophysics, v. 36, no. 1, p. 1-26.

Walcott, R. I., 1978, Present tectonics and Late Cenozoic evolution of New Zealand: Geophysical Journal of the Royal Astronomical Society, v. 52, no. 1, p. 137164.

Wallace, L., Barnes, P., Beavan, J., Van Dissen, R., Litchfield, N., Mountjoy, J., Langridge, R., Lamarche, G., and Pondard, N., 2012, The kinematics of a transition from subduction to strike-slip: An example from the central New Zealand plate boundary: Journal of Geophysical Research: Solid Earth, v. 117, no. B2. 
Wallace, L. M., Beavan, J., McCaffrey, R., Berryman, K., and Denys, P., 2007, Balancing the plate motion budget in the South Island, New Zealand using GPS, geological and seismological data: Geophysical Journal International, v. 168, no. 1 , p. 332-352.

Wandres, A. M., Bradshaw, J. D., Weaver, S., Maas, R., Ireland, T., and Eby, N., 2004, Provenance of the sedimentary Rakaia sub-terrane, Torlesse Terrane, South Island, New Zealand: the use of igneous clast compositions to define the source: Sedimentary Geology, v. 168, no. 3, p. 193-226.

Wech, A., Boese, C., Stern, T., and Townend, J., 2012, Tectonic tremor and deep slow slip on the Alpine Fault: Geophysical Research Letters, v. 39, no. 10.

Weissel, J. K., Hayes, D. E., and Herron, E. M., 1977, Plate tectonics synthesis: the displacements between Australia, New Zealand, and Antarctica since the Late Cretaceous: Marine geology, v. 25, no. 1, p. 231-277.

Wellman, H., 1953, Data for the study of Recent and late Pleistocene faulting in the South Island of New Zealand: New Zealand journal of science and technology, v. 34, p. $270-288$.

Wellman, H., 1955, New Zealand quaternary tectonics: Geologische Rundschau, v. 43, no. 1, p. 248-257.

Wellman, H., 1979, An uplift map for the South Island of New Zealand, and a model for uplift of the Southern Alps: Bull. R. Soc. NZ, v. 18, p. 13-20.

Wellman, H., and Willett, R., The geology of the west coast from Abut Head to Milford Sound1942, Royal Society of New Zealand.

Wells, A., Yetton, M. D., Duncan, R. P., and Stewart, G. H., 1999, Prehistoric dates of the most recent Alpine fault earthquakes, New Zealand: Geology, v. 27, no. 11, p. $995-998$.

Whiteford, C. M., and Lumb, J. T., 1973, Geophysics Division Rock Catalogue: An Introduction and Guide to Recording Data, Geophysics Division, Department of Scientific and Industrial Research.

Whiteford, C. M., and Lumb, J. T., 1975, A catalogue of physical properties of rocks, Geophysics Division, Department of Scientific and Industrial Research.

Whitehouse, I., 1986, Geomorphology of a compressional plate boundary, Southern Alps, New Zealand: International Geomorphology, p. 897-924.

Williams, P. W., 1996, A 230 ka record of glacial and interglacial events from Aurora Cave, Fiordland, New Zealand: New Zealand Journal of Geology and Geophysics, v. 39, no. 2, p. 225-241.

Wilson, C., 2001, The 26.5 ka Oruanui eruption, New Zealand: an introduction and overview: Journal of Volcanology and Geothermal Research, v. 112, no. 1, p. 133-174. 
Wodzicki, A., 1974, Geology of the pre-Cenozoic basement of the Taranaki-Cook Strait-Westland area, New Zealand, based on recent drillhole data: New Zealand journal of geology and geophysics, v. 17, no. 4, p. 747-757.

Wood, R., 1991, Structure and seismic stratigraphy of the western Challenger Plateau: New Zealand journal of geology and geophysics, v. 34, no. 1, p. 1-9.

Woodward, D., 1979, The crustal structure of the Southern Alps, New Zealand, as determined by gravity: The origin of the Southern Alps, v. 18, p. 95-98.

Woodward, D. J., and Carman, A. F., 1984, Computer program to reduce precise gravity observations: Wellington, N.Z.

Wright, C., 1998, Geology and paleoseismicity of the central Alpine Fault, New Zealand: MSc Thesis. University of Otago, Dunedin, New Zealand. 